\title{
Marine biodiversity and ecosystem function: empirical approaches and future research needs
}

\author{
Idea and coordination:
}

\author{
M. Solan, D. G. Raffaelli, D. M. Paterson, P. C. L. White, G. J. Pierce
}

\section{CONTENTS}

M. Solan, D. G. Raffaelli, D. M. Paterson,

P. C. L. White, G. J. Pierce

Introduction

$175-178$

J. E. Duffy, J. J. Stachowicz

Why biodiversity is important to oceanography: potential roles of genetic, species, and trophic diversity in pelagic ecosystem processes

R. M. Forster, V. Créach, K. Sabbe,

W. Vyverman, L. J. Stal

Biodiversity-ecosystem function relationship in microphytobenthic diatoms of the Westerschelde estuary

J. L. Ruesink, B. E. Feist, C. J. Harvey, J. S. Hong,

A. C. Trimble, L. M. Wisehart

Changes in productivity associated with four introduced species: ecosystem transformation of a 'pristine' estuary

G. G. Waldbusser, R. L. Marinelli

Macrofaunal modification of porewater advection: role of species function, species interaction, and kinetics

$217-231$

\section{J. E. Duffy}

Biodiversity and the functioning of seagrass

ecosystems...

\section{J. J. Stachowicz, J. E. Byrnes}

Species diversity, invasion success and ecosystem functioning: disentangling the influence of resource competition, facilitation, and extrinsic factors

E. N. Ieno, M. Solan, P. Batty, G. J. Pierce

How biodiversity affects ecosystem functioning: roles of infaunal species richness, identity and density in the marine benthos ...

\section{S. Naeem}

Expanding scaleffs in biodiversity-based researck. challenges and solutions for marine systems

\section{G. Raffaelli}

Biodiversity and ecosystem functioning: issues of scale and trophic complexity

M. T. Bulling, P. C. L. White, D. G. Raffaelli, G. J. Pierce

Using model systems to address the biodiversity-

\section{Introduction}

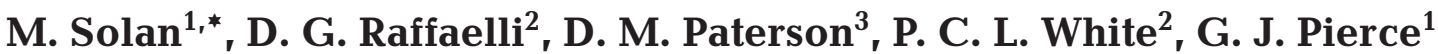 \\ ${ }^{1}$ Oceanlab, University of Aberdeen, Main Street, Newburgh, Aberdeenshire AB41 6AA, UK \\ ${ }^{2}$ Environment Department, University of York, Heslington, York YO10 5DD, UK \\ ${ }^{3}$ University of St. Andrews, Gatty Marine Laboratory, Sediment Ecology Research Group, St. Andrews, Fife KY16 8LB, UK
}

Marine systems are among the world's most productive and diverse ecosystems, but they are also subject to intense human pressures; approximately $40 \%$ of the world's population lives within $100 \mathrm{~km}$ of the coast (Cohen et al. 1997) and a significant proportion of these inhabitants depend on the ocean for food, economic prosperity and well-being. As in many terres- trial systems, a multitude of direct and indirect human influences have significantly altered the composition and diversity of marine communities at almost every trophic level (e.g. Pauly et al. 1998). This has led to concern over the functional consequences of biodiversity loss, which are especially relevant given the high levels of extinction already witnessed and the anti- 
cipated future influence of anthropogenic forcing (Sala et al. 2000). In response to such anxiety, an unprecedented increase in research over the last decade or so has explicitly examined the proposition that a reduction in biodiversity will cause a decrease in the provision of ecosystem-level processes (reviewed in Hooper et al. 2005). The establishment of this line of inquiry is credited to the proceedings of a seminal conference that sought to formalize, for the first time, the association between biodiversity and ecosystem function (Schulze \& Mooney 1993). Understanding the mechanisms that underpin this presumed causal relationship has since become one of the primary research goals in ecology (Hooper et al. 2005).

Following the emergence of a novel paradigm, the road towards a new consensus is supported by a parallel progression of observational, experimental and theoretical evidence. These are the primary axes along which fundamental ecological principles are derived and, providing that the conclusions drawn from these alternative approaches merge, are the means by which inferences about cause-effect relationships can be validated. In the biodiversity-ecosystem function arena (hereafter BEF) the mainstay of research to date has almost exclusively been weighted towards ecological experimentation in terrestrial plant systems, although there have been a small number of notable contributions on the marine environment (e.g. compare citations in Hooper et al. 2005 with Covich et al. 2004). Curiously, correlational evidence or anecdotal observations in support of BEF relationships (Emmerson \& Huxham 2002) are seldom cited on their own, or alongside new findings, and are generally viewed with skepticism, despite overwhelming support for the notion that biological diversity regulates ecosystem processes (Schläpfer et al. 1999). Yet the use of experimental systems is not without issue, nor do they provide a scientific panacea in the context of BEF related research. Experimental data generated from simple synthetic model communities in highly controlled systems (mesocosms) have been routinely criticized on many levels (for summary, see Mooney 2002).

Whether or not the same mechanistic processes identified from synthetic laboratory experiments are equally valid and transferable to the real world (terrestrial and/or marine) remains an open question. Historical and cultural differences between specialists within ecology (Raffaelli et al. 2005) have meant that the marine community has often lagged behind their terrestrial counterparts; the BEF process has been no exception. Aquatic ecologists were less enthusiastic and initially failed to see the significance of BEF research, despite direct appeals for participation (Emmerson \& Huxham 2002) and the publication of methodologies that demonstrate how marine ecology could contribute to the BEF dialogue (Raffaelli et al. 2003). One of the most significant barriers to interspecialist cohesion within the BEF community related to the treatment of biodiversity as an explanatory variable, rather than as the response variable, as had been common practice (e.g. Flint \& Kalke 2005). This conceptual stalemate emerged because contemporary perspectives within the BEF framework challenged older and more familiar conventional marine ideology (Raffaelli et al. 2005). Although these differences have largely been reconciled, the gap in research effort between marine and terrestrial ecology remains an issue, particularly as BEF research could greatly benefit from insights yet to be gleaned from marine systems (Raffaelli et al. 2003). This is particularly true since the manipulation of terrestrial systems with their longlived and static primary producers is more logistically difficult than experimentation in marine systems where small, mobile and abundant organisms can be selected and established in culture as the basis of experimentation (Defew et al. 2002, Paterson 2005).

As in many instances within the scientific process, controversy and debate can stimulate enlightenment and progress. It is in this spirit that we assembled the current 'Theme Section', where we have attempted to bring together a broad range of marine ecologists and encouraged them to express their opinions, substantiated or otherwise, alongside more traditional scientific prose within a BEF framework. We include contributions that represent a wide range of trophic levels, habitats and scales as well as a broad range of conceptual approaches. Our aim is to stimulate discussion both within and between the traditional domains of terrestrial and marine ecology within the BEF framework.

The Theme Section starts with Duffy \& Stachowicz (2006) who present selected examples of how genetic, species, and functional group diversity may affect pelagic ocean ecosystem processes. They argue that several mechanisms known to underpin observed diversity effects in marine benthic and terrestrial systems are likely to operate in pelagic systems. Next, Forster et al. (2006) examine the relationship between the diversity of intertidal benthic diatom biofilms and estimated net primary production. In so doing, they highlight the difficulties of using biomass as a surrogate for primary productivity in marine systems. Ruesink et al. (2006) use a case study to examine the impact that introduced species have on primary and secondary production in an estuary. They conclude that gains in species - as much as species lossescan markedly influence ecosystem processes and that associated changes in ecosystem functioning are often directly attributable to a few high-impact species. The effect of such species also forms the basis of the contribution by Waldbusser \& Marinelli (2006). Reporting on 
results obtained from a series of field experiments in an intertidal muddy-sand flat, they show that specific behavior and interactions between organisms appear to affect sediment function.

In a review of seagrass systems, Duffy (2006) suggests that future BEF investigations within seagrass and other aquatic ecosystems would benefit from broadening the concept of biodiversity to encompass the hierarchy of genetic through landscape diversity. Using a few explicit experimental tests of BEF relationships and by inferring from other lines of evidence, he argues that future studies would benefit from focusing on links between diversity and trophic interactions, and on links between regional diversity, local diversity, and ecosystem processes. Next, Stachowicz \& Byrnes (2006) apply observational data to study the consequences of species loss for invasion, in order to assess the generality across scales and relative importance of experimental results. They remind us that the BEF process has mostly been framed in the context of what will happen to ecosystem functioning as species richness declines and that there are virtually no data that address the reverse position, despite the fact that it is clear that invasive species can affect ecosystem structure and function.

Ieno et al. (2006) return to the issue of dominant species effects and uncertainties in experimental design. Solutions used to distinguish such effects in terrestrial systems are not always directly transferable to analogous marine experiments, because cumulative processes are routinely used as surrogates for ecosystem function. They present a post hoc experimental validation procedure to distinguish biodiversity effects from effects related to species identity and density when the relative contribution of each species in a mixture cannot be determined. The issues of experimental design are also considered by Naeem (2006), who recognizes that marine ecologists must deal with the large scales of marine systems and the logistical difficulties of attempting to conduct the kinds of complex, combinatory experiments that have been done in terrestrial ecology. By way of solution, he presents an alternative approach that obviates the need for complex experiments and goes beyond the limited scales of current BEF studies. Raffaelli (2006) continues with the issue of scale and trophic complexity and argues that it is possible, through the parallel development of alternate non-experimental approaches, to carry out BEF experiments at the spatial and temporal scales appropriate to those issues that affect society's needs. Finally, Bulling et al. (2006) examine the strengths and limitations of model systems and assess how useful these systems might be in addressing spatial scales, multiple trophic levels, variation and environmental stochasticity.
Acknowledgements. We thank the authors and over 50 reviewers for their willingness to participate. The assembly of this Theme Section was supported by NERC (NER/A/S/ 2003/00577). Open Access publication of this Theme Section is supported by the Marine Biodiversity and Ecosystem Functioning EU Network of Excellence (www.marbef.org).

\section{LITERATURE CITED}

Bulling MT, White PCL, Raffaelli D, Pierce GJ (2006) Using model systems to address the biodiversity-ecosystem functioning process. Mar Ecol Prog Ser 311:295-309 (in this Theme Section)

Cohen JE, Small C, Mellinger A, Gallup J, Sachs J (1997) Estimates of coastal populations. Science 278:1209

Covich AP, Austen M, Bärlocher F, Chauvet E and 7 others (2004) The role of biodiversity in the functioning of freshwater and marine benthic ecosystems. BioScience 54(8): 767-775

Defew EC, Paterson DM, Hagerthey SE (2002) The use of natural microphytobenthic assemblages as laboratory model systems. Mar Ecol Prog Ser 237:15-25

Duffy JE (2006) Biodiversity and the functioning of seagrass ecosystems. Mar Ecol Prog Ser 311:233-250 (in this Theme Section)

Duffy JE, Stachowicz JJ (2006) Why biodiversity is important to oceanography: potential roles of genetic, species, and trophic diversity in pelagic ecosystem processes. Mar Ecol Prog Ser 311:179-189 (in this Theme Section)

Emmerson M, Huxham M (2002) How can marine ecology contribute to the biodiversity-ecosystem functioning debate? In: Loreau M, Naeem S, Inchausti P (eds) Biodiversity and ecosystem functioning: synthesis and perspectives. Oxford University Press, p 139-146

Flint RW, Kalke RD (2005) Reinventing the wheel in ecology research? Science 307:1875

Forster RM, Créach V, Sabbe K, Vyverman W, Stal LJ (2006) Biodiversity-ecosystem function relationship in microphytobenthic diatoms of the Westerschelde estuary. Mar Ecol Prog Ser 311:191-201 (in this Theme Section)

Hooper DU, Chapin FS, Ewel JJ, Hector A and 11 others (2005) Effects of biodiversity on ecosystem functioning: a consensus of current knowledge. Ecol Monogr 75(1):3-35

Ieno EN, Solan M, Batty P, Pierce GJ (2006) How biodiversity affects ecosystem functioning: roles of infaunal species richness, identity and density in the marine benthos. Mar Ecol Prog Ser 311:263-271 (in this Theme Section)

Mooney HA (2002) The debate on the role of biodiversity in ecosystem functioning. In: Loreau M, Naeem S, Inchausti $P$ (eds) Biodiversity and ecosystem functioning: synthesis and perspectives. Oxford University Press, p 12-17

Naeem S (2006) Expanding scales in biodiversity-based research: challenges and solutions for marine systems. Mar Ecol Prog Ser 311:273-283 (in this Theme Section)

Paterson DM (2005) Biodiversity and functionality of aquatic ecosystems. In: Barthott W, Porembski S, Linsenmair KE (eds) Biodiversity: structure and function. Encyclopedia of life support systems (EOLSS). EOLSS developed under the auspices of UNESCO. Publishers, Oxford (www.eolss.net)

Pauly D, Christensen V, Dalsgaard J, Froese R, Torres F (1998) Fishing down marine food webs. Science 279:860-863

Raffaelli D (2006) Biodiversity and ecosystem functioning: issues of scale and trophic complexity. Mar Ecol Prog Ser 311:285-294 (in this Theme Section)

Raffaelli D, Emmerson M, Solan M, Biles C, Paterson D (2003) Biodiversity and ecosystem functioning in shallow coastal 
waters: an experimental approach. J Sea Res 49(2): 133-141

Raffaelli D, Solan M, Webb TJ (2005) Do marine and terrestrial ecologists do it differently? Mar Ecol Prog Ser 304: 283-289

Ruesink JL, Feist BE, Harvey CJ, Hong JS, Trimble AC, Wisehart LM (2006) Changes in productivity associated with four introduced species: ecosystem transformation of a 'pristine' estuary. Mar Ecol Prog Ser 311:203-215 (in this Theme Section)

Sala OE, Chapin FS III, Armesto JJ, Berlow E and 15 others (2000) Global biodiversity scenarios for the year 2100 . Science 287:1770-1774
Schläpfer F, Schmid B, Seidl I (1999) Expert estimates about effects of biodiversity on ecosystem processes and services. Oikos 84(2):346-352

Schulze ED, Mooney HA (1993) Biodiversity and ecosystem function. Springer-Verlag, Berlin

Stachowicz JJ, Byrnes JE (2006) Species diversity, invasion success and ecosystem functioning: disentangling the influence of resource competition, facilitation, and extrinsic factors. Mar Ecol Prog Ser 311:251-262 (in this Theme Section) Waldbusser GG, Marinelli RL (2006) Macrofaunal modification of porewater advection: role of species function, species interaction, and kinetics. Mar Ecol Prog Ser 311: 217-231 (in this Theme Section) 


\title{
Why biodiversity is important to oceanography: potential roles of genetic, species, and trophic diversity in pelagic ecosystem processes
}

\author{
J. Emmett Duffy ${ }^{1, *}$, John J. Stachowicz ${ }^{2}$ \\ ${ }^{1}$ School of Marine Science and Virginia Institute of Marine Science, The College of William and Mary, 1208 Greate Road, \\ Gloucester Point, Virginia 23062-1346, USA \\ ${ }^{2}$ Section of Evolution and Ecology, University of California, Davis, California 95616, USA
}

\begin{abstract}
The functioning of the global ecosystem is mediated in large part by pelagic marine organisms through their influence on biomass production, elemental cycling, and atmospheric composition. Growing theoretical and empirical evidence suggests that the stability and functioning of this complex system may depend, not only on aggregate biomass and production of pelagic producers and consumers, but also on the composition and richness of taxa within those compartments. Yet rigorous experimental tests of relationships between diversity and these aspects of pelagic ecosystem functioning are virtually unknown. Here, we argue for more attention to such research, and we marshal preliminary evidence that several mechanisms underlying diversity effects on ecosystem processes in marine benthic and terrestrial systems also may operate in pelagic systems. We review selected examples of how genetic, species, and functional group diversity may affect ocean ecosystem processes. We consider 3 types of examples that detail how (1) producer richness or composition can directly affect ecosystem processes, (2) consumer diversity can directly and indirectly affect these same processes, and (3) diversity at and below the species level can reduce variation of communities through time and enhance their resistance to perturbations. We suggest several promising avenues for assessing the role of biodiversity in pelagic ecosystems. Understanding and predicting responses of the global ocean ecosystem to accelerating climate and environmental change will be enhanced by more explicit and systematic attention to the functional diversity of microbial and macroscopic marine life.
\end{abstract}

KEY WORDS: Biodiversity $\cdot$ Ecosystem functioning $\cdot$ Pelagic $\cdot$ Production $\cdot$ Global change

\section{INTRODUCTION}

The biological composition and richness of most of the Earth's major ecosystems are changing as a result of harvesting, habitat destruction, pollution, exotic invasions, and climate change. Stimulated in part by these transformations, theoretical and empirical research in ecology has turned actively to the relationship between biodiversity and ecosystem functioning, i.e. aggregate, ecosystem-level processes such as production, element cycling, and trophic transfer (Chapin et al. 1997, Tilman 1999, Loreau et al. 2001). An influential series of field experiments, conducted primarily in terrestrial grass- lands, has demonstrated that the identity and number (richness) of plant species in a system can strongly influence primary productivity, efficiency of nutrient use, disease dynamics, invasibility by exotic species, and stability in the face of natural climate forcing and human perturbations (Tilman 1999, Loreau et al. 2001, 2002). Similarly, experiments in laboratory microcosms show that changing biodiversity in multilevel food webs also can have pervasive ecosystem impacts (Naeem \& Li 1997, Petchey et al. 2002).

Relative to terrestrial systems, the study of these issues in the marine pelagic zone is in its infancy, and there is little indication that this body of research 
has significantly influenced biological oceanography, although it is beginning to influence benthic ecology (Stachowicz et al. 1999, 2002, Duarte 2000, Emmerson et al. 2001, Bolam et al. 2002, Emmerson \& Huxham 2002, Duffy et al. 2003, 2005, Allison 2004, Solan et al. 2004, Waldbusser et al. 2004). This oversight is important for several reasons. First, it is increasingly clear that richness and composition of taxa in the marine pelagic zone may have a similarly strong influence on ecosystem processes to that observed on land. Second, the pelagic ecosystems of the open oceans are central mediators of planetary ecosystem processes with direct impacts on human welfare and economies, including carbon cycling and storage, greenhouse gas dynamics, harmful algal blooms, and human food production (Daily 1997, Falkowski et al. 1998, Balmford et al. 2002). Finally, and most importantly, human activities are demonstrably impacting the food web structure and taxonomic composition of even the most remote pelagic ecosystems on Earth (Shiomoto et al. 1997, Pauly et al. 1998, Beaugrand et al. 2002, Smith et al. 2003, Springer et al. 2003). It would be surprising indeed if these activities did not cause significant changes in the way that the ocean ecosystem functions, and, by extension, on the basic ecosystem services that it provides to human society (see Fig. 1).

In the present paper, we ask the question: Is biodiversity important to understanding the functioning of marine pelagic ecosystems? Although explicit experiments addressing this question are very rare, we argue that available evidence, mostly indirect, suggests that the answer is yes. Our aim is not a comprehensive review of such evidence, but a brief perspective that we hope will encourage more focused attention on links between biodiversity and pelagic ecosystem processes. By ecosystem functioning we mean the aggregate processes of central interest to biological oceanographers, such as primary and higher-level production, carbon and nutrient cycling and sequestration, and trophic transfer, as well as the stability of these processes over time and in the face of environmental change.

Previous research linking biodiversity to ecosystem functioning has focused primarily on species and functional group richness. We favor a concept of biodiversity expanded both downward and upward in the taxonomic hierarchy, to encompass genetic variation within species and variety of higher taxa, respectively. Such an expansion is especially important in marine ecosystems for 2 reasons. First, many marine ecosystem processes are dominated by microbes, many of which can only be distinguished genetically (Venter et al. 2004) and for which species concepts are vague. Indeed, with the advent of genomic approaches, functional differences among strains within nominal 'species' of marine phytoplankton and other microbes are increasingly evident (e.g. Knowlton \& Rohwer 2003, Rocap et al. 2003). Second, the oceans contain a far more diverse collection of kinds of organisms than occur on land, both from taxonomic and functional perspectives. Whereas nearly all terrestrial primary producers come from a single clade, the Embryophyta, marine autotrophs come from at least 8 evolutionarily ancient groups (Falkowski et al. 2004). Of the 33 animal phyla recognized by Margulis \& Schwartz (1988), 32 have marine representatives, and 15 of these are exclusively marine. Similarly, from a functional perspective, there are few, if any, terrestrial equivalents of suspension feeders or structure-forming sessile heterotrophs (e.g. some corals, sponges). Thus, both functional and higher-level taxonomic diversity tends to be higher in marine systems than on land or in fresh water.

Since few, if any, experiments have explicitly tested effects of diversity on functioning in marine pelagic ecosystems, our discussion relies on a mixture of examples from other habitats (including the marine benthos), combined with relevant ecological and natural history data on pelagic systems, to argue for the plausibility of diversity effects on ecosystem processes in pelagic systems. We build on the arguments of Verity \& Smetacek (1996, see also Verity et al. 2002) that top-down processes acting through the food web often have important, and still underappreciated, controlling influences on biomass, productivity, and composition of pelagic communities. This kind of 'vertical' diversity of trophic levels within food webs is clearly important, but we also argue that complementary use of resources and responses to environmental change, as well as interspecific facilitation by species within trophic levels (i.e. horizontal diversity) can enhance the consistency and stability of such basic ecosystem processes as primary production and nutrient cycling (see Fig. 2). We divide our examples into 3 sections that detail how (1) producer richness/ composition can directly affect ecosystem processes, (2) consumer diversity can have direct and indirect impacts on these same processes, and (3) diversity at and below the species level can reduce variation of communities through time and their resistance to perturbations. We conclude with suggestions of areas in which more explicit tests of diversity-functioning relationships might prove illuminating. We reiterate that our goal is not to exhaustively review the literature, but to explore how diversity might be important for pelagic ecosystem functioning and stimulate further research in this area.

\section{ECOSYSTEM CONSEQUENCES OF PHYTOPLANKTON AND MICROBIAL DIVERSITY}

The elemental stoichiometry of plankton biomass and seawater constitutes a complex feedback system 
fundamental to organic production and the global carbon cycle. Both macro- and micronutrient quotas in algae reflect consistent, anciently evolved differences in stoichiometry among major taxa of phytoplankton (Quigg et al. 2003). Although these quotas are to some degree plastic within species as growth conditions change, much of the variance in phytoplankton nutrient ratios is distributed among species or higher taxa. Moreover, theory (Klausmeier et al. 2004) and experiments (Sommer 1994) confirm that different nutrient profiles in the water column select for phytoplankton species with different stoichiometries. Changing phytoplankton species composition can, in turn, influence $\mathrm{CO}_{2}$ drawdown (Arrigo et al. 1999) and $\mathrm{C}$ sedimentation (Sieracki et al. 1993). These considerations suggest that spatial and temporal variance in rates of primary production and other ecosystem processes in the Earth's varied marine waters may be dampened by taxonomic and functional diversity within the phytoplankton (Fig. 1). Better understanding the functional significance of this diversity is especially timely, because community composition of both phytoplankton (Karl et al. 2001) and zooplankton (Beaugrand et al.
2002) is changing on a global scale, and these changes propagate up food chains on similarly large scales (Richardson \& Schoeman 2004).

Several examples of functional differentiation within species of marine microalgae illustrate these consequences nicely. In coastal Washington (USA), successive spring blooms of the centric diatom Ditylum brightwellii are comprised of genetically distinct clones, each of which grows best under different conditions (Rynearson \& Armbrust 2004, T. Rynearson unpubl. data). As a result, total biomass and production may be greater and extend over a longer time period than if the species represented a single, undifferentiated population. Experiments that examine the production of these strains in monocultures versus polycultures under realistically changing environmental conditions would be useful as a more rigorous test. Although the consequences of this producer diversity for animal populations have yet to be addressed, it is tempting to speculate that widening the window of the spring bloom may enhance the probability of survival for a variety of species that depend on it for food. A similar example from a benthic system involves the dinofla-

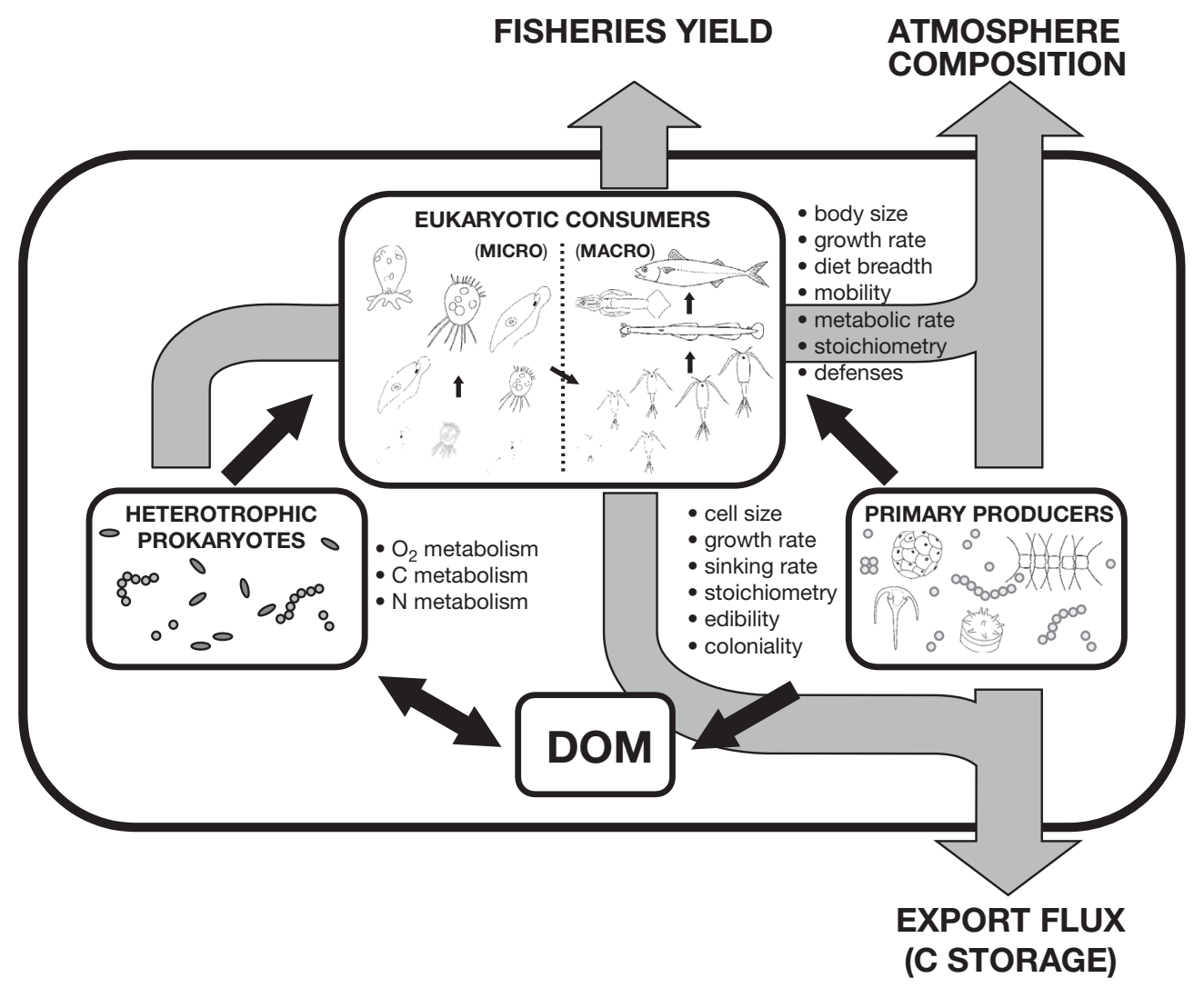

Fig. 1. Summary of some proposed links between pelagic biodiversity and marine ecosystem processes. A stylized food web, divided into 3 major components linked by trophic flows (black arrows), is shown. Beside each compartment is a list of traits likely to affect trophic flows, and gray arrows show influences of those compartments on ecosystem services. Compartments are presented as separate enclosed areas for clarity, although in reality ocean microorganisms span a metabolic continuum from pure autotrophs, through facultative autotrophs, mixotrophs, and facultative heterotrophs, to pure heterotrophs. DOM: dissolved organic matter 
gellate symbionts (zooxanthellae) on which scleractinian corals depend. These are a genetically diverse group of organisms that differ in their performance under different environmental conditions (e.g. Rowan et al. 1997, Knowlton \& Rohwer 2003). Some data suggest a trade-off among symbiont genotypes in the ability to resist bleaching versus their benefit to corals under 'normal' conditions (see review by Sotka \& Thacker 2005). If such trade-offs are confirmed, then maintaining a diversity of symbionts (or at least having a diverse pool of symbionts to draw from) may enhance the growth and persistence of reef-building corals and the entire ecosystem that depends on them.

Analogous genetic differentiation occurs within photosynthetic marine prokaryotes, which play important roles in primary production (Partensky et al. 1999) and nitrogen fixation (Karl 1999, Zehr et al. 2001) in most oceanic environments. Recent genomic studies suggest that different strains within a 'species' of marine microbe differ in the forms of nitrogen they can use (Dufresne et al. 2003, Palenik et al. 2003, Rocap et al. 2003), implying that a diverse assemblage may be able to utilize available nutrients more completely and efficiently, thereby increasing primary production, especially when integrated over time, space, or depth. Functional diversity at the microbial level appears to have been vastly underestimated historically, and we suspect that evidence for the importance of this diversity to ecosystem processes will continue to mount. Experimental approaches are needed to complement existing comparative data, but experiments in terrestrial and marine benthic systems show that when species have temporally or spatially complementary distributions, diversity can increase total resource use and enhance production (e.g. Tilman et al. 1996, Stachowicz et al. 2002).

\section{BIODIVERSITY AND THE FUNCTIONING OF OCEAN FOOD WEBS}

Trophic processes generally, and fishery production specifically, are strongly influenced by the specific routes and efficiency with which primary production fluxes through the food web (Pauly \& Christensen 1995, Fig. 1). Taxonomic composition of the plankton influences such trophic transfer, as well as vertical carbon flux (Lasker 1975, Parsons et al. 1984, Michaels \& Silver 1988). But trophic transfer and the strength of top-down control are predicted to depend not only on the types, but also on the number of producer and consumer taxa present and the degree to which consumers are specialists versus generalists (Duffy 2002, Thébault \& Loreau 2003). More diverse primary producer assemblages are expected to be more resistant to grazing control, primarily because they are more likely to contain grazer-resistant taxa that can dominate when edible taxa are depleted (Leibold et al. 1997, Duffy 2002). Several lines of evidence support this theory for aquatic systems. First, laboratory experiments show that naturally diverse freshwater algal assemblages are much more resistant to grazer control than unialgal cultures of edible algae (Steiner 2001). Second, a recent meta-analysis of 172 experiments showed that grazing impact on total biomass of benthic microalgae was reduced as algal species richness increased (Hillebrand \& Cardinale 2004). Similarly, at the next trophic level up, experimental data show that a diverse assemblage of benthic crustacean grazers lost less biomass to predators, on average, than did single grazer populations (Duffy et al. 2005). These results hint that gross ecological efficiency, i.e. the proportion of production at one trophic level that is converted to production at the next level in the food web, can depend significantly on the composition and richness of taxa within levels.

These examples show that prey diversity can reduce the efficiency of consumers, and thus dampen their impact on prey biomass. Conversely, diversity of consumers could increase their aggregate efficiency of resource use and, thus, increase both consumer (secondary) production and strength of top-down control (Holt \& Loreau 2002). This could occur either by resource partitioning, as different predators suppress different prey, or by predator facilitation, in which one predator species alters prey behavior, making it more susceptible to a second predator (see Ives et al. 2005 for a fuller discussion). Alternatively, antagonistic intraguild interactions in which predators consume other predators as well as herbivores could lead to reduced herbivore control with increasing predator diversity (Finke \& Denno 2004, Ives et al. 2005). In pelagic systems, however, predators and prey often share the same spatial refuge from a common top predator, and the resulting predator-induced behavioral shifts may turn such intraguild interactions into predator facilitation (Fisken et al. 2005). For example, predator facilitation might occur when copepods are subject to both visual predators (e.g. fishes) at the surface and non-visual predators (e.g. chaetognaths, ctenophores) that remain at depth during the day to avoid fish predation (Ohman 1990). In this case, the reverse diel migration strategy employed by copepods to avoid invertebrate predators leads to an increase in consumption by fish predators at the surface (Fisken et al. 2005). Thus, synergistic interactions among predators may lead to enhanced herbivore control and increases in phytoplankton biomass.

While consumer diversity effects have not been explicitly tested in pelagic systems, they receive some 
experimental support from other systems. For example, mesocosm experiments in a seagrass system showed that increasing species richness of invertebrate grazers enhanced both their own secondary production and their impact on the algal resource (Duffy et al. 2003, 2005). Similarly, kelp forest mesocosm experiments showed that increasing predator diversity enhanced the suppression of herbivorous invertebrates, because of complementary effects of predators on different herbivores, resulting in greater kelp biomass (Byrnes et al. 2006). Also, increased diversity of suspension-feeding stream invertebrates enhanced collective feeding efficiency and particle capture by creating a more heterogeneous substratum that enhanced turbulent flow and prevented food depletion in the boundary layer (Cardinale et al. 2002). As discussed previously, enhancement of production and resource use with increasing diversity is also commonly (although not always) found within basal trophic levels in both aquatic and terrestrial systems (Hector et al. 1999, Naeem et al. 2000, Tilman et al. 2001, Stachowicz et al. 2002), suggesting that a positive relationship between diversity and resource use commonly occurs. If similar effects of biodiversity on trophic transfer do, in fact, occur in pelagic systems, maintaining diversity might lead, for example, to more consistently high fishery yields. The low fishery yields of highly diverse, tropical gyres may at first seem inconsistent with this conclusion. But productivity of these-and all-ecosystems is ultimately constrained by resource input. Theory and limited evidence suggest that, at a given level of resource input, diversity influences how efficiently available resources are used.

Finally, a recent study confirms that explicitly recognizing functional diversity within a trophic level can fundamentally alter our conclusions about how ocean food webs work. Meta-analyses of experiments in marine pelagic systems have found that predator effects appear to attenuate at intermediate levels in the food web, with little effect on phytoplankton (Micheli 1999, Shurin et al. 2002). However, detailed analysis of an expanded data base shows that effects of predator deletions in the marine pelagic do often cascade to phytoplankton biomass, but the sign of their influence on phytoplankton depends on whether they cascade through a 3- or 4-link food chain, which in turn depends on cell size (hence, taxonomic composition) of the dominant taxa (Stibor et al. 2004). Because earlier studies averaged results from 3- and 4 -link chains, the strong influence of predators on phytoplankton was masked. The revised conclusion that top-down control has pervasive impacts on marine pelagic food webs is also consistent with field data (Shiomoto et al. 1997).

\section{BIODIVERSITY AND MARINE ECOSYSTEM STABILITY}

Human welfare depends on the stability of both ecosystems and economies (Armsworth \& Roughgarden 2003). Theory (Tilman et al. 1997, Yachi \& Loreau 1999) predicts that increasing species richness can stabilize ecosystem processes through time and space, and in the face of perturbations (Fig. 2). Experiments in terrestrial grasslands (Tilman \& Downing 1994, Tilman 1996) and aquatic protist communities (Naeem \& Li 1997) support this theory, and a few marine benthic experiments suggest that similar patterns may hold in the sea (Stachowicz et al. 2002, Stachowicz \& Byrnes
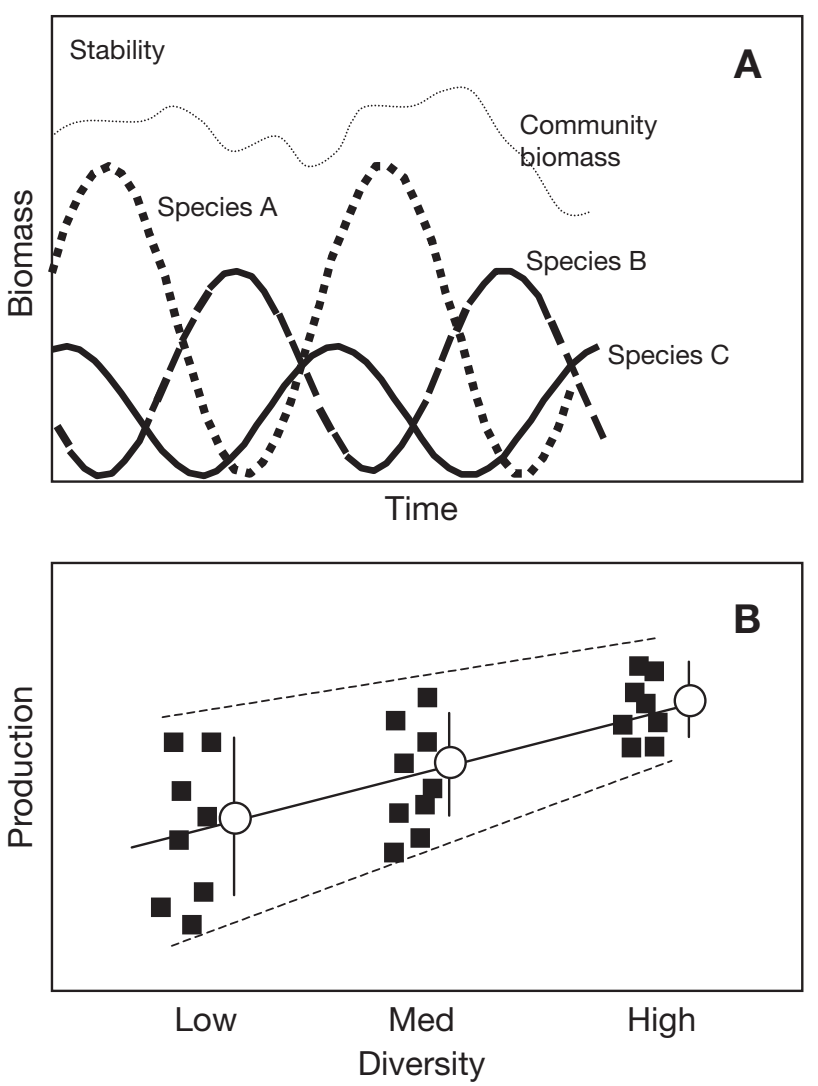

Fig. 2. Some proposed mechanisms linking biodiversity to ecosystem functioning. (A) Stability: in a hypothetical system, temporal variation in aggregate trophic level biomass is reduced relative to variability of individual species (see Stachowicz et al. 2002 for a real example). (B) Productivity: mean biomass production is greater in hypothetical assemblages with higher diversity, because species interact to enhance aggregate productivity (complementarity) and/or because highly productive species are more likely to be present in a diverse assemblage (sampling effect) (see Duffy et al. 2003 for a real example). $\mathbf{\square}$ : means for individual species or combinations; O: mean (with estimate of variance) of all combinations at that level of diversity; —_: trend of mean productivity with species richness; - - - - bounds of the range of productivity. Note that variance in productivity is higher in diverse mixtures than at low diversity (e.g. for single species) as in (A) 
2006, in this Theme Section). In general, however, marine studies have been more heterogeneous in their approach to this question, with increased focus on diversity below the species level. Several disparate lines of empirical evidence suggest that marine ecosystem stability may be enhanced by high genetic or phenotypic diversity within key species. Field manipulations of seagrass (Zostera marina) genotypic diversity showed that higher diversity enhanced community resistance to disturbance by grazing geese and the stress associated with transplantation, resulting in more stable seagrass biomass and higher abundances of invertebrates and other associated species (Hughes \& Stachowicz 2004); similar stabilizing effects of genetic diversity against temperature extremes were demonstrated in Baltic eelgrass (Reusch et al. 2005). In another example, individual salmon stocks fluctuated in response to year-to-year environmental variation, but the total salmon catch was buffered from these fluctuations, because, when one stock had low abundance for a series of years, another was above average for those years (Hilborn et al. 2003). As a result, the genetic composition of the overall salmon catch fluctuated greatly from year to year, but the total catch (total fish abundance) was more constant. These stabilizing effects of genetic diversity are remarkably similar to effects of species diversity in terrestrial grasslands and sessile marine invertebrate communities. In these systems, results generally have shown that as species diversity increases, the stability of individual species' abundances decreases, but stability of overall community biomass increases (Tilman 1999, Stachowicz et al. 2002). These results are also consistent with theory that predicts that negative covariances among species in their response to environmental fluctuations should produce a stabilizing effect of diversity on total community biomass (Tilman 1999).

\section{WHAT SHOULD WE DO NOW?}

In the preceding sections we have outlined areas in which existing data suggest that biodiversity should affect pelagic ecosystem processes and have highlighted a few areas in which further experimentation is needed. Given how few rigorous experiments have been conducted on this topic, virtually any effort promises to advance our understanding, and we encourage experimentation to complement existing correlational and anecdotal evidence. Indeed the combination of observational and experimental approaches has proven quite profitable in terrestrial and marine benthic systems (e.g. Tilman et al. 1996, Levine 2000, Stachowicz et al. 2002, Stachowicz \& Byrnes 2006). However, there are some cautions to be heeded and lessons to be learned from recent debate on the interpretation of such experiments in terrestrial systems. Early work manipulating 'biodiversity' sometimes confounded the effects of species composition (identity) and species richness (number). For example, experiments in which low-diversity treatments are created by deleting some portion of the species from an intact high-diversity community are ecologically realistic in that they mimic species extinction, but they cannot distinguish between effects of diversity per se (i.e. interactions among species) and effects of particularly important species (Huston 1997). Such effects can be distinguished by including treatments in which each species (or genotype, functional group) in the intact, diverse community is also grown in monoculture, allowing the comparison of species singly and in mixture. In particular, this type of design is helpful in distinguishing between effects of diversity due to complementary species properties versus the increasing probability of including a species with dominant effects as diversity increases, i.e. the sampling effect (see Huston 1997, Tilman et al. 1997, Allison 1999, Schmid et al. 2002, for more discussion on the design of these experiments).

A second lesson emerging from early research in this field is that the most powerful concept of ecosystem functioning requires considering multiple response variables. Most early grassland experiments focused on the single response variable of aggregate plant biomass accumulation, considered a proxy for productivity in these systems with relatively low grazing pressure. In marine systems, standing biomass of algae is a poor proxy for productivity, since production is often cropped as rapidly as it is produced. The absence of significant species richness effects on productivity in several terrestrial experiments, the commonness of the sampling effect in others, and the general saturation of productivity at relatively low species richness has led some authors to argue that species diversity has little appreciable influence on ecosystem functioning (e.g. Schwartz et al. 2000, Wardle et al. 2000). But this conclusion may be an artifact of the narrow focus on a single response variable: species influence many aspects of ecosystem functioning, and particular functions are often most strongly influenced by different species (Eviner \& Chapin 2003). Hence, even when one process (e.g. primary productivity) is dominated by a single species in a diverse mixture, the overall functioning of the diverse system may nevertheless differ considerably from that of any single monoculture. This phenomenon has been termed the 'multivariate dominance effect' (Duffy et al. 2003). It is supported by experimental data from a seagrass system, in which different grazer species maximized grazing pressure, secondary production, and sedi- 
mentary organic carbon content, with the diverse mixture showing comparably high values of each of these response variables (Duffy et al. 2003). Similarly, particular algal foods often maximize grazer growth, whereas others maximize survival, and still others reproduction, such that total grazer production may be highest when a diversity of foods is present (e.g. Cruz-Rivera \& Hay 2000, Dam \& Lopes 2003). This phenomenon is likely to be common, as evidenced by the analysis of Petchey \& Gaston (2002), who showed that as more functional traits (e.g. height, leaf $\mathrm{N}$ content, palatability, temperature tolerance) were incorporated into their multivariate index of functional diversity, the relationship between species richness and functional diversity became more linear. Yet the potential role of the multivariate dominance effect in linking biodiversity to ecosystem functioning remains unstudied empirically.

Finally, a fundamental difference between marine and terrestrial systems is the larger role of advection and habitat connectivity in marine systems. Several recent reviews have emphasized the potential influence of advection and flow on relationships between aquatic biodiversity and ecosystem processes (Biles et al. 2003, Covich et al. 2004, Giller et al. 2004). Further, benthic microcosm studies suggest that the strength of the biodiversity effect may weaken in open compared to closed systems (Matthiessen et al. in press) Given the fluid nature of the pelagic ecosystem, this is clearly an important consideration that underscores the importance of extending studies on biodiversityecosystem functioning, historically conducted at small spatial scales, to incorporate meta-community dynamics and linkages between different habitats (e.g. Loreau et al. 2003), particularly benthic-pelagic coupling.

Building on insights from pioneering terrestrial and microbial experiments and considering the unique aspects of ocean ecosystems, we offer the following, non-comprehensive list of suggestions for future research on how biodiversity may mediate pelagic ecosystem processes.

What is the importance of changing biodiversity relative to the demonstrated importance of physical forcing in influencing ecosystem structure and function? Few experiments have attempted to quantify the relative importance of changing diversity compared with typical variance in nutrient loading, temperature, and light levels for ecosystem process rates. Somewhat conflicting results have emerged from those that are available (e.g. Naeem \& Li 1997, Reich et al. 2004), suggesting the need for broader understanding of the conditions under which each of these factors exerts a dominant influence on ecosystem processes.
How does phytoplankton biodiversity-genotypes, species, higher taxa-influence production dynamics and trophic transfer? Phytoplankton biomass is commonly measured as bulk chlorophyll. But variance in both environmental tolerances and intrinsic growth rates among species, higher taxa, and even among genotypes of phytoplankton are increasingly well documented. How important is such functional diversity in influencing the magnitude of production, spatial and temporal extent of blooms, and thus the ability of higher trophic levels to exploit them? To what extent are the patterns and mechanisms elucidated in terrestrial plant assemblages even applicable to the other $70 \%$ of the Earth's surface? There are fundamental differences in mechanisms of resource use (nutrient uptake), relative biomass of photosynthetic versus structural material, and biomass turnover rates between the dominant producers on land (vascular plants) and in the sea (algae). Concordance of results from marine versus terrestrial systems (e.g. Bruno et al. 2005) would greatly increase the robustness of any conclusions.

What is the role of bacterial diversity in dissolved organic carbon dynamics? Dissolved organic carbon is the largest reservoir of organic carbon in the oceans, analogous to the humic fraction of soil organic matter. This material is a complex mixture of labile and highly refractory components, and processing it likely requires a suite of metabolic adaptations. In laboratory experiments, diverse bacterial assemblages can decompose a greater range of organic substrates (Naeem et al. 2000). The growing power of genomics in identifying bacterial genotypes should make it possible to begin testing whether similar phenomena are important in ocean ecosystem processes.

How does diversity of higher order consumers affect ecosystem functioning? Given that extinctions in the sea (and elsewhere) tend to be biased toward large consumers (Pauly et al. 1998, Jackson et al. 2001), a better understanding of the consequences of changing predator diversity for biomass, productivity, and community composition of lower trophic levels is critical. Further, the effects of diversity at one level often depend on the diversity at others (e.g. Duffy 2002, Gamfeldt et al. 2005), suggesting that, where possible, a factorial approach to diversity manipulations across trophic levels might prove insightful. Despite clear reductions in predator diversity and abundance in the sea (Myers \& Worm 2003, Worm et al. 2005), ecologically meaningful predators still play important roles in many if not most marine ecosystems. This, combined with the long history of studying trophic interactions in marine systems, suggests that marine ecologists are well poised to address this question. 
What are the economic costs of declining biodiversity? Oceanic processes are linked in a variety of ways to issues of importance to society, including human health, food production, water quality, greenhouse gas dynamics, and harmful algal blooms (Daily 1997, Falkowski et al. 1998, Balmford et al. 2002). If biodiversity is found to affect the specific ocean processes involved, then perhaps we can begin to quantify the direct economic 'costs' of declines in marine biodiversity.

A fundamental challenge in addressing all of these questions involves the bidirectional causal influences between biodiversity, productivity, and stability (Loreau et al. 2001, Naeem 2002, Worm \& Duffy 2003). This bidirectionality means that observational and correlational studies will need to be coupled with experimental manipulations to test definitively the relative roles of community structure (including diversity) versus extrinsic forcing in mediating rates of ecosystem processes.

\section{Concluding remarks}

The oceans harbor tremendous biological diversity. To render this diversity manageable, models of ocean ecosystem processes historically employed simplified food web structures, often with highly aggregated compartments. It is clearly impossible to account for every species in such models (Frost 1984, deYoung et al. 2004), and there is an inherent trade-off between increasing realism versus the inability to parameterize complex models. Nevertheless, the examples discussed above emphasize that there is a strong incentive to incorporate more realistic functional diversity of marine pelagic organisms in ocean ecosystem models. Several oceanographers have recently emphasized the necessity of doing so, and recent advances in this direction have been quite promising (e.g. Armstrong 2003, Gentleman et al. 2003, Le Quéré et al. 2005). Even slight disaggregation of traditional 'boxes' in these models can lead to dramatic changes in model predictions or experimental results (e.g. Stibor et al. 2004), suggesting that experimental approaches that either use simple systems with few species or that aggregate species into a manageable number of functional groups might be a profitable place to begin. Incorporating biodiversity into already complex ecosystem and biogeochemical models will be challenging, but is of pressing importance in the face of accelerating global environmental change. As one example, consider that serious proposals have been put forward to mitigate rising atmospheric $\mathrm{CO}_{2}$ levels by fertilizing remote ocean regions with iron. These proposals rely implicitly on a simplistic box- model concept of the ocean, in which carbon is taken up at constant stoichiometry by a homogeneous 'phytoplankton' compartment and transported to the deep ocean via sedimentation, either directly or as fecal pellets from a homogeneous 'grazer' compartment. Yet an extensive body of research shows that nutrient addition routinely leads not only to increases in biomass of primary producers, but also to changes in phytoplankton community composition (Leibold et al. 1997, Boyd et al. 2000, Landry 2002). Lehman (1988) used a simple model to show that dividing the phytoplankton into even a few species that differ realistically in nutrient quotas and grazing susceptibility can change substantially the magnitude and even the sign of the system's response to iron (or presumably other nutrient) addition. Field data indeed confirm that $\mathrm{CO}_{2}$ drawdown in the Southern Ocean depends strongly on phytoplankton species composition (Arrigo et al. 1999).

These examples indicate that our understanding of responses of the ocean ecosystem to anthropogenic perturbations will profit from the growing trend toward incorporating diversity in ocean ecosystem models. There is reason for optimism. Hulot et al. (2000) developed a model that divided lake phytoplankton into edible and inedible compartments, and showed that the model successfully predicted the responses of 3 trophic levels to manipulation in field experiments. Stibor et al. (2004) similarly showed that simply dividing phytoplankton into small- and largecelled taxa explained major variance in strength of marine pelagic trophic cascades. Even on the scale of regional seas and ocean basins, size-based models of food web interactions and nutrient use have successfully reproduced spatial and temporal patterns of production and carbon flux (e.g. Blackford \& Burkill 2002, Moore et al. 2002). While matching models to empirical data will not always be straightforward, these examples confirm that incorporating functional diversity into ocean ecosystem models can substantially enhance their power. The recent advances in ocean ecosystem modeling also suggest that ecologists interested in biodiversity-functioning relationships can learn from the successes of oceanographers in seeking to identify the minimal diversity necessary to reproduce-and predict-realistic patterns of ecosystem functioning and biogeochemistry.

Acknowledgements. We thank M. Solan for the invitation to contribute to this Theme Section; the NCEAS Working Group on Marine Biodiversity and Ecosystem Services for stimulating discussion; H. Ducklow, R. Hughes, and 4 anonymous reviewers for comments that improved the manuscript; and the NSF for support (OCE 03-52343 to J.E.D. and OCE 0351778 to J.J.S.). This paper is Contribution 2730 from the Virginia Institute of Marine Science. 


\section{LITERATURE CITED}

Allison GW (1999) The implications of experimental design for biodiversity manipulations. Am Nat 153:25-45

Allison GW (2004) The influence of species diversity and stress intensity on community resistance and resilience. Ecol Monogr 74:117-134

Armstrong RA (2003) A hybrid spectral representation of phytoplankton growth and zooplankton response: the 'control rod' model of plankton interaction. Deep-Sea Res II 50:2895-2916

Armsworth PR, Roughgarden JE (2003) The economic value of ecological stability. Proc Natl Acad Sci USA 100: $7147-7151$

Arrigo KR, Robinson DH, Worthen DL, Dunbar RB, DiTullio GR, VanWoert M, Lizotte MP (1999) Phytoplankton community structure and the drawdown of nutrients and $\mathrm{CO}_{2}$ in the Southern Ocean. Science 238:365-367

Balmford A, Bruner A, Cooper P, Costanza R and 15 others (2002) Economic reasons for conserving wild nature. Science 297:950-953

Beaugrand G, Reid PC, Ibaez F, Lindley JA, Edwards M (2002) Reorganization of North Atlantic marine copepod biodiversity and climate. Science 296:1692-1694

Biles CL, Solan M, Isaksson I, Paterson DM, Emes C, Raffaelli DG (2003) Flow modifies the effect of biodiversity on ecosystem functioning: an in situ study of estuarine sediments. J Exp Mar Biol Ecol 285/286:165-177

Blackford JC, Burkill PH (2002) Planktonic community structure and carbon cycling in the Arabian Sea as a result of monsoonal forcing: the application of a generic model. J Mar Syst 36:239-267

Bolam SG, Fernandes TF, Huxham M (2002) Diversity biomass and ecosystem processes in the marine benthos. Ecol Monogr 72:599-615

Boyd PW, Watson AJ, Law CS, Abraham AR and 31 others (2000) A mesoscale phytoplankton bloom in the polar Southern Ocean stimulated by iron fertilization. Nature 407:695-702

Bruno JF, Boyer KE, Duffy JE, Lee SC, Kertes JS (2005) Effects of macroalgal species identity and richness on primary production in benthic marine communities. Ecol Lett 8:1165-1174

Byrnes J, Stachowicz JJ, Hultgren KM, Hughes AR, Olyarnik SV, Thornber CS (2006) Predator diversity strengthens trophic cascades in kelp forests by modifying herbivore behaviour. Ecol Lett 9:61-71

Cardinale BJ, Palmer MA, Collins SL (2002) Species diversity enhances ecosystem functioning through interspecific facilitation. Nature 426:426-429

Chapin FS III, Walker BH, Hobbs RJ, Hooper DU, Lawton JH, Sala OE, Tilman D (1997) Biotic control over the functioning of ecosystems. Science 277:500-504

Covich AR, Austen MC, Bärlocher F, Chauvet E and 8 others (2004) The role of biodiversity in the functioning of freshwater and marine benthic ecosystems. BioScience 54: $767-775$

Cruz-Rivera E, Hay ME (2000) The effects of diet mixing on consumer fitness: macroalgae, epiphytes, and animal matter as food for marine amphipods. Oecologia 123: $252-264$

Daily GC (ed) (1997) Nature's services: societal dependence on natural ecosystems. Island Press, Washington, DC

Dam HG, Lopes RM (2003) Omnivory in the calanoid copepod Temora longicornis: feeding, egg production and egg hatching rates. J Exp Mar Biol Ecol 292:119-137

deYoung B, Heath M, Werner F, Chai F, Megrey B, Monfray P
(2004) Challenges of modeling ocean basin ecosystems. Science 304:1463-1466

Duarte CM (2000) Marine biodiversity and ecosystem services: an elusive link. J Exp Mar Biol Ecol 250:117-131

Duffy JE (2002) Biodiversity and ecosystem function: the consumer connection. Oikos 99:201-219

Duffy JE, Canuel EA, Richardson JP (2003) Grazer diversity and ecosystem functioning in seagrass beds. Ecol Lett 6: $1-9$

Duffy JE, Richardson JP, France KE (2005) Ecosystem consequences of diversity depend on food chain length in estuarine vegetation. Ecol Lett 8:301-309

Dufresne A, Salanoubat M, Partensky F, Artiguenave F and 17 others (2003) Genome sequence of the cyanobacterium Prochlorococcus marinus SS120, a nearly minimal oxyphototrophic genome. Proc Natl Acad Sci USA 100: 10020-10025

Emmerson M, Huxham M (2002) How can marine ecology contribute to the biodiversity-ecosystem functioning debate? In: Loreau M, Naeem S, Inchausti P (eds) Biodiversity and ecosystem functioning. Oxford University Press, New York, p 139-146

Emmerson MC, Solan, M, Emes C, Paterson DM, Raffaelli D (2001) Consistent patterns and the idiosyncratic effects of biodiversity in marine systems. Nature 411:73-77

Eviner VT, Chapin FS III (2003) Functional matrix: a conceptual framework for predicting multiple plant effects on ecosystem processes. Annu Rev Ecol Evol Syst 34:455-485

Falkowski PG, Barber RT, Smetacek V (1998) Biogeochemical controls and feedbacks on ocean primary production. Science 281:200-206

Falkowski PG, Katz ME, Knoll AH, Quigg A, Raven JA, Schofield O, Taylor FJR (2004) The evolution of modern eukaryotic phytoplankton. Science 305:354-360

Finke DL, Denno RF (2004) Predator diversity dampens trophic cascades. Nature 429:407-410

Fiskin O, Eliassen S, Titelman J (2005) Multiple predators in the pelagic: modeling behavioral cascades. J Anim Ecol 74:423-429

Frost BW (1984) Utilization of phytoplankton production in the surface layer. In: Global ocean flux study: proceedings of a workshop. National Academy Press, Washington, DC, p 125-135

Gamfeldt L, Hillebrand H, Jonsson PR (2005) Species richness changes across two trophic levels simultaneously affect prey and consumer biomass. Ecol Lett 8:696-703

Gentleman W, Leising A, Frost B, Strom S, Murray J (2003) Functional responses for zooplankton feeding on multiple resources: a review or assumptions and biological dynamics. Deep-Sea Res II 50:2847-2875

Giller PS, Hillebrand H, Berninger UG, Gessner MO and 8 others (2004) Biodiversity effects on ecosystem functioning: emerging issues and their experimental test in aquatic environments. Oikos 104:423-436

Hector A, Schmid B, Beierkuhnlein C, Caldeira MC and 30 others (1999) Plant diversity and productivity experiments in European grasslands. Science 286:1123-1127

Hilborn R, Quinn TP, Schindler DE, Rogers DE (2003) Biocomplexity and fisheries sustainability. Proc Natl Acad Sci USA 100:6564-6568

Hillebrand H, Cardinale BJ (2004) Consumer effects decline with prey diversity. Ecol Lett 7:192-201

Holt RD, Loreau M (2002) Biodiversity and ecosystem functioning: the role of trophic interactions and the importance of system openness. In: Kinzig AP, Pacala SW, Tilman D (eds) The functional consequences of biodiversity. Princeton University Press, Princeton, NJ, p 246-262 
Hughes AR, Stachowicz JJ (2004) Genetic diversity enhances the resistance of a seagrass ecosystem to disturbance. Proc Natl Acad Sci USA 101:8998-9002

Hulot FD, Lacroix G, Lescher-Moutoué F, Loreau M (2000) Functional diversity governs ecosystem response to nutrient enrichment. Nature 405:340-344

Huston MA (1997) Hidden treatments in ecological experiments: re-evaluating the ecosystem function of biodiversity. Oecologia 110:449-460

Ives AR, Cardinale BJ, Snyder WE (2005) A synthesis of subdisciplines: predator-prey interactions, and biodiversity and ecosystem functioning. Ecol Lett 8:102-116

Jackson JBC, Kirby MX, Berger WH, Bjorndal KA and 15 others (2001) Historical overfishing and the recent collapse of coastal ecosystems. Science 293:629-638

Karl DM (1999) A sea of change: biogeochemical variability in the North Pacific subtropical gyre. Ecosystems 2: $181-214$

Karl DM, Bidigare RR, Letelier RM (2001) Long-term changes in plankton community structure and the productivity of the North Pacific subtropical gyre. Deep-Sea Res II 48: $1449-1470$

Klausmeier CA, Litchman E, Daufresne T, Levin SA (2004) Optimal nitrogen-to-phosphorus stoichiometry of phytoplankton. Nature 429:171-174

Knowlton N, Rohwer F (2003) Multispecies microbial mutualisms on coral reefs: the host as a habitat. Am Nat 162: 51-62

Landry MR (2002) Integrating classical and microbial food web concepts: evolving views from the open-ocean tropical Pacific. Hydrobiologia 480:29-39

Lasker R (1975) Field criteria for survival of anchovy larvae: the relation between inshore chlorophyll maximum layers and successful first feeding. Fish Bull 73:453-462

Lehman JT (1988) Ecological principles affecting community structure and secondary production by zooplankton in marine and freshwater environments. Limnol Oceanogr 33:931-945

Leibold MA, Chase JM, Shurin JB, Downing AL (1997) Species turnover and the regulation of trophic structure. Annu Rev Ecol Syst 28:467-494

Le Quéré C, Harrison SP, Prentice IC, Buitenhuis ET and 16 others (in press) Ecosystem dynamics based on plankton functional types for global ocean biogeochemistry models. Global Change Biol 11:2016-2040

Levine JM (2000) Species diversity and biological invasions: relating local process to community pattern. Science 288: 852-854

Loreau M, Naeem S, Inchausti P, Bengtsson J and 8 others (2001) Biodiversity and ecosystem functioning: current knowledge and future challenges. Science 294:804-808

Loreau M, Naeem S, Inchausti P (eds) (2002) Biodiversity and ecosystem functioning. Synthesis and perspectives. Oxford University Press, Oxford

Loreau M, Mouquet N, Gonzalez A (2003) Biodiversity as spatial insurance in heterogeneous landscapes. Proc Natl Acad Sci USA 100:12765-12770

Margulis L, Schwartz KV (1988) Five kingdoms: an illustrated guide to the phyla of life on Earth, 2nd edn. Island Press, Washington, DC

Matthiessen B, Gamfeldt L, Jonsson P, Hillebrand H (in press) Effects of grazer richness and composition on algal biomass in a closed and open marine system. Ecology

Michaels AF, Silver MW (1988) Primary production, sinking fluxes and the microbial food web. Deep-Sea Res 35: 473-490

Micheli F (1999) Eutrophication, fisheries, and consumer- resource dynamics in marine pelagic ecosystems. Science 285:1396-1398

Moore JK, Doney SC, Kleypas JA, Glover DM, Fung IY (2002) An intermediate complexity marine ecosystem model for the global domain. Deep-Sea Res II 49:403-462

Myers RA, Worm B (2003) Rapid worldwide depletion of predatory fish communities. Nature 423:280-283

Naeem S (2002) Ecosystem consequences of biodiversity loss: the evolution of a paradigm. Ecology 83:1537-1552

Naeem S, Li S (1997) Biodiversity enhances ecosystem predictability. Nature 390:507-509

Naeem S, Hahn DR, Schuurman G (2000) Producer-decomposer co-dependency influences biodiversity effects. Nature 403:762-764

Ohman MD (1990) The demographic benefits of diel vertical migration by zooplankton. Ecol Monogr 60:257-281

Palenik B, Brahamsha B, Larimer FW, Land M and 11 others (2003) The genome of a motile marine Synechococcus. Nature 424:1037-1042

Parsons TR, Takahashi M, Hargrave B (1984) Biological oceanographic processes, 3rd edn. Pergamon, Oxford

Partensky F, Hess WR, Vaulot D (1999) Prochlorococcus, a marine photosynthetic prokaryote of global significance. Microbiol Mol Biol Rev 63:106-127

Pauly D, Christensen V (1995) Primary production required to sustain global fisheries. Nature 374:255-257

Pauly D, Christensen V, Dalsgaard J, Froese R, Torres F Jr (1998) Fishing down marine food webs. Science 279: 860-863

Petchey OL, Gaston KJ (2002) Functional diversity (FD), species richness and community composition. Ecol Lett 5: 402-411

Petchey OL, Morin PJ, Hulot FD, Loreau M, McGrady-Steed J, Naeem S (2002) Contributions of aquatic model systems to our understanding of biodiversity and ecosystem functioning. In: Kinzig AP, Pacala SW, Tilman D (eds) The functional consequences of biodiversity. Princeton University Press, Princeton, NJ, p 127-138

Quigg A, Finkel ZV, Irwin AJ, Rosenthal Y and 5 others (2003) The evolutionary inheritance of elemental stoichiometry in marine phytoplankton. Nature 425:291-294

Reich PB, Tilman D, Naeem S, Ellsworth DS, Knops J, Craine J, Wedin D, Trost J (2004) Species and functional group diversity independently influence biomass accumulation and its response to $\mathrm{CO}_{2}$ and N. Proc Natl Acad Sci USA 101:10101-10106

Reusch TBH, Ehlers A, Hämmerli A, Worm B (2005) Ecosystem recovery after climatic extremes enhanced by genotypic diversity. Proc Natl Acad Sci USA 102:2826-2831

Richardson AJ, Schoeman DS (2004) Climate impact on plankton ecosystems in the northeast Atlantic. Science 305:1609-1612

Rocap G, Larimer FW, Lamerdin J, Malfatti S and 20 others (2003) Genome divergence in two Prochlorococcus ecotypes reflects oceanic niche differentiation. Nature 424: 1042-1047

Rowan R, Knowlton N, Baker A, Jara J (1997) Landscape ecology of algal symbionts creates variation in episodes of coral bleaching. Nature 388:265-269

Rynearson T, Armbrust V (2004) Genetic differentiation among populations of the planktonic marine diatom Ditylum brightwellii (Bacillariophyceae). J Phycol 40:34-43

Schmid B, Joshi J, Schläpfer F (2002) Empirical evidence for biodiversity-ecosystem functioning relationships. In: Kinzig AP, Pacala SW, Tilman D (eds) The functional consequences of biodiversity. Princeton University Press, Princeton, NJ, p 120-150 
Schwartz MW, Brigham CA, Hoeksema JD, Lyons KG, Mills $\mathrm{MH}$, van Mantgem PJ (2000) Linking biodiversity to ecosystem function: implications for conservation ecology. Oecologia 122:297-305

Shiomoto A, Tadokoro K, Nagasawa K, Ishida Y (1997) Trophic relations in the subarctic North Pacific ecosystem: possible feeding effect from pink salmon. Mar Ecol Prog Ser 150:75-85

Shurin JB, Borer ET, Seabloom EW, Anderson K, Blanchette CA, Broitman B, Cooper SD, Halpern BS (2002) A crossecosystem comparison of the strength of trophic cascades. Ecol Lett 5:785-791

Sieracki ME, Verity PG, Stoecker DK (1993) Plankton community response to sequential silicate and nitrate depletion during the 1989 North Atlantic spring bloom. Deep-Sea Res II 40:213-225

Smith RC, Fraser WR, Stammerjohn SE (2003) Climate variability and ecological response of the marine ecosystem in the western Antarctic Peninsula (WAP) region. In: Greenland D, Goodin DG, Smith RC (eds) Climate variability and ecosystem response at long-term ecological research sites. Oxford University Press, New York, p 158-173

Solan M, Cardinale BJ, Downing AL, Engelhardt KA, Ruesink JL, Srivastava DS (2004) Extinction and ecosystem function in the marine benthos. Science 306:1177-1180

Sommer U (1994) The impact of light intensity and day length on silicate and nitrate competition among marine phytoplankton. Limnol Oceanogr 39:1680-1688

Sotka EE, Thacker RW (2005) Do some corals like it hot? Trends Ecol Evol 20:59-62

Springer AM, Estes JA, van Vliet GB, Williams TM, Doak DF, Danner EM, Forney KA, Pfister B (2003) Sequential megafaunal collapse in the North Pacific Ocean: an ongoing legacy of industrial whaling? Proc Natl Acad Sci USA 100: 12223-12228

Stachowicz JJ, Byrnes JE (2006) Species diversity, invasion success and ecosystem functioning: disentangling the influence of resource competition, facilitation, and extrinsic factors. Mar Ecol Prog Ser 311:251-262 (in this Theme Section)

Stachowicz JJ, Whitlatch RB, Osman RW (1999) Species diversity and invasion resistance in a marine ecosystem. Science 286:1577-1579

Stachowicz JJ, Fried H, Osman RW, Whitlatch RB (2002) Biodiversity, invasion resistance and marine ecosystem function: reconciling pattern and process. Ecology 83: 2575-2590

Steiner CF (2001) The effects of prey heterogeneity and consumer identity on the limitation of trophic-level biomass. Ecology 82:2495-2506

Stibor H, Vadstein O, Diehl S, Gelzleichter A and 10 others

Editorial responsibility: Martin Solan (Guest Editor), Newburgh, UK
(2004) Copepods act as a switch between alternative trophic cascades in marine pelagic food webs. Ecol Lett 7: 321-328

Thébault E, Loreau M (2003) Food-web constraints on biodiversity-ecosystem functioning relationships. Proc Natl Acad Sci USA 100:14949-14954

Tilman D (1996) Biodiversity: population versus ecosystem stability. Ecology 77:350-363

Tilman D (1999) The ecological consequences of changes in biodiversity: a search for general principles. Ecology 80: 1455-1474

Tilman D, Downing JA (1994) Biodiversity and stability in grasslands. Nature 367:363-365

Tilman D, Wedin D, Knops J (1996) Productivity and sustainability influenced by biodiversity in grassland ecosystems. Nature 379:718-720

Tilman D, Lehman C, Thompson K (1997) Plant diversity and ecosystem productivity: theoretical considerations. Proc Natl Acad Sci USA 94:1857-1861

Tilman D, Reich PB, Knops J, Wedin D, Mielke T, Lehman C (2001) Diversity and productivity in a long-term grassland experiment. Science 294:843-845

Venter JC, Remington K, Heidelberg JF, Halpern AL and 19 others (2004) Environmental genome shotgun sequencing of the Sargasso Sea. Science 304:66-74

Verity PG, Smetacek V (1996) Organism life cycles, predation, and the structure of marine pelagic ecosystems. Mar Ecol Prog Ser 130:277-293

Verity PG, Smetacek V, Smayda TJ (2002) Status, trends and the future of the marine pelagic ecosystem. Environ Conserv 29:207-237

Waldbusser, GG, Marinelli RL, Whitlatch RB, Visscher PT (2004) The effects of infaunal biodiversity on biogeochemistry of coastal marine sediments. Limnol Oceanogr 49: $1482-1492$

Wardle DA, Huston MA, Grime JP, Berendse F, Garnier E, Lauenroth WK, Setälä H, Wilson SD (2000) Biodiversity and ecosystem function: an issue in ecology. Bull Ecol Soc Am July 2000:235-239

Worm B, Duffy JE (2003) Biodiversity, productivity, and stability in real food webs. Trends Ecol Evol 18:628-632

Worm B, Sandow M, Oschlies A, Lotze HK, Myers RA (2005) Global patterns of predator diversity in the open oceans. Science 309:1365-1369

Yachi S, Loreau M (1999) Biodiversity and ecosystem productivity in a fluctuating environment: the insurance hypothesis. Proc Natl Acad Sci USA 96:1463-1468

Zehr JP, Waterbury JB, Turner PJ, Montoya JP, Omoregie E, Steward GF, Hansen A, Karl DM (2001) Unicellular cyanobacteria fix $\mathrm{N}_{2}$ in the subtropical North Pacific Ocean. Nature 412:635-638

Submitted: February 8, 2005; Accepted: October 21, 2005 Proofs received from author(s): March 6, 2006 



\title{
Biodiversity-ecosystem function relationship in microphytobenthic diatoms of the Westerschelde estuary
}

\author{
R. M. Forster ${ }^{1,3}$, V. Créach ${ }^{1,3, *}$, K. Sabbe ${ }^{2}$, W. Vyverman ${ }^{2}$, L. J. Stal ${ }^{1}$ \\ ${ }^{1}$ Netherlands Institute of Ecology (KNAW-NIOO-CEME), PO Box 140, 4400 AC Yerseke, The Netherlands \\ ${ }^{2}$ Laboratory of Protistology and Aquatic Ecology, Department of Biology, Ghent University, Krijgslaan 281-S8, \\ 9000 Ghent, Belgium
}

${ }^{3}$ Present address: Centre for Environment, Fisheries and Aquaculture Science (CEFAS), Pakefield Road, Lowestoft, Suffolk NR33 OHT, UK

\begin{abstract}
Studies investigating the role of species diversity in sustaining key ecosystem processes, such as primary production, have until now mainly focused on terrestrial plant and soil communities. Although the relationship remains controversial, most evidence suggests that decreases in species diversity adversely affect ecosystem functions. It is unclear, however, whether conclusions derived from terrestrial systems can be readily transferred to aquatic systems. In the present study, the relationship between the diversity of intertidal benthic diatom biofilms and their estimated net primary production $\left(P_{\mathrm{n}}\right)$ in the macrotidal Westerschelde estuary was investigated. Diversity measures were calculated on the basis of relative cell counts down to species level. Biomass was estimated as chlorophyll $a$, and $P_{\mathrm{n}}$ was modelled using a vertically resolved primary production model on the basis of measurements of photosynthetic activity, biomass and abiotic parameters. Species composition of benthic diatoms differed significantly between sites along the salinity gradient of the estuary. As epipelic species were strongly correlated with photosynthetically active surface biofilm biomass and, hence, also with primary productivity, we focused on the diversity of this functional group. The results indicate that (1) biomass appears to be inversely related to the diversity of the biofilms (Periods of low biomass did not show low diversity [as reported in phytoplankton], possibly because these events were driven by grazing pressure and not by nutrient stress) and (2) relationships between diversity (species richness and Shannon index) and $P_{\mathrm{n}}$ appeared to be site specific, with either a significant positive or a unimodal relationship between both parameters.
\end{abstract}

KEY WORDS: Benthic diatoms $\cdot$ Biodiversity $\cdot$ Biomass $\cdot$ Net primary production

\section{INTRODUCTION}

Coastal zones and wetlands are among the most productive natural systems in the world, with high economic and ecological value (Woodward \& Wui 2001). Although spatially resolved assessments of coastal ecosystem metabolism are still at an early stage (Gazeau et al. 2004), it is clear that estuaries are important sites of biogeochemical activity (Heip et al. 1995). Intertidal and shallow subtidal sediments of estuaries are areas where particularly high rates of elemental cycling occur (Middelburg et al. 2005), due to the presence of key functional groups such as denitrifying bac- teria, suspension-feeding molluscs, bioturbating polychaetes, as well as macrophyte and microalgal primary producers. In order to understand how future changes in external factors such as salinity, nutrients and mean sea level will impact coastal systems, the responses of these key groups of organisms must be analysed (Heip et al. 2003). The relationship between the number of species or functional groups and the function of the ecosystem as a whole should be clarified, so that any adverse results of species loss can be predicted.

To date, research on the role of species diversity in sustaining ecosystem processes has focused primarily on terrestrial plant and soil communities (Waide et al. 
1999, Loreau 2000). For these systems, the hypothesis of a direct relationship between species diversity and productivity is based on the assumption that interspecific differences in the use of resources by plants enhance their use of the available resources, e.g. in terrestrial experiments with grasses (Wardle et al. 2000).

Similar effects have been observed in marine benthic ecosystems, but no general conclusions can be drawn, as experimental designs have often been performed on small-scale assemblages with low numbers of species (reviewed by Covich et al. 2004).

Estuaries are unusual in that high biogeochemical rates are accounted for by relatively low taxonomic diversity and low numbers of species (Costanza et al. 1993). This is due to physical stress: the tidally driven variations in salinity and water level that characterise most estuarine systems exert a strong selectional pressure. Only a limited number of species have adapted to changing salinity via, for example, the use of osmoregulatory systems (Webb et al. 1997). In low-diversity ecosystems, there is potentially a greater chance that certain species or groups of species may be critical to the maintenance of function (i.e. there is a lower level of redundancy).

In the case of estuarine sediments, a considerable amount of biological activity is associated with a thin layer of microscopic algae that inhabit the sediment surface (Cahoon 1999). The algal layer is important in a number of ecosystem processes. Microphytobenthos are an important source of new organic carbon (Underwood \& Kromkamp 1999), including the production of fatty acids, which are essential for higher trophic levels (Dunstan et al. 1994). The microphytobenthic layer can also control the rate and direction of inorganic nutrient exchange between benthic and pelagic compartments
(Sundbäck et al. 2000), and the physical presence of a smooth, overlapping layer of diatom cells and excreted polymeric substances can increase erosion resistance (Tolhurst et al. 2003). Recent investigations have shown considerable spatial separation (Underwood et al. 1998) and niche separation among different species of benthic diatoms (Underwood \& Provot 2000), but there is as yet no information on the extent to which overall biofilm metabolism corresponds to species richness.

The aims of this study were to evaluate the relationship between the diversity of benthic diatom species along the natural salinity gradient of a macrotidal estuary and their most important ecosystem function, net primary production ( $P_{\mathrm{n}}$, Gattuso et al. 1998). It is difficult to manipulate species richness in artificial microbial assemblages, as some species are uncultivable or disappear when natural sediment samples are brought into the laboratory (Defew et al. 2002); therefore, we compared direct measurements of biomass and primary productivity with diversity indices of natural biofilms sampled in the field.

\section{MATERIALS AND METHODS}

Site description. By sampling at points along a natural salinity gradient, at different shore heights and at all times of year, the aim was to capture the maximum variation in estuarine environmental conditions. It was assumed that this would drive ecological diversity in microphytobenthic communities. Environmental conditions, microphytobenthic biomass, photosynthetic activity and biodiversity were measured repeatedly at 3 intertidal locations, Appelzak (A), Biezelingsche Ham (B) and Paulina polder (P), along the natural

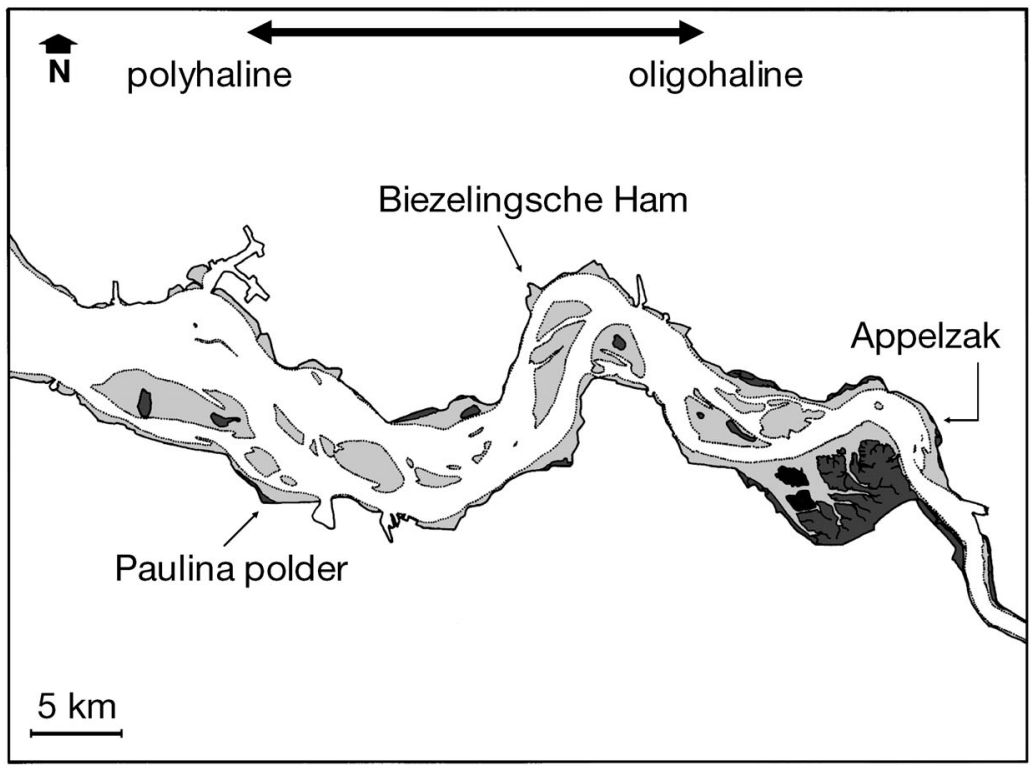

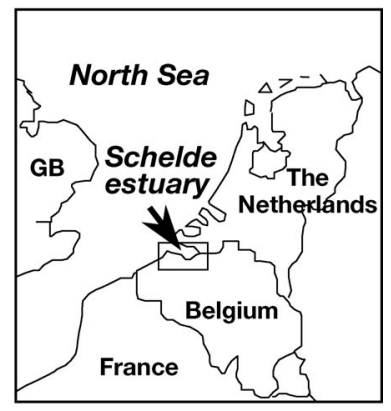

Fig. 1. Westerschelde estuary showing locations of the sampling sites: Appelzak (A), Biezelingsche Ham (B), Paulina polder $(\mathrm{P})$ 
salinity gradient of the Westerschelde estuary in the south-west of the Netherlands (Fig. 1). At each location, high-shore (A1, B1, P1) and mid-shore (A2, B2, P2) stations were selected on the exposed mudflats. Positions were determined by GPS (global positioning system), and each site was visited 8 times during the period from May 2002 to September 2003. Site visits were made during daytime low tides, within the time period from 10:00 to 14:00 h. Shore heights of the stations relative to lowest and highest tidal levels were determined by reference to a digital elevation model of the estuary, and were confirmed by direct observation of the timing of emersion and immersion periods. The key physical and biological parameters for each site are listed in Table 1.

Sampling. Surface sediment samples (upper $2 \mathrm{~mm}$ ) were taken with a contact corer (Ford \& Honeywill 2002). This layer includes all photosynthetically active cells, as well as the bulk of sediment chlorophyll, which is highly concentrated at the surface at these locations. On each sampling occasion, 5 replicate samples were taken within $5 \mathrm{~m}$ of the GPS location. Individual cores were used for determination of microphytobenthic biomass and water content. Pooled samples $(n=5)$ were used for grain size analysis and diatom species composition, as these parameters did not differ at this spatial scale. In addition, 4 fresh core samples of $4.5 \mathrm{~cm}$ diameter and $1 \mathrm{~mm}$ depth were pooled and transported to the laboratory for photosynthesis assays. Sediment surface temperatures (SST) were measured with an electrical thermometer during each of the field campaigns, and were found to correlate well with the maximum air temperature (MAT) measured at a nearby meteorological station. Accordingly, MAT was used as a proxy for SST on days when measurements were not available (see primary production modelling). The mean irradiance (PAR; $\mu$ mol photons $\mathrm{m}^{-2} \mathrm{~s}^{-1}$ ) was recorded at hourly intervals dur- ing 2002 and 2003 by a Licor Li-192 sensor located at the Netherlands Institute of Ecology in Yerseke, approximately $50 \mathrm{~km}$ from the field sites. Hourly PAR data was used for modelling the daily primary production of the stations throughout the period of the study.

Microphytobenthic biomass. Algal biomass was estimated from measurement of chlorophyll a (chl a). Pigments were extracted from freeze-dried contact core samples with $90 \%$ acetone. Mechanical disruption using a Bead Beater ensured an efficient release of pigment. Acetone extracts were quantified using highperformance liquid chromatography (HPLC) to give chlorophyll concentration in milligrams per square metre.

Ecosystem function: net primary production. Photosynthesis-irradiance response: Photosynthetic rates at different irradiances were measured on suspensions of microphytobenthos in filtered estuary water. The rate of photosynthesis was quantified using radiocarbon uptake (Barranguet \& Kromkamp 2000); 2 ml of optically thin microphytobenthos suspension was placed in flat-bottomed glass scintillation vials and exposed to 9 different irradiances for $30 \mathrm{~min}$. A thermostatically cooled aluminium photosynthetron was used to hold the vials in place in the light field (Lewis \& Smith 1983). The incubation temperature was set to $20^{\circ} \mathrm{C}$, and 2 replicate measurements were made on a suspension from each site. Carbon fixation rates were normalised to the algal biomass of the suspension, which was sampled in triplicate, with filters being taken before, during and after the filling of the vials. Simultaneous least-squares fitting was used to fit the cardinal parameters of the photosynthesis-irradiance curves using the target theory equation (Henley 1993). The resulting values for modelling are the light-saturated rate, $P_{\mathrm{MAX}}\left(\mathrm{mg} \mathrm{C} \mathrm{mg}^{-1} \mathrm{chl} \mathrm{a} \mathrm{h}^{-1}\right)$ and the initial slope, $\left.\alpha\left(\mathrm{mg} \mathrm{C} \mathrm{mg}^{-1} \mathrm{chl} \mathrm{a} \mathrm{h}^{-1} \text { [ } \mu \mathrm{mol} \text { photon } \mathrm{m}^{-2} \mathrm{~s}^{-1}\right]^{-1}\right)$.

Photosynthesis-temperature response: The effect of temperature on microphytobenthic photosynthesis was

Table 1. Ranges and annual means of abiotic and biotic parameters at 3 sampling sites in the Westerschelde high- (1) and mid- (2) shore stations. Standard deviations are in parentheses. Species richness and Shannon index diversity measures were calculated from species that represent a relative abundance (RA) of 1 and $5 \%$ in at least 1 sample

\begin{tabular}{|c|c|c|c|c|c|c|c|c|c|c|}
\hline & Salinity & $\begin{array}{l}\text { Water } \\
\text { content } \\
(\%)\end{array}$ & $\begin{array}{l}\text { Grain } \\
\text { size } \\
(\mu \mathrm{m})\end{array}$ & $\begin{array}{c}\text { Emersion } \\
\text { time/ light } \\
\text { hours per } 24 \mathrm{~h}\end{array}$ & $\begin{array}{c}\text { Organic } \\
\text { matter } \\
(\%)\end{array}$ & $\begin{array}{l}\text { Chloro- } \\
\text { phyll a } \\
\left(\mathrm{mg} \mathrm{m}^{-2}\right)\end{array}$ & $\begin{array}{c}\text { Net primary } \\
\text { production } \\
\left(\mathrm{mg} \mathrm{C} \mathrm{m}^{-2} \mathrm{~d}^{-1}\right)\end{array}$ & $\begin{array}{r}\text { Spec } \\
\text { inde } \\
\mathrm{RA}>1 \%\end{array}$ & $\begin{array}{l}\text { ex } \\
\text { RA > 5\% }\end{array}$ & $\begin{array}{l}\text { Shannon } \\
\text { RA > 5\% }\end{array}$ \\
\hline \multicolumn{11}{|c|}{ Appelzak } \\
\hline A1 & $9(5)$ & $65.7(18.1)$ & $55.8(58.7)$ & $17.8(1.5) / 14.1$ to 20.2 & $2.6(1.6)$ & 25.8 to 290.4 & -531 to 1280 & 11 to 34 & 3 to 9 & 0.14 to 1.61 \\
\hline $\mathrm{A} 2$ & $10.4(5)$ & $57.3(11.9)$ & $42(8.9)$ & $12.8(1.2) / 9.8$ to 14.1 & $2.3(1.2)$ & 11.6 to 292.1 & -713 to 909 & 14 to 32 & 3 to 10 & 0.26 to 1.95 \\
\hline \multicolumn{11}{|c|}{ Biezelingsche Ham } \\
\hline B1 & $21.1(4)$ & $65.4(8.6)$ & $26.2(3.6)$ & $14.2(0.6) / 13.6$ to 15.3 & $2.3(0.6)$ & 19.6 to 183.6 & -313 to 809 & 21 to 34 & 5 to 10 & 1.14 to 1.88 \\
\hline B2 & $21.3(5)$ & $52.1(7.2)$ & $45.5(16.9)$ & $11.6(0.6) / 10.9$ to 12.6 & $1.4(0.6)$ & 4 to 126.5 & -774 to 891 & 21 to 30 & 3 to 7 & 0.37 to 1.63 \\
\hline \multicolumn{11}{|c|}{ Paulina polder } \\
\hline $\mathrm{P} 1$ & $23.7(4)$ & $23.3(1.8)$ & $218.1(24.5)$ & $15.8(1.4) / 12.2$ to 17.6 & $0.4(0.3)$ & 18.4 to 229.2 & -2304 to $>3000$ & 20 to 28 & 2 to 8 & 0.15 to 1.50 \\
\hline P2 & $24.1(4)$ & $43.5(8.6)$ & $56.7(22.4)$ & $12.6(1.2) / 9.8$ to 13.9 & $0.8(0.5)$ & 4.7 to 163.9 & -904 to 1761 & 18 to 35 & 5 to 9 & 0.8 to 2.0 \\
\hline
\end{tabular}


not measured in this study, but has been examined in detail by Blanchard et al. $(1996,1997)$ and by Morris \& Kromkamp (2003). In these studies $\alpha$ was independent of temperature, and $P_{\mathrm{MAX}}$ had a predictable, unimodal relationship with temperature (see also similar results of Behrenfeld \& Falkowski 1997 for phytoplankton). The temperature response equations and coefficients of Blanchard et al. (1997) were used to convert $P_{\text {MAX }}$ values at $20^{\circ} \mathrm{C}$ to predicted values at the in situ SST of the site.

Respiration rate: Net primary production is the balance between gross primary carbon fixation and respiratory losses by photoautotrophs. As no data was available on the respiratory losses of microphytobenthos, it was assumed that this would vary in proportion to metabolic activity (Geider 1992). Accordingly, the respiration rate (RES) was set to a fixed value of $P_{\text {MAX }} \times$ 0.05 (Forster \& Kromkamp 2006), which should be related to the growth rate and activity of the microphytobenthic cells. Carbon losses due to exopolymer secretion and other processes such as grazing were beyond the scope of this modelling exercise.

Vertically resolved primary production model: The photosynthetic measurements described above give potential, hourly rates of carbon fixation under fixed irradiance and temperature conditions. However, natural sediments are exposed to continuously changing environmental conditions due to diurnal and bi-weekly cycles of insolation and tides (Serôdio \& Catarino 2000). Therefore, in order to predict rates of carbon fixation over a time frame appropriate for measuring changes in species composition, a modelling approach must be used (Barranguet \& Kromkamp 2000, Guarini et al. 2000). The primary production model used here featured an explicit description of irradiance conditions both at the surface and within the sediment for each of the sites.

Emersion times were calculated for each site by comparing the site elevation to measured tidal heights, which were available at 10 min time-steps from automated tidal gauges at 5 locations within the estuary (www.hmcz.nl). As tidal heights and timing of emersion periods vary along the length of the estuary, measuring gauges closest to the field sites were used. Measured water heights are preferred to predicted tidal curves because water levels in the estuary are partly dependent on wind direction. Due to the strong attenuation of irradiance by the water column of this estuary, photosynthesis was considered to be 0 during periods of immersion. Incident irradiance was calculated individually for each site, and for each hour of emersion during the period of study using the irradiance data from Yerseke.

Irradiance at the sediment surface was propagated downwards into the sediment using a sediment optical model (Forster \& Kromkamp 2004). The model assumes that irradiance is attenuated by both nonbiological material (sediment plus organic matter) and biological material (chl a). Specific attenuation coefficients of $0.011 \mathrm{~m}^{2} \mathrm{mg}^{-1}$ dry weight and $0.02 \mathrm{~m}^{2} \mathrm{mg}^{-1}$ chl a were used, respectively (Forster \& Kromkamp 2004). The distribution of chl a was defined by an exponential decrease away from the surface (Perkins et al. 2003), which is caused by the pronounced migration of cells to the surface during low-tide daytime exposures (Herlory et al. 2004). Time- and irradiancedependent differences in the shape of the chlorophyll profile, and in the surface species composition, are known to occur, but were not considered here due to the complexity of factors that can influence migration (Consalvey et al. 2004). Irradiance at depth $x\left(E_{x}\right)$ was calculated for discrete depth layers from the surface down to a depth of $2 \mathrm{~mm}$ with:

$$
E_{X, \mathrm{PAR}}=E_{(x-z, \mathrm{PAR})} \times \mathrm{e}^{-k_{d(\text { sum })} \times z}
$$

where $k_{d \text { (sum) }}$ is the sum of attenuation due to biological and non-biological material and $z$ is the depth interval $(10 \mu \mathrm{m})$.

From the irradiance and biomass at each depth, net hourly rates of photosynthesis at each depth were calculated according to:

$$
P_{z}=\left[P_{\max } \times\left(1-\mathrm{e}^{-\alpha \cdot E_{(z, \mathrm{PAR})} / P_{\max }}\right)-\mathrm{RES}\right] \times \operatorname{chl} a
$$

Net photosynthetic rates were integrated over the upper $1 \mathrm{~mm}$ of the sediment in order to give the areal hourly primary production in milligrams carbon per square metre. Integration over a $24 \mathrm{~h}$ period was then performed in order to calculate the daily net primary production for each site $\left(P_{\mathrm{n} i} \mathrm{mg} \mathrm{C} \mathrm{m} \mathrm{C}^{-1}\right)$, which is our desired measure of ecosystem function (Costanza et al. 1993, Herman et al. 1999). Note that negative net production estimates can arise when respiratory losses during periods of low irradiance and darkness outweigh carbon gains due to photosynthesis. The mean daily $P_{\mathrm{n}}$ for a period of $5 \mathrm{~d}$ before the collection of microphytobenthic samples was used for comparison with biodiversity data. This period was chosen to reflect the time required for species shifts to occur in relatively slowly growing microphytobenthic biofilms.

Microphytobenthos counts and biodiversity. Microscopic observations of live samples and HPLC analysis of accessory pigments indicated that diatoms were the dominant algal group at all sites. In order to visualise the ultrastructural features of the siliceous cell wall for identification and counting purposes, samples were oxidised with a 1:1 mixture of hydrogen peroxide (30\%) and acetic acid (100\%) and rinsed several times with distilled water. Oxidised materials were then mounted in Naphrax. Identifications and relative cell counts were made using a Leitz Diaplan microscope equipped with 
Differential Interference Contrast. Identifications were based on Sabbe (1997). Per sample, ca. 300 diatom valves were counted (min. 277, max. 336), and relative abundances calculated. Microscopic analyses of live and fixed materials allowed assignment of all taxa to the following 4 functional categories on the basis of their predominant growth form: (1) epipsammic (attached to or closely associated with individual sand grains); (2) epipelic (free-living); (3) tychoplankton (diatoms which are frequently encountered both in the water column and sediments [Vos \& de Wolf 1993], and which may have an amphibious life style) and (4) true plankton.

Biodiversity measures used were species richness (total number of species: SR) and the Shannon index ( $H^{\prime}$, Magurran 1988), which was calculated using the program Primer 5 for Windows (Version 5.2.2). Biodiversity calculations were based on the abundance data of benthic diatoms and epipelic species, which reach a relative abundance of 1 and $5 \%$ in at least 1 sample, respectively.

\section{RESULTS}

Diverse sets of environmental parameters were encountered at the 6 stations in the course of the study. Lowest salinity values were recorded at Stns A1 and A2, with intermediate values at B1 and B2 and highest values at P1 and P2 (Table 1). Sediment composition ranged from muddy sand with a high water and organic matter content at Stns A1, A2, B1 and B2 to fine sand at Stn P1 (Table 1). The microalgal pigment concentrations were significantly different according to collection dates (ANOVA, df = 7, F = 4.67, p < 0.0001), but not for the site or station. Multiple comparison indicated that the chl a was lower in February $\left(23 \mathrm{mg} \mathrm{m}^{-2}\right.$ ) and September $\left(29 \mathrm{mg} \mathrm{m}^{-2}\right)$ compared to March $\left(97 \mathrm{mg} \mathrm{m}^{-2}\right)$, April (171 $\mathrm{mg} \mathrm{m}^{-2}$ ) and May 2003 (112 $\mathrm{mg} \mathrm{m}^{-2}$ ). The highest microalgal biomass was recorded at Stns A1 and A2. At these 2 sites there was a clearly defined spring bloom beginning in March and ending in May, with low biomass throughout the summer and winter. In contrast, a broader peak in biomass values was found at Stn P1 from April to September. The lowest biomass was found at B2, which had the lowest elevation and thus received the least amount of light.

In total 158 diatom taxa were identified in the samples collected between May
2002 and September 2003. The proportions of the different diatom functional groups varied according to collection site. The least abundant group was composed of the epipsammic diatoms. Their contribution for all stations was particularly low, $<6 \%$, except for Stn P1, where this group represented on average $54 \%$. The abundance of planktonic diatoms was also low, between 1 and $17 \%$. The tychoplanktonic diatoms showed a very large range of abundance from $4 \%$ (P1) to $39 \%$ (P2). The contribution of epipelic diatoms was consistently highest at Site A, with a mean annual value of $57 \%$ at A1 and $53 \%$ at A2 and mean abundances of between 30 and $35 \%$ for Sites B and P. The diatoms in this functional group were particularly well represented in March and May for all stations; 17 species of epipelic diatoms were identified as the numerically dominant taxa in the estuary (Fig. 2), composed mainly of species from the group of Navicula. This species complex represented between 87 and $99 \%$ of the epipelic diatoms. Site A showed a different epipelic species composition compared to B and $\mathrm{P}$ (Fig. 2). N. flanatica was the dominant species at A1 and $\mathrm{A} 2$, whereas $N$. gregaria was dominant in $\mathrm{P} 1$ and $N$. arenaria var. rostellata at P2. Stns B1 and B2 did not show any dominant species. Other species such as $N$. phyllepta and $N$. perminuta were present at all stations, but with lower abundance. Except for P1 and P2 (sandy versus muddy station), species composition did not differ between the upper and mid-shore elevations within the intertidal transects (Fig. 2). Within any sample, the num-



Fig. 2. Species distributions of epipelic diatoms encountered at the 6 collection sites. Relative abundance of species was calculated from 8 field campaigns between May 2002 and September 2003. P: Paulina polder; B: Biezelingsche Ham; A: Appelzak; 1: upper shore; 2 : mid shore 
ber of dominant epipelic diatoms (e.g. relative abundance $>5 \%$ ) was always $>2$, but $<10$ (Table 1 ). The contribution of the functional groups varied according to the chl a concentration of the biofilm, with a significant shift $\left(\mathrm{R}^{2}=0.56, \mathrm{p}<0.001, \mathrm{n}=48\right)$ towards a dominance of epipelic species as biomass increased (Fig. 3).

The relationship between microalgal biomass and biodiversity (species richness) differed depending on whether total diatom species or only epipelic diatom species were considered. The total number of diatom species from all groups showed a weak but significant negative relationship with increasing biomass $\left(R^{2}=\right.$ $0.28, \mathrm{p}<0.001, \mathrm{n}=48$ ), whereas the most important functional group, epipelic diatoms, did not show any significant relationship ( $\mathrm{p}=0.38$, Fig. 4 ). The same trends were also found when the Shannon index was used as the diversity measure.

Due to a low variability in the photosynthetic parameters $P_{\mathrm{MAX}}$ and $\alpha$, areal net primary production was determined primarily by a combination of the amount of photosynthetically active biomass, length of photoperiod, the incident irradiance during emersion and the SST. Thus, predicted daily $P_{\mathrm{n}}$ was lowest (negative: $-304 \mathrm{mg} \mathrm{C} \mathrm{m}^{-2} \mathrm{~d}^{-1}$ ) at Stn A1 in March 2003 during a period of cloudy weather when respiratory losses were in excess of photosynthetic gains. The highest estimated $P_{\mathrm{n}}$ value was recorded at P1 in May 2002 (3635

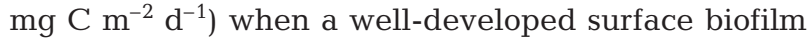
was exposed to several days of high irradiance and favourable temperatures. As carbon fixation rates in the model were not constrained by the availability of dissolved inorganic carbon (DIC) in the sediment porewater, it is highly likely that the model overestimated net daily production at P1 in May 2002. DIC limitation is known to be important in dense microphytobenthic communities (Admiraal 1984). Modelled $P_{\mathrm{n}}$ for Sites A, B and P showed sitespecific relationships with biodiversity, but the strength of effect was dependent upon the choice of index (Fig. 5a,b). Regardless of the indices, Site A showed a significant, positive relationship $\left(\mathrm{R}^{2}=0.5, \mathrm{p}<0.01, \mathrm{n}=13\right)$ between $P_{\mathrm{n}}$ and species richness or Shannon index. However, the net primary production decreased when the number of species was $>8$ (Fig. 5a) or when the Shannon index was superior to 1.6 (Fig. 5b). Site B also showed a significant positive relationship between $P_{\mathrm{n}}$ and Shannon index $\left(\mathrm{R}^{2}=0.3, \mathrm{p}<0.01, \mathrm{n}=13\right)$, but not with the species richness. The speciesrichness data from Site P followed for both indices a unimodal distribution, showing that the highest net primary production occurred for an intermediate species richness of 5 and Shannon index of 1.2 (Fig. 5a,b).

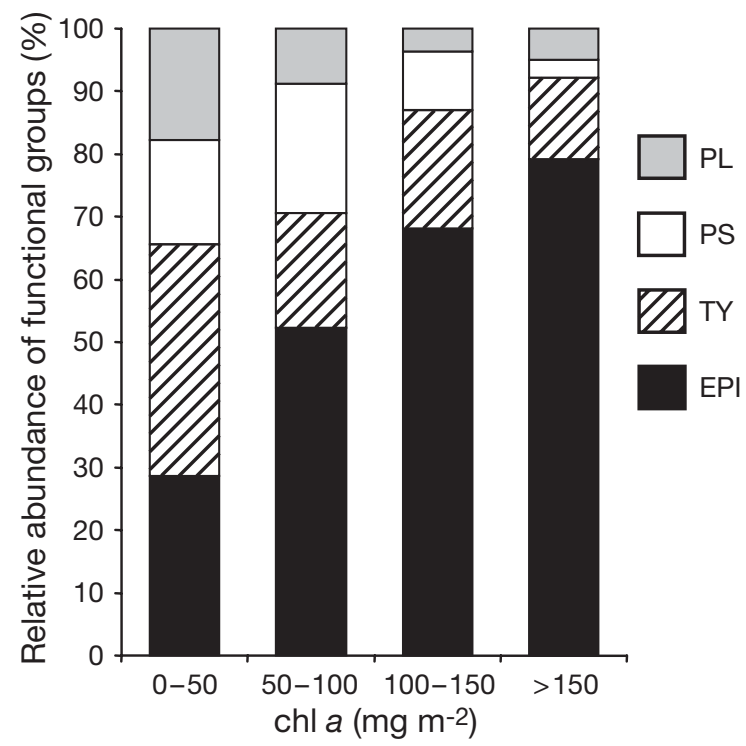

Fig. 3. Relative abundance of functional groups (PL: planktonic; PS: episammic; TY: tychoplanktonic; EPI: epipelic) of diatoms recorded in sediment samples between May 2002 and September 2003. The dataset was subdivided according to the chlorophyll a ( $\mathrm{chl} \mathrm{a}$ ) concentration $\left(\mathrm{mg} \mathrm{m}^{-2}\right)$ at the collection sites

\section{DISCUSSION}

The importance of biodiversity from an anthropocentric viewpoint is to maintain the useful characteristics of an ecosystem, which are the patterns and the rates of biochemical process, in the face of changes in the external environment. The theoretical foundations, as well as the experimental approach required to understand marine biodiversity and ecosystem function, are



Fig. 4. Biomass ( $\mathrm{chl} \mathrm{a}$ in $\mathrm{mg} \mathrm{m}^{-2}$ ) as a function of species richness (SR) for all benthic diatoms with a relative abundance (RA) $>1 \%$ (filled symbols) and epipelic diatoms with RA > 5\% (open symbols) in at least 1 sample at Appelzak (A: $\diamond)$, Biezelingsche Ham (B: $\square$ ) or Paulina polder (P: O). Linear regression: $\mathrm{R}^{2}=0.28, \mathrm{p}<0.001, \mathrm{n}=48$ for benthic diatoms with RA $>1 \%$ 

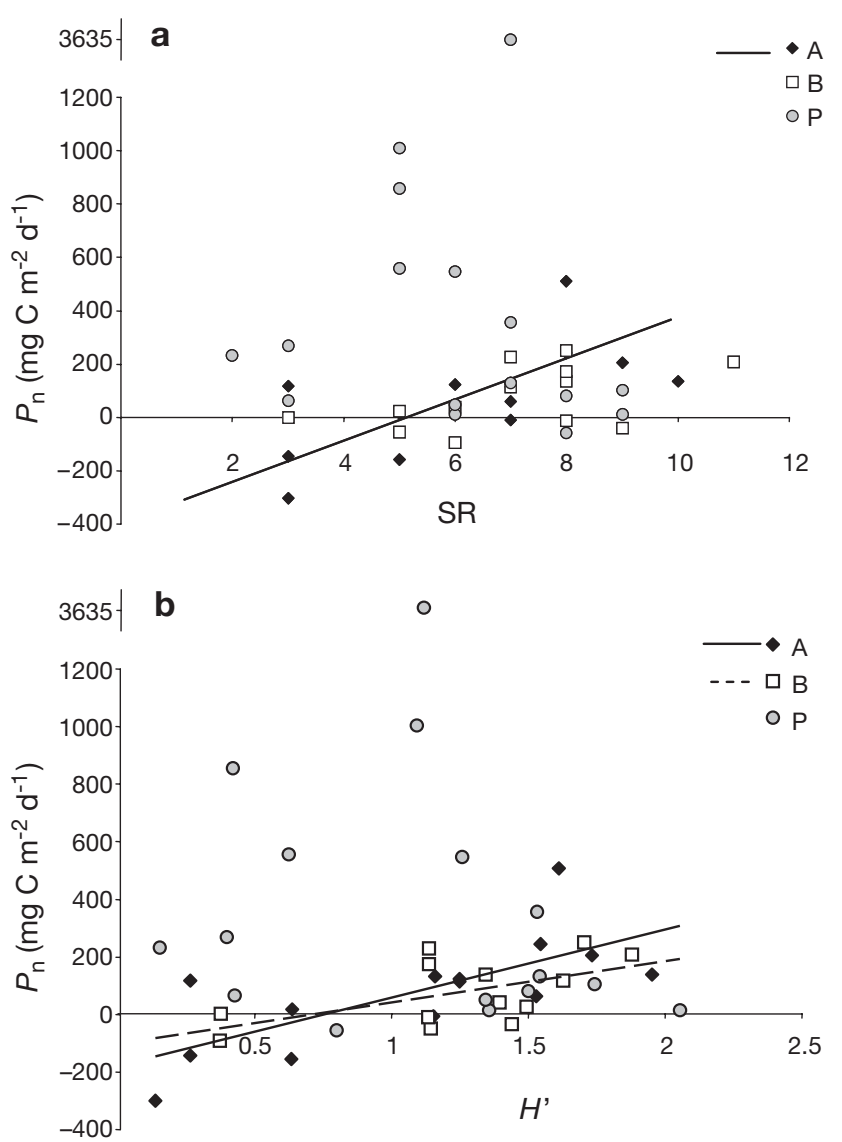

Fig. 5. Net primary production $\left(P_{\mathrm{n}}: \mathrm{mg} \mathrm{C} \mathrm{m}^{-2} \mathrm{~d}^{-1}\right)$ as a function of diversity indices: (a) species richness (SR) and (b) Shannon index $\left(H^{\prime}\right)$, for Appelzak (A: $\bullet$ ), Biezelingsche Ham (B: $\square$ ) and Paulina polder ( $\mathrm{P}: \mathrm{O})$. Linear regression: Panels a \& $\mathrm{b}: \mathrm{R}^{2}=0.5$, $\mathrm{p}<0.01, \mathrm{n}=13$ for Appelzak; Panel b: $\mathrm{R}^{2}=0.3, \mathrm{p}<0.01, \mathrm{n}=13$ for Biezelingsche Ham

very poorly developed compared to terrestrial ecology, and it remains to be seen whether terrestrial and marine systems are similar enough to allow theory from one domain to be used for the other (Covich et al. 2004). For example, marine systems are characterised by low population densities of small autotrophic primary producers being responsible for a disproportionately large amount of organic matter production (Heip et al. 2003). Thus, the standing stock of autotrophs may not be synonymous with primary production, as has been assumed in many terrestrial diversity-function experiments (Hector et al. 1999), but also in studies on marine phytoplankton (Irigoien et al. 2004). The expression of biodiversity also differs between studies. This can be the number of species as well as different indices (Gray 2000). In addition to these differences in processes and index definition, there are also different spatial scales and trophic levels to consider. Thus, comparison of diversity-function relationships between different studies is difficult. In this study, 2 measures of ecosystem function were chosen: (1) chl $a$ to represent the biomass of microalgal primary producers, which is an important food source for benthic invertebrates, and (2) the net primary production of the microalgae, which is closely related to growth rate and the resilience of the surface biofilm to losses. We expressed the level of biodiversity and its heterogeneity by species richness and the Shannon index.

Estuarine benthic diatom assemblages are species rich, with patterns of distribution and relative abundance of different species that vary consistently over seasonal and spatial scales (Admiraal 1984). Although careful autoecological work has revealed the preferences of different species for particular niches (Underwood \& Provot 2000), there is no consensus as to the main factors that determine community composition at the estuary scale. Some studies have highlighted the importance of sediment composition (e.g. Paterson \& Hagerthy 2001), in others, sediment ammonium concentration appeared to be an important factor influencing the distribution of benthic diatom species in salt marshes (Sullivan 1999) and mudflats (Peletier 1996, Underwood et al. 1998). In the Westerschelde there are consistent differences in species composition along the gradients of sediment composition and salinity (Sabbe \& Vyverman 1991) in terms of relative abundance (see also Fig. 2), but most species can be described as euryhaline, particularly in the Navicula group.

In spite of the variations in salinity and tidal height, which one would expect to negatively affect the number of species, the Westerschelde estuary presents a high number of diatom taxa compared to other mudflat ecosystems (e.g. Ribeiro et al. 2003 for the Tagus estuary; Thornton et al. 2002 for the Colne estuary). However, only a limited number of species had a high enough relative abundance to be classed as important in ecosystem function. Seventeen of these were epipelic, and the majority belonged to the genus Navicula, which are also key players in other tidal estuaries (Admiraal \& Peletier 1980, Colijn \& Dijkema 1981, Oppenheim 1991).

Species richness relative to total microphytobenthic diatoms showed a significant inverse relationship with biomass. This relationship was not significant when only epipelic species were considered. However, as in the study by Colijn \& Dijkema (1981), we found that sites with high biomasses showed dominance by a single species, or a low number of species (Fig. 4). Notably, the shape of the biomass-diversity curve for microphytobenthos differs from that for phytoplankton, for which both low and high biomass events are associated with low taxonomic diversity (Irigoien et al. 2004). As in phytoplankton, biodiversity was also suppressed at high cell densities occurring during the bloom periods of microphytobenthos, possibly due to 
competitive interactions for limiting resources. However, in the microphytobenthic community of the Westerschelde, low biomasses were generally associated with high rather than low diversity. In winter and early spring, when conditions were unfavourable for growth and chlorophyll concentrations were low, a diverse mix of species appeared to be present. These cells probably form the seed population for rapid biofilm development in spring. It is likely that there are strong founder effects in intertidal sediments, as in certain other aquatic ecosystems (De Meester et al. 2002). A fixed set of more competitive species, particular to each site, then monopolised the space in the upper sediment throughout the period of favourable growth. Epipelic species were dominant during this phase, but monospecific biofilms were not recorded. Rather, dominance was shared by a small number of species (typically 2 to 10), suggesting that there may be niche differentiation within the upper millimetres of the sediment photic zone. Species-specific differences in the depth or timing of migratory movements between the nutrient-rich aphotic zone and the nutrient-poor photic zone could be one mechanism of niche separation (Saburova \& Polikarpov 2003). The low number of dominant species and the regular appearance of the same set of species at particular sites suggest that this phase of the microphytobenthic system may be resistant to invasion by non-native species. Later in the year, low levels of chlorophyll were recorded at the low- and mid-salinity sites. This was probably driven by grazing and not by lack of nutrients, as porewater and estuarine water nutrients were at all times in excess of growth requirements. A high rate of grazing may promote diversity (and boost production, see below) by selective removal of the larger epipelic species (Hagerthey et al. 2002). In epilithic communities the effect of grazing on algal diversity was dependent upon the level of nutrient enrichment (Worm et al. 2002). A caveat must be added to this analysis: the dataset was obtained from field observations, in which neither biodiversity nor ecosystem function were manipulated experimentally. The biodiversity-function relationships that were apparent could also be a result of independent responses of each variable to changes in other parameters. So-called 'hidden' treatments in biodiversity-function experiments have been of major concern to terrestrial ecologists (Huston 1997).

In the marine environment, studies on the relationship between diversity and functioning are still rare, and the most common index of ecosystem function has been the rate and direction of inorganic nutrient flow between benthic and pelagic compartments (Emmerson et al. 2001, Covich et al. 2004). Primary production in phytoplankton from different sites generally showed a positive relationship with increasing species richness (Vadrucci et al. 2003). Although there have been many studies of benthic primary production (see Underwood \& Kromkamp 1999), none have directly linked production rates to species composition. Since the base of the trophic web in marine systems is dominated by singlecelled algae, with a high (and variable) ratio of production to biomass, it is inappropriate to use microalgal standing stock as an index of primary production (see discussion in Emmerson \& Huxham 2003). Indeed, no correlation was observed in the dataset described here between microphytobenthic biomass and estimated $P_{\mathrm{n}}$. The approach used here is therefore to model net production from a combination of photosynthetic measurements, algal abundance, sediment optical conditions and abiotic factors. Although our model was not detailed enough to account for within-day changes in species composition at the sediment surface, the performance of the model was tested in a laboratory mesocosm experiment in which the growth of a mixedspecies microphytobenthic biofilm was followed in detail for $2 \mathrm{wk}$. In that experiment, calculated values of $P_{\mathrm{n}}$ closely followed changes in carbon biomass as a biofilm developed (Morris 2005). The direct approach to the measurement of primary production, based on intensive, repeated sampling of cell number, carbon, or chlorophyll over relevant periods (e.g. spring-neap tidal cycle, Herlory et al. 2004) could be preferable to the modelling approach used here, especially in situations where losses due to grazing and resuspension are low, but for logistical reasons could not be performed with the multiple sites and seasons of this study.

The present study only involves 1 trophic level and takes into account the function of species in 1 taxonomic group: the epipelic diatoms. A linear relationship between chlorophyll concentration and the abundance of epipelic cells was found, thus confirming that the epipelon was the dominant functional component of biofilms in the Westerschelde, as in other estuaries (MacIntyre et al. 1996, Underwood \& Kromkamp 1999). In addition, epipelic cells migrate up to the sediment surface during daytime tidal emersion (Serôdio 2003). Thus, this group dominated not only the bulk chlorophyll, but also formed a large part of the photosynthetically active biomass, that is, the cells which are optimally positioned to intercept light. The relationship between species diversity (either richness or $H^{\prime}$ ) and $P_{\mathrm{n}}$ differed widely between sites within the estuary. The results should be interpreted with caution, as biodiversity was not deliberately manipulated as an independent variable in this study. The low- and midsalinity sites (A \& B) both showed significantly increasing rates of net production as biodiversity increased. Sampling events during periods of low or negative net production (mainly driven by low irradi- 
ance) were associated with low species richness and Shannon indices, which can be interpreted in 2 ways (Gessner et al. 2004). Either some species were sensitive to this form of environmental stress, which caused a decrease in biodiversity, or the low number of species was responsible for decreased rates of production. The latter scenario is perhaps less likely as biomassnormalised maximum rates of photosynthesis were relatively constant throughout the study. Site P at the seaward end of the estuary also showed low $P_{\mathrm{n}}$ at the lowest levels of diversity, but showed much higher rates of production at intermediate levels of diversity. All 3 sites showed similar $P_{\mathrm{n}}$ at the highest levels of diversity, e.g. species richness $>10$ and Shannon $H^{\prime}>$ 1.8. The dissimilarity in the response of microphytobenthos at Site P can be explained by the later appearance and slower decline of the spring biomass maximum at this site, possibly due to lower rates of grazing. Diatom biofilms persisted into late spring or summer at the high-shore site, and therefore encountered improved conditions of light and temperature for photosynthesis. Interestingly, these more favourable environmental circumstances did not feed back at the community level to an increased level of biodiversity. This may be related to the fact that many species may not be able to withstand drying out of the sediments during the warmer months of the year. Alternatively, the different diversity-production relationships may be related to the fact that epipsammic diatoms, which were not taken into account in our analyses, may have significantly contributed to production at the more sandy station (P1).

\section{CONCLUSIONS}

Studies of the biodiversity-function relationship began in terrestrial ecology, and the main question for the marine ecologist is: Can we use the same hypotheses and the same tools in the marine environment? According to Emmerson \& Huxham (2003) there are considerable advantages of using biomass as a measure of functioning in terrestrial ecology. However, in the marine coastal environment, changes in standing stock may be impossible to determine for each species, due to the open nature of the ecosystem. Moreover, the biomass represents the standing stock of organic matter, but may not reflect ecosystem metabolism if turnover rates are high. The results confirmed that biomass and primary production were not interchangeable, as they did not show the same relationship with diversity.

Site-specific differences were also found, especially in the relationships of $P_{\mathrm{n}}$ and biodiversity. Two sites showed that the enrichment of a key benthic functional group was related to enhanced production, but at the third site an intermediate level of richness corresponded to the highest level of production. The causes of this variability in the relationship are multiple. The scale of the study seems to be one of the factors (Chase \& Leibold 2002), due to variability in abiotic parameters along the estuary, such as salinity, sedimentation dynamics and nutrient supply. All these parameters drive the composition of the diatom community, as well as that of associated bacterial communities and consumers. Thus, the developmental history of the biofilm will influence the observed rates of ecosystem processes (Fukami \& Morin 2003). Experimental manipulations of diatom species richness under conditions in which abiotic parameters can be controlled, such as in climate-controlled tidal mesocosms, may give more direct insights into the functional consequences of biodiversity change. Finally, in order to have a better picture of the diversity-processes relationship in intertidal sediments, future studies should also take multiple trophic levels into account by manipulating consumer abundance.

Acknowledgements. This study was financed by EU Program Number EVK3-CT-2001-00052 'A system of hierarchical monitoring methods for assessing changes in the biological and physical state of intertidal areas' and the Dutch-Flemish Cooperation Program for Marine Research (VLaNeZo) Project Number 832.11.003;13 and BOF-GOA Project 01G00705 (Ghent University, Belgium). Renaat Dasseville and Jan Peene gave expert assistance during field sampling and production measurements. This is NIOO-KNAW Publication Number 3682.

\section{LITERATURE CITED}

Admiraal W (1984) The ecology of estuarine sediment-inhabiting diatoms. Prog Phycol Res 3:271-318

Admiraal W, Peletier HDSB (1980) Distribution of diatom species on an estuarine mud flat and experimental analysis of the selective effect of stress. J Exp Mar Biol Ecol 46: $157-175$

Barranguet C, Kromkamp J (2000) Estimating primary production rates from photosynthetic electron transport in estuarine microphytobenthos. Mar Ecol Prog Ser 204: $39-52$

Behrenfeld MJ, Falkowski PG (1997) Photosynthetic rates derived from satellite-based chlorophyll concentration. Limnol Oceanogr 42:1-20

Blanchard GF, Guarini JM, Richard P, Gros P, Mornet F (1996) Quantifying the short-term temperature effect on lightsaturated photosynthesis of intertidal microphytobenthos. Mar Ecol Prog Ser 134:309-313

Blanchard GF, Guarini JM, Gros P, Richard P (1997) Seasonal effect on the relationship between the photosynthetic capacity of intertidal microphytobenthos and temperature. J Phycol 33:723-728

Cahoon LB (1999) The role of benthic microalgae in neritic ecosystems. Oceanogr Mar Biol Annu Rev 37:47-86

Chase JM, Leibold MA (2002) Spatial scale dictates the productivity-biodiversity relationship. Nature 416:427-429 
Colijn F, Dijkema KS (1981) Species composition of benthic diatoms and distribution of chlorophyll $a$ on an intertidal flat in the Dutch Wadden Sea. Mar Ecol Prog Ser 4:9-21

Consalvey M, Paterson DM, Underwood GJC (2004) The ups and downs of life in a benthic biofilm: migration of benthic diatoms. Diatom Res 19:181-202

Costanza R, Kemp WM, Boynton WR (1993) Predictability, scale, and biodiversity in coastal and estuarine ecosystems-implications for management. Ambio 22:88-96

Covich AP, Austen MC, Barlocher F, Chauvet E and 8 others (2004) The role of biodiversity in the functioning of freshwater and marine benthic ecosystems. BioScience 54: 767-775

Defew EC, Paterson DM, Hagerthey SE (2002) The use of natural microphytobenthic assemblages as laboratory model systems. Mar Ecol Prog Ser 237:15-25

De Meester L, Gomez A, Okamura B, Schwenk K (2002) The monopolization hypothesis and the dispersal-gene flow paradox in aquatic organisms. Acta Oecol Int J Ecol 23: 121-135

Dunstan GA, Volkman JK, Barrett SM, Leroi JM, Jeffrey SW (1994) Essential polyunsaturated fatty-acids from 14 species of diatom (Bacillariophyceae). Phytochemistry 35:155-161

Emmerson MC, Huxham M (2003) How can marine ecology contribute to the biodiversity-ecosystem functioning debate? In: Loreau M, Naeem S, Inchausti P (eds) Biodiversity and ecosystem functioning, synthesis and perspectives. Oxford University Press, Oxford, p 139-146

Emmerson MC, Solan M, Emes C, Paterson DM, Raffaelli D (2001) Consistent patterns and the idiosyncratic effects of biodiversity in marine ecosystems. Nature 411:73-77

Ford RB, Honeywill C (2002) Grazing on intertidal microphytobenthos by macrofauna: is pheophorbide a a useful marker? Mar Ecol Prog Ser 229:33-42

Forster RM, Kromkamp JC (2004) Modelling the effects of chlorophyll fluorescence from subsurface layers on photosynthetic efficiency measurements in microphytobenthic algae. Mar Ecol Prog Ser 284:9-22

Forster RM, Kromkamp JC (2006) Estimating benthic primary production: scaling up from point measurements to the whole estuary. In: Kromkamp JC, de Brouwer JFC, Blanchard GF, Forster RM, Creach V (eds) Functioning of microphytobenthos in estuaries. KNAW, Amsterdam

Fukami T, Morin PJ (2003) Productivity-biodiversity relationships depend on the history of community assembly. Nature 424:423-426

Gattuso JP, Frankignoulle M, Wollast R (1998) Carbon and carbonate metabolism in coastal aquatic ecosystems. Annu Rev Ecol Syst 29:405-434

Gazeau F, Smith SV, Gentili B, Frankignoulle M, Gattuso JP (2004) The European coastal zone: characterization and first assessment of ecosystem metabolism. Estuar Coast Shelf Sci 60:673-694

Geider RJ (1992) Respiration: taxation without representation. In: Falkowski PG, Woodhead AD (eds) Primary productivity and biogeochemical cycles in the sea. Plenum, New York

Gessner MO, Inchausti P, Persson L, Raffaelli DG, Giller PS (2004) Biodiversity effects on ecosystem functioning: insights from aquatic systems. Oikos 104:419-422

Gray JS (2000) The measurement of marine species diversity, with an application to the benthic fauna of the Norwegian continental shelf. J Exp Mar Biol Ecol 250:23-49

Guarini JM, Blanchard GF, Gros P, Gouleau D, Bacher C (2000) Dynamic model of the short-term variability of microphytobenthic biomass on temperate intertidal mudflats. Mar Ecol Prog Ser 195:291-303
Hagerthey SE, Defew EC, Paterson DM (2002) Influence of Corophium volutator and Hydrobia ulvae on intertidal benthic diatom assemblages under different nutrient and temperature regimes. Mar Ecol Prog Ser 245:47-59

Hector A, Schmid B, Beierkuhnlein C, Caldeira MC and 30 others (1999) Plant diversity and productivity experiments in European grasslands. Science 286:1123-1127

Heip CHR, Goosen NK, Herman PMJ, Kromkamp J, Middelburg JJ, Soetaert K (1995) Production and consumption of biological particles in temperate tidal estuaries. Oceanogr Mar Biol Annu Rev 33:1-149

Heip C, Brandt A, Gattuso JP, Anita A and 12 others (2003) Ecosystem functioning and biodiversity. In: Wefer $G$, Lamy F, Mantoura F (eds) Marine science frontiers for Europe. Springer-Verlag, Berlin

Henley WJ (1993) Measurement and interpretation of photosynthetic light-response curves in algae in the context of photoinhibition and diel changes. J Phycol 29:729-739

Herlory O, Guarini JM, Richard P, Blanchard GF (2004) Microstructure of microphytobenthic biofilm and its spatio-temporal dynamics in an intertidal mudflat (Aiguillon Bay, France). Mar Ecol Prog Ser 282:33-44

Herman PMJ, Middelburg JJ, Van de Koppel J, Heip CHR (1999) Ecology of estuarine macrobenthos. Adv Ecol Res 29:195-240

Huston MA (1997) Hidden treatments in ecological experiments: re-evaluating the ecosystem function of biodiversity. Oecologia 110:449-460

Irigoien X, Huisman J, Harris RP (2004) Global biodiversity patterns of marine phytoplankton and zooplankton. Nature 429:863-867

Lewis MR, Smith JC (1983) A small volume, short-incubationtime method for measurement of photosynthesis as a function of incident irradiance. Mar Ecol Prog Ser 13:99-102

Loreau M (2000) Biodiversity and ecosystem functioning: recent theoretical advances. Oikos 91:3-17

MacIntyre HL, Geider RJ, Miller DC (1996) Microphytobenthos-the ecological role of the secret garden of unvegetated, shallow-water marine habitats. 1. Distribution, abundance and primary production. Estuaries 19:186-201

Magurran AE (1988) Ecological diversity and its measurement. Princeton University Press, Princeton

Middelburg JJ, Duarte CM, Gattuso JP (2005) Respiration in coastal benthic communities. In: del Giorgio PA, Williams $\mathrm{P}$ (eds) Respiration in aquatic systems. University of Wales, Bangor

Morris EP (2005) Quantifying primary production of microphytobenthos: application of optical methods. $\mathrm{PhD}$ thesis, University of Groningen, Groningen

Morris EP, Kromkamp JC (2003) Influence of temperature on the relationship between oxygen and fluorescence-based estimates of photosynthetic parameters in a marine benthic diatom (Cylindrotheca closterium). Eur J Phycol 38: $133-142$

Oppenheim DR (1991) Seasonal changes in epipelagic diatoms along an intertidal shore, Berrow Flats, Somerset. J Mar Biol Assoc UK 71:579-596

Paterson DM, Hagerthey SE (2001) Microphytobenthos in contrasting coastal ecosystems: biology and dynamics. In: Reise K (ed) Ecological studies, Vol 151. Ecological comparisons of sedimentary shores. Springer-Verlag, Berlin, p 105-125

Peletier H (1996) Long-term changes in intertidal estuarine diatom assemblages related to reduced input of organic waste. Mar Ecol Prog Ser 137:265-271

Perkins RG, Honeywill C, Consalvey M, Austin HA, Tolhurst TJ, Paterson DM (2003) Changes in microphytobenthic 
chlorophyll $a$ and EPS resulting from sediment compaction due to de-watering: opposing patterns in concentration and content. Cont Shelf Res 23:575-586

Ribeiro L, Brotas V, Mascarell G, Coute A (2003) Taxonomic survey of the microphytobenthic communities of two Tagus estuary mudflats. Acta Oecol Int $\mathrm{J}$ Ecol 24: $117-123$

Sabbe K (1997) Systematics and ecology of intertidal benthic diatoms of the Westerschelde estuary (The Netherlands). Thesis, University of Ghent, Ghent

Sabbe K, Vyverman W (1991) Distribution of benthic diatom assemblages in the Westerschelde (Zeeland, The Netherlands). Belg J Bot 124:91-101

Saburova MA, Polikarpov IG (2003) Diatom activity within soft sediments: behavioural and physiological processes. Mar Ecol Prog Ser 251:115-126

Serôdio J (2003) A chlorophyll fluorescence index to estimate short-term rates of photosynthesis by intertidal microphytobenthos. J Phycol 39:33-46

Serôdio J, Catarino F (2000) Modelling the primary productivity of intertidal microphytobenthos: time scales of variability and effects of migratory rhythms. Mar Ecol Prog Ser 192:13-30

Sullivan MJ (1999) Applied diatom studies in estuarine and shallow coastal environments. In: Stoermer EF, Smol JP (eds) The diatoms: applications for the environmental and earth sciences. Cambridge University Press, Cambridge, p 334-351

Sundbäck K, Miles A, Goransson E (2000) Nitrogen fluxes, denitrification and the role of microphytobenthos in microtidal shallow-water sediments: an annual study. Mar Ecol Prog Ser 200:59-76

Thornton DCO, Dong LF, Underwood GJC, Nedwell DB (2002) Factors affecting microphytobenthic biomass, species composition and production in the Colne estuary (UK). Aquat Microb Ecol 27:285-300

Editorial responsibility: Martin Solan (Guest Editor), Newburgh, UK
Tolhurst TJ, Jesus B, Brotas V, Paterson DM (2003) Diatom migration and sediment armouring - an example from the Tagus estuary, Portugal. Hydrobiologia 503:183-193

Underwood GJC, Kromkamp J (1999) Primary production by phytoplankton and microphytobenthos in estuaries. Adv Ecol Res 29:93-153

Underwood GJC, Provot L (2000) Determining the environmental preferences of four estuarine epipelic diatom taxa: growth across a range of salinity, nitrate and ammonium conditions. Eur J Phycol 35:173-182

Underwood GJC, Phillips J, Saunders K (1998) Distribution of estuarine benthic diatom species along salinity and nutrient gradients. Eur J Phycol 33:173-183

Vadrucci MR, Vignes F, Fiocca A, Basset A, Santarpia I, Carrada GC, Cabrini M, Umani SF (2003) Space-time patterns of co-variation of biodiversity and primary production in phytoplankton guilds of coastal marine environments. Aquat Conserv 13:489-506

Vos PC, de Wolf H (1993) Diatoms as a tool for reconstructing sedimentary environments in coastal wetlands - methodological aspects. Hydrobiologia 269:285-296

Waide RB, Willig MR, Steiner CF, Mittelbach G, Gough L, Dodson SI, Juday GP, Parmenter R (1999) The relationship between productivity and species richness. Annu Rev Ecol Syst 30:257-300

Wardle DA, Bonner KI, Barker GM (2000) Stability of ecosystem properties in response to above-ground functional group richness and composition. Oikos 89:11-23

Webb P, Wooldridge T, Schlacher T (1997) Osmoregulation and spatial distribution in four species of mysid shrimps. Comp Biochem Physiol A 117:427-431

Woodward RT, Wui YS (2001) The economic value of wetland services: a meta-analysis. Ecol Econ 37:257-270

Worm B, Lotze HK, Hillebrand H, Sommer U (2002) Consumer versus resource control of species diversity and ecosystem functioning. Nature 417:848-851

Submitted: January 28, 2005; Accepted: October 21, 2005

Proofs received from author(s): March 9, 2006 



\title{
Changes in productivity associated with four introduced species: ecosystem transformation of a 'pristine' estuary
}

\author{
J. L. Ruesink ${ }^{1, *}$, B. E. Feist ${ }^{2}$, C. J. Harvey ${ }^{2}$, J. S. Hong ${ }^{3}$, A. C. Trimble ${ }^{1}$, L. M. Wisehart ${ }^{4}$ \\ ${ }^{1}$ Department of Biology, University of Washington, Box 35100, Seattle, Washington 98195-1800, USA \\ ${ }^{2}$ Northwest Fisheries Science Center, Fishery Resource Analysis and Monitoring Division, NOAA Fisheries, \\ 2725 Montlake Boulevard E, Seattle, Washington 98112-2097, USA \\ ${ }^{3}$ Department of Oceanography, Inha University, Incheon 402-751, Republic of Korea \\ ${ }^{4}$ Zoology Department, Oregon State University, Corvallis, Oregon 97331, USA
}

\begin{abstract}
Multiple stressors in estuaries can cause declines in native species and impairment of ecosystem goods and services. In contrast, one stressor - the introduction of non-native speciesactually leads to higher local richness. We examined the changes in ecosystem function associated with introductions into Willapa Bay, Washington, USA, a relatively undeveloped estuary with 45 documented exotic marine species. The replacement of native oysters by 2 new bivalve species has increased secondary production of harvested suspension feeders by $250 \%$ over peak historic values $\left(3.3 \times 10^{5}\right.$ vs. $0.9 \times 10^{5} \mathrm{~kg}$ dry wt $\left.\mathrm{yr}^{-1}\right)$, based on $>150 \mathrm{yr}$ of records of harvested biomass. Key aspects of aquaculture - particularly planted area - have remained constant over time, so we attribute much of the altered secondary production to higher growth rates of non-native species. The addition of 2 tracheophytes has increased primary production on the tideflats by $>50 \%\left(5.3 \times 10^{7} \mathrm{vs} .3 .5 \times 10^{7} \mathrm{~kg}\right.$ dry wt $\mathrm{yr}^{-1}$ ), which we calculated by scaling up local measurements of plant growth to the total area occupied by each species. These changes in production are also associated with altered detritus, water filtration, and biogenic habitat. Because other stressors are largely absent from Willapa Bay, the addition of particular exotic species has dramatically enhanced system production, while fundamentally reshaping the ecological character of the estuary. These strong ecological impacts of introduced species have rarely been measured at whole-ecosystem scales, and they occur in part because new species occupy habitats where similar native species were not present.
\end{abstract}

KEY WORDS: Crassostrea gigas $\cdot$ Invasion $\cdot$ Ostreola conchaphila $\cdot$ Spartina alterniflora $\cdot$ Ruditapes philippinarum $\cdot$ Zostera marina $\cdot$ Zostera japonica

Resale or republication not permitted without written consent of the publisher

\section{INTRODUCTION}

Many recent studies reveal a saturating relationship between ecosystem functions and species richness, with marginal change attributable to additional species when many others are already present (Hooper et al. 2005). In contrast, the addition of species through ecological invasion can cause dramatic change. Ecosystem functions are expected to be altered by exotic species that play entirely new roles in ecosystems (Shea \& Chesson 2002, Cuddington \& Hastings 2004), and some empirical examples exist (e.g. Myrica faya alters nutrient cycling in Hawaii where no native N-fixing plants occur; Vitousek \& Walker 1989). However, to date, ecologists have been presented with few opportunities to study whole-ecosystem impacts of introduced species. For instance, Parker et al. (1999) found just 18 examples of ecosystem-level impacts of invaders reported over a $10 \mathrm{yr}$ period, across all taxa and ecosystems, whereas impacts at individual, population, and community levels were studied more frequently ( $>90 \%$ of total). A unique opportunity arises in Willapa Bay, Washington, USA $\left(46^{\circ} 40^{\prime} \mathrm{N}, 124^{\circ} 0^{\prime} \mathrm{W}\right.$; surface area at mean sea level $=24000 \mathrm{ha})$, where 
lengthy time series and spatially explicit data allow reconstruction of primary production of tracheophytes and secondary production of bivalves over more than a century, during which period numerous nonindigenous species arrived. In this paper, we focus on 4 introduced species in Willapa Bay and document their contributions to primary and secondary production in the estuary. This case study illustrates 2 points: first, that gains in species - as much as species losses - can markedly influence whole-ecosystem functioning and therefore warrant the attention of predictive ecology and, second, that major changes in ecosystem functioning can be attributed to a few high-impact species rather than increases or decreases in numbers of species per se.

To set the stage for calculating whole-ecosystem changes and discussing their generality, we first present an ecological history of the bay. Willapa Bay is widely touted as pristine and productive (Wolf 1993, NOAA 1997), as it is largely unaffected by the pollution and coastal development that plague other estuaries. Chemical and nutrient pollution has historically been negligible, due to the sparse human population, minimal development in the watershed, and the absence of major industrial activities. About $30 \%$ of the 3500 ha of tidal marsh between mean high and extreme high water has been lost to diking for agriculture or expanding towns (Borde et al. 2003), but little other bathymetric modification has occurred since 1977 when maintenance dredging of the Willapa River channel ended (Hedgpeth \& Obrebski 1981). Sediment loads to the bay have likely varied over the past century of logging within the watershed (Hedgpeth \& Obrebski 1981, Kehoe 1982, Komar et al. 2004), and as a result of damming the Columbia River, the second largest river of the continental United States, which exits just south and often influences conditions at the bay's mouth (Simenstad et al. 1992, Peterson et al.
2000). The impacts of diking and sediment loading peaked by the mid-20th century and have since been constant or declined. The bay is also highly productive, as evidenced by its shellfish industry: although it is only $1 / 30$ the size of Chesapeake Bay on the east coast of the United States, nearly $10 \%$ of the United States' oysters are harvested there (US total $=16804$ metric tons shucked annually; Pritchard 2004), and shellfish production has contributed significantly to the local economy for $>150$ yr (Espy 1977). In contrast, over the same time period, oyster production on the east coast of the United States has dropped by $>90 \%$ (Kirby 2004), in part due to habitat degradation.

While its physical and chemical changes have been minimal (therefore remaining relatively 'pristine'), Willapa Bay has been biologically transformed by introduced species (Fig. 1). The tally now stands at 45 new plants, algae, and invertebrates (Wonham \& Carlton 2005), which comprise $>10 \%$ of the total estuarine biota (Ferraro \& Cole 2004). Two introduced taxa are particularly prominent: bivalve molluscs and aquatic tracheophyte plants. Pacific oysters Crassostrea gigas (Thunberg, 1793) were introduced to Willapa Bay in 1928 after native oysters Ostreola conchaphila (=Ostrea lurida) (Carpenter, 1857) were overexploited and transplants from eastern North America (Crassostrea virginica [Gmelin, 1791]) failed to thrive (Kincaid 1968). Early aquaculture activities involving these introduced oysters served as a vector for numerous other introductions (Carlton 1992).

The baseline bivalve community included thick accumulations of Ostreola conchaphila, covering up to $10 \%$ of the area of the bay, primarily in subtidal areas according to old charts (Collins 1892, Townsend 1896). O. conchaphila was commercially extinct by the early 20th century and, despite almost a century of low exploitation, remains rare in Willapa Bay (and throughout most of its range; Cook et al. 2000).
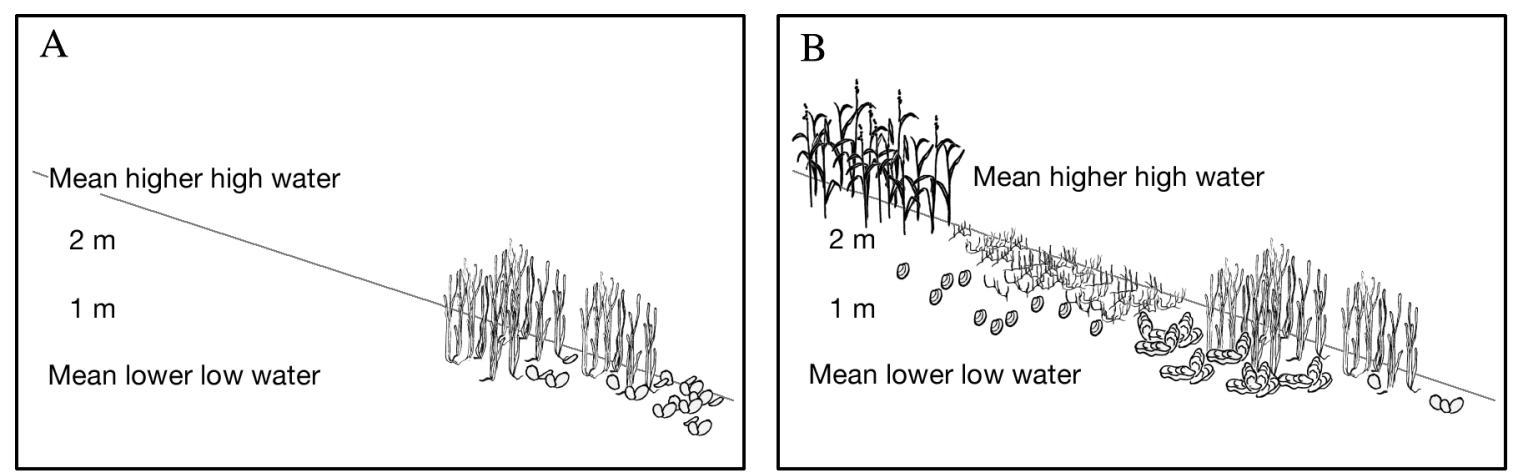

Fig. 1. Dominant space-occupying species on the tideflats of Willapa Bay. Vertical elevations (mean lower low water, $1 \mathrm{~m}$ above MLLW, $2 \mathrm{~m}$ above MLLW and mean higher high water) are provided to show where these species are found on tideflats. The slope of the tideflat (angled line) is exaggerated relative to field conditions. (A) Before 1900: native eelgrass Zostera marina and oysters Ostreola conchaphila. (B) After 2000: cordgrass Spartina alterniflora, Manila clams Ruditapes philippinarum, Japanese eelgrass Zostera japonica, and Pacific oysters Crassostrea gigas, in addition to native eelgrass and reduced densities of native oysters 
The introduced oyster Crassostrea gigas constitutes the bulk of oysters currently harvested from the bay (at least 3 other introduced oysters are planted in small numbers) and occurs in 2 habitats. In upper portions of the estuary, it recruits reliably and forms dense intertidal hummocks $\left(<1\right.$ to $\left.100 \mathrm{~m}^{2}\right)$ of tightly connected shell and live oysters. Many of these oysters are never harvested due to slow growth and irregular shapes. Nearer to the mouth, oysters are planted at relatively low densities directly on the bottom; oysters originate from natural recruitment elsewhere in the bay or from hatcheries.

A third bivalve, the Manila clam or Japanese littleneck Ruditapes (=Venerupis = Tapes) philippinarum (Adams \& Reeve, 1850) is now regularly harvested from the bay. Manila clams were introduced to the eastern Pacific as hitchhikers on Crassostrea gigas in 1936 (Carlton 1992); they are now cultivated on midintertidal flats. As with C. gigas, the distribution of Manila clams in Willapa Bay reflects both natural recruitment and planting. Little is known of the historic densities and distributions of other clams, although some insight comes from short periods of harvest records for introduced softshell clams Mya arenaria (Linnaeus, 1758) and for native razor clams Siliqua patula (Dixon, 1789) and littlenecks Protothaca staminea (Conrad, 1837). The 3 major harvested bivalve species allow a comparison, through historical records of yields, of the contributions to secondary production by native and introduced species.

Introduced oysters have been the vector of 2 plant species that occupy what were previously unvegetated mudflats (Fig. 1). The baseline condition for aquatic tracheophytes included native eelgrass Zostera marina (Linnaeus, 1753) in pools and extensive beds, generally at and just below mean lower low water (Borde et al. 2003). At upper tidal elevations, an invasive smooth cordgrass Spartina alterniflora (Loisel.) has increased rapidly over the past 2 decades, although its unintentional introduction occurred around 1890, presumably as discarded packing material for transplanted Crassostrea virginica (Townsend 1893, 1896, Feist \& Simenstad 2000). No native Spartina species occur in Willapa Bay, and $S$. alterniflora is considered a noxious weed in Washington State, with nearly \$2 million spent annually towards Spartina control. A small eelgrass species (Zostera japonica [Aschers. et Graebn.]) arrived on the British Columbia coast with transplanted C. gigas by 1957, but may have been in coastal Washington even earlier (Harrison \& Bigley 1982). In Willapa Bay, it now fills much of the tideflat between $Z$. marina and $S$. alterniflora. Ironically, Z. japonica in Washington state enjoys the same protection afforded the native species of eelgrass (Wonham 2003). These 3 plant species allow a comparison, through data on distribution and growth, of the contributions to primary production by native and introduced species.

We focus on 3 topics relating invasion and ecosystem functioning: (1) primary production by aquatic tracheophytes in Willapa Bay (1 native, 2 introduced species); (2) secondary production by bivalves in the bay (1 native, 2 introduced species); and (3) associated changes in biogenic habitat, detrital production, and filtration capacity. By compiling information from a variety of sources, we are able to estimate primary and secondary production by conspicuous species and how these have changed with the local rise in species richness accompanying introductions.

\section{MATERIALS AND METHODS}

Change in primary production in Willapa Bay. The area covered by the 2 eelgrass species was estimated from an unsupervised classification of a LANDSAT satellite image, acquired at low tide $(-0.307 \mathrm{~m}$ relative to mean lower low water [MLLW]) at 18:30 h GMT (Greenwich mean time) on 5 May 1997 (B. E. Feist \& C. A. Simenstad unpubl. data) (Fig. 2). Although it was possible to distinguish eelgrass beds of different density (dense vs. sparse) based on spectral differences, we did not use this information in our calculation of estuary-wide production, because our unit-production estimates came from a range of sites and eelgrass densities in the bay. Because it was not possible to distinguish the 2 species of Zostera in the LANDSAT image, we used additional groundtruthing data to determine coverage by each species. An independent assessment of habitat types was carried out by NOAA Coastal Services Center (NOAA CSC 2000) in 1997, which included 20 points within the area we classified as eelgrass and 74 outside. Commission errors were low: only 8 of 53 points without eelgrass were classified as eelgrass present. However, the LANDSAT image classification did miss considerable eelgrass, and only 12 of 41 points with eelgrass were classified as such. Overall, $60 \%$ of the points were classified correctly, with some bias towards underestimating total area of eelgrass (no correction to total area was attempted). We determined the percentage of georeferenced points observed to contain each species (55.5\% Z. marina, $44.4 \%$ Z. japonica) and multiplied the total area of eelgrass by the fraction represented by each species. For comparison, bathymetric considerations provide an estimate of 4845 ha potentially occupied by $Z$. marina in the 1950s, and 3139 ha, in the 1850s, when bay depths were lower on average (Borde et al. 2003). Our estimate of area covered by $Z$. marina fell within this range (3424 ha), likely at the lower end because other habitat types occupy some of the potential eelgrass zone ( 0 to $-1.2 \mathrm{~m}$ MLLW). 


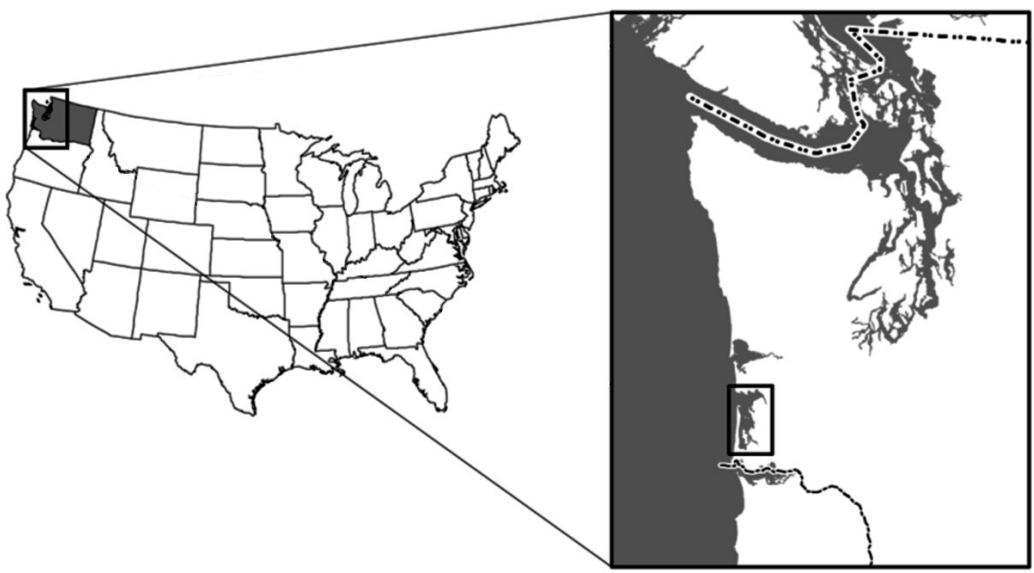

Fig. 2. Zostera marina and Z. japonica (left panel) and Spartina alterniflora (right panel). Distribution of dominant macrophyte species of Willapa Bay, ca. 1997. Inset shows location of Willapa Bay on the west coast of the United
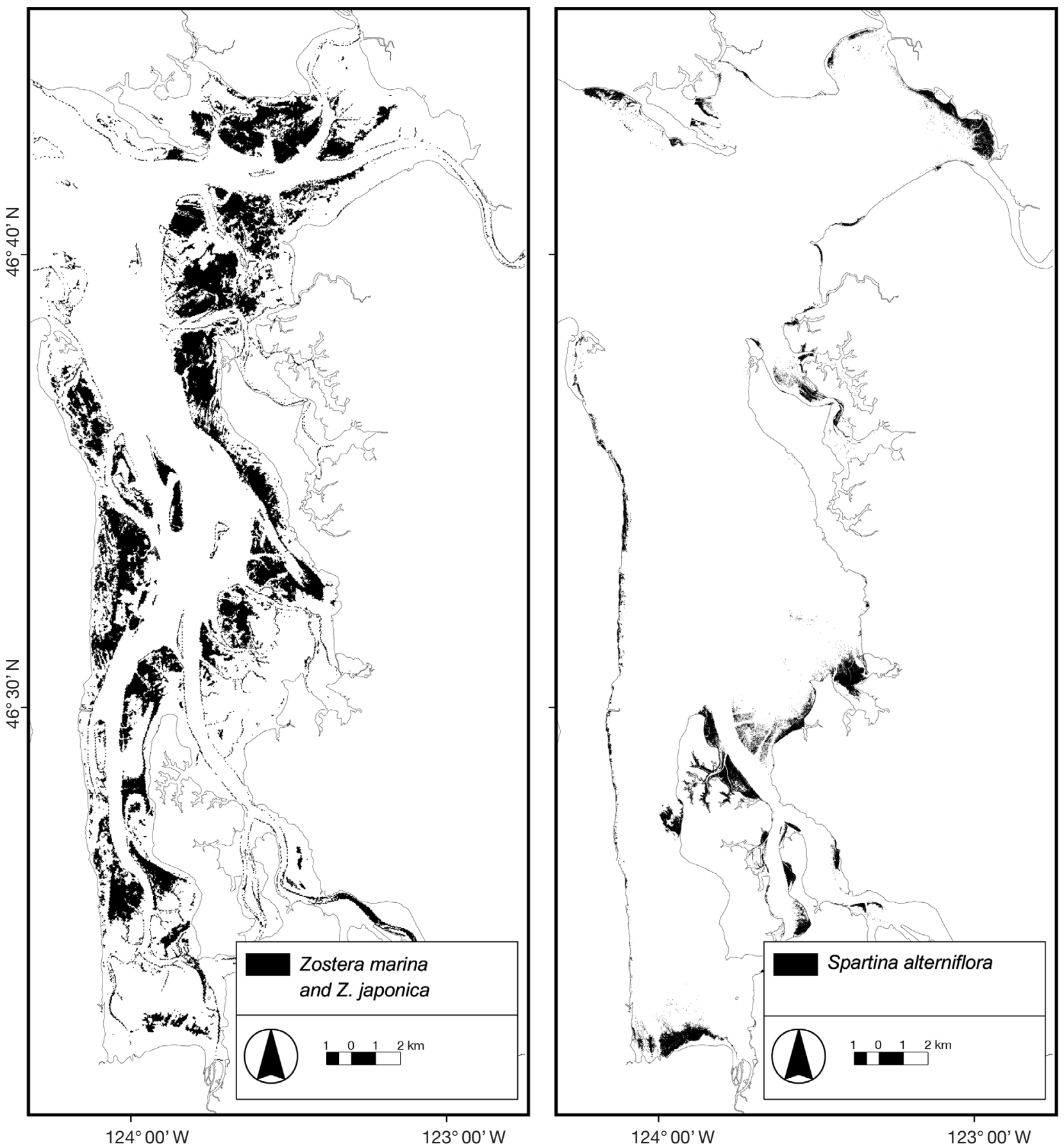
Annual production of Zostera marina on a unit-area basis was derived from shoot densities and growth measured seasonally at 7 locations spread across a distance of $20 \mathrm{~km}$ in Willapa Bay. Shoot density was based on the average shoot count in ten $0.25 \mathrm{~m}^{2}$ quadrats placed near 0 MLLW at each location. Adjacent to each quadrat, 5 shoots were pricked with an 18 gauge needle at the leaf sheath (Zieman \& Wetzel 1980). After 2 to 4 d, these shoots were collected, and growing leaves were separated into original (from needle mark to leaf tip) and new (from leaf sheath to needle mark) material and dried to constant weight at $60^{\circ} \mathrm{C}$. The masses of new material were averaged to estimate growth at each site. We measured shoot density and growth 4 times in 2004: winter (February), spring (early May), summer (late June), and autumn (early September). The product of shoot density and growth yielded unit-area production per day in each season. Annual unit-area production was calculated by extending daily measurements to each season, and summing across seasons. Obviously, these calculations require addition and multiplication that complicate calculations of error structure. To avoid problems associated with adding and multiplying error terms, we took a Monte Carlo approach. The entire calculation was repeated 100 times, each time selecting density and growth values at random from among the 7 locations for each season. From these 100 iterations, we calculated a mean and standard deviation. Finally we multiplied this unit-area annual production by the estimated area covered by $Z$. marina.

To assess annual production of Zostera japonica, we measured shoot densities and growth at 6 locations across $10 \mathrm{~km}$ in Willapa Bay: 3 locations were in the upper range occupied by $Z$. japonica, $+1.2 \mathrm{~m} \mathrm{MLLW,} \mathrm{and}$ 3 were at the lower end, $+0.6 \mathrm{~m}$ MLLW. Because $Z$. japonica blades are too narrow $(<1 \mathrm{~mm})$ for the holepunching technique, we instead used a comparable protocol (Kaldy 2006). Shoots were counted in nine $10 \mathrm{~cm}$ diameter areas at each sampling location. Growth was measured in 5 nearby $10 \mathrm{~cm}$ diameter areas, distinguished by PVC sleeves pushed $10 \mathrm{~cm}$ into the sediment and flush with the surface. We initially trimmed all shoots just above the leaf sheath. After $2 \mathrm{wk}$, shoots were again counted and trimmed, and the above-ground material was dried to constant weight at $60^{\circ} \mathrm{C}$. Growth rate was determined from the amount of new biomass relative to shoot number when the shoots were collected, divided by the number of days between initial and final trims. Because photosynthetic tissue was lost during the initial trim, regrowth may have slowed and growth rates are conservative (Ferraro \& Oesterheld 2002). Density and growth were sampled 5 times in 2004: March, May, July, September, and December. These measurements were extrapolated to 2 mo periods (except $4 \mathrm{mo}$ in winter). To estimate above- ground unit-area primary production, we selected values for density and growth at random from among the 6 locations at each time period. We multiplied density, growth, and the number of days in each season, then summed across seasons. This procedure was repeated 100 times to incorporate uncertainty. We calculated mean annual unit-area production (and standard deviation) from these 100 randomizations, then multiplied by the estimated tideflat area occupied by $Z$. japonica to generate a production estimate for the entire bay.

The Washington State Department of Natural Resources calculated the total solid area covered by Spartina alterniflora in Willapa Bay in 1997 using falsecolor infrared aerial photographs and ESRI ArcView shapefiles (WADNR 1999) (Fig. 2). This method slightly underestimated coverage because patches of $<1.36 \mathrm{~m}^{2}$ could not be detected. In contrast to eelgrass, cordgrass loses little of its production during the growing season, instead accumulating tissue above ground before dying back at the end of the year. Consequently, above-ground biomass per area served as a proxy for annual production; these values were available for Willapa Bay in Grevstad et al. (2003), as mean values for 3 locations. We multiplied this production per unit area by area covered by $S$. alterniflora to derive production for the whole bay.

Concerning other tracheophytes, no data are available for primary production in Willapa Bay's tidal marsh, which currently occupies 2484 ha between mean high water and extreme high water (Borde et al. 2003). Marsh plants have been replaced by terrestrial species in areas diked for grazing, but the more recent expansion of introduced aquatic tracheophytes has probably not further altered the contribution of high marsh to primary production in the bay-both introduced species grow below mean high water, whereas in Willapa Bay native marsh occurs above this level (Borde et al. 2003, Zhang et al. 2004, authors' pers. obs.).

Change in secondary production in Willapa Bay. We estimated annual production of the focal native bivalve (Ostreola conchaphila) and introduced bivalves (Crassostrea gigas and Ruditapes philippinarum) from aquaculture yields in Willapa Bay, as reported to the Washington Department of Fish and Wildlife (Fig. 3). Long-term average yields usually represent a minimum estimate of annual production, because the new biomass in each year must replace the biomass of bivalves removed by harvest. For each species, uncertainty in production was based on interannual variation over a period of 13 to 33 yr (arbitrarily selected as representative of sustained harvest levels), even though this variation may be due more to economic than to ecological conditions. Oyster yields were reported as pounds of shucked meat, which we converted to dry tissue mass by assuming a dry mass:fresh mass ratio of 0.22 (Kobayashi et al. 1997). Clam yields were reported as 


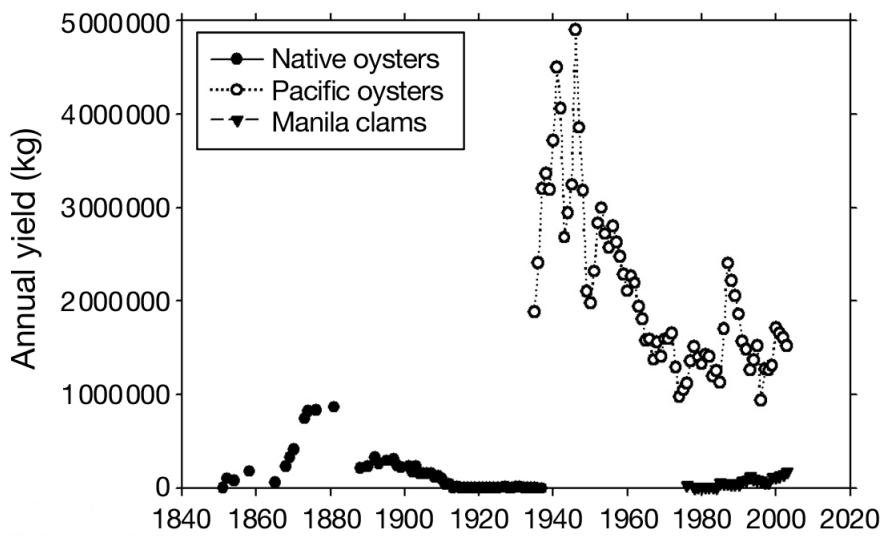

Fig. 3. Ostreola conchaphila, Crassostrea gigas, and Ruditapes philippinarum. Yields of bivalve species from Willapa Bay over 150 yr from Washington Department of Fish and Wildlife marine fish and shellfish landings annual reports. $O$. conchaphila (native oysters) and C. gigas (Pacific oysters) are displayed in units of shucked-meat weight (fresh), and $R$. philippinarum (Manila clams) in units of whole-clam weight

pounds in the shell, which we converted to dry tissue mass by assuming a dry mass:whole fresh mass ratio of 0.066 for 40 to $50 \mathrm{~mm}$ clams (Solidoro et al. 2003).

Historical trends of other bivalves are mostly unknown because poor records exist even for those species that are occasionally harvested. However, these harvest records for 1980 to 1991 suggest that other bivalves occurred at fairly low densities relative to oysters and Manila clams. For instance, native littlenecks Protothaca staminea and razor clams Siliqua patula averaged $1 \times 10^{4} \mathrm{~kg}$ live weight harvested per year, $\sim 10 \%$ of recent harvests of Manila clams (Fig. 3). Introduced softshell clams Mya arenaria were considered for a fishery in the late 1800 s, but populations declined abruptly before commercial exploitation began (Palacios et al. 2000).

Other ecosystem functions. Primary and secondary production in estuaries directly influence other ecosystem functions, such as habitat provision, inputs to detrital food webs, and water filtration. To assess changes in habitat, we focused on area occupied by native and introduced species. These data were readily available from LANDSAT and aerial photographs for tracheophytes (see 'Materials and methods Change in primary production in Willapa Bay'), but bivalves have not been similarly mapped. Both native and Pacific oysters recruit naturally in the southern part of Willapa Bay, due to warmer water temperatures and higher larval retention, but aquaculture primarily occurs closer to the mouth of the estuary, where growth rates are rapid (Ruesink et al. 2003).

All primary production was assumed to enter the detrital food web following senescence, because few herbivores consume eelgrass or cordgrass. In addition to changing detrital biomass, introduced species potentially influence both the timing and the quality (carbon:nitrogen ratio) of dead plant material. This matter may be a source of food or nutrients for some biota, and a source of disturbance to other biota sensitive to wrack burial. We have not quantified detritus fate, but offer a qualitative summary of information on eelgrassand cordgrass-derived detritus.

Filtration of Willapa Bay's water derives in part from cultured bivalves, and, consequently, we estimated filtration capacity based on secondary production. Filtration rates for each species were not measured directly in Willapa Bay, but a consistent relationship exists between size and filtration rate across many bivalve species (Powell et al. 1992). Consequently, we incorporated individual filtration rates of $3 \mathrm{l} \mathrm{h}^{-1}$ for Crassostrea gigas (100 mm, $2.4 \mathrm{~g}$ dry wt; Kobayashi et al. 1997) and $1 \mathrm{l} \mathrm{h}^{-1}$ for Ruditapes philippinarum (50 mm, $3.9 \mathrm{~g}$ dry $\mathrm{wt}_{\text {; }}$ Solidoro et al. 2003) and for Ostreola conchaphila (50 mm, $0.4 \mathrm{~g}$ dry wt; Brennan 1939). We determined the number of individuals of each bivalve species as the ratio of total harvest:individual biomass, and multiplied this estimate of density by per capita filtration rate. We then compared filtration by each species to the bay's total volume $\left(7.6 \times 10^{11} 1\right.$ at mean sea level; Hickey \& Banas 2003).

\section{RESULTS}

\section{Change in primary production in Willapa Bay}

The essential components for estimating primary production by aquatic tracheophytes in Willapa Bay included estimates of area occupied and annual production per area. Based on habitat classification from recent satellite images, each eelgrass species occupied about 3000 ha in Willapa Bay, and Spartina alterniflora occupied about 1300 ha in 1997 (Fig. 2). Annual rates of production per area were similar for S. alterniflora, based on peak standing biomass, and for Zostera marina based on seasonal measurements of growth rate $\left(\sim 1000 \mathrm{~g}\right.$ dry $\mathrm{wt} \mathrm{m}^{-2} \mathrm{yr}^{-1}$; Table 1$)$. These rates fall close to other published reports of net primary productivity for $S$. alterniflora (Dai \& Wiegert 1996) and $Z$. marina (Kentula \& McIntire 1986, Thom 1990). Production for $Z$. japonica, which reaches a high density but is a very small plant, was much lower $\left(\sim 170 \mathrm{~g}\right.$ dry wt $\mathrm{m}^{-2}$ $\left.\mathrm{yr}^{-1}\right)$, but was also similar to previous production estimates (Thom 1990).

We estimated that native eelgrass Zostera marina produced $>35000 \mathrm{t}$ of dry matter annually in Willapa Bay (Table 2). The 2 introduced species appear to have recently raised primary production by aquatic tracheophytes by $>50 \%$. The cordgrass Spartina alterniflora 
Table 1. Components of production by dominant macrophytes in Willapa Bay. Mean and standard deviation (SD) for shoot density and growth were calculated from $\mathrm{N}$ sites (in square brackets) throughout the bay. SD (in parentheses) for annual production per area of eelgrass was based on 100 Monte Carlo randomizations of values for each variable contributing to the calculation of annual production, specifically shoot growth and shoot density in different seasons

\begin{tabular}{|c|c|c|c|c|}
\hline \multirow[t]{2}{*}{ Species } & \multirow{2}{*}{$\begin{array}{l}\text { Area } \\
\text { (ha) }\end{array}$} & \multirow[t]{2}{*}{ Period } & \multicolumn{2}{|c|}{ Production per area } \\
\hline & & & $\begin{array}{l}\text { Shoot density } \\
\qquad\left(\mathrm{m}^{-2}\right)\end{array}$ & $\begin{array}{l}\text { Shoot growth } \\
\left(\mathrm{mg} \mathrm{dry} \mathrm{wt} \mathrm{shoot}^{-1} \mathrm{~d}^{-1}\right)\end{array}$ \\
\hline \multirow{5}{*}{$\begin{array}{l}\text { Zostera } \\
\text { marina }\end{array}$} & \multirow[t]{5}{*}{3423.6} & Winter & $161.7(30.4)[6]$ & $3.03(0.545)[5]$ \\
\hline & & Spring & $141.9(30.2)[7]$ & $24.3(9.18)$ \\
\hline & & Summer & 159.5 (33.9) [7] & $35.8(15.0)$ \\
\hline & & Autumn & $105.4(35.9)[7]$ & $14.9(4.19)$ \\
\hline & & Annual & \multicolumn{2}{|c|}{$\begin{array}{l}\text { Biomass, g dry wt m }{ }^{-2} \text { : } \\
1.03 \times 10^{3}\left(0.40 \times 10^{3}\right)\end{array}$} \\
\hline \multirow{6}{*}{$\begin{array}{l}\text { Zostera } \\
\text { japonica }\end{array}$} & \multirow[t]{6}{*}{2738.8} & Mar & $2242(1211)[6]$ & \multirow{5}{*}{$\begin{array}{l}0.0955(0.0200)[6] \\
0.2026(0.0529)[6] \\
0.2127(0.0667)[6] \\
0.1594(0.0607)[6] \\
0.0487(0.0178)[6]\end{array}$} \\
\hline & & May & 3271 (1718) [6] & \\
\hline & & Jul & $5996(1870)[6]$ & \\
\hline & & Sep & 3624 (2132) [6] & \\
\hline & & Dec & 1931 (653) [6] & \\
\hline & & Annual & \multicolumn{2}{|c|}{$\begin{array}{l}\text { Biomass, g dry wt m }{ }^{-2} \\
1.75 \times 10^{2}\left(0.51 \times 10^{2}\right)\end{array}$} \\
\hline $\begin{array}{l}\text { Spartina } \\
\text { alterniflora }\end{array}$ & 1298.5 & Annual & \multicolumn{2}{|c|}{$\begin{array}{l}\text { Biomass, g dry wt m }{ }^{-2}: \\
1.01 \times 10^{3}\left(0.49 \times 10^{3}\right)\end{array}$} \\
\hline
\end{tabular}

was estimated to produce an annual standing crop in excess of $13000 \mathrm{t}$, and the small-sized introduced eelgrass $Z$. japonica was estimated to produce nearly $4800 \mathrm{t}$, increases of 37 and $14 \%$, respectively. Considerable uncertainty exists around these average values, particularly due to spatial variation in shoot density (Table 1). However, the additional production estimated from introduced species exceeds the variation (standard deviation) within species.

\section{Change in secondary production in Willapa Bay}

Recent yields of Pacific oysters and Manila clams from Willapa Bay far outweigh historical landings of native oysters (Fig. 3, Table 2). The annual yield of introduced Crassostrea gigas at the end of the 20th century was almost 4 times higher than annual yields of native Ostreola conchaphila at the end of the 19th century. Venerupis philippinarum actually contributed little additional production, even though landings since 1985 have increased about $6 \%$ annually. We estimated that native oysters used to produce about $92 \mathrm{t}$ of dry matter annually, excluding shells. Secondary production from native oysters has largely disappeared, but introduced bivalves, particularly C. gigas, currently generate $330 \mathrm{t} \mathrm{yr}^{-1}$. Clearly, this secondary production is dwarfed by the primary production of aquatic tracheophytes, which have production values $>2$ orders of magnitude higher.

\section{Other ecosystem functions}

Habitat

Willapa Bay contains extensive intertidal flats, and, in the absence of introduced species, $39 \%$ of the bay's area would consist of unstructured intertidal habitat (Borde et al. 2003). In our spatial analyses, native Zostera marina occupied $9.6 \%$ of the bay's area (>3400 ha of 35700 ha; Table 1), and tidal flats have been modified by introduced Z. japonica (7.7\% of bay area) and Spartina alterniflora $(3.6 \%)$. Areas intensively cultivated for bivalves occupy $10 \%$ (Feldman et al. 2000), and, because both native and non-native species have been cultivated in these areas, we believe there has been little trend in cultivated area over the past century (Townsend 1896, Hedgpeth \& Obrebski 1981). However, wild populations of native Ostreola conchaphila were reportedly subtidal, accessible only at extreme low tides (Collins 1892), whereas hummocks of introduced Crassostrea gigas occur intertidally (authors' pers. obs.). Thus, oyster habitat has shifted from sub-tidal to intertidal areas where oysters recruit naturally, but precise dimensions are not available.

Table 2. Estimated annual production (prod.) by dominant macrophyte and bivalve species in Willapa Bay. No sample sizes (N) are provided for primary production because SD (in parentheses) was based on Monte Carlo randomizations. For secondary production, $\mathrm{N}$ (in brackets) is number of years of sustained harvests

\begin{tabular}{|c|c|c|c|c|}
\hline \multirow[t]{2}{*}{ Species } & \multirow{2}{*}{$\begin{array}{l}\text { Native/ } \\
\text { Introduced }\end{array}$} & \multicolumn{2}{|c|}{ Years of measurements } & \multirow{2}{*}{$\begin{array}{c}\text { Annual production } \\
\left(\mathrm{kg} \text { dry wt } \mathrm{yr}^{-1}\right)\end{array}$} \\
\hline & & Area & Prod. & \\
\hline Zostera marina & Native & 1997 & 2004 & $3.53 \times 10^{7}\left(1.37 \times 10^{7}\right)$ \\
\hline Zostera japonica & Introduced & 1997 & 2004 & $4.79 \times 10^{6}\left(1.40 \times 10^{6}\right)$ \\
\hline Spartina alterniflora & Introduced & 1997 & 2001 & $1.31 \times 10^{7}\left(0.63 \times 10^{7}\right)$ \\
\hline Ostreola conchaphila & Native & \multicolumn{2}{|c|}{$1866-1900$} & $9.16 \times 10^{4}\left(0.54 \times 10^{4}\right)[16]$ \\
\hline Crassostrea gigas & Introduced & \multicolumn{2}{|c|}{$1971-2003$} & $3.23 \times 10^{5}\left(0.72 \times 10^{5}\right)[33]$ \\
\hline Ruditapes philippinarum & Introduced & \multicolumn{2}{|c|}{$1991-2003$} & $6.94 \times 10^{3}\left(0.22 \times 10^{3}\right)[13]$ \\
\hline
\end{tabular}


These new habitats influence the entire community composition of smaller estuarine organisms. For instance, epibenthic organisms are more diverse on $C$. gigas than in open mudflats (Hosack 2003). Estuarine invertebrates respond to $S$. alterniflora and $Z$. japonica in complicated ways: some species increase and some decline relative to nearby mudflats, but, as with oysters, the overall effect is to alter community structure (Posey 1988, Wonham 2003).

\section{Detritus}

The calculated increase in the bay's macrophyte production over the past century due to invaders likely had a concomitant effect on detritus. In addition to the overall increase in detrital biomass (>50\%), both the type and timing of detrital production have changed. Zostera japonica detritus has a lower C:N ratio (C. J. Harvey unpubl. data) and more rapid decomposition than the native eelgrass (Hahn 2003). In contrast, Spartina alterniflora has a higher C:N ratio than $Z$. marina (C. J. Harvey unpubl. data). Rather than producing detritus throughout the growing season, $S$. alterniflora accumulates biomass, and detritus appears in autumn. In Willapa Bay, wrack builds up substantially on beaches, where its effects on plant regeneration and invertebrate communities are presumably similar to those in its native range (Ranwell 1967, McCaffrey 1976). Wrack-burial disturbance has been shown to alter salt marsh structure (Boston 1983), plant zonation and community structure (Brewer et al. 1998, Pennings \& Richards 1998), sediment chemistry (Pennings \& Richards 1998), and plant clonal morphology (Brewer \& Bertness 1996). Prior to the arrival of $S$. alterniflora, Willapa Bay was not subjected to heavy annual inputs from wrack generated by marsh plant dieback.

\section{Filtration}

The filtration capacity of bivalves can substantially influence the overall state of an estuary (Jackson et al. 2001). Scaling up to annual yields, we estimated that native oysters could have filtered $6.0 \times 10^{9} \mathrm{l} \mathrm{d}^{-1}$ prior to exploitation, and the 2 introduced bivalves filter at least $9.7 \times 10^{9} \mathrm{ld}^{-1}$. Daily, these respective rates would affect 0.8 and $1.3 \%$ of the bay's volume $\left(7.6 \times 10^{11} \mathrm{l}\right.$ at mean sea level; Hickey \& Banas 2003). Although these percentages appear small, they only account for feeding by harvested bivalves, leaving out unreported collections, beds where bivalves have not reached market size, feral populations, and other suspension-feeding species. The calculated difference in historic and cur- rent filtration rates is less than the difference in yield, because smaller individuals (e.g. native oysters) have higher per biomass filtration than larger individuals (e.g. Pacific oysters).

\section{DISCUSSION}

\section{Primary and secondary production in heavily invaded estuaries}

As new species entered Willapa Bay over the past century, total primary production by focal aquatic tracheophytes increased by $>50 \%$, and total secondary production by focal bivalves increased by $250 \%$, despite the decline of the native oyster (Table 2). In fact, we have likely underestimated change in secondary production: harvested biomass was not sustainable for native oysters, suggesting it overestimates historical production, whereas introduced oysters and clams occur in feral populations outside aquaculture, and harvested biomass likely underestimates current production. Of course, these calculations for macrophytes and bivalves include just 1 native and 2 introduced species in each case, and they do not account for diverse additional native and non-native species. However, it is extremely unusual to know wholeecosystem production for even 6 species, and the contributions from other bivalves and tracheophytes appear to be small and/or relatively stable over the past 50 yr (see 'Materials and methods').

More generally, none of the introduced species we examined fully occupies its potential habitat in Willapa Bay, so there may be capacity for further increases in production. Such is particularly true of tracheophytes, which continue to expand rapidly. In 2000 relative to 1997, the area of Spartina alterniflora in Willapa Bay increased by $23 \%$ (to 1601 ha; WADNR 2003). Given a total intertidal area of 18200 ha, perhaps half of which is potentially invasible by cordgrass, annual production could increase by up to 6-fold if left uncontrolled. According to analyses by Pacific County (in Hedgpeth \& Obrebski 1981), oyster yields (and therefore secondary production) could be enhanced by an order of magnitude, although oyster expansion is constrained by the availability of settlement substrate, and will lag behind expansion of tracheophytes unless there are changes in aquaculture practices. Furthermore, recent oceanographic models of the bay indicate that increased biomass could come at the expense of slowed individual growth rates (N. S. Banas et al. unpubl. data).

The introduced species considered here have modified production, and likely a variety of other ecosystem processes, because they consist disproportionately of ecosystem engineers (Jones et al. 1994, Gutierrez et al. 
2003, Cuddington \& Hastings 2004). Both macrophytes and oysters provide biogenic structure and modify their local environment in self-reinforcing ways, for instance by accumulating sediment (Spartina alterniflora; Zipperer 1996) or providing hard substrate for recruitment (oysters; Mobius 1883). The introduced species of bivalves and tracheophytes in Willapa Bay may play particularly high-impact roles, because these tideflats were previously unstructured (Fig. 1), and the new species do not simply replace native species, which tend to be restricted to different tidal elevations. The previously unstructured mudflats certainly supported other primary producers and filter feeders in the past. Given our reliance on harvest records and remote-sensing data to estimate production for even the most prolific introduced species, we cannot make quantitative estimates of production changes for benthic diatoms, small native bivalves, burrowing shrimp, or other filter- or deposit-feeding infauna. Nor can we conclude how the production rates of organisms associated with new substrates (e.g. benthic diatoms, macroalgae, and filter feeders living on oyster shell substrates; epiphytes living on Zostera japonica) compare with rates on open mudflats without further study.

Ecological theory suggests that environments with free resources (empty niches) are particularly susceptible to invasion (Shea \& Chesson 2002), and new species that modify their environment to their own benefit have particularly high impacts (Crooks 2002, Cuddington \& Hastings 2004). Our data directly indicate how species that play novel roles in an ecosystem can affect production, with further implications for habitat, detritus, and filtration. For example, Crassostrea gigas reefs and culture sites provide extensive, otherwise unavailable hard substrate for fish, invertebrates, and macroalgal species such as Ulva spp. and Enteromorpha spp., both of which have become abundant in intertidal zones where $C$. gigas culture or hummocks are present. In addition, Willapa's introduced engineers probably also affect biogeochemical cycles. In another coastal estuary, introduced Zostera japonica serves as a sink for water-column nutrients (Larned 2003), and bivalves can store nutrients in biodeposits (Chapelle et al. 2000), or, at high densities, enhance nutrient release (Bartoli et al. 2001). Furthermore, oyster expansion has occurred at the expense of burrowing shrimp and other infauna, undoubtedly causing changes in sediment porosity and bioturbation and further affecting biogeochemistry (Webb \& Eyre 2004).

The Willapa Bay case history is also compelling, because similar shifts in ecosystem function are likely occurring in other tideflat-dominated estuaries where these and other introduced species have become established (e.g. Cohen \& Carlton 1995, Castillo 2000). We expect that this same suite of introduced species will have, or is already having, similar effects in other estuaries in the region, many of which have comparable native taxa, aquacultural practices, geological ages, tidal amplitudes, and sediment-accretion rates (e.g. Emmett et al. 2000), and often much greater levels of human activity and anthropogenic disturbance. It is possible to imagine additional engineering species that could further transform west coast tideflats, such as burrowing fiddler crabs (e.g. McCraith et al. 2003).

\section{Biodiversity-ecosystem function relationships for native and non-native species}

Most conceptual models and much empirical data about the relationship between biodiversity and ecosystem functioning portray a linear or asymptotic curve (Hooper et al. 2005). In native systems, we expect ecosystem processes to asymptote as species richness increases, due to competition for and partitioning of space and other resources among functional group members. In contrast, in invasion biology, it is well recognized that a small proportion of introduced species have disproportionately high impacts (Williamson \& Fitter 1996). Thus, the expansion of primary producers and filter feeders higher into the intertidal zone of Willapa Bay represents a step change in several major ecosystem processes. A small number of highly successful invaders has dramatically altered ecosystem processes even though species richness increased only slightly (Fig. 4). Such step functions are by-products of the invaders' typically high rates of productivity, fecundity, and dispersal relative to the native community (Mack et al. 2000), particularly if they play a novel ecosystem role. Additionally, inherent differences between closely related native and introduced species can magnify the impact of the introduction; in the present case, the total area occupied by Crassostrea gigas under cultivation $(\sim 10 \%$ of bay area; Feldman et al. 2000) probably does not greatly exceed the historical area of native oysters. However, there are profound

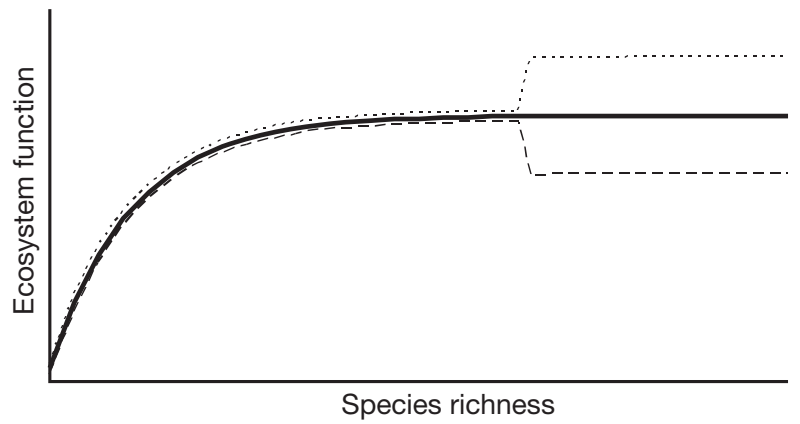

Fig. 4. Step change in ecosystem functioning associated with the introduction of a high-impact species to an otherwise intact ecosystem 
biological differences between the 2 oyster species that drastically affect their ecological impacts: C. gigas grows several times faster (Ruesink et al. 2005, A. C. Trimble et al. unpubl. data), reaches a larger maximum size (30 vs. 6 cm; Baker 1995), and has greater desiccation and temperature tolerance (Korringa 1976) than Ostreola conchaphila. These 2 branches of thought in community ecology - one emphasizing the role of species or functional group richness and the other emphasizing the high impacts of particular species - remain unreconciled.

Three considerations may help reconcile research focused on biodiversity versus invasion: scale, trophic complexity, and real differences in how native and non-native species affect ecosystem processes. The 'scale' issue reflects methodological differences: biodiversity-ecosystem function studies have been carried out by comparing species richness across sites or experimentally manipulating the number of species locally (Stachowicz et al. 2002, Duffy et al. 2003, Raffaelli et al. 2003), generally by random removal of species (but see Solan et al. 2004). Invasion biology tends to emphasize impacts at the level of a site, and there is by necessity biased selection of study species that have high impacts. Thus, invasion biologists find that particular species matter because that is the hypothesis they test. Trophic complexity is generally low in biodiversity-ecosystem function studies, where suites of species compete for a common resource. In contrast, many high-impact invaders are consumers and thus introduce new trophic roles into a community. It should be noted, however, that studies of multiple trophic levels of native species have also shown that consumer impacts can trump species richness in determining production (Paine 2002). So, different amounts of trophic complexity incorporated in study design may also explain differing results. Finally, it is possible that native species with a long history of coevolution do indeed interact differently than nonnatives entering a novel recipient community. This leads to the expectation that, while both native and non-native species can influence ecosystem processes, native species do so primarily through resource use efficiency and non-natives through sampling effects. Resource use efficiency would be expected in a group of species that has had the opportunity to adapt, specialize, and partition resources (Ruesink \& Srivastava 2001). In contrast, in newly introduced species, production might improve primarily through a sampling effect, because a small proportion of exotics strongly influences ecosystem functioning. A major research need is for small-scale studies that explicitly address patterns of production across richness levels of native species versus natives and non-natives combined.
Because the Willapa Bay community has been irreversibly altered, it is difficult to reconstruct the biodiversity-ecosystem function relationship for native species alone. However, the tremendous amount of habitat available to invasion makes it very likely that step functions have occurred in functions such as primary production, detritus generation, filtration, and sediment-water exchanges (Fig. 4). These step functions derive from gains in species, rather than from losses. Some previously important species have declined in abundance, but none has been eliminated entirely. Evidence from other systems suggests more attention should be paid to ecosystem responses as species invade. Outside of islands and lakes, introduced species rarely cause outright extinction, although they often change the relative abundance of species and therefore diversity (Wilcove et al. 1998, Gurevitch \& Padilla 2004). Consequently, local invasions exceed extinctions for many taxa (Sax et al. 2002), and theory also suggests that global biotic homogenization will tend to enhance local richness (Rosenzweig 2000).

\section{Management response}

Changes in production in Willapa Bay have had substantial economic consequences, as well as ecological. In general, management is directed at fostering the production of bivalves and reducing the production of tracheophytes (even though these species all provide valuable ecosystem functions where they are native). Introduced Spartina alterniflora is targeted for control with herbicides, estimated at about 40001 of imazapyr in 2004 (Hedge et al. 2003, Patten 2003). In contrast, introduced bivalves are planted for economic benefit, which on a local scale precludes production by other species. Dredging during oyster culture can remove native eelgrass, which is protected under a Washington state policy of no net loss (Pawlak \& Olson 1995), and pesticides (2000 kg of carbaryl annually around 1990; WDF/WDOE 1992) are sprayed to kill native burrowing shrimp Neotrypaea californiensis (Dana, 1854), a 'pest' species that displaces eelgrass and smothers oysters (Feldman et al. 2000, Dumbauld \& Wyllie-Echeverria 2003).

Within taxa, management also differs. At the same time that millions of dollars are being spent on Spartina control, Zostera japonica, another introduced macrophyte in a similar habitat, is protected in Washington (Wonham 2003). Our analysis suggests that the discrepancy stems in part from $S$. alterniflora's higher production and therefore impact in Willapa Bay (Table 2). Similarly, introduced species of oysters and clams are being farmed in preference to native species. Here too, relative productivity may weigh heavily in aquaculturists' decisions (Table 2). 
The lesson from Spartina alterniflora and Zostera japonica is that alterations of the food web can cause management problems, which are difficult to reverse. New species should be introduced with caution, and spread of established invasive plants should be controlled. The lesson from Crassostrea gigas and Ruditapes philippinarum is that careful planting (preventing overexploitation) and protection of water quality can result in sustained estuarine resources for humans. While these bivalves cannot be eliminated, due to their economic importance and widespread distribution, it is possible that many feral oysters could be removed and native oysters could be restored in subtidal areas. Humans depend on the productivity of the earth's living systems, including estuarine ecosystems, and they also transform the local species involved in production, both intentionally and unintentionally, through introductions. The challenge facing managers is to determine cumulative risk, where the impacts of introduced species on native species, estuarine biodiversity, and ecosystem function are viewed in the context of all the perturbations, natural and anthropogenic, that affect estuaries.

Acknowledgements. Estimates of eelgrass primary production were collected with help from S. Bradley, B. Dumbauld, S. Hacker, L. McCoy, E. L. Wagner, and J. M. White. We gratefully acknowledge the Washington Department of Fish and Wildlife, particularly B. Kauffman, for providing data on shellfish harvests. Our research in Willapa Bay would have been impossible without intertidal access granted by the following shellfish growers: Coast Seafoods, Northern Oyster, Oysterville Sea Farms, Taylor Shellfish, and Wiegardt Brothers Jolly Roger Oysters. Funding for portions of this research was provided by USDA Western Regional Aquaculture Center (to J.L.R.) and the Andrew W. Mellon Foundation (to J.L.R. and A.C.T.). The ideas in this paper are those of the authors and do not represent positions of their employers or funding agencies.

\section{LITERATURE CITED}

Baker P (1995) Review of ecology and fishery of the Olympia oyster, Ostrea lurida, with annotated bibliography. J Shellfish Res 14:501-518

Bartoli M, Nizzoli D, Viaroli P, Turolla E, Castaldelli G, Fano EA, Rossi R (2001) Impact of Tapes philippinarum farming on nutrient dynamics and benthic respiration in the Sacca di Goro. Hydrobiologia 455:203-212

Borde AB, Thom RM, Rumrill S, Miller LM (2003) Geospatial habitat change analysis in Pacific Northwest coastal estuaries. Estuaries 26:1104-1116

Boston KG (1983) The development of salt pans on tidal marshes, with particular reference to south-eastern Australia. J Biogeogr 10:1-10

Brennan W (1939) Forty-sixth to forty-ninth, inclusive, annual reports of the state Department of Fisheries, state of Washington, Dept. of Fisheries, Olympia, WA

Brewer JS, Bertness MD (1996) Disturbance and intraspecific variation in the clonal morphology of salt marsh perennials. Oikos 77:107-116
Brewer JS, Levine JM, Bertness MD (1998) Interactive effects of elevation and burial with wrack on plant community structure in some Rhode Island salt marshes. J Ecol 86: $125-136$

Carlton JT (1992) Introduced marine and estuarine mollusks of North America: an end-of-the-20th century perspective. J Shellfish Res 11:489-505

Castillo GC (2000) Benthic biological invasions in two temperate estuaries and their effects on trophic relations of native fish and community stability. PhD thesis, Oregon State University, Corvallis, OR

Chapelle A, Menesguen A, Deslous-Paoli JM, Souchu P, Mazouni N, Vaquer A, Millet B (2000) Modelling nitrogen, primary production and oxygen in a Mediterranean lagoon. Impacts of oysters farming and inputs from the watershed. Ecol Model 127:161-181

Cohen, AN, Carlton JT (1995) Nonindigenous aquatic species in a United States estuary: a case study of the biological invasions of the San Francisco Bay and Delta. United States Fish and Wildlife Service, Washington, DC

Collins JW (1892) Report of the commissioner for 1888, United States Commission of Fish and Fisheries. Government Printing Office, Washington, DC

Cook AE, Shaffer JA, Dumbauld BR, Kauffman BE (2000) A plan for rebuilding stocks of Olympia oysters (Ostreola conchaphila, Carpenter, 1857) in Washington State. J Shellfish Res 19:409-412

Crooks JA (2002) Characterizing ecosystem-level consequences of biological invasions: the role of ecosystem engineers. Oikos 97:153-166

Cuddington K, Hastings A (2004) Invasive engineers. Ecol Model 178:335-347

Dai T, Wiegert RG (1996) Estimation of the primary productivity of Spartina alterniflora using a canopy model. Ecography 19:410-423

Duffy JE, Richardson JP, Canuel EA (2003) Grazer diversity effects on ecosystem functioning in seagrass beds. Ecol Lett 6:637-645

Dumbauld BR, Wyllie-Echeverria S (2003) The influence of burrowing thalassinid shrimps on the distribution of intertidal seagrasses in Willapa Bay, Washington, USA. Aquat Bot 77:27-42

Emmett R, Llanso R, Newton J, Thom R and 5 others (2000) Geographic signatures of North American West Coast estuaries. Estuaries 23:765-792

Espy WR (1977) Oysterville. University of Washington Press, Seattle, WA

Feist BE, Simenstad CA (2000) Expansion rates and recruitment frequency of exotic smooth cordgrass, Spartina alterniflora (Loisel), colonizing unvegetated littoral flats in Willapa Bay, Washington. Estuaries 23:267-274

Feldman KL, Armstrong DA, Dumbauld BR, DeWitt TH, Doty DC (2000) Oysters, crabs, and burrowing shrimp: review of an environmental conflict over aquatic resources and pesticide use in Washington State's (USA) coastal estuaries. Estuaries 23:141-176

Ferraro SP, Cole FA (2004) Benthic macrofaunal aliens in Willapa Bay (Poster). Pacific Estuarine Research Society annual meeting, May 18, 2004, Port Townsend, Washington

Ferraro DO, Oesterheld M (2002) Effect of defoliation on grass growth: a quantitative review. Oikos 98:125-133

Grevstad FS, Strong DR, Garcia-Rossi D, Switzer RW, Wecker MS (2003) Biological control of Spartina alterniflora in Willapa Bay, Washington, using the planthopper Prokelisia marginata: agent specificity and early results. Biol Control 27:32-42 
Gurevitch J, Padilla DK (2004) Are invasive species a major cause of extinctions? Trends Ecol Evol 19:470-474

Gutierrez JL, Jones CG, Strayer DL, Iribarne OO (2003) Mollusks as ecosystem engineers: the role of shell production in aquatic habitats. Oikos 101:79-90

Hahn DR (2003) Alteration of microbial community composition and changes in decomposition associated with an invasive intertidal macrophyte. Biol Invest 5:45-51

Harrison PG, Bigley RE (1982) The recent introduction of the seagrass Zostera japonica Aschers. \& Graebn. to the Pacific Coast of North America. Can J Fish Aquat Sci 39:1642-1648

Hedge P, Kriwoken LK, Patten K (2003) A review of Spartina management in Washington State, U.S. J Aquat Plant Manag 41:82-90

Hedgpeth JW, Obrebski S (1981) Willapa Bay: a historical perspective and a rationale for research. FWS/OBS-81/03, Office of Biological Services, U.S. Fish and Wildlife Service, Washington, DC

Hickey BM, Banas NS (2003) Oceanography of the U.S. Pacific Northwest coastal ocean and estuaries with application to coastal ecology. Estuaries 26:1010-1031

Hooper DU, Chapin FS III, Ewel JJ, Hector A and 11 others (2005) Effects of biodiversity on ecosystem functioning: a consensus of current knowledge. Ecol Monogr 75:3-35

Hosack G (2003) Effects of Zostera marina and Crassostrea gigas culture on the intertidal communities of Willapa Bay, Washington. MS thesis, University of Washington, Seattle, WA

Jackson JBC, Kirby MX, Berger WH, Bjorndal KA and 15 others (2001) Historical overfishing and the recent collapse of coastal ecosystems. Science 293:629-638

Jones CG, Lawton JH, Shachak M (1994) Organisms as ecosystem engineers. Oikos 69:373-386

Kaldy JE (2006) Production ecology of the non-indigenous seagrass, dwarf eelgrass (Zostera japonica Ascher. \& Graeb.), in a Pacific Northwest estuary, USA. Hydrobiologia 553:201-217

Kehoe DM (1982) Sources of sediment to Grays Harbor estuary. U.S. Army Corps of Engineers, Seattle, Washington

Kentula ME, McIntire CD (1986) The autecology and production dynamics of eelgrass (Zostera marina L.) in Netarts Bay, Oregon. Estuaries 9:188-199

Kincaid T (1968) The ecology of Willapa Bay, Washington, in relation to the oyster industry. Kincaid (self-published), Seattle, WA

Kirby MX (2004) Fishing down the coast: historical expansion and collapse of oyster fisheries along continental margins. Proc Natl Acad Sci 101:13096-13099

Kobayashi M, Hofmann EE, Powell EN, Klinck JM, Kusaka K (1997) A population dynamics model for the Japanese oyster, Crassostrea gigas. Aquaculture 149:285-321

Komar PD, McManus J, Styllas M (2004) Sediment accumulation in Tillamook Bay, Oregon: natural processes versus human impacts. J Geol 112:455-469

Korringa P (1976) Farming the flat oysters of the genus Ostrea: a multidisciplinary treatise. Elsevier Scientific, Amsterdam

Larned ST (2003) Effects of the invasive, nonindigenous seagrass Zostera japonica on nutrient fluxes between the water column and benthos in a NE Pacific Estuary. Mar Ecol Prog Ser 254:69-80

Mack RN, Simberloff D, Lonsdale WM, Evans H, Clout M, Bazzaz FA (2000) Biotic invasions: causes, epidemiology, global consequences, and control. Ecol Appl 10:689-710

McCaffrey CA (1976) The major vegetation communities of the Virginia Coast Reserve. In: The Virginia Coast Reserve study, Vol I. The ecosystem description. The Nature Conservancy, Arlington, VA

McCraith BJ, Gardner LR, Wethey DS, Moore WS (2003) The effect of fiddler crab burrowing on sediment mixing and radionuclide profiles along a topographic gradient in a southeastern salt marsh. J Mar Res 61:359-390

McLusky DS, Martins T (1998) Long-term study of an estuarine mudflat subjected to petro-chemical discharges. Mar Pollut Bull 36:791-798

Mobius K (1883) The oyster and oyster-culture. In: United States Commission of Fish and Fisheries, Part VIII. Report of the Commissioner for 1880, Appendix H. The oyster. Government Printing Office, Washington, DC (translated by H. J. Rice), p 683-751

NOAA (National Oceanic and Atmospheric Administration) (1997) 1995 National Shellfish Register, National Estuarine Inventory. NOAA, Washington, DC

NOAA CSC (National Oceanic and Atmospheric Administration Coastal Services Center) (2000) Willapa Bay, Washington Field Data Points, 1997. Geographic Information System (GIS) Electronic Map, Charleston, SC

Paine RT (2002) Trophic control of production in a rocky intertidal community. Science 296:736-739

Palacios R, Armstrong DA, Orensanz J (2000) Fate and legacy of an invasion: extinct and extant populations of the softshell clam (Mya arenaria) in Grays Harbor (Washington). Aquat Conserv Mar Freshw Ecosyst 10:279-303

Parker IM, Simberloff D, Lonsdale WM, Goodell K and 7 others (1999) Toward a framework for understanding the ecological effects of invaders. Biol Invest 1:3-19

Patten K (2003) Persistence and non-target impact of imazapyr associated with smooth cordgrass control in an estuary. J Aquat Plant Manag 41:1-5

Pawlak BT, Olson AM (1995) Policies and management practices of Washington state agencies as they pertain to the seagrasses Zostera marina and Zostera japonica: an ecological analysis. Puget Sound Res 2:516-521

Pennings SC, Richards CL (1998) Effects of wrack burial in salt-stressed habitats: Batis maritima in a southwest Atlantic salt marsh. Ecography 21:630-638

Peterson CD, Doyle DL, Barnett ET (2000) Coastal flooding and beach retreat from coseismic subsidence in the Central Cascadia Margin, USA. Environ Eng Geosci 6:255-269

Posey MH (1988) Community changes associated with the spread of an introduced seagrass, Zostera japonica. Ecology 69:974-983

Powell EN, Hofmann EE, Klinck JM, Ray SM (1992) Modeling oyster populations. 1. A commentary on filtration rate. Is faster always better? J Shellfish Res 11:387-398

Pritchard ES (ed) (2004) Fisheries of the United States 2003. National Marine Fisheries Service, Office of Science and Technology, Fisheries Statistics Division, Silver Spring, MD

Raffaelli D, Emmerson M, Solan M, Biles C, Paterson D (2003) Biodiversity and ecosystem processes in shallow coastal waters: an experimental approach. J Sea Res 49:133-141

Ranwell DS (1967) World resources of Spartina townsendii (sensu lato) and economic use of Spartina marshland. J Appl Ecol 4:239-256

Rosenzweig ML (2000) Biodiversity in equations. Recherche 333:68-70

Ruesink JL, Srivastava DS (2001) Numerical and per capita responses to species loss: mechanisms maintaining ecosystem function in a community of stream insect detritivores. Oikos 93:221-234

Ruesink JL, Roegner GC, Dumbauld BR, Newton JA, Armstrong DA (2003) Contributions of coastal and watershed 
energy sources to secondary production in a northeastern Pacific estuary. Estuaries 26:1079-1093

Ruesink JL, Lenihan HS, Trimble AC, Heiman KW, Micheli F, Byers JE, Kay M (2005) Introduction of non-native oysters: ecosystem effects and restoration implications. Annu Rev Ecol Evol Syst 36:643-689

Sax DF, Gaines SD, Brown JH (2002) Species invasions exceed extinctions on islands worldwide: a comparative study of plants and birds. Am Nat 160:766-783

Shea K, Chesson P (2002) Community ecology theory as a framework for biological invasions. Trends Ecol Evol 17:170-176

Simenstad CA, Jay DA, Sherwood CR (1992) Impacts of watershed management on land-margin ecosystems: the Columbia River estuary. In: Naiman RJ (ed) Watershed management: balancing sustainability and environmental change. Springer-Verlag, New York, p 266-306

Solan M, Cardinale BJ, Downing AL, Engelhardt KAM, Ruesink JL, Srivastava DS (2004) Extinction and ecosystem function in the marine benthos. Science 306: $1177-1180$

Solidoro C, Melaku Canu D, Rossi R (2003) Ecological and economic considerations on fishing and rearing of Tapes phillipinarum in the lagoon of Venice. Ecol Model 170: 303-318

Stachowicz JJ, Fried H, Osman RW, Whitlach RB (2002) Biodiversity, invasion resistance, and marine ecosystem function: reconciling pattern and process. Ecology 83: 2575-2590

Thom RM (1990) Spatial and temporal patterns in plant standing stock and primary production in a temperate seagrass system. Bot Mar 33:497-510

Townsend CH (1893) Report of observations respecting the oyster resources and oyster fishery of the Pacific coast of the United States. In: U.S. Fisheries Commission Report. Government Printing Office, Washington, DC, p 343-372

Townsend $\mathrm{CH}$ (1896) The transplanting of eastern oysters to Willapa Bay, Washington, with notes on the native oyster industry. In: U.S. Fisheries Commission Report. Government Printing Office, Washington, DC, p 193-202

Vitousek PM, Walker LR (1989) Biological invasions by Myrica faya in Hawaii: plant demography, nitrogen fixation, ecosystem effects. Ecol Monogr 59:247-265

WDF/WDOE (Washington Department of Fisheries/Washington Department of Ecology) (1992) Use of the insecticide

Editorial responsibility: Martin Solan (Guest Editor), Newburgh, UK carbaryl to control ghost and mud shrimp in oyster beds of Willapa Bay and Grays Harbor. Supplemental Environmental Impact Statement, Washington Department of Fisheries and Washington Department of Ecology, Olympia, WA

WADNR (Washington Department of Natural Resources) (1999) 1997 Spartina alterniflora infestation mapped on Willapa Bay, WA. Geographic Information System (GIS) Electronic Map, WADNR, Aquatic Resources Division, Olympia, WA

WADNR (Washington Department of Natural Resources) (2003) 2000 Spartina alterniflora infestation mapped on Willapa Bay, WA. Geographic Information System (GIS) Electronic Map, WADNR, Aquatic Resources Division, Olympia, WA

Webb AP, Eyre BD (2004) Effect of natural populations of burrowing thalassinidean shrimp on sediment irrigation, benthic metabolism, nutrient fluxes and denitrification. Mar Ecol Prog Ser 268:205-220

Wilcove DS, Rothstein D, Dubow J, Phillips A, Losos E (1998) Quantifying threats to imperiled species in the United States. BioScience 48:607-615

Williamson M, Fitter A (1996) The varying success of invaders. Ecology 77:1661-1666

Wolf EC (1993) A tidewater place: portrait of the Willapa ecosystem. Willapa Alliance, EcoTrust Publications, Long Beach, WA

Wonham MJ (2003) Ecological gambling: expendable extinctions versus acceptable invasions. In: Kareiva P, Levin SA (eds) The importance of species. University Press, Princeton, NJ, p 179-205

Wonham MJ, Carlton JT (2005) Trends in marine biological invasions at local and regional scales: the Northeast Pacific Ocean as a model system. Biol Invest 7:369-392

Zhang RS, Shen YM, Lu LY, Yan SG, Wang YH, Li JL, Zhang ZL (2004) Formation of Spartina alterniflora salt marshes on the coast of Jiangsu Province, China. Ecol Eng 23: 95-105

Zieman JC, Wetzel RG (1980) Productivity in seagrasses: methods and rates. In: Phillips RC, McRoy CP (eds) Handbook of seagrass biology: an ecosystem perspective. Garland STPM Press, New York, p 87-115

Zipperer VT (1996) Ecological effects of the introduced cordgrass, Spartina alterniflora, on the benthic community structure of Willapa Bay, Washington. MS thesis, University of Washington, Seattle, WA

Submitted: December 4, 2004; Accepted: October 21, 2005 Proofs received from author(s): March 9, 2006 



\title{
Macrofaunal modification of porewater advection: role of species function, species interaction, and kinetics
}

\author{
George G. Waldbusser*, Roberta L. Marinelli \\ Chesapeake Biological Laboratory, One Williams Street, PO Box 38, Solomons, Maryland 20688, USA
}

\begin{abstract}
Sedimentary habitats are complex associations of biotic, chemical, and physical processes comprising 'ecosystem function'. The relative importance of these processes to biogeochemical cycling in highly reactive, permeable sediments remains poorly understood. We report results from several field experiments in a muddy-sand intertidal flat dominated by 2 functionally different types of bioturbating macrofauna in False Bay, Washington, USA: (1) the arenicolid polychaete Abarenicola pacifica and (2) 2 species of thalassinid shrimp (Upogebia pugettensis and Neotrypaea californiensis). Experimental plots composed primarily of one of the study taxa or mixed communities of both were evaluated for their effects on porewater advection, solute concentrations, and sediment characteristics. Fluorescein-impregnated acrylamide gels were used to infer rates of transport, and acrylamide gel peepers were used to record porewater concentrations of diagenetically important constituents among experimental plots. Laboratory studies evaluated rates of diffusive transport in non-bioturbated sediments for comparative analysis. We found that (1) functionally different macrofauna affect rates of porewater advection in permeable sediments, (2) organism effects are not attributable to changes in average measures of sediment granulometry, (3) species interactions may further complicate the advective environment and the resulting diagenetic processes, and (4) species effects vary according to reaction rate kinetics. We hypothesize that species-related effects on transport are due to inhibition of arenicolid feeding by thalassinid tubes that serve to block sediment fluidization and advective flow. Thus, specific behaviors and interactions among organisms appear to affect transport rates and sediment function in advectively permeable habitats. The results indicate the importance of integrating behavior, kinetics, and transport into future studies of sedimentary biodiversity and ecosystem function.
\end{abstract}

KEY WORDS: Species interaction · Porewater advection · Arenicolid · Thalassinid · Biogeochemistry

\section{INTRODUCTION}

Marine sedimentary systems are complex associations of biological, chemical, and physical processes that operate on varying spatial and temporal scales. From these collective elements, ecosystem function emerges. The difficulty in understanding intermediate- and smallscale process complexity of coastal sedimentary systems arises, in part, from current limitations in our characterization of macro-organism interactions with physical and biogeochemical processes (Marinelli \& Waldbusser 2005). Studies increasingly point to the importance of species-related differences in activity rates (Boudreau \& Marinelli 1994) and density-dependent processes (Marinelli \& Williams 2003, Lohrer et al. 2004) that create geochemical variability with fundamental ecological significance. For example, keystone species such as urchins or maldanid polychaetes that alter local community structure and small-scale sediment geochemistry have broad-scale effects on ecosystem function when integrated over larger scales (Levin et al. 1997, Widdicombe \& Austen 1998, Waldbusser et al. 2004). The diagenetic setting, dictated by rates of organic input and internal geochemical cycling (Canfield et al. 1993a,b, 
Thamdrup et al. 1994, Jahnke \& Jahnke 2000), is an additional element of complexity that co-determines the outcome of ecosystem processes (Kristensen et al. 1985). Lastly, physical-biological interactions related to boundary layer dynamics affect interfacial processes (Eckman 1983, Huettel et al. 1998), with significant implications for resource utilization (Taghon et al. 1980), population dynamics (Eckman 1996), and sedimentseawater exchange (Jahnke et al. 2000). Given the diversity of processes and potential interactions among them, identification of mechanisms that alter system function is crucial to developing predictable relationships between ecosystem structure and function (Levin et al. 2001).

It is increasingly clear that consideration of the geochemical milieu helps elucidate the mechanisms by which biodiversity alters system function. For example, Waldbusser et al. (2004) found that biodiversity effects associated with lower than predicted phosphate fluxes (underyielding) were largely explained by depthintegrated oxygen concentrations within the sediment and the effect of oxygen on phosphate adsorption. This relationship was driven by the presence of 1 active deepdwelling organism in the experimental treatments and, therefore, may be considered a selection effect (Wardle 1999). The extensive literature on diagenetic and other sedimentary processes may readily provide explanatory mechanisms for many of the effects found in biodiversity and ecosystem function studies of sediments. Ongoing debate regarding the nature of biodiversity effects (Kinzing et al. 2001) and lack of congruity among conclusions from sediment-diversity experiments (Emmerson et al. 2001, Bolam et al. 2002, Biles et al. 2003) point to the need for a more integrated and thorough investigation of sediment dynamics.

Concurrent with the expansion of biodiversity research in benthic environments has been the increased recognition of permeable sediments (and associated porewater advective flows) as habitats of significant and rapid biogeochemical cycling. As Rocha (2000) argues, the basis for modern diagenetic research has focused on non-permeable sediments, with diffusion and bioirrigation as the primary transport mechanisms. Extant bioirrigation models have successfully captured average geochemical environments inhabited by organisms in diffusive sediments (Guinasso \& Schink 1975, Aller 1980, Boudreau 1984). However, these models generally are not suited to permeable sedimentary habitats due to assumptions regarding diffusive transport around organism burrows. A common assumption regarding advectively dominated environments is the erasing of chemical potential gradients generated by organism burrows, and therefore a dampening or lack of sedimentary organism effects. Rather, the primary importance of infauna in permeable sediments are as creators of topographic features and associated pressure gradients that, in turn, drive advective flow (Huettel \& Webster 2001, but see D'Andrea et al. 2002, 2004 for counter examples). Furthermore, de Beer et al. (2005) estimated roughly $25 \%$ of the exchange between sediment and overlying water on an advective intertidal sand flat was due to bioturbational activities of infauna, emphasizing the potential importance these communities may have on geochemical cycling in permeable sediments. Although recent findings indicate the importance of infauna on sedimentary processes in permeable sediments, it is critical to biodiversity/ecosystem function research that we understand whether functionally different species and interactions among them create ecologically significant variance in permeable sediment processes.

In the current study, we conduct several field experiments in a muddy-sand intertidal flat dominated by 3 species of 2 functionally different bioturbating macrofauna, consider the complexity associated with nondiffusion-dominated environments, and discuss the implications for biodiversity/ecosystem studies in terms of species interactions. Our questions in this study are as follows: (1) Do 2 functionally different bioturbating infauna have different effects on sedimentary processes in this permeable sedimentary habitat? (2) Does the interaction between the 2 functional types affect the transport of porewater and solute distributions? (3) What are the possible mechanisms for any organism effects found on sediment dynamics? (4) What are the implications for the future of biodiversity and ecosystem function research within permeable sediments, as well as in other habitats?

\section{MATERIALS AND METHODS}

Site and organisms. This study was conducted in False Bay, Washington, USA (latitude $=48.488^{\circ}$, longitude $=-123.065^{\circ}$ ), an intertidal flat approximately $1 \mathrm{~km}^{2}$ in area during maximum exposure, located on San Juan Island. The tides are mixed semi-diurnal, with a maximum tidal range of $4 \mathrm{~m}$ and daily exposure times of nearly $12 \mathrm{~h}$ during late spring and summer, imparting considerable temperature fluctuations of overlying water and within the sediment (G. G. Waldbusser unpubl. data). The sediment column in the study area was underlain by an impermeable clay layer roughly $30 \mathrm{~cm}$ beneath the sediment surface. All experiments were conducted at the $+1 \mathrm{~m}$ tidal height (from mean low water).

The study area is relatively pristine and has a diverse infauna, including errant (e.g. nereidid and glycerid polychaetes) and relatively sedentary species (e.g. the bivalve Macoma sp. and lumbrinereid polychaetes). 
However, the dominant taxa are the lugworm Abarenicola pacifica and 2 species of thalassinid shrimp, Upogebia pugettensis and Neotrypaea californiensis. Maximum densities of surface features, a proxy for organism density, were roughly 75 fecal mounds or burrow openings $\mathrm{m}^{-2}$ for arenicolid and thalassinid taxa, respectively (Krager \& Woodin 1993, our Table 1). No differentiation could be made between the thalassinid species without destructive sampling, and therefore they are treated as 1 taxonomic unit.

The arenicolid and thalassinids are characterized by differences in feeding mode and burrowing. Abarenicola pacifica is a head-down deposit feeder with a body length of up to $10 \mathrm{~cm}$. It maintains a mucus-lined, $\mathrm{j}$-shaped tube and feeds indirectly on surface material by fluidizing the sediment above the feeding area at the tube base and subducting surface material downward. Taghon (1988) measured fecal production rates of up to $280 \mathrm{~d}^{-1}$ (grams of sediment to grams of ash-free dry weight worm per day) for A. pacifica. A significant body of literature exists on the ecology of arenicolids, and the reader is directed to Hobson (1967), Brenchley (1981), Riisgård \& Banta (1998), Linton \& Taghon (2000), and references therein for further information. The presence and abundance of A. pacifica can be verified by characteristic fecal mounds found on the sediment surface next to its well-formed tail shaft (Krager \& Woodin 1993).

In contrast, thalassinid species create large subsurface galleries with $\geq 1$ openings to the sediment surface (Nickell \& Atkinson 1995). They excavate large volumes of sediment, often suspending fine particles, increasing turbidity of the overlying water, and negatively affecting other organisms (MacGinite 1930, Suchanek 1983, Posey et al. 1991, Pinn et al. 1998, Feldman et al. 2000). Both Upogebia pugettensis and Neotrypaea californiensis are obligate burrow dwellers, and are considered to be facultative suspension and deposit feeders, respectively (Posey et al. 1991). Further, differences in reproduction and lifehistory strategies seem to allow these sympatric species to co-occur (Dumbauld et al. 1996, Coelho et al. 2000, and references therein).

Experimental plots of areas dominated by the arenicolid, thalassinids, and mixed communities were identified in mid-June and maintained until the end of August. Three $0.5 \times 0.5 \mathrm{~m}$ plots within 3 larger blocks were selected by visual inspection of the sediment surface for features characteristic of each taxon. All plots within a block were within 1 to $2 \mathrm{~m}$ of each other, and blocks were $\sim 50$ to $100 \mathrm{~m}$ apart and at similar tidal heights. Plots were designated as (1) arenicolid dominated, (2) thalassinid dominated, or (3) mixed communities of the 2 taxa. At 3 intervals over the field season, a series of daily photographs were taken at low tide
(23 to 25 June, 19 to 22 July, and 4 to 7 August) to verify these designations and the persistence of the organisms. Photographic image data, used to estimate the abundances of arenicolids and thalassinids by surface features, were analyzed using Image-J software.

Advection and diffusion measurements. The potential importance of advective porewater movement within the experimental area was evaluated using a conservative tracer, fluorescein, released from an acrylamide gel diffuser over an outgoing and incoming tide. A $20 \%$ acrylamide gel plug $(2.54 \mathrm{~cm}$ diameter, $5 \mathrm{~cm}$ length), containing $1 \mathrm{mg} \mathrm{ml}^{-1}$ fluorescein was made according to Browne \& Zimmer (2001). A $1 \mathrm{~m}$ transect line was established parallel to the long axis of the bay, on a sand bar with a gradual slope, within a site that appeared to lack any obvious surface features that would indicate the presence of large bioturbating infauna. At 12:00 $\mathrm{h}$ the gel was inserted (via core replacement) into the middle of the transect with the center of the gel roughly at $5 \mathrm{~cm}$ depth. The gel was then covered with sediment such that the surface was flush with the surrounding area. Starting at 12:45 h and every subsequent hour, a small volume $(\sim 1 \mathrm{ml})$ of porewater was taken at $5 \mathrm{~cm}$ depth, along both directions of the linear transect, at 3 locations: 1,3 , and $5 \mathrm{~cm}$ from the gel. The sample was obtained by inserting a canula, attached to a syringe, to the $5 \mathrm{~cm}$ depth interval and gently withdrawing fluid at depth. The last sample was taken at $18: 30 \mathrm{~h}_{\text {; }}$ this was the time the incoming tide had begun to cover the experimental area. We assumed that the major axis of flow would be horizontal, based on the pressure gradient generated by the retention and drainage of porewater within the sediments, though some vertical transport probably occurred. Upon retrieval, all samples were filtered through a $0.45 \mu \mathrm{m}$ filter and placed in a dark cooler until analysis on a Turner-Quantech fluorometer. The acrylamide gel plug was left in the sediment for $3 \mathrm{~d}$ before retrieval on 26 May 2004, when the porewater sampling was repeated, as above.

To evaluate the relative magnitude of advective versus diffusive transport in these sediments, a laboratory experiment was conducted to measure tracer movement in a diffusion-dominated environment. Since diffusive transport is the sum of random non-directional Brownian movements resulting in transport down a gradient, the vertical or horizontal orientation of the experimental set up is irrelevant on this spatial scale, and thus measures of vertical diffusion in a controlled experiment can be compared to measures of advective transport measured in situ in a horizontal direction. A PVC pipe $10 \mathrm{~cm}$ in diameter and $30 \mathrm{~cm}$ long was capped on the bottom, outfitted with a vertical line of sampling ports drilled at $1.5 \mathrm{~cm}$ intervals to a height of $15 \mathrm{~cm}$, and fitted with rubber septa as described in 
Marinelli et al. (1998). A $20 \%$ acrylamide solution with $1 \mathrm{mg} \mathrm{ml}^{-1}$ fluorescein was made, poured into the bottom of the PVC pipe, and allowed to polymerize. Sediment from the study site was collected, mixed, and defaunated by allowing the mixture to go anoxic for 2 wk. Once defaunated, the sediment was carefully added to the pipe to a depth of roughly $10 \mathrm{~cm}$ on 9 July 2004 (Day 0). The diffusion experiment was kept at constant room temperature, and did not reflect the temperature variability found at the site. Temperature changes of surface sediments due to solar heating were roughly $10^{\circ} \mathrm{C}$ at the field site (G. G. Waldbusser unpubl. data). Using the Wilke-Chang formula to calculate the temperature dependence of changes in the diffusion coefficient of fluorescein (Browne \& Zimmer 2001), the free solution diffusion coefficient varied by $0.1 \times 10^{-6} \mathrm{~cm} \mathrm{~s}^{-1}$, with a $10^{\circ} \mathrm{C}$ temperature change from 10 to $20^{\circ} \mathrm{C}$. Thus, the consequence of not mimicking field temperatures on diffusive transport is minimal. Porewater samples ( 1 to $2 \mathrm{ml}$ ) were taken on Days 10, 18 , and 25, filtered, and analyzed for fluorescein concentration immediately, as described above.

Fluorescein-loss experiments. To assess differences in rates of porewater advection between plots dominated by functionally different fauna, we deployed acrylamide gels infused with fluorescein in the experimental plots, described above. The fluorescein concentrations remaining in the gels after a given period of time acted as a proxy for relative rates of porewater advection. We hypothesized that gels in areas of higher advective flows would lose fluorescein faster due to the increased flushing of the surrounding sediment.

Acrylamide plugs (1.1 cm diameter, $9 \mathrm{~cm}$ length) were made with a $15 \%$ gel (Browne \& Zimmer 2001, as above) containing $1 \mathrm{mg} \mathrm{ml}^{-1}$ fluorescein. After polymerization, the gels were removed from the cylinders and wrapped individually in a single layer of No. 75 Nitex mesh. On 19 July 2004, 5 replicate gels were deployed in each experimental plot (described above), $10 \mathrm{~cm}$ apart along a $0.5 \mathrm{~m}$ transect perpendicular to the axis of advective flow measured previously. The gels were retrieved on 21 July 2004 by taking a $5 \mathrm{~cm}$ diameter sediment core around the plug and then breaking apart the core to obtain the gel plug. Excess sediment was gently wiped from the exterior, and two $5 \mathrm{~mm}$ subsections of the plug were taken roughly $\sim 1 \mathrm{~cm}$ from each end of the plug. The subsections were placed in pre-weighed sample vials and covered with foil to prevent photo-degradation of fluorescein within the gels. Immediately upon returning from the field, the sample vials were reweighed, and $2.5 \mathrm{ml}$ of deionized (DI) water was added to each vial for backequilibration of fluorescein out of the gel and into solution. The samples were placed on a shaker table in the dark for $48 \mathrm{~h}$. The fluorescein concentration in the back-equilibrated water was then determined via fluorometry, and the fluorescein remaining in the gel was corrected based on the dilution factor and the volume of the acrylamide.

Sediment porewater solutes. Porewater peepers, containing acrylamide gels as solute recorders (modified from Hesslein 1976, Mortimer et al. 1999), were used to measure depth profiles of ammonium, phosphate, silicate, alkalinity, and $\mathrm{pH}$ at the study site and to evaluate the effects of biologically modified porewater flow on sediment biogeochemistry. Each peeper had 10 wells $(0.75 \mathrm{~cm}$ deep by $3.2 \mathrm{~cm}$ wide by $8 \mathrm{~mm}$ high) of approximately $2 \mathrm{ml}$ in volume, allowing the measurement of a $10 \mathrm{~cm}$ profile from $1 \mathrm{~cm}$ below the sediment surface to $11 \mathrm{~cm}$ depth. To each well, $2 \mathrm{ml}$ of a $15 \%$ acrylamide gel was added. Gels were made with potassium persulfate as an initiator rather than ammonium persulfate, to avoid ammonium contamination (Engstrom \& Marinelli 2005). After polymerization, the peeper wells were covered with $0.45 \mu \mathrm{m}$ Magna nylon filter paper and were prehydrated in $30 \mathrm{psu}$ $\mathrm{NaCl}$ solution for $5 \mathrm{~d}$ prior to deployment in the field on 4 August 2004. Peepers were deployed in the same experimental plots used to measure fluorescein loss, but $11 \mathrm{~d}$ after these experiments were concluded. Three replicate peepers were deployed in each plot within all 3 blocks, with the narrow edge facing the dominant axis of flow. Peepers were retrieved on 10 August 2004 (6 d deployment), wiped clean of sediment, placed in plastic bags, and refrigerated. Subsequently, the individual gels from each depth interval were removed using clean stainless steel spatulas and latex gloves and placed in $15 \mathrm{ml}$ sterile centrifuge tubes containing $8 \mathrm{ml}$ of DI water. For back-equilibration, tubes were placed in the dark on a shaker table in a cold room at $10^{\circ} \mathrm{C}$ for $48 \mathrm{~h}$. Solutes and $\mathrm{pH}$ were then measured on the back-equilibrated solution and corrected for the dilution. Random checks of salinity on the back-equilibrated water were done to detect possible evapo-concentration of solutes within the gels, either in the course of handling or during deployment in the field.

Calculations were made to verify the response time of the gels to changes in surrounding porewater concentrations. Using free solution diffusion coefficients for ammonium, phosphate, and silicate (Boudreau 1997), the acrylamide-specific diffusion coefficients were calculated and Bessel series summations were performed as in Browne \& Zimmer (2001). Roughly $10 \%$ or less of the solute would be present in the gel (75 mm diffusion length based on well depth) after $1 \mathrm{~d}$ of equilibration, if exposed to solute-free water. In other words, it would take roughly $24 \mathrm{~h}$ for the gel to equilibrate to within $90 \%$ of surrounding concentra- 
tions, if those concentrations were constant. Integrating the temporal variability associated with the tidal draining and saturation of these sediments requires extended sampling. We estimated that a deployment time of $6 \mathrm{~d}$ would be sufficient to allow for the gels to accurately record average porewater values; this was true based on prior measures of sediment porewater constituents using direct extraction (G. G. Waldbusser unpubl. data). Therefore, gels successfully integrated temporal variability in porewater constituents over the deployment period.

Chemical analyses. Analyses of ammonium, phosphate, silicate, and alkalinity were performed on a Smartchem discrete chemical analyzer (Westco Scientific). Ammonium was analyzed using a modification of the phenol method as outlined by Koroleff (1976). Phosphate analysis followed a modification of the Environmental Protection Agency's (EPA) Method 365.2 and Eaton et al. (1995). Silicate was analyzed according to Strickland \& Parsons (1972). Alkalinity was determined using the methyl orange method (EPA 310.2). Dissolved inorganic carbon was calculated from the $\mathrm{pH}$ and alkalinity measures by dissociation constants using a MATLAB routine (csys.m and equic.m) developed by R. E. Zeebe and D. A. Wolf-Gladrow (www.awi-bremerhaven.de/Carbon/co2book.html). The measurement of $\mathrm{pH}$ was conducted using a $\mathrm{pH}$ electrode and meter (VWR Scientific Model 8000).

Sediment parameters and measured permeability. Grain size analysis was conducted on composite samples from each experimental plot using standard sieving techniques and graphical analysis of the cumulative percent distributions following Folk \& Ward (1957). Three $3 \mathrm{~cm}$ diameter cores of roughly $7 \mathrm{~cm}$ depth were taken from each plot and were combined to obtain a composite sample of each plot on 14 August 2004. Composite samples were weighed, dried, and reweighed to calculate porosity [volume pore water/ volume (sediment + porewater)]. A value of $2.65 \mathrm{~g} \mathrm{ml}^{-1}$ was used to correct for the density of quartz, and $1.023 \mathrm{~g} \mathrm{ml}^{-1}$, for seawater in the calculations. Permeability was calculated by the Rumpf-Gupte equation (Boudreau 1997) using grain size and porosity measures. Sediment organic carbon and nitrogen were determined for three $1 \mathrm{~cm}$ diameter surface cores (0.5 to $1.0 \mathrm{~cm}$ depth) taken in each plot using a Carlo Erba-440 elemental analyzer.

As an independent permeability measure, 1 intact sediment core $(5.08 \mathrm{~cm}$ diameter by $\sim 10 \mathrm{~cm}$ high sediment column) was taken in the middle of each plot within 1 of the 3 blocks and returned to the laboratory. These cores lacked obvious surface features that would indicate the presence of large bioturbating infauna. Permeability of these intact cores was determined using the falling-head permeameter method (Gray 1958). The measured permeability is based on the actual velocity of porewater movement through an intact sediment core (given a certain pressure head), whereas the calculated permeability uses theoretical considerations and empirically derived relationships between porosity and grain size (Boudreau 1997).

Data analysis. Porewater profiles were depthintegrated using trapezoidal integration. A 2-way ANOVA, with treatment, block, and treatment $\times$ block interaction effects, was used to analyze differences in fluorescein-loss and integrated porewater data as a function of the dominant taxon/treatment (arenicolid, thalassinids, or mixed). The fluorescein-loss and integrated porewater data were transformed to meet the assumptions of normality and homogeneity of variance in the ANOVA tests as follows: fluoresceinloss data and porewater data were natural log transformed, and organism abundance data were square root transformed. When no block effect was found, the block effect was dropped from the model, and data were reanalyzed as a 1-way ANOVA. A TukeyKramer correction was used on the individual Student's $t$-tests of treatment differences. Statistically determined outlier values were found and removed from the fluorescein-loss analysis in 3 observations of the thalassinid treatment and 1 observation of the mixed treatment. All statistical analyses were conducted using SAS Version 8.

Two types of post hoc exploratory regression analyses were conducted to investigate possible density dependence and interaction effects of these 2 species on variability in sediment porewater constituents. In the analyses, the abundance data obtained from the August photographs were averaged over the $3 \mathrm{~d}$ period. The chemistry data ( 3 replicates plot $^{-1}$ ) were not averaged for each experimental plot, in order to reflect spatial variability of porewater within each plot. The original treatment assignments of arenicolid, thalassinid, and mixed were ignored, and the densities of each organism within all plots were regressed against the porewater solute concentrations. We acknowledge the observations are not independent, but point to 2 reasons why such a method may be appropriate in this exploratory analysis. First, there is a lack of straightforward statistical analysis that may deal with variables that vary on differing spatial scales, such as porewater chemistry and organism abundance. If we were to average up to the largest scale (plots in this analysis), we would hide the variance of the porewater chemistry that may be relevant and could be accounted for in a regression analysis. Secondly, standard ANOVA is simply a special case of regression, in which measures of a dependent variable are assigned to an ordered categorical independent variable. The determination 
of a significant slope in such a regression analysis (ANOVA) is the equivalent of a significant treatment effect in a 1-way ANOVA. Although our approach is non-traditional, we feel the results provide considerable insight into the data in spite of the limitations of such a post hoc exploratory analysis.

The first series of post hoc exploratory analyses consisted of simple linear regressions of each chemical parameter versus organism density for each species (as determined by surface features). The second series of post hoc exploratory analyses contained multiple linear regressions using each chemical parameter versus organism density plus a species overlap index (Schoener 1970). Species overlap was calculated by a modification of Schoener's index (1970):

$$
\text { Overlap }=1-\left|p_{\mathrm{a}}-p_{\mathrm{t}}\right|
$$

where $p_{\mathrm{a}}$ is the proportion of arenicolids and $p_{\mathrm{t}}$ is the proportion of thalassinids. Application of a spatial overlap index would account for potential non-linearities in sediment geochemistry resulting from interactions among infauna. The closer in value the percentages of the 2 species are, the smaller the absolute difference between them and the closer to an overlap value of 1 . Overlap indices were arcsine transformed because they were proportions. After transformations, all parameters within the data set were standardized (or nondimensionalized), so each parameter had a mean of 0 and a standard deviation of 1 . These values have units of standard deviations and are called standardized deviates or Z-scores (Sokal \& Rolf 1969) and are calculated by:

$$
Z_{i}=\frac{X_{i}-\mu}{\sigma}
$$

where $X_{i}$ is the value of parameter $X$ and observation $i_{\text {, }}$ $\mu$ is the mean of the measured parameter, $\sigma$ is the standard deviation of the measured parameter, and $Z_{i}$ is the new standardized value of observation $i$. Regression parameters estimated using $Z$-scores can be directly compared to each other even if the original observations had different units. Differences in magnitude among the standardized regression parameters can be used to investigate which dependent variables (integrated porewater concentrations) are most influenced by density of arenicolids or thalassinids.

Assumptions (normality, homogeneity of variance) were checked, and potential outliers were examined using Cook's distance, DFBETA values, and Studentized residuals (Sokal \& Rolf 1969). In all cases, 1 to 3 outliers were detected, and in most cases it was the same observation for different solutes; therefore, those points were excluded from the regression as true outliers due to overly influential effects on parameter estimates.

\section{RESULTS}

\section{Organism abundance}

Results from the photographic surveys indicate the treatment assignments were appropriate and differences among plots remained relatively consistent with time (Table 1). No attempt was made to control or regulate the actual abundance of the 2 major taxa in the plots throughout the course of these experiments, because we wanted to minimize disturbance to the sediment fabric. Therefore, small changes in the relative abundances were expected due to natural variability associated with undisturbed habitats, and minor variability in surface features not directly related to abundance.

\section{Advection and diffusion experiments}

Results from the field measurements of tracer release from a gel diffuser indicate that advective flows are occurring in these sediments over a tidal cycle. Measurable fluorescein concentrations were found $1 \mathrm{~cm}$ from the gel source toward the mouth of

Table 1. Density of surface features per square meter (mean \pm SD) from photographic surveys of experimental plots for the 3 blocks and for 2 of the 3 experiment dates. July values correspond to the fluorescein-loss experiments, and the August values correspond to the porewater peeper experiments. Values represent number of fecal mounds (arenicolids, Abarenicola pacifica) and burrow openings (thalassinids, Upogebia pugettensis and Neotrypaea californiensis). The last column is the ratio of fecal mounds to burrow openings

\begin{tabular}{|c|c|c|c|c|}
\hline \multirow{2}{*}{$\begin{array}{l}\text { Date } \\
\text { Plot }\end{array}$} & \multirow[t]{2}{*}{ Block } & \multicolumn{3}{|c|}{- Surface features } \\
\hline & & Arenicolid & Thalassinid & Ratio \\
\hline \multicolumn{5}{|l|}{ July } \\
\hline \multirow[t]{3}{*}{ Arenicolid } & I & $49.33 \pm 7.42$ & $2.66 \pm 1.33$ & 18.54 \\
\hline & II & $70.66 \pm 9.61$ & $16.00 \pm 4.00$ & 4.41 \\
\hline & III & $36.00 \pm 6.92$ & $12.00 \pm 0.00$ & 3.00 \\
\hline \multirow[t]{3}{*}{ Mixed } & I & $37.33 \pm 2.66$ & $21.33 \pm 4.80$ & 1.75 \\
\hline & II & $20.00 \pm 6.11$ & $50.66 \pm 5.81$ & 0.39 \\
\hline & III & $21.33 \pm 3.52$ & $54.66 \pm 2.66$ & 0.39 \\
\hline \multirow{3}{*}{ Thalassinid } & I & $2.00 \pm 2.00$ & $34.00 \pm 6.00$ & 0.05 \\
\hline & II & $2.66 \pm 1.33$ & $61.33 \pm 9.61$ & 0.04 \\
\hline & III & $2.66 \pm 1.33$ & $62.66 \pm 8.11$ & 0.04 \\
\hline \multicolumn{5}{|l|}{ August } \\
\hline \multirow[t]{3}{*}{ Arenicolid } & I & $74.66 \pm 10.41$ & $18.66 \pm 2.66$ & 4.00 \\
\hline & II & $81.33 \pm 3.52$ & $25.33 \pm 9.33$ & 3.21 \\
\hline & III & $37.33 \pm 3.52$ & $28.00 \pm 4.00$ & 1.33 \\
\hline \multirow[t]{3}{*}{ Mixed } & $\mathrm{I}$ & $50.00 \pm 10.00$ & $28.00 \pm 4.00$ & 1.78 \\
\hline & II & $25.33 \pm 4.80$ & $50.66 \pm 10.41$ & 0.50 \\
\hline & III & $36.00 \pm 4.00$ & $58.66 \pm 3.52$ & 0.61 \\
\hline \multirow[t]{3}{*}{ Thalassinid } & I & $1.33 \pm 1.33$ & $65.33 \pm 11.85$ & 0.02 \\
\hline & II & $9.33 \pm 1.33$ & $74.66 \pm 13.13$ & 0.12 \\
\hline & III & $6.66 \pm 6.66$ & $48.00 \pm 6.92$ & 0.13 \\
\hline
\end{tabular}
for each plot 
the bay and slightly down slope $1 \mathrm{~h}$ and $45 \mathrm{~min}$ from the time of insertion, with a maximum $\left(75 \mathrm{\mu g} \mathrm{ml}^{-1}\right)$ occurring at $3 \mathrm{~h}$ and $45 \mathrm{~min}$ from gel insertion (Fig. 1). On the opposite side of the gel, maximum fluorescein concentrations at $1 \mathrm{~cm}$ distance reached a peak of only $\sim 2 \mu \mathrm{g} \mathrm{ml}^{-1}$ (data not shown). Thus, transport was asymmetric and rapid, likely due to advective processes associated with pressure gradients generated during drainage of the tidal flat. A concern of extracting porewater samples is the possibility of inducing transport via the removal of porewater. Although we cannot unequivocally dismiss some sampling effect of porewater extraction, the directionality of the measured transport is suggestive of advection. The missing section of the curve in Fig. 1 ( $4 \mathrm{~h}$ and 45 min from time of gel insertion) was due to little to no extractable porewater in the sediments at $5 \mathrm{~cm}$ depth. Three days subsequent to the gel insertion, porewater samples were again taken at $5 \mathrm{~cm}$ depth along the same transect as the first sample set (Fig. 2). Results confirm a similar pattern of asymmetrical concentration gradients.

A comparison of tracer concentration and transport time in the field to that obtained in the laboratory diffusion experiments confirms the occurrence of advective porewater movement in these sediments. Compared to field data $\left(\sim 80 \mu \mathrm{g} \mathrm{ml}^{-1}\right.$ at $1 \mathrm{~cm}$ after $\left.0.17 \mathrm{~d}\right)$, a similar concentration in the diffusion experiment was

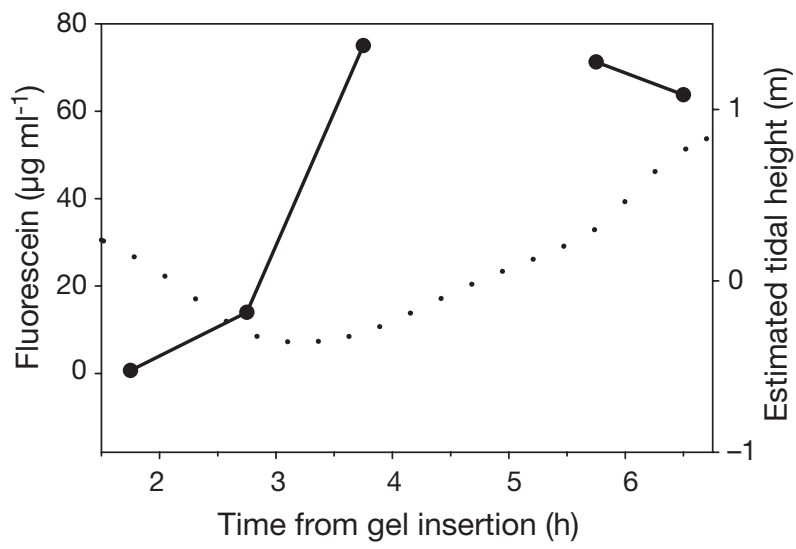

Fig. 1. Results from preliminary studies of porewater advection in False Bay sediments. Left $y$-axis shows fluorescein concentration (solid line) at $1 \mathrm{~cm}$ distance from the gel edge, toward the mouth of the bay, at $5 \mathrm{~cm}$ depth in the sediment. The $x$-axis is the time from gel insertion into the sediment. The broken section of the solid line corresponds to the sampling period when no porewater could be extracted from the sediment. Right $y$-axis shows estimated tidal height (dotted line) in False Bay in meters, based on observations and predicted tides in Friday Harbor. The directionality in concentration away from the gel plug down slope and not up indicates the importance of tidally generated pressure gradients in facilitating porewater advection



Fig. 2. Spatial transect showing fluorescein concentration at $5 \mathrm{~cm}$ depth on 26 May 2004, 3 d after the gel was inserted. The peak at $1 \mathrm{~cm}$ illustrates the effect of tidally induced pressure gradients on porewater movement and indicates directional (advective) transport. The solid vertical line at $x=0$ represents the location of the fluorescein-impregnated gel

found between $10 \mathrm{~d}\left(5.50 \mu \mathrm{g} \mathrm{ml}^{-1}\right.$ at $\left.1.5 \mathrm{~cm}\right)$ and $18 \mathrm{~d}$ (95.00 $\mu \mathrm{g} \mathrm{ml}^{-1}$ at $1.5 \mathrm{~cm}$ ) (Fig. 3). The difference in time and concentration between advection field experiments and diffusion experiments indicates that advective processes have substantial impacts on porewater transport in this habitat.

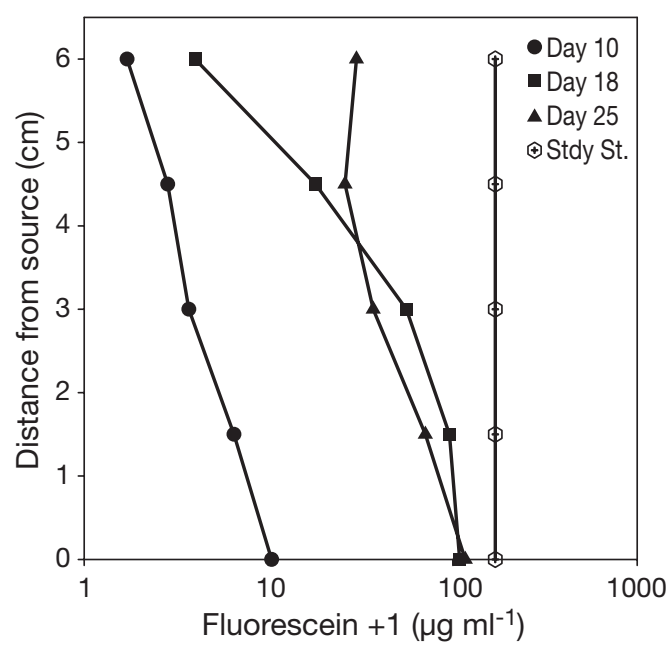

Fig. 3. Time series of fluorescein concentration profiles obtained from diffusion experiment in a controlled sediment tower with no advective transport. The profiles refer to time from initiation of the experiment. The vertical line is the theoretical profile at steady state (Stdy St.), assuming no loss of tracer. This profile was calculated based on the known concentration of tracer in a given volume of gel, volume of sediment and water in the column overlying the gel, and a representative porosity of the sediments in the experiments. Depth 0 is the depth adjacent to the acrylamide gel source 


\section{Fluorescein-loss experiments}

The recovery of the fluorescein-impregnated gels was not completely efficient. For each treatment, there should have been a total of 30 observations (5 surface and 5 deep gel sections per plot in each of 3 blocks). The actual recoverable gel samples for each treatment were 23, 15, 25 for the arenicolid, mixed, and thalassinid treatments, respectively. Thus, the degrees of freedom were relatively balanced between the arenicolid and thalassinid treatments, but the mixed treatment had fewer observations.

In spite of these difficulties, significant differences were found in the fluorescein-loss data $(\mathrm{p}<0.0001$, $\left.F_{2,58.7}=14.03\right)$. Fluorescein loss was higher in the arenicolid plots relative to the thalassinid and mixed plots, suggesting that porewater transport was highest in arenicolid regions. No significant effect of depth $(\mathrm{p}=$ $\left.0.2480, F_{1,57}=1.36\right)$ or block $\left(\mathrm{p}=0.3018, F_{2,57}=1.22\right)$ was found; therefore, the data were pooled and a 1-way ANOVA was conducted with block and depth as covariates. Once again, a significant treatment effect was found, with the arenicolid plots showing significantly less fluorescein remaining in the gels relative to the mixed ( $\left.\mathrm{p}=0.0049, t_{59.5}=3.28\right)$ and thalassinid plots $\left(p<0.0001, t_{57.6}=5.19\right)$, respectively. No significant difference was found between the mixed and thalassinid plots ( $p=0.5368, t_{59.4}=1.07$ ) (Fig. 4). These differences in fluorescein loss suggest that macrofaunal species composition is an important regulator of the extent of advective transport in permeable sediments. In particular, the arenicolids appear to be greater facilitators of advective transport relative to thalassinids. The lack of difference between deep $(\sim 8 \mathrm{~cm})$ and surface $(\sim 2 \mathrm{~cm})$ sections of the gel also indicate that these differences are not driven by organism effects on surface topography. Surface topography-driven flows tend to have shallow (3 to $5 \mathrm{~cm}$ ) penetration into the sediment column (e.g. Huettel et al. 1998).

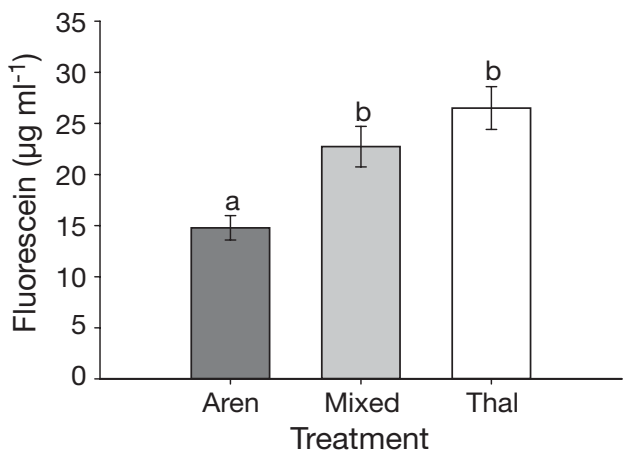

Fig. 4. Mean values $( \pm 1 \mathrm{SE})$ of fluorescein remaining in the gels for each treatment: arenicolid (aren), mixed and thalassinid (thal). Data are pooled for block and depth as no significant effect was found for either factor. Common letters indicate no significant difference between treatments

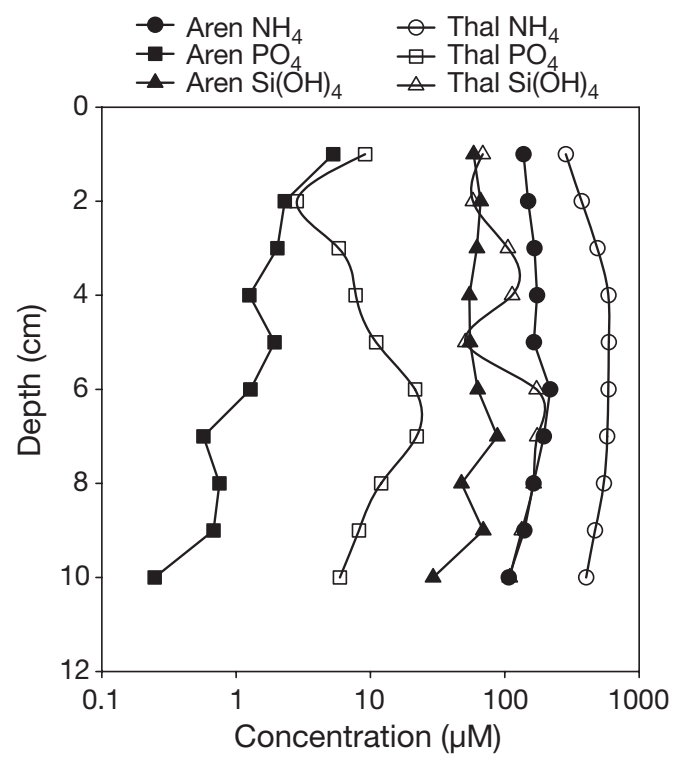

Fig. 5. Representative porewater profiles from 2 peeper deployments, 1 in an arenicolid (aren) plot (filled symbols) and 1 in a thalassinid (thal) plot (open symbols). Profiles of ammonium (circle), phosphate (square), and silicate (triangle) are shown

\section{Sediment porewater solutes}

The porewater peepers with acrylamide gels appeared to accurately record average porewater solute concentrations (Fig. 5), and corresponded well to direct porewater extractions at this site (Marinelli 1994, G. G. Waldbusser unpubl. data). Overall trends in the porewater data support differential rates of porewater transport associated with the different taxa in this study. In most cases the depth-integrated porewater concentrations were lower in the arenicolid plots relative to the thalassinid plots (Fig. 6). However, mixed plots showed considerable variation. For all solutes measured $\left(\mathrm{NH}_{4}{ }^{+}, \mathrm{PO}_{4}{ }^{3-}, \mathrm{Si}(\mathrm{OH})_{4}\right.$, dissolved inorganic carbon (DIC), alkalinity, and $\mathrm{pH}$ ), there was a significant treatment $\times$ block interaction in the 2-way ANOVA, making the interpretation of main treatment effects somewhat difficult (Table 2, Fig. 6). Closer examination of the data revealed that, in most cases, the interaction is driven by significant variation in the mixed treatment across blocks, perhaps associated with differences in abundance of the 2 organisms in these plots (Table 1). Because of the significant interaction terms in the original 2-way ANOVA, the possibility of density-dependent effects (Tables 1 \& 2), and the kinetic differences in solute reaction rates, post hoc regression analyses were conducted to explore relationships between organism density and porewater solute concentrations.

Linear regression results support the prediction of both density effects and kinetic effects. Parameter esti- 

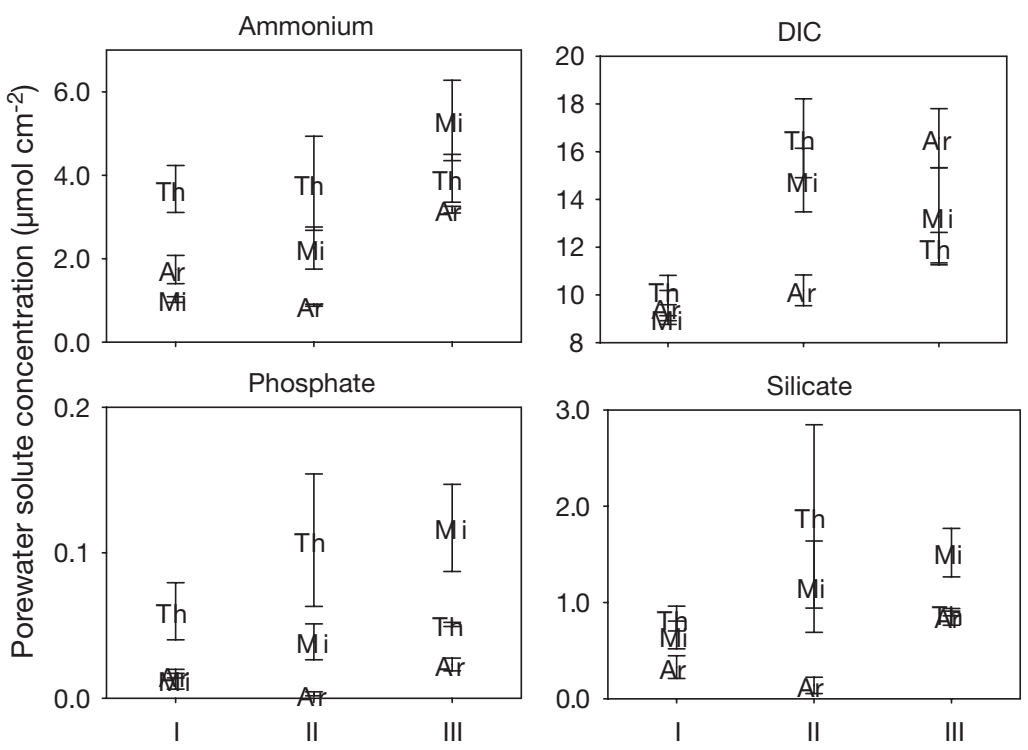

Fig. 6. Calculated least square means and standard errors for depth-integrated porewater profiles of each plot within each block (I to III). The $x$-axis refers to block number; the $y$-axis is the depth-integrated porewater solute concentration $\left(\mu \mathrm{mol} \mathrm{cm} \mathrm{cm}^{-2}\right)$. Note: scales are different. Ar: arenicolid; Mi: mixed; Th: thalassinid; DIC: dissolved inorganic carbon

mates suggest a stronger, negative effect of arenicolid density and a positive effect of thalassinid density, on ammonium and phosphate concentration relative to silicate concentration (Table 3). However, a pattern was detected in the distribution of the residuals for several of the simple linear regressions. Positive residuals were clustered about intermediate abundances (occurring generally in mixed plots), and negative residuals were found at the extremes (occurring generally in the single species plots). The presence of this non-random pattern in residuals, as well as failure of the data to meet the Shapiro-Wilks' test for normality, indicates that an additional variable may be needed in the regression analyses.

The results from multiple linear regressions, with overlap index, show better fits than the single linear models in most cases, as indicated by p-values and adjusted $\mathrm{R}^{2}$ of the 2 parameter model (Table 4 ). The

Table 2. F-values for the interaction terms in the 2-way ANOVA for block (blk) and treatment (trt) effects. The interaction is highly significant in all cases except silicate. DIC: dissolved inorganic carbon

\begin{tabular}{|lcrrr|}
\hline Solute & Effect & df & F-value & p-value \\
\hline Ammonium & blk $\times$ trt & 4,18 & 6.89 & 0.0015 \\
Phosphate & blk $\times$ trt & 4,18 & 6.57 & 0.0019 \\
Silicate & blk $\times$ trt & 4,18 & 4.16 & 0.0148 \\
DIC & blk $\times$ trt & 4,18 & 5.95 & 0.0031 \\
Alkalinity & blk $\times$ trt & 4,18 & 6.83 & 0.0016 \\
pH & blk $\times$ trt & 4,18 & 10.32 & 0.0002 \\
\hline
\end{tabular}

results also indicate a positive relationship between degree of species overlap and depth-integrated porewater concentrations of silicate, ammonium and DIC. This suggests that, while species identity and kinetic effects may contribute to overall porewater concentrations (Table 3), species interaction effects are also operative.

\section{Sediment parameters}

Granulometric analysis of composite sediment samples indicated very little difference in sediment grain size, porosity, and other measures among the experimental plots (Table 5). This argues against the hypothesis that the effects of the different organisms on porewater transport are related directly to changes in bulk sediment characteristics. In addition, organic $\mathrm{C}$ and $\mathrm{N}$ measures of surficial sediments among plots also show very little difference (Table 5).

Consistent with the bulk sediment analyses, the calculated permeability from each site shows no clear distinction as a function of experimental treatment, nor is it related to fluorescein-loss data (Figs. 4 \& 7). A simple linear regression between fluorescein remaining in the gels and the calculated permeability for the experimental plots was not significant $\left(\mathrm{p}=0.6038, F_{1,8}=0.30\right.$, $\left.\mathrm{R}^{2}=0.04\right)$. The porosity measures could be biased toward low values, since the sediment samples were taken at low tide and the drainage may have removed some of the water, though this should not affect among-site comparisons. However, the values calculated by the loss of weight via drying are very close to

Table 3. Results from the standardized simple linear regression analysis for effects of arenicolid and thalassinid density on integrated porewater solute concentrations. Analyses were performed on standardized data; therefore, the parameter estimates are directly comparable. Significance: ${ }^{*} p=0.05,{ }^{* *} p=$ 0.01 , and ${ }^{* * *} p=0.001$. Degrees of freedom for each analysis were between 27 and 24 and dependent on outlier detection and removal. Adj.: adjusted; DIC: dissolved inorganic carbon

\begin{tabular}{|c|c|c|c|c|}
\hline \multirow[t]{2}{*}{ Solute } & \multicolumn{2}{|c|}{ Arenicolid } & \multicolumn{2}{|c|}{ Thalassinid } \\
\hline & Estimate & Adj. $R^{2}$ & Estimate & Adj. $R^{2}$ \\
\hline Ammonium & $-0.698^{* * *}$ & 0.42 & $0.737^{* * *}$ & 0.49 \\
\hline Phosphate & $-0.532^{* * *}$ & 0.37 & $0.678^{* * *}$ & 0.59 \\
\hline Silicate & $-0.412^{* *}$ & 0.24 & $0.456^{* * *}$ & 0.39 \\
\hline DIC & $-0.505^{*}$ & 0.18 & $0.411^{*}$ & 0.14 \\
\hline Alkalinity & $-0.616^{* * *}$ & 0.38 & $0.829^{* * *}$ & 0.68 \\
\hline $\mathrm{pH}$ & -0.109 & -0.03 & 0.126 & -0.02 \\
\hline
\end{tabular}


Table 4. Results from the standardized multiple linear regression analysis inclusive of the overlap index and density effects on integrated porewater solute concentration. Parameter estimates for both density and overlap are presented for models run with arenicolid (Aren) density and thalassinid (Thal) density for each solute. Significance: ${ }^{*} p=0.05,{ }^{* *} p=0.01$, and ${ }^{* * *} \mathrm{p}=0.001$. Adj.: adjusted; DIC: dissolved inorganic carbon

\begin{tabular}{|lclllllr|}
\hline \multirow{2}{*}{ Solute } & \multicolumn{3}{c}{ Aren \& overlap } & \multicolumn{3}{c|}{ Thal \& overlap } \\
& Aren & Overlap & Adj. $\mathrm{R}^{2}$ & \multicolumn{2}{c}{ Thal } & Overlap & Adj. $\mathrm{R}^{2}$ \\
\hline Ammonium & $-0.972^{* * *}$ & $0.439^{*}$ & 0.50 & $0.901^{* * *}$ & 0.180 & 0.55 \\
Phosphate & $-0.684^{* * *}$ & 0.227 & 0.40 & $0.808^{* * *}$ & 0.183 & 0.60 \\
Silicate & $-0.783^{* * *}$ & $0.514^{* *}$ & 0.48 & $0.670^{* * *}$ & $0.329^{* *}$ & 0.58 \\
DIC & $-0.690^{* *}$ & $0.647^{* *}$ & 0.29 & $0.766^{* * *}$ & $0.643^{* * *}$ & 0.48 \\
Alkalinity & $-0.617^{* *}$ & 0.067 & 0.37 & $0.879^{* * *}$ & 0.114 & 0.68 \\
pH & 0.041 & 0.110 & -0.06 & 0.068 & 0.007 & -0.08 \\
\hline
\end{tabular}

milieu of marine sediments requires investigation of geochemical and physical processes in concert with biological characterization. Geochemical parameters such as organic matter input and reaction rate kinetics, physical parameters such as boundary layer interactions, and sediment granulometry all interact with organism characteristics (behavior, activity rates) and community level processes (density dependence) to determine the ecological landscape. Integration of these features over various scales in space and time determine the emergent ecosystem function.

earlier porosity measures made in the same area by using direct measurements of changes in volume of dried sediment added to known volumes of water (G. G. Waldbusser unpubl. data).

Results of the measured permeability using the falling-head permeameter experiments of intact sediment cores taken from Block I showed the following coefficients of permeability: arenicolid $\left(26.49 \mathrm{~cm} \mathrm{~h}^{-1}\right)$, mixed (18.55 $\left.\mathrm{cm} \mathrm{h}^{-1}\right)$, and thalassinid $\left(23.60 \mathrm{~cm} \mathrm{~h}^{-1}\right)$. As noted above, these values were based on 1 core from each site and, therefore, do not capture the extent of variability within the experimental plots. Qualitative comparison of the calculated permeability (Fig. 7) and the measured permeability (above) show similar patterns in the values between arenicolid and thalassinid plots, but not in the mixed plot.

\section{DISCUSSION}

To understand the effect of biodiversity and community structure on system function in benthic environments, it is important to adopt a mechanistic approach that includes both organisms and processes (Bolam et al. 2002, Reise 2002, Lohrer et al. 2004). The complex
The results from the present study underscore the need for an integrative approach to studies of advectively permeable sediments, an environment that is prominent and biogeochemically significant in coastal and continental shelf habitats (Jahnke et al. 2000,

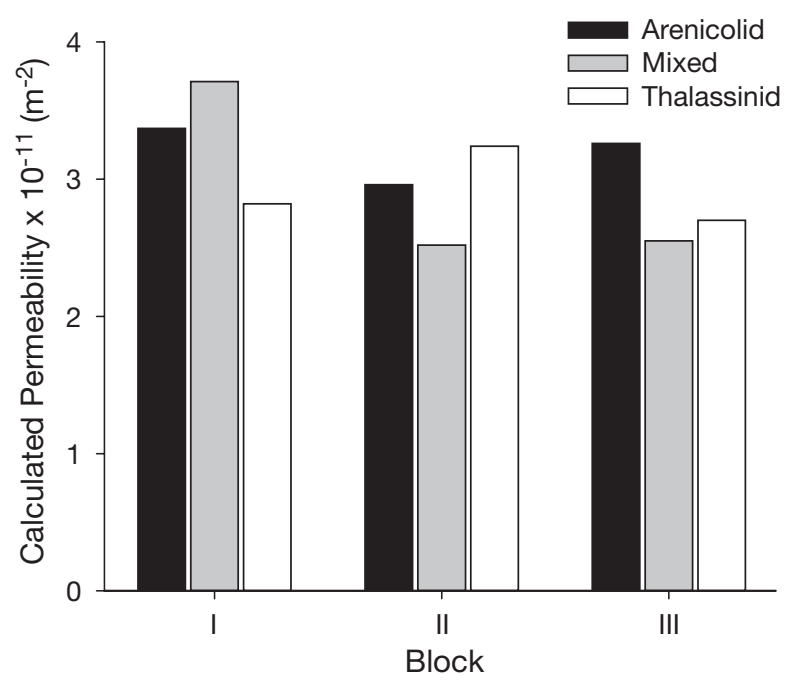

Fig. 7. Calculated permeability by the Rumpf-Gupte equation for composite samples from each plot among blocks

Table 5. Sediment characteristics from composite samples of all the experimental plots, blocks (I, II, III), and treatments (M: mixed; A: arenicolid; T: thalassinid). Organic carbon and nitrogen are from replicate samples (3) within each plot (in \% w/w, $\pm 1 \mathrm{SD})$; standard deviations in organic nitrogen within site were $<0.00$. Categorical classification of sediments is given in the right-hand column (from Folk \& Ward 1957)

\begin{tabular}{|lrrrrrrrrrr|}
\hline Measure & I/M & I/A & I/T & II/M & II/A & II/T & III/M & III/A & III/T & Classification \\
\hline Grain (phi) & 2.88 & 2.88 & 2.93 & 2.93 & 2.71 & 2.83 & 3.11 & 2.99 & 3.07 & Fine sands \\
Sorting & 1.78 & 1.78 & 1.78 & 1.91 & 1.77 & 1.84 & 1.88 & 1.79 & 1.86 & Poorly sorted \\
Skewness & 0.00 & 0.01 & 0.01 & -0.02 & -0.02 & -0.01 & 0.01 & 0.01 & 0.02 & Symmetrical \\
Kurtosis & 1.11 & 1.11 & 1.08 & 1.05 & 1.08 & 1.07 & 1.08 & 1.07 & 1.09 & Mesokurtic \\
Porosity & 0.44 & 0.43 & 0.42 & 0.42 & 0.41 & 0.43 & 0.44 & 0.44 & 0.44 & \\
Organic C & 0.17 & 0.21 & 0.21 & 0.19 & 0.18 & 0.21 & 0.18 & 0.20 & 0.17 & \\
Org. C SD & \pm 0.01 & \pm 0.09 & \pm 0.02 & \pm 0.01 & \pm 0.01 & \pm 0.03 & \pm 0.01 & \pm 0.06 & \pm 0.02 & 0.02 \\
Organic N & 0.02 & 0.02 & 0.03 & 0.03 & 0.02 & 0.03 & 0.02 & 0.02 & 0.02 \\
\hline
\end{tabular}


2003, Rocha 2000, Rusch et al. 2001, Reimers et al. 2004). Such environments are characterized by porous sediments with low standing stock but high throughput of organic material and rapid rates of biogeochemical cycling and porewater exchange (Marinelli et al. 1998). We utilized the natural variability of dominant infauna in this permeable sediment habitat to more accurately represent the role of functionally different infauna and their interaction on ecosystem-type processes over previous manipulated experimental systems. An important concern in using unmanipulated naturally occurring infaunal communities is the potential for other larger-scale correlated parameters to be the drivers of among-treatment variability. The spatial proximity of plots, lack of differences in granulometry, and lack of any noticeable pattern in species distributions across the flat all indicate that species distributions (on the scale of the experiment) are not the result of larger-scale physical factors that may be confounding treatment effects. In other words, on our scales of measurement, the biology seems to be a causative agent, not responding to our measured parameters. We have shown that (1) functionally different macrofauna affect rates of porewater advection in permeable sediments, (2) the effects are not attributable to changes in average vertically integrated measures of sediment granulometry or other plot-specific characteristics that may be due to non-biological effects, (3) species interactions may further complicate the advective environment and the resulting diagenetic processes, and (4) species effects on geochemistry vary according to reaction rate kinetics of particular spoutes (described below).

Previous studies of infaunal effects on permeable sediments have emphasized surface processes related to topographic variation or sediment disturbance (Huettel et al. 1998, D'Andrea et al. 2002). This study emphasizes below-surface processes, including species-specific effects and species interactions. Although D'Andrea et al. (2002) also examined below-surface effects on sediment dynamics, our results suggest a different suite of mechanisms for organism effects on transport. In their study, thalassinids were found to increase organic matter reaction rates in closer proximity to burrows and to increase flushing rates at depth in the less-permanent sections of the burrow. Our study emphasizes the effects of functionally different species' burrow morphology and feeding behavior on below-surface advective transport. In addition, belowsurface species interactions appear to promote nonlinear relationships between infauna and sediment geochemistry that may form the basis for 'biodiversity effects' in sedimentary habitats (Waldbusser et al. 2004).

Surface processes that generate porewater advection include surface gravity waves in shallow water and interactions between surface topography and fluid flow fields (Huettel \& Gust 1992, Reimers et al. 2004). Both of these mechanisms are present at False Bay. However, the lack of difference between near surface and deep sections of the gel indicates that transport does not decrease with depth (across the interval we studied, surface to $\sim 10 \mathrm{~cm}$ ), as is often the case with surface processes affecting the upper $5 \mathrm{~cm}$ of the sediment column (Huettel et al. 1998). Examination of the photographic data found roughly 5 to 7 sand ripple peaks in the sediment surface across a $50 \mathrm{~cm}$ transect, corresponding to an average ripple wave length of roughly $10 \mathrm{~cm}$. The shape of the ripples indicates that the dominant flow direction during the flood tide is counter to the direction of the tracer gradient after $3 \mathrm{~d}$ of gel deployment (Fig. 2). Observations made during the gel diffuser experiments found that overlying water covers the sediment faster than it can percolate through it horizontally due to the pressure gradient. Therefore, the lack of a depth effect on fluorescein loss, the size and shape of the sediment ripples, and the observed direction of tracer transport all indicate that pressure gradients associated with tidal drainage and flooding, coupled with fine-scale variation driven by organisms, are likely the dominant mechanisms driving patterns of advective exchange. Other sources of pressure differentials, such as boundary interactions, surface gravity waves, and thermal convection, may also contribute to rapid transport within these sediments.

The fluorescein-loss experiments and sedimentpermeability analyses suggest that fine-scale measurements and consideration of organism behavior may be necessary to capture the mechanisms that promote the observed species differences in advective flow. Finer-scale features, such as burrow wall composition or channels associated with feeding and sediment fluffing, are likely to be extremely important in either blocking or facilitating flow; these are not captured by traditional bulk analyses. More advanced measures such as high-resolution CT Scan or ultrasound may be required to reveal these features and their significance to transport in coastal sediments (Solan et al. 2003, Wethey \& Woodin 2005). Therefore, based on our findings and many prior studies, we must look to organism-specific attributes for discerning the mechanism(s) behind the differences we found.

We hypothesize that the higher flushing rates found in the arenicolid plots compared to the thalassinid plots probably relate to differences in motility, feeding, and burrow construction between the 2 dominant taxa. During feeding, arenicolids fluidize sediment at the base of the feeding area and create localized hot spots of vertical advective throughput (Huettel 1990, Riisgård \& Banta 1998, Timmermann et al. 2002, 2003). 
In addition, recent ultrasound measurements (Wethey \& Woodin 2005) indicate advective pumping of the area immediately below and surrounding the burrow opening (upper 2 to $3 \mathrm{~cm}$ ) during near hourly defecation events. The effects of vertical advective displacement of particles and fluid by arenicolids may directly or indirectly influence the rate of horizontal transport due to pressure gradients generated through tidal sediment saturation and draining. Arenicolids also appear to move reasonably frequently (Krager \& Woodin 1993), perhaps in response to food patches (S. A. Woodin unpubl. data), ammonium concentrations (R. L. Marinelli unpubl. data), or in relation to life stage (Linton \& Taghon 2000). Thus, sediment fluidization and movement may link resources and life history with advective transport. The potential effect of these linkages and their relation to microbial activity, benthic primary production, and nutrient cycling has been noted by Jumars et al. (1990), but little to no empirical evidence exists to verify or nullify these ideas.

In contrast to arenicolids, thalassinids create large feeding galleries where they feed directly in the sediment within the gallery (Neotrypaea californiensis), or filter feed by pumping overlying water (Upogebia pugettensis). Some investigators have suggested that microbes yielded through 'gardening' are also an important food source for thalassinids (Jumars et al. 1990, Kinoshita et al. 2003). Thalassinid species are often observed to eject fines (MacGinite 1930, Suchanek 1983, Posey et al. 1991, Pinn et al. 1998, Feldman et al. 2000) or have high pumping rates of burrow water compared to the physical processes of tidal exchange (Dworschak 1981); therefore, it should be expected that they would, in turn, increase the transport rates of porewater within sediments and affect rates of organic matter remineralization (Ziebis et al. 1996, D'Andrea et al. 2002). In contrast to prior studies, our study found no difference in grain size distributions (Table 5), and transport rates were slower in thalassinid areas compared to arenicolid areas (Fig. 4), though true organism-free control plots were lacking. It should also be noted that surface features often found in association with thalassinid burrows were lacking from the experimental area. The redistribution of the fine-grained sediment during tidal flows or the dominance of the filter-feeding $U$. pugettensis (Griffis \& Suchanek 1991) are 2 potential reasons sediment mounds associated with burrow openings were not found. Observations from various burrows around the experimental site found that the upper portions of the thalassinid burrows are thickly lined with clay and appear to be impermeable. In addition, pressure sensors placed near thalassinid burrows indicate little to no signal associated with feeding or movement, suggesting the walls are extremely thick relative to arenicolid burrow walls (D. S. Wethey \& S. A. Woodin unpubl. data). We suggest that thalassinids in False Bay actually decrease bulk permeability through creation of near-solid structures that serve to interrupt flow. Analogous to pipes running through the sediment column, these near-solid structures may interfere with arenicolid feeding via inhibition of sediment fluidization and subduction.

The use of organism density in our analyses of porewater solutes coupled with kinetic differences among the solutes provides a mechanistic basis for interpreting the complex results obtained. The significant block by treatment interactions in the original 2-way ANOVA of porewater data are not surprising, given the differences in relative densities of the 2 experimental organisms across the mixed treatments (Table 1). Prior investigations of benthic community dynamics and sedimentary functioning used biomass to account for bulk organism effects (Emmerson et al. 2001, Bolam et al. 2002), but measures of abundance more explicitly account for the effects of burrow surface area on sediment-seawater exchange (Aller 1980) and individual interactions (Marinelli 1994). Furthermore, recent investigators have found density-dependent effects on sediment chemistry (Gilbert et al. 2003, Marinelli \& Williams 2003, Lohrer et al. 2004), driven in part by kinetic effects. We predicted that, based on kinetics arguments (Aller 1980, Marinelli 1992, Boudreau \& Marinelli 1994), ammonium and phosphate should be most sensitive to advective processes facilitated by infauna and exhibit strong density dependence. Both ammonium and phosphate are produced by organic matter decomposition, and production is not affected by porewater concentration. Such solutes are highly sensitive to the degree of biologically mediated transport in sediments. Phosphate also is readily adsorbed to particles in the presence of oxygen, so rapid advection of oxic seawater is likely to further decrease phosphate concentrations in the porewater. Conversely, silica dissolution is abiotic, partly controlled by the degree of saturation, and less sensitive to biologically driven transport. Thus, differences in the effects of infauna on solute concentration may relate in part to interactions between density and reaction rate kinetics, as observed in the regression parameters (Tables $3 \& 4$ ).

The inclusion of the overlap parameter also resulted in better model fits, a more detectable density effect, and some congruence with the expected relationship between density, kinetics, and solute loss (Table 4). A possible mechanism behind the significant overlap effect may lie in our proposed interaction between arenicolids and thalassinids, where thalassinid burrows act as impermeable objects that restrict the feeding and fluidizing behaviors of the arenicolids. Posey 
et al. (1991), and references therein, have shown the negative effects of thalassinids on smaller macrofauna related to bioturbation and/or adult-larval interactions. Similar negative effects have been documented with arenicolid feeding and depositional burial of smaller macrofauna (Riisgård \& Banta 1998, and references therein). More importantly to the current study, we present a potential inhibition of arenicolid feeding by thalassinid burrows, linking organism behavior and transport mechanisms in sediments, possibly cascading into ecosystem functions such as nutrient cycling, microbial dynamics, and benthic primary production. Current models of advective transport include bulk sediment parameters and hydraulic pressure heads (Boudreau 1997), but do not reflect this level of complexity. Experiments incorporating the fine-scale measures of these processes are required if we are to incorporate biologically complex parameters into current models of elemental cycling in permeable sediments and into our evaluation of ecosystem services provided by coastal habitats.

Complex associations of the biological, chemical, and physical processes co-act to determine ecosystem function. Our findings illustrate the importance of behavior and ecological considerations in studies of sediment dynamics and, conversely, the importance of dynamics and processes in studies of biodiversity and ecosystem function. Developing predictive models of the effects that species loss has on the functioning of coastal systems requires a mechanistic, process-based approach. Given the broad scope of anthropogenic impacts on many coastal ecosystems and the well documented changes in the structure of the coastal marine biological community (Levin et al. 2001), integrative studies are critical to understanding and maintaining living resources.

Acknowledgements. Comments made by 4 anonymous reviews were constructive and helpful in improving this manuscript. This research was supported by a Maryland Sea Grant Graduate Research Fellowship (\#NA16RG2207) and an Alan Kohn Fellowship from Friday Harbor Laboratories to G.G.W. and by grants from the Office of Naval Research and Maryland Sea Grant (\#SA07-5-28051Q) to R.L.M. We thank the administration, staff, and faculty of Friday Harbor Laboratories for their unbridled help and support, as well as the many friends and colleagues who made the stay memorable. We also thank S. A. Woodin and D. S. Wethey who contributed both intellectually and logistically. S. E. Kolesar provided support during G.G.W.'s stay at Friday Harbor and made thoughtful comments on earlier versions of this manuscript. This research has been conducted by G.G.W. as partial fulfillment of requirements for a $\mathrm{PhD}$ from the University of Maryland. The statements, findings, conclusions, and recommendations are those of G.G.W. and R.L.M. and do not necessarily reflect the views of Maryland Sea Grant, the National Oceanic and Atmospheric Administration, or the US Dept. of Commerce.

\section{LITERATURE CITED}

Aller RC (1980) Quantifying solute distributions in the bioturbated zone of marine sediments by defining an average microenvironment. Geochim Cosmochim Acta 44: 1955-1965

Biles CL, Solan M, Isaksson I, Paterson DM, Emes C, Raffaelli DG (2003) Flow modifies the effect of biodiversity on ecosystem function: an in situ study of estuarine sediments. J Exp Mar Biol Ecol 285/286:165-177

Bolam S, Fernandes T, Huxham M (2002) Diversity, biomass, and ecosystem processes in the marine benthos. Ecol Monogr 72:599-615

Boudreau BP (1984) On the equivalence of nonlocal and radial-diffusion models for porewater irrigation. J Mar Res 42:731-735

Boudreau BP (1997) Diagenetic models and their implementation. Springer-Verlag, Berlin

Boudreau BP, Marinelli RL (1994) A modeling study of discontinuous biological irrigation. J Mar Res 52:947-968

Brenchley GA (1981) Disturbance and community structure: an experimental study of bioturbation in marine softbottom environments. J Mar Res 9:767-790

Browne KA, Zimmer RK (2001) Controlled field release of a waterborne chemical signal stimulates planktonic larvae to settle. Biol Bull (Woods Hole) 200:87-91

Canfield DE, Jørgensen BB, Fossing H, Glud R and 6 others (1993a) Pathways of organic carbon oxidation in three continental margin sediments. Mar Geol 113:27-40

Canfield DE, Thamdrup B, Hansen JW (1993b) The anaerobic degradation of organic matter in Danish coastal sediments: iron reduction, manganese reduction, and sulfate reduction. Geochim Cosmochim Acta 57:3867-3883

Coelho VR, Cooper RA, Rodrigues SA (2000) Burrow morphology and behavior of the mud shrimp Upogebia omissa (Decapoda: Thalassinidea: Upogebiidae). Mar Ecol Prog Ser 200:229-240

D'Andrea AF, Aller RC, Lopez GR (2002) Organic matter flux and reactivity on a South Carolina sandflat: the impacts of porewater advection and macrobiological structures. Limnol Oceanogr 47:1056-1070

D'Andrea AF, Lopez GR, Aller RC (2004) Rapid physical and biological particle mixing on an intertidal sandflat. J Mar Res 62:67-92

de Beer D, Wenzhöfer F, Ferdelman TG, Boehme SE and 5 others (2005) Transport and mineralization rates in North Sea sandy intertidal sediments, Sylt-Rømø Basin, Wadden Sea. Limnol Oceanogr 50:113-127

Dumbauld BR, Armstrong DA, Feldman KL (1996) Lifehistory characteristics of two sympatric thalassinidean shrimps, Neotrypaea californiensis and Upogebia pugettensis, with implications for oyster culture. J Crustac Biol 16:689-708

Dworschak PC (1981) The pumping rates of burrowing shrimp Upogebia pusilla (Petagna) (Decapoda: Thalassinidea). J Exp Mar Biol Ecol 52:25-35

Eaton AD, Clesceri LS, Greenberg AE (1995) Standard methods for the examination of water and wastewater, 19th edn. American Public Health Association, Washington, DC

Eckman JE (1983) Hydrodynamic processes affecting benthic recruitment. Limnol Oceanogr 28:241-257

Eckman JE (1996) Closing the larval loop: linking larval ecology to the population dynamics of marine benthic invertebrates. J Exp Mar Biol Ecol 200:207-237

Emmerson MC, Solan M, Emes C, Paterson DM, Raffaelli DG (2001) Consistent patterns and the idiosyncratic effects of biodiversity in marine ecosystems. Nature 411:73-77 
Engstrom S, Marinelli RL (2005) Recruitment responses of benthic infauna to manipulated sediment geochemical properties in natural flows. J Mar Res 63:407-436

Feldman KL, Armstrong DA, Dumbauld BR, DeWitt TH, Doty DC (2000) Oysters, crabs, and burrowing shrimp: review of an environmental conflict over aquatic resources and pesticide use in Washington State's (USA) coastal estuaries. Estuaries 23:141-176

Folk RL, Ward WC (1957) Brazos River bar: a study of significance of grain size parameters. J Sediment Petrol 27:3-26

Gilbert F, Aller RC, Hulth S (2003) The influence of macrofaunal burrow spacing and diffusive scaling on sedimentary nitrification and denitrification: an experimental simulation and model approach. J Mar Res 61:101-125

Gray H (1958) Suggested method of test for permeability of porous granular materials by the falling-head permeameter. In: Procedures for testing soils. American Society for Testing Materials, Philadelphia, PA, p 253-255

Griffis RB, Suchanek TH (1991) A model of burrow architecture and trophic modes in thalassinidean shrimp (Decapoda: Thalassinidea). Mar Ecol Prog Ser 79:171-183

Guinasso NL, Schink DR (1975) Quantitative estimates of biological mixing rates in abyssal sediments. J Geophys Res 80:3032-3043

Hesslein RH (1976) An in situ sampler for close interval pore water studies. Limnol Oceanogr 21:912-914

Hobson KD (1967) The feeding and ecology of two North Pacific Abarenicola species (Abarenicolidae, Polychaete). Biol Bull (Woods Hole) 33:343-354

Huettel M (1990) Influence of the lugworm Arenicola marina on porewater nutrient profiles of sand flat sediments. Mar Ecol Prog Ser 62:241-248

Huettel M, Gust G (1992) Impact of bioroughness on interfacial solute exchange in permeable sediments. Mar Ecol Prog Ser 89:253-267

Huettel M, Webster IT (2001) Porewater flow in permeable sediments. In: Boudreau BP, Jørgensen BB (eds) The benthic boundary layer: transport processes and biogeochemistry. Oxford University Press, New York, p 144-179

Huettel M, Ziebis W, Forester S, Luther GW III (1998) Advective transport affecting metal and nutrient distributions and interfacial fluxes in permeable sediments. Geochim Cosmochim Acta 62:613-631

Jahnke RA, Jahnke DP (2000) Rates of C, N, P, and Si recycling and denitrification at the US mid-Atlantic continental slope depocenter. Deep-Sea Res I 47:1405-1428

Jahnke RA, Nelson JR, Marinelli RL, Eckman JE (2000) Benthic flux of biogenic elements on the southeastern US continental shelf: influence of pore water advective transport and benthic microalgae. Cont Shelf Res 20:109-127

Jahnke RA, Alexander CR, Kostka JE (2003) Advective pore water input of nutrients to the Satilla River estuary, Georgia, USA. Estuar Coast Shelf Sci 56:641-653

Jumars PA, Mayer LM, Deming JW, Baross JA, Wheatcroft RA (1990) Deep-sea deposit-feeding strategies suggested by environmental and feeding constraints. Philos Trans R Soc Lond 331:85-101

Kinoshita K, Wada M, Kogure K, Furota T (2003) Mud shrimp burrows as dynamic traps and processors of tidal-flat materials. Mar Ecol Prog Ser 247:159-164

Kinzing AP, Pacala SW, Tilman D (2001) The functional consequences of biodiversity. Princeton University Press, Princeton, NJ

Koroleff F (1976) Determination of $\mathrm{NH}_{4}-\mathrm{N}$. In: Grasshoff K (ed) Methods of seawater analysis. Verlag Chemie, Weinheim, p 127-133

Krager CD, Woodin SA (1993) Spatial persistence and sedi- ment disturbance of an arenicolid polychaete. Limnol Oceanogr 38:509-520

Kristensen E, Jensen MH, Andersen TK (1985) The impact of polychaete (Nereis virens Sars) burrows on nitrification and nitrate reduction in estuarine sediments. J Exp Mar Biol Ecol 85:75-91

Levin L, Blair N, DeMaster D, Plaia G, Fornes W, Martin C, Thomas C (1997) Rapid subduction of organic matter by maldanid polychaetes on the North Carolina slope. J Mar Res 55:595-611

Levin LA, Boesch DF, Covich A, Dahm C and 8 others (2001) The function of marine critical transition zones and the importance of sediment biodiversity. Ecosystems 4: $430-451$

Linton DL, Taghon GL (2000) Feeding, growth, and fecundity of Abarenicola pacifica in relation to sediment organic concentration. J Exp Mar Biol Ecol 254:85-107

Lohrer AM, Thrush SF, Gibbs MM (2004) Bioturbators enhance ecosystem function through complex biogeochemical interactions. Nature 431:1092-1095

MacGinite GE (1930) The natural history of the mud shrimp Upogebia pugenttensis (Dana). Ann Mag Nat Hist 10: $36-47$

Marinelli RL (1992) Effects of polychaetes on silicate dynamics and fluxes in sediments: importance of species, animal activity and polychaete effects on benthic diatoms. J Mar Res 50:745-779

Marinelli RL (1994) Effects of burrow ventilation on activities of a terebellid polychaete and silicate removal from sediment pore waters. Limnol Oceanogr 39:303-317

Marinelli RL, Waldbusser GG (2005) Plant-animal-microbe interactions: closing the ecological loop. In: Kirstensen E, Haese RR, Kostka JE (eds) Interactions between macroand microorganisms in marine sediments. Coastal and Estuarine Studies, Vol 60. American Geophysical Union, Washington, DC, p 233-249

Marinelli RL, Williams TJ (2003) Evidence for density dependent effects of infauna on sediment biogeochemistry and benthic-pelagic coupling in nearshore systems. Estuar Coast Shelf Sci 57:179-192

Marinelli RL, Jahnke RA, Craven DB, Nelson JR, Eckman JE (1998) Sediment nutrient dynamics on the South Atlantic Bight continental shelf. Limnol Oceanogr 43:1305-1320

Mortimer RJG, Krom MD, Boyle DR, Nishir A (1999) Use of a high resolution porewater gel profiler to measure groundwater fluxes at an underwater saline seepage site in Lake Kinneret, Israel. Limnol Oceangr 44:1802-1809

Nickell LA, Atkinson RJA (1995) Functional morphology of burrows and trophic modes of three thalassinidean shrimp species, and a new approach to the classification of thalassinidean burrow morphology. Mar Ecol Prog Ser 128: 181-197

Pinn EH, James R, Atkinson A, Rogerson A (1998) Particle size selectivity and resource partitioning in five species of Thalassinidea (Crustacea: Decapoda). Mar Ecol Prog Ser 169:243-250

Posey MH, Dumbauld BR, Armstrong DA (1991) Effects of a burrowing mud shrimp, Upogebia pugettensis (Dana), on abundances of macro-infauna. J Exp Mar Biol Ecol 148: 283-294

Reise K (2002) Sediment mediated species interactions in coastal waters. J Sea Res 48:127-141

Reimers CE, Stecher HA III, Taghon GL, Fuller CM, Huettel M, Rusch A, Ryckelynck N, Wild C (2004) In situ measurements of advective solute transport in permeable shelf sands. Cont Shelf Sci 24:183-201

Riisgård HU, Banta GT (1998) Irrigation and deposit feeding 
by the lugworm Arenicola marina, characteristics and secondary effects on the environment. A review of current knowledge. Vie Milieu 48:243-257

Rocha C (2000) Density-driven convection during flooding of warm, permeable intertidal sediments: the ecological importance of the convective turnover pump. J Sea Res 43: $1-14$

Rusch A, Forster S, Huettel M (2001) Bacteria, diatoms and detritus in an intertidal sandflat subject to advective transport across the water-sediment interface. Biogeochemistry 55:1-27

Schoener TW (1970) Nonsynchronous spatial overlap of lizards in patchy habitats. Ecology 51:408-418

Sokal RR, Rohlf FJ (1969) Biometry. Freeman, San Francisco, CA

Solan M, Germano JD, Rhoads DC, Smith C and 11 others (2003) Towards a greater understanding of pattern, scale and process in marine benthic systems: a picture is worth a thousand words. J Exp Mar Biol Ecol 285/286:313-338

Strickland JDH, Parsons TR (1972) A practical handbook of seawater analysis. Fish Res Board Can. Bulletin 167

Suchanek TH (1983) Control of seagrass communities and sediment distribution by Callianassa (Crustacea, Thalassinidea) bioturbation. J Mar Res 41:281-298

Taghon GL (1988) The benefits and costs of deposit feeding in the polychaete Abarenicola pacifica. Limnol Oceanogr 33: 1166-1175

Taghon GL, Nowell ARM, Jumars PA (1980) Induction of suspension feeding in spionid polychaetes by high particulate

Editorial responsibility: Martin Solan (Guest Editor), Newburgh, UK fluxes. Science 210:562-564

Thamdrup B, Fossing H, Jørgensen BB (1994) Manganese, iron, and sulfur cycling in a coastal marine sediment, Aarhus Bay, Denmark. Geochim Cosmochim Acta 58: $5115-5129$

Timmermann K, Christensen JH, Banta GT (2002) Modeling of advective solute transport in sandy sediments inhabited by the lugworm Arenicola marina. J Mar Res 60:151-169

Timmermann K, Banta GT, Larsen J, Andersen O (2003) Modelling paticle and solute transport in sediments inhabited by Arenicola marina. Effects of pyrene on transport processes. Vie Milieu 53:187-200

Waldbusser GG, Marinelli RL, Whitlatch RB, Visscher PT (2004) The effects of infaunal biodiversity on biogeochemistry of coastal marine sediments. Limnol Oceanogr 49: 1482-1492

Wardle DA (1999) Is 'sampling effect' a problem for experiments investigating biodiversity-ecosystem function relationships? Oikos 87:403-407

Wethey DS, Woodin SA (2005) Infaunal hydraulics generate porewater pressure signals. Biol Bull 209:139-145

Widdicombe S, Austen MC (1998) Experimental evidence for the role of Brissopsis lyrifera (Forbes, 1841) as a critical species in the maintenance of benthic diversity and the modification of sediment chemistry. J Exp Mar Biol Ecol 228:241-255

Ziebis W, Forster S, Huettel M, Jørgensen BB (1996) Complex burrows of the mud shrimp Callianassa truncata and their geochemical impact on the sea bed. Nature 382:619-622

Submitted: December 15, 2004; Accepted: October 21, 2005 Proofs received from author(s): March 7, 2006 



\title{
Biodiversity and the functioning of seagrass ecosystems
}

\author{
J. Emmett Duffy* \\ School of Marine Science and Virginia Institute of Marine Science, The College of William and Mary, Gloucester Point, \\ Virginia 23062-1346, USA
}

\begin{abstract}
Biodiversity at multiple levels - genotypes within species, species within functional groups, habitats within a landscape-enhances productivity, resource use, and stability of seagrass ecosystems. Several themes emerge from a review of the mostly indirect evidence and the few experiments that explicitly manipulated diversity in seagrass systems. First, because many seagrass communities are dominated by 1 or a few plant species, genetic and phenotypic diversity within such foundation species has important influences on ecosystem productivity and stability. Second, in seagrass beds and many other aquatic systems, consumer control is strong, extinction is biased toward large body size and high trophic levels, and thus human impacts are often mediated by interactions of changing 'vertical diversity' (food chain length) with changing 'horizontal diversity' (heterogeneity within trophic levels). Third, the openness of marine systems means that ecosystem structure and processes often depend on interactions among habitats within a landscape (landscape diversity). There is clear evidence from seagrass systems that advection of resources and active movement of consumers among adjacent habitats influence nutrient fluxes, trophic transfer, fishery production, and species diversity. Future investigations of biodiversity effects on processes within seagrass and other aquatic ecosystems would benefit from broadening the concept of biodiversity to encompass the hierarchy of genetic through landscape diversity, focusing on links between diversity and trophic interactions, and on links between regional diversity, local diversity, and ecosystem processes. Maintaining biodiversity and biocomplexity of seagrass and other coastal ecosystems has important conservation and management implications.
\end{abstract}

KEY WORDS: Food web · Habitat structure $\cdot$ Landscape $\cdot$ Production $\cdot$ Stability $\cdot$ Trophic transfer Resale or republication not permitted without written consent of the publisher

\section{INTRODUCTION}

Seagrass beds are among the most widespread and productive coastal ecosystem types worldwide, and range from the tropics to boreal margins of every ocean (Hemminga \& Duarte 2000). Seagrasses provide physical structure on otherwise largely featureless sediment bottoms, enhancing community diversity, biomass, and primary and secondary production. The leaves provide a substratum for growth of epiphytic microalgae that fuel food webs and a shelter for invertebrates and fishes that reach substantially greater densities than in unvegetated benthic habitats (Heck \& Orth 1980, Orth et al. 1984). This combined productivity of seagrasses and associated algae ranks seagrass beds among the most productive ecosystems on earth (Duarte \& Cebrián 1996), and their provision of nursery areas for juvenile stages of commercially important species (Heck et al. 2003) contributes significantly to the economic importance of estuarine fisheries (Anderson 1989, Costanza et al. 1997). Moreover, because much seagrass production ends up in below-ground tissues and ungrazed detritus, seagrass beds are an important global sink for carbon, accounting for an estimated $15 \%$ of net $\mathrm{CO}_{2}$ uptake by marine organisms on a global scale, despite contributing only $1 \%$ of marine primary production (Duarte \& Chiscano 1999).

Unfortunately, seagrass beds are also among the most threatened of marine habitats (Short \& WyllieEchevarria 1996, Duarte 2002). As in most other shallow marine ecosystems, 3 threats stand out as being especially pervasive. These are eutrophication (Howarth et al. 2000, Cloern 2001), overfishing (Jackson et al. 2001), and the destruction of physical and 
biogenic habitat (Watling \& Norse 1998, Thrush \& Dayton 2002). These impacts, along with pollution, have caused major changes in abundance, species composition, and structure of marine communities, including regional and even global extinctions (Carlton et al. 1999, Jackson et al. 2001). Of the several types of human insults that the natural world faces, however, species extinction is arguably unique in being the only one that is irreversible. Thus, there are compelling reasons for understanding how declining biodiversity mediates ecosystem functional processes such as productivity, trophic transfer, and carbon storage.

Recognizing these links, the potential influence of changing biodiversity on ecosystem functioning (BEF) has become a central topic in ecology and conservation biology (Tilman 1999, Loreau et al. 2001, Naeem 2002, Srivastava \& Vellend 2005) and a controversial one (Huston 1994, Huston et al. 2000, Schwartz et al. 2000, Wardle et al. 2000). By ecosystem functioning, I mean aggregate processes of whole ecosystems, such as primary and secondary production, trophic transfer, biogeochemical fluxes, and resistance and resilience of ecosystem-level properties to disturbance. In this review, I consider whether and how changing biodiversity, across a hierarchy of taxonomic and ecological scales, may influence the functioning of seagrass ecosystems, based on the few explicit experimental tests of such relationships and on inferences from other lines of evidence. I close with thoughts on how this research might inform our response to mitigating worldwide seagrass decline and its consequences for ecosystem services important to human society.

\section{FUNCTIONAL ASPECTS OF BIODIVERSITY}

Living organisms vary at every level of the phylogenetic hierarchy from individual genes through higher taxa, and ecological assemblages vary in composition from guilds or functional groups, through communities, to landscapes. This variation is of interest in understanding ecosystem functioning insofar as it provides a proxy for variation in traits important to processes such as growth, production, and resource use (e.g. Norberg et al. 2001). Historically, most research exploring biodiversity effects on ecosystem functioning has equated 'biodiversity' with the number of species (Tilman 1999, Loreau et al. 2001). In principal, however, diversity at any level might influence ecosystem processes, and there is evidence that variation at several levels does so, as reviewed below.

Conceptually, diversity can be partitioned into variation in identity (often called composition in the BEF literature) and number (or richness) of elements, whether those elements are species, genotypes, or other enti- ties. It has long been recognized that the identities of species in a system strongly influence its functioning. Particular keystone species, dominant species, and ecosystem engineers have pervasive impacts on structure and functioning of a wide range of ecosystems (Jones et al. 1994, Power et al. 1996, Grime 1998). In seagrass systems, specifically, identity of the dominant seagrass and macroalgal species strongly influences sediment biogeochemistry, nutrient cycling, water-column oxygen profiles, water filtration capacity, primary and secondary production, carbon storage, support of higher trophic levels including commercially important species, and response to disturbance (Heck \& Orth 1980, Duarte 1991, Lemmens et al. 1996, Cebrián et al. 1997, Duarte et al. 1997, Valiela et al. 1997, Wigand et al. 1997, Lipcius et al. 1998, Hemminga \& Duarte 2000, Deegan et al. 2002). For example, shallow eutrophic estuaries are often dominated by macroalgae (Valiela et al. 1997), which support much sparser animal populations than seagrass beds (Deegan 2002). Experimental removal of macroalgae in a eutrophic estuary shifted dominance back to eelgrass Zostera marina, substantially enhancing abundances of fishes and decapod crustaceans, and reducing water-column hypoxia (Deegan et al. 2002). At a finer taxonomic scale, 4 Mediterranean seagrass species spanned an order of magnitude in the proportion of their production stored as refractory detritus (Cebrián et al. 1997), and a suite of Philippine seagrass species responded quite differently to experimental sediment loading, with some species declining rapidly, but others showing an opportunistic growth increase (Duarte et al. 1997).

Similarly, the identity of herbivore taxa is important to ecosystem processes; fishes and sea urchins often injure seagrasses by feeding on them, whereas most gastropods and crustaceans facilitate seagrasses by grazing their competitors (Hughes et al. 2004, Valentine \& Duffy 2005). Even superficially similar grazer taxa can have widely different impacts on the structure and functioning of seagrass systems (Duffy et al. 2003, 2005). In short, the ecosystem consequences of variation in species identity are well documented and uncontroversial for seagrass beds and other ecosystems.

The more challenging question is whether and how the richness or variety of elements (genotypes, species, habitat types) in a system influence its functioning. That is, are there general relationships between species richness and ecosystem processes, or are species effects entirely idiosyncratic? Under what circumstances might we expect diversity effects or idiosyncrasy? These and related questions have been a primary focus of recent research in ecology (reviewed by Tilman 1999, Loreau et al. 2001, 2002b, Kinzig et al. 
2002). The abundant functional variation among species in seagrass communities provides much raw material by which diversity might influence ecosystem properties. Accordingly, I focus here on whether and how the number (richness) of genotypes, species, higher taxa, and habitat types in seagrass systems influences production, trophic transfer, biogeochemical fluxes, and resistance to disturbance. Existing data suggest that biodiversity at a range of scales can significantly influence the functioning of seagrass ecosystems and enhances the magnitude and stability of services that they provide to humans.

\section{EVIDENCE AND INFERENCE}

Since much controversy has surrounded proposed relationships between biodiversity and ecosystem function (Huston 1997, Huston et al. 2000, Wardle et al. 2000), it is important to consider the nature of available evidence. A logical first pass at evaluating such relationships might involve mining the extensive datasets on community composition and rates of ecosystem processes available for marine systems. Emmerson \& Huxham (2002) used this approach in a thoughtful review of potential links between diversity and ecosystem properties in marine sedimentary systems. Using individual sites or studies as data points, they found positive correlations between benthic invertebrate species richness and ammonium flux, particle clearance from the water column, and secondary production. Using a similar approach, Duarte (2000) found that aggregate seagrass biomass and species richness of seagrasses covaried positively in southeast Asian beds.

While such relationships are intriguing, it is critical to bear in mind, as Emmerson \& Huxham (2002) noted, that correlation is not causation. Relationships between species diversity and productivity, for example, are bidirectional (Loreau et al. 2001, Naeem 2002, Worm \& Duffy 2003). Species richness varies predictably with resource availability, disturbance, and other abiotic gradients (Huston 1994). Typically, withinhabitat diversity increases as resource availability (productivity potential) increases from very low to moderate levels, above which excess nutrient loading can reduce diversity again (the 'paradox of enrichment', Rosenzweig 1971). The initially rising diversity is attributable in large part to the greater carrying capacity and favorability of more productive environments, which allows additional species to persist that could not do so under very low resource availability. Such cross-site comparisons explicitly consider a gradient in the abiotic environment and assume that a regional pool of species is available to colonize all sites.
In this scenario, then, one expects a positive correlation between aggregate biomass, which reflects carrying capacity, and diversity. However, it is because resource availability (environmental 'productivity') is driving diversity, rather than vice versa.

Studies of how biodiversity influences ecosystem processes address a very different question, namely the consequences o irreversible species loss from a system in which the abiotic environment is held constant. That is, they simulate the consequences of global or regional extinction. The distinction is critical, and has often been misunderstood. The most rigorous way to test this latter hypothesis is through experimental manipulation of biodiversity. In contrast, surveys of unmanipulated systems rarely can rigorously test whether diversity influences aggregate biomass (or other ecosystem processes) because, in open systems, diversity and biomass patterns are both responses to resource availability.

\section{THREATS TO BIODIVERSITY OF SEAGRASS ECOSYSTEMS}

Whether and how changing biodiversity influences ecosystem functioning obviously depend on which taxa are lost-and which are gained via invasion. Experiments (Jonsson et al. 2002, Zavaleta \& Hulvey 2004) and simulations (Ostfeld \& LoGiudice 2003, Solan et al. 2004) show that the identity and order in which species are lost from a system strongly influence how those losses translate to changing ecosystem functioning. Several patterns in how humans influence biodiversity appear to apply across a broad range of aquatic (and many terrestrial) systems (Fig. 1). Perhaps the most consistent is that overharvesting results in large animals being the first species to be lost, or rendered so rare as to be ecologically extinct (Jackson et al. 2001, Pandolfi et al. 2003, Lotze \& Milewski 2004). Thus, one of the first consequences of human impact on most ecosystems is 'trophic skew', i.e. flattening of the trophic biomass pyramid with general reduction in impacts of large predators (Duffy 2003). Such overharvesting followed rapidly after human occupation of sites worldwide, even with low human population densities and primitive hunting technologies (Jackson et al. 2001, Wing \& Wing 2001). Reduction of large animals can have several ecosystem-level consequences. Depending on the number and discreteness of effective trophic levels (Strong 1992), reduced predator abundance may actually increase grazing pressure via a trophic cascade. Such cascades have not yet been demonstrated conclusively in seagrass beds, but are documented or inferred in other coastal systems. For example, hunting of sea otters in the 19th century 

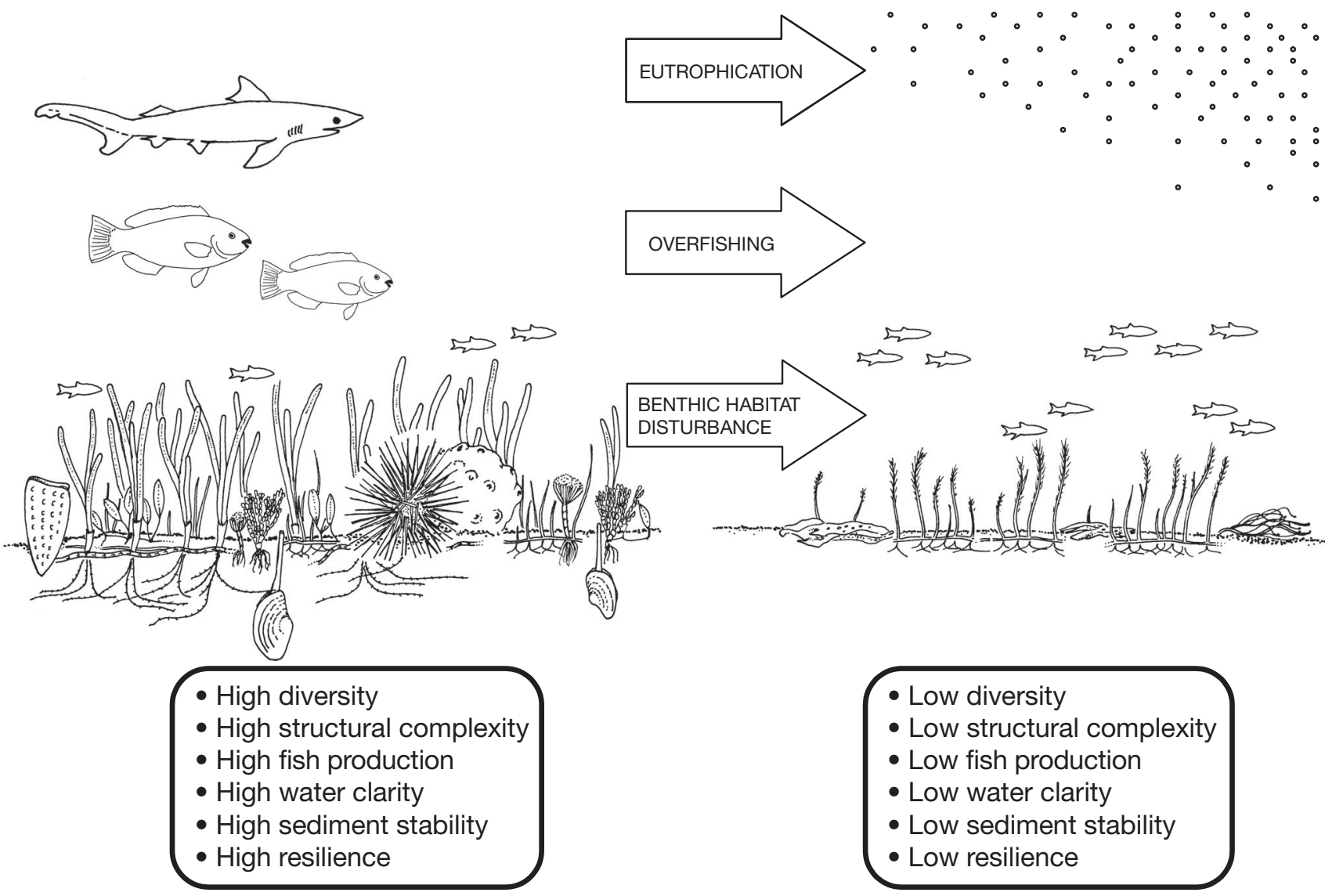

Fig. 1. Schematic illustration of major human-induced impacts on a tropical seagrass system, their common influences on biodiversity and habitat structure, and some of their consequences for ecosystem functioning

caused a phase shift from productive kelp beds to structureless sea urchin barrens (Estes \& Duggins 1995). Similarly, destructive grazing of salt-marsh cordgrass by abundant snails in the southeastern United States may have been exacerbated by overfishing of their main predator, the blue crab Callinectes sapidus (Silliman \& Bertness 2002). Finally, perennial seaweeds like rockweeds Fucus and giant kelp have occasionally been decimated by outbreaks of grazing crustaceans in recent decades (e.g. Kangas et al. 1982, Haahtela 1984, Tegner \& Dayton 1987), although the link to reduced predation has not been made conclusively in these cases. Because many large marine vertebrates are highly mobile, loss of these animals may also break important functional links between habitats that involve transport of materials or consumer influence (Polis et al. 1997, Lundberg \& Moberg 2002).

In modern coastal regions, anthropogenic habitat destruction and eutrophication (Fig. 1) are also nearly universal, and are major threats to seagrass systems (Short \& Wyllie-Echeverria 1996, Duarte 2002). Like harvesting, habitat destruction tends to influence large, slow-growing plants and animals most heavily, leading to dominance by opportunistic 'weedy' taxa with small bodies and fast growth (Watling \& Norse 1998). This loss of large plants and sessile invertebrates removes important habitat structure for associated mobile organisms. Moreover, since large species tend to have correspondingly large per-capita effects on ecosystem processes (Emmerson \& Raffaelli 2004, Solan et al. 2004), loss of large mobile invertebrates can reduce bioturbation, with important biogeochemical consequences (e.g. Aller \& Yingst 1978, 1985, Emmerson et al. 2004, Lohrer et al. 2004, Waldbusser et al. 2004, Widdicombe et al. 2004). Finally, eutrophication generally selects for fast-growing algae (including phytoplankton) over perennial seagrasses (Valiela et al. 1997). Hence, under human impact, biodiversity loss most severely affects large animals, high trophic levels, and perennial benthic plants. What is left are physically fragmented systems dominated by small, opportunistic species tolerant of various anthropogenic stressors (Fig. 1).

While human activities have reduced biodiversity through the mechanisms just discussed, they have also transported and established many species outside their 
native ranges, both intentionally and inadvertently. For example, the Asian seagrass Zostera japonica has become established on the northwest coast of North America, essentially converting intertidal mudflats into seagrass beds, and increasing benthic animal diversity, abundance, and sediment organic matter much as native seagrasses do (Posey 1988). Although such invasions often increase local species richness, at least in the short term (Sax \& Gaines 2003), exotic predators, disease organisms, and competitors also frequently have large detrimental impacts on the structure and functioning of native ecosystems (Simberloff et al. 2005), including seagrass systems. For example, invasion and aggressive growth of the non-indigenous alga Caulerpa taxifolia in the Mediterranean are threatening seagrass beds there (deVilléle \& Verlaque 1995). In California, USA, the exotic mussel Musculista senhousia reduces the rhizome extension rates of eelgrass Zostera marina, suggesting that these invaders might be particularly detrimental to eelgrass beds that have already been fragmented (Reusch \& Williams 1998).

\section{BIODIVERSITY AND FUNCTIONING OF SEAGRASS ECOSYSTEMS}

\section{Conceptual background}

Diversity and resource use and productivity

Theory predicts that declining biodiversity should reduce community resource use and productivity, alter trophic interactions, and reduce a system's stability in the face of natural and human-induced perturbations. Tilman (1999) has reviewed the theoretical basis, as well as the first generation of experiments supporting the influence of plant species diversity on resource use and productivity. Briefly, diverse assemblages are predicted to be more productive, on average, than species-poor assemblages, because their larger range of traits allows exploitation of a greater fraction of available resources (niche complementarity), and because diverse assemblages are more likely, by chance alone, to contain species that grow well under the local conditions (the sampling effect). Most manipulations of grassland plant diversity have supported these predictions (Hector et al. 1999, Tilman 1999), although there are conspicuous exceptions (Hooper \& Vitousek 1997, Pfisterer \& Schmid 2002) and debate continues over interpretation of results (e.g. Huston \& McBride 2002). While the theory was developed primarily for plants, it should apply in principle to competitive assemblages of any type of organism, and experiments have indeed shown that species richness also enhances efficiency of resource use by sessile marine invertebrates (Stachow- icz et al. 1999, 2002), stream suspension feeders (Cardinale et al. 2002), mobile grazers (Naeem \& Li 1998, Duffy et al. 2003), aquatic detritivores (Jonsson \& Malmqvist 2000), and heterotrophic bacteria (Naeem et al. 2000). Thus, the greater efficiency of resource use by more diverse assemblages appears to be a common phenomenon in a range of taxa and ecosystems.

\section{Diversity and trophic interactions}

Within a food web, biodiversity can be thought of as having 2 dimensions: a 'vertical' component summarized by the length of food chains and a 'horizontal' component representing the number of species or functional groups within trophic levels (Fig. 2). Changes in vertical diversity (e.g. food chain length) often strongly influence ecosystem properties through changing trophic interactions (e.g. Pace et al. 1999, Shurin et al. 2002, Borer et al. 2005). Horizontal diversity influences ecosystem functioning through competition, facilitation, and resource partitioning, topics which have been the focus of most of the previous BEF research (Kinzig et al. 2002, Loreau et al. 2002b). Lowdiversity systems often function approximately as simple linear food chains with strong trophic cascades, as shown in temperate lakes (Carpenter et al. 1985, Jones \& Sayer 2003), high-latitude kelp beds (Estes et al. 1998), and the boreal ocean (Worm \& Myers 2003). Higher-diversity systems, in contrast, are expected to show weaker cascades and weaker top-down control (Leibold 1989, 1996, Strong 1992). The reason is that more diverse assemblages contain a wider range of predator-resistant taxa, such that predation shifts dominance toward resistant species ('species turnover', Leibold 1996) rather than reducing aggregate prey biomass as in simple food chains (Duffy 2002). This buffering effect of diversity against top-down control is supported by a meta-analysis of periphyton-grazer experiments (Hillebrand \& Cardinale 2004), a metaanalysis of terrestrial trophic cascade experiments (Schmitz et al. 2000), data on parasitoid control in terrestrial food webs (Montoya et al. 2003), and an explicit experimental test in a seagrass system (Duffy et al. 2005). Conversely, the effects of changing predator diversity on aggregate prey biomass have received little study (Duffy 2002, but see Finke \& Denno 2004, Bruno \& O'Connor 2005). In general, available data suggest that increasing diversity within a trophic level (or other functional group) often increases that level's relative influence on ecosystem functioning, as it leads to both greater resource use and greater resistance to control by higher-order predators. Nevertheless, trophic cascades have been observed in several highly diverse systems (Pace et al. 1999, Borer et al. 2005), 




Fig. 2. Vertical (food chain length) and horizontal (heterogeneity) components of biodiversity, illustrated in a partial food web from an eelgrass bed (Zostera marina) in Chesapeake Bay, USA. Changes in biodiversity may influence ecosystem functioning via changes in food chain length (e.g. loss of predators), and thus in the strength of top-down control, by eliminating entire functional groups (gray rectangles), by changing species diversity within functional groups, or by interactions among these processes

confirming that keystone species and other strong interactors can override the potentially buffering effects of diversity in some situations.

\section{Diversity and stability}

Finally, biodiversity is hypothesized to enhance stability of aggregate ecosystem properties (e.g. total plant biomass) under changing environmental conditions (Naeem 1998, Yachi \& Loreau 1999), because functionally redundant species can provide insurance when any one species is lost and because variation among species in response to environmental change (response diversity, Elmqvist et al. 2003) can even-out temporal fluctuations in community biomass. Some terrestrial and aquatic microbial experiments support these predictions. For example, in experimental moss assemblages, more diverse plots showed greater resistance to drought stress, that is, aggregate biomass was less affected by drought than in lower-diversity plots (Mulder et al. 1999). In microbial microcosms, ecosystem biomass was more predictable under changing resource (light and nutrient) conditions when more species were present (Naeem \& Li 1998). In the marine benthos, experiments and surveys both showed that more diverse fouling assemblages were more resistant to invasion by non-indigenous species (Stachowicz et al. 1999, 2002). Thus, high diversity often appears to buffer against effects of disturbance in a variety of ecosystems.

\section{Special considerations in seagrass ecosystems}

The current themes of BEF research are based largely on research aimed at terrestrial plants. Although several ecosystem-level effects of diversity have been demonstrated in a variety of systems and 
taxa, understanding potential effects of biodiversity on functioning of seagrass and other marine ecosystems also requires recognizing their typically strong topdown control, strong species dominance, and discordance between biomass and productivity. First, the strong consumer pressure characteristic of many aquatic systems (Cyr \& Pace 1993, Shurin et al. 2002) and the special vulnerability of large marine predators (Pauly et al. 1998, Worm et al. 2005) mean that effects of changing diversity on marine ecosystem functioning will likely entail complex interactions of changing diversity within levels and changing food chain length (Duffy 2003, Duffy et al. 2005). Second, many temperate seagrass systems are dominated by 1 or a few foundation species, the characteristics of which are likely to dominate ecosystem processes (Grime 1998). In such cases we may expect, by analogy with the effects of species richness, that genetic and phenotypic diversity within foundation species will be important (Reusch \& Hughes 2006). Finally, the use of standing plant biomass as a proxy for plant production, as is typically done in terrestrial experiments, is inappropriate in aquatic algal-based systems, because much algal production is rapidly grazed (Cyr \& Pace 1993), resulting in poor correlations between biomass and productivity. Moreover, the existence of many aquatic macrophyte systems depends paradoxically on dominance of the least productive primary producer species in the community. Seagrasses generally have substantially lower biomass-specific productivity than marine macro- and microalgae, which outcompete them under eutrophication or relaxed grazing pressure (Valiela et al. 1997). Yet, seagrass beds typically support considerably higher secondary production than sediment bottoms dominated by more productive macroalgae (e.g. Klumpp et al. 1989, Deegan 2002), because seagrass beds provide more a favorable physical structure, which supports both growth of microalgal food and shelter from predators for small animals. Thus, plant species composition, rather than total productivity, is important to the functioning of seagrass ecosystems.

\section{Functional consequences of primary-producer species diversity}

In an early discussion of marine BEF linkages, Duarte (2000) summarized evidence for differences among seagrass species in growth capacity and response to disturbance, and argued that these differences should lead to enhanced productivity and stability in diverse tropical seagrass assemblages, as they do in some terrestrial grasslands (Hector et al. 1999, Tilman 1999). Although his discussion predated experimental tests of such links in marine systems, much circumstantial evidence is con- sistent with Duarte's suggestions. For example, in the Caribbean, co-occurring seagrass species differ in rooting depth, with Halodule and rhizophytic algae near the surface, Syringodium below, and Thalassia occupying the deepest layer (Williams 1990). This partitioning of the rooting zone may foster complementarity of resource use, and thus greater aggregate efficiency of resource use by the plant assemblage, as has been demonstrated experimentally in terrestrial grasslands (Tilman 1999, Hector et al. 1999).

Despite dominance of plant biomass in seagrass beds by 1 or a few seagrass species, macroalgae are also characteristic components of seagrass communities and can play important functional roles. Although macroalgal blooms can smother seagrasses under excess nutrient loading (Raffaelli et al. 1998, Hauxwell et al. 2001), macroalgae can also facilitate seagrass growth under normal, low-nutrient conditions. Two examples illustrate this role. First, field experiments in a Caribbean seagrass bed suggest that rhizophytic green algae facilitate seagrass recolonization of cleared plots because decomposition of below-ground algal tissues increases nutrient concentrations in these oligotrophic sediments (Williams 1990). Such apparent facilitation is reminiscent of that between legumes and grasses in terrestrial grasslands. Second, Caribbean turtlegrass Thalassia testudinum beds often support a dense understory of the calcareous alga Halimeda. In Puerto Rico, turtlegrass associated with Halimeda mounds was denser, and had higher biomass and productivity, than turtlegrass away from Halimeda; ${ }^{13} \mathrm{C}$ signatures of leaves growing from the mounds suggested that the calcareous alga elevated dissolved $\mathrm{CO}_{2}$ in the interstices of the mounds, enhancing turtlegrass productivity (Kenworthy \& Reid 2003). These examples suggest that facilitation and niche complementarity among co-occurring plant species in seagrass beds may enhance resource use and aggregate production above those found in more pure stands.

\section{Functional consequences of seagrass genetic diversity}

In communities with strong dominance, such as many seagrass beds, intraspecific genetic diversity within dominant species may enhance the species' performance by analogous mechanisms to the niche complementarity and facilitation among species discussed above (Reusch \& Hughes 2006). Several studies from seagrass systems support such effects. Williams (2001) tested how allelic diversity at the individual (or clone) level influenced eelgrass performance, transplanting eelgrass shoots of known allozyme genotypes into the field in southern California to achieve treatments with higher allelic diversity (heterozygous at 1 or both of 2 
loci) and lower allelic diversity (homozygous at both loci). The metabolic enzyme loci studied $(M D H$ and GPI-2) are known to be influenced by selection in other taxa, and thus may not be ideal proxies for genomewide genetic diversity. Nevertheless, the more heterozygous plots produced greater shoot density by the end of the 2 yr experiment. In a separate mesocosm experiment measuring eelgrass growth responses to temperature stress, heterozygous genotypes also showed lower variability among treatments than did homozygotes (Williams 2001). Finally, seeds from a genetically depauperate transplant site had lower germination success than those from a more genetically diverse bed.

The link between population genetic diversity and stability was demonstrated conclusively by a field experiment on the central California coast that established replicated eelgrass plots spanning a range in clonal diversity, identified using microsatellite markers, from 1 to 8 genotypes per plot (Hughes \& Stachowicz 2004). The ecological consequence of higher genotypic diversity in this experiment was expressed as enhanced eelgrass resistance to disturbance by grazing geese and the stress associated with transplantation, resulting in more stable seagrass biomass and higher abundances of invertebrates and other associated species. A similar positive effect of genotypic diversity on eelgrass performance was demonstrated in the North Sea (Reusch et al. 2005), where more diverse plots achieved higher biomass during the anomalously hot summer of 2003.

Fisher's fundamental theorem of natural selection states that the adaptive evolutionary potential of a population is proportional to its genetic diversity. The examples reviewed here show that genetic diversity can also be important to the population's ability to cope with environmental change in ecological time. High genetic diversity within populations of dominant seagrasses can enhance growth performance and stability in the face of perturbations; thus, maintenance of high genetic diversity within seagrass populations may be important to maintaining the normal structure and functioning of the ecosystems they support. Positive consequences of genotypic diversity within foundation species for system stability and performance also may be common in other systems with strong dominance such as salt marshes, kelp beds, oyster reefs, deep-sea coral reefs, and pelagic upwelling systems. This possibility has clear conservation implications and deserves further study.

\section{Functional consequences of consumer diversity}

Human impacts on marine communities generally begin with depletion of large vertebrate predators and herbivores (Fig. 1), reducing the vertical component of biodiversity (Fig. 2). The consequences of this depletion will be mediated via cascading trophic interactions. In seagrass systems, the impacts of depleted large vertebrates have been inferred largely from indirect evidence and are speculative (as is true in most other systems), but it seems clear that large vertebrates were formerly far more abundant, particularly in tropical seagrass ecosystems, than they are today. Historical records suggest, for example, that sea turtles, some of which feed primarily on seagrasses, were orders of magnitude denser in the Caribbean prior to European contact (Jackson et al. 2001), and probably imposed strong grazing pressure on tropical seagrass beds, as dugongs probably did in the Indo-Pacific (Domning 2001). In addition to such mega-herbivores, predatory fishes have been greatly reduced in most coastal and oceanic ecosystems (Pauly et al. 1998, Jackson et al. 2001, Myers \& Worm 2003, Worm \& Myers 2003). Comparisons with other systems suggest that these losses should cascade down to affect the structure and functioning of seagrass beds, although there is little hard evidence to evaluate the possibility (Williams \& Heck 2001).

The expected ecosystem consequences of changing consumer diversity are inherently more complex than those of changing plant diversity (Holt \& Loreau 2002, Thébault \& Loreau 2003). Whether effects of shortened food chains on seagrasses are primarily positive or negative will depend, for example, on the number and distinctness of links in the chain (Hairston et al. 1960, Strong 1992), on diet breadth of consumers (Duffy 2002), and on whether herbivores feed preferentially on seagrasses or their competitors. Herbivores in modern seagrass systems include both direct grazers on seagrasses, such as sea urchins, turtles, and some fishes, as well as grazers on epiphytes, which include most crustaceans and molluscs. Meta-analysis confirms that these 2 groups are functionally distinct, with negative and positive effects, respectively, on seagrass growth and production (Hughes et al. 2004). As epiphyte grazers tend to be more diverse and abundant than seagrass grazers, especially in modern temperate systems, grazing in many seagrass systems tends, on average, to favor seagrasses (Hughes et al. 2004) and facilitate their positive impacts on ecosystem services.

The strength of top-down control generally, and trophic cascades specifically, should also be influenced by diversity within trophic levels, i.e. the horizontal component of biodiversity (Fig. 2; Leibold 1996, Duffy 2002). Supporting these predictions, recent mesocosm experiments in an eelgrass system demonstrated that declining species richness of crustacean mesograzers decreased their aggregate impact on the resource (algae) and decreased mesograzer production, in parallel with patterns demonstrated under declining plant 
diversity (Duffy et al. 2003). Specifically, treatments with 1 or 3 grazer species imposed lower total grazing impact on algae and accumulated less grazer biomass (secondary production), on average, than assemblages of 6 grazer species (Duffy et al. 2003). In a subsequent experiment that added a third trophic level (juvenile blue crabs Callinectes sapidus), declining grazer diversity also reduced the grazer assemblage's average resistance to predation, because diverse assemblages more consistently contained grazer species that eluded capture (Duffy et al. 2005). The latter experiment illustrates the important point that biodiversity and food chain length (i.e. presence or absence of predators) interactively influence ecosystem functioning and that neither factor's impact is predictable in isolation. In general, grazer diversity effects on resource use and production were stronger in the presence of a predator (Duffy et al. 2005), suggesting that increasing diversity within a trophic level buffered that level from topdown control. Finally, in both experiments with and without predatory crabs, declining mesograzer diversity reduced the dominance of eelgrass over macroalgae and epiphytes (Duffy et al. 2003, 2005). Thus, in this eelgrass system, high diversity of epiphyte grazers enhanced both control of epiphytes and macroalgae and the production of crustacean biomass, a critical link in food chains to higher trophic levels.

\section{Biodiversity and stability}

Among the most important hypothesized benefits of biodiversity for ecosystem functioning is provision of insurance that stabilizes the system against natural and anthropogenic environmental change (Naeem 1998, Yachi \& Loreau 1999, Loreau et al. 2002a). This insurance is provided by variation among the species within a functional group in response to change, or response diversity (Elmqvist et al. 2003). Importantly, such species might be considered functionally redundant under 'normal' conditions, but their response diversity (i.e. greater range of functional response traits, Naeem \& Wright 2003) makes the diverse assemblage better able to cope with environmental change.

There is mounting evidence that both genetic diversity and species richness provide such response diversity against perturbations in seagrass systems. This is because species or genotypes that appear functionally redundant under some circumstances fill different roles under changing conditions, as illustrated by 2 experiments. First, in the experiment discussed previously, Hughes \& Stachowicz (2004) found no effect of eelgrass genotypic diversity on either eelgrass biomass or the associated faunal assemblage in the absence of disturbance, suggesting that the genotypes were func- tionally redundant under normal circumstances. The importance of genetic diversity only became evident after disturbance, as the genotypes responded differently to a pulse of intense goose grazing. Second, response diversity among peracarid grazer species was demonstrated experimentally in eelgrass mesocosms (Duffy et al. 2005). In the absence of predation, the 4 grazer species had similar and strong impacts on epiphyte biomass, that is, they were functionally redundant. In the presence of predatory crabs, however, epiphyte control differed widely among grazer species, because of their differential vulnerability to predation, and grazing efficiency was higher in more diverse grazer assemblages. Finally, non-experimental evidence for response diversity comes from the varied responses of co-occurring seagrass species to experimental burial (Duarte et al. 1997) and the shift in dominance from Zostera to Ruppia during the 1997/1998 El Niño-Southern Oscillation event in Southern California (Johnson et al. 2003). Such response diversity is likely to be especially important in maintaining the stability of ecosystem services as the pace of anthropogenic environmental change accelerates. Thus, 'functional redundancy' may often be a misleading concept (Loreau 2004), and maintaining multiple, superficially similar species within functional groups is important to insuring seagrass and other ecosystems against unexpected surprises.

\section{STRUCTURAL COMPLEXITY AND FUNCTIONING OF SEAGRASS ECOSYSTEMS}

\section{Patch-scale processes}

Diversity can also influence ecosystem processes through its effects on habitat physical structure or complexity, which pervasively influence ecological processes, including productivity, trophic transfer, and maintenance of species diversity. Several of these topics are especially pertinent and well studied in seagrass systems, and have recently been comprehensively reviewed (Bell et al. 2006).

Plant diversity and faunal production

Seagrasses are classic ecosystem engineers, transforming relatively monotonous sediment bottoms into structurally complex, diverse, and highly productive habitats (Fig. 1). In addition to the seagrasses themselves, seagrass beds often recruit macroalgae, sponges, corals, large bivalves, and other sessile invertebrates that are rare or absent on unvegetated bottoms. Structural complexity of seagrass beds derives from both the 
physical arrangement of seagrass units within bedsshoot density, leaf length, patch structure-and from the richness and identity of other co-occurring sessile organisms.

Structurally complex habitats support higher diversity of mobile organisms in a wide range of systems (e.g. Kohn 1967, Abele 1974, Kotler \& Brown 1988). Several lines of evidence, mostly indirect, suggest that diversity of primary producers and sessile invertebrates influences structural complexity and associated functioning of seagrass systems. Stoner \& Lewis (1985) found that the understory of calcareous algae (Halimeda) in a Caribbean turtlegrass bed roughly doubled the surface area available for epifaunal habitat, relative to pure stands of turtlegrass, and that epifaunal densities were accordingly higher in plots with Halimeda. Moreover, while aggregate abundance of epifauna appeared closely related to plant surface area across all plots, 8 of the 15 dominant crustacean species were more abundant (per unit surface area) in plots with Halimeda. Thus, seagrass plots with macroalgae supported epifaunal assemblages that differed both quantitatively and qualitatively from those in pure seagrass stands. Similarly, Parker et al. (2001) showed experimentally in Chesapeake Bay that epifaunal abundance in mixed stands of seagrasses and macroalgae was proportional to total plant surface area, but that epifaunal species differed in their associations with particular macrophyte species such that epifaunal diversity was only slightly higher in plots of mixed seagrass and macroalgal species. These results recall similarly significant but weak relationships between plant diversity and insect diversity in terrestrial grasslands (Siemann et al. 1998). As is often true, however, too much of a good thing can be detrimental: in eutrophic systems, fleshy macroalgae outcompete seagrasses, increase water-column hypoxia, and support reduced animal abundance and production (Deegan et al. 2002).

Roles of sessile invertebrates

In tropical seas, sessile invertebrates are characteristic features of seagrass landscapes. Sponges, in particular, fulfill several important functions in these systems. These suspension feeders can have very high rates of water clearance, and symbiotic bacteria in some species make them disproportionately important to element cycling. Incubations of 4 common Caribbean sponges yielded the highest mass-specific rates of dissolved inorganic nitrogen production yet recorded from a benthic community (Diaz \& Ward 1997), and suggest that sponge-mediated nitrification may be substantial in shallow tropical environments where they are abundant. Sponges also provide unique and important physical habitat in seagrass systems, and many animals shelter within and under large sponges. A dramatic example of the importance of sponges became evident after the ecosystem phase shift that affected Florida Bay, USA, in the early 1990s. Large areas affected by blooms of planktonic cyanobacteria suffered severe mortality of sponges, thus losing critical shelter habitat for juvenile spiny lobsters and other animals; as a result, abundance of lobsters, which constitute a valuable fishery resource, declined wherever artificial shelters were unavailable (Butler et al. 1995).

\section{Habitat complexity and trophic transfer}

Among the most important and well-studied ecosystem services provided by seagrass beds is the provision of habitat for small animals and, thus, the enhancement of secondary production. A rich history of research shows that increasing seagrass structural complexity enhances epifaunal abundance and production, but conversely decreases the efficiency by which that production is transferred to predators (reviewed by Heck \& Orth 1980, 2006). This research has focused primarily on the role of seagrass density (often referred to as 'complexity') in mediating predator-prey interactions, but there is also evidence that species of seagrasses and macroalgae differ in the total density, and species relative abundances, of associated epifauna they support (Lewis 1987, Virnstein \& Howard 1987a,b, Jernakoff \& Nielsen 1998, Parker et al. 2001). Experiments have illuminated the mechanistic bases for these relationships, showing that variation among plant species in epifaunal density is largely, but not entirely, explained by plant surface area (Stoner \& Lewis 1985, Parker et al. 2001). Experiments also suggest that the relationship between seagrass density and effectiveness of predation is non-linear (reviewed by Heck \& Orth 2006), a conclusion also reached for juvenile decapod prey sheltering among macroalgae in seagrass beds (Lipcius et al. 1998). Although debate continues on the precise form of relationships between plant density and predation rate, it seems clear that some threshold density of vegetation is usually necessary to reduce predation rates on epifauna. Recent experiments on oyster reefs add an intriguing twist, indicating that at high predator densities, predation may be more, rather than less, effective in complex habitats, because habitat complexity reduces interference competition among predators (Grabowski \& Powers 2004). A central challenge for future research is determining how the higher densities of both prey and predators in denser seagrass interact with reduced per capita effectiveness of predators to mediate trophic transfer (Heck \& Orth 2006). 


\section{Landscape diversity}

Research in a wide range of systems demonstrates that interactions among the communities of different habitats in a landscape, mediated by both migrations of organisms and advection of resources, can profoundly influence community structure and ecosystem functioning (Polis et al. 1997, 2004). Such landscape diversity should be especially important to the functioning of marine systems, because they tend to be much more open than terrestrial systems (Witman et al. 2004, Heck \& Orth 2006).

\section{Seagrass patch structure}

The most basic aspect of landscape structure in seagrass systems involves the arrangement of seagrass patches relative to the matrix of unvegetated sediment area. Seagrasses are patchily distributed at a wide range of spatial scales, and there has accordingly been substantial research on the role of patch size and structure on associated animals and trophic interactions (Bell et al. 2006). Evidence to date suggests that relationships between patch size and animal abundance are idiosyncratic, and few consistent patterns have emerged (Bell et al. 2006). Nevertheless, several studies support the hypothesis that seagrass patch edges can act as ecotones where both epifaunal settlement and predation are elevated, potentially enhancing trophic transfer. In turtlegrass beds in the Gulf of Mexico, USA, density and estimated production of invertebrates was greater at the edges than in the interiors of patches (Bologna \& Heck 2002). Both adult peracarids in turtlegrass (Bologna \& Heck 2000) and newly settled sessile invertebrates in eelgrass (Orth 1992) were more abundant near patch edges, suggesting that abundance is determined in part by encounter rates of drifting larvae with seagrass, creating settlement shadows in the interior of patches. Predation also commonly appears to be elevated in patchy seagrass landscapes, as is also true in many terrestrial ecosystems (e.g. Hartley \& Hunter 1998, Chalfoun et al. 2002). Experiments have demonstrated elevated predation rates on juvenile blue crabs in seagrass patches separated by large expanses of sand (Hovel \& Lipcius 2002), and clams and scallops also showed lower survival in patchy than in continuous seagrass beds (Irlandi 1994, Irlandi et al.1995). These results suggest that trophic transfer is often elevated along patch edges and in fragmented seagrass landscapes relative to continuous ones.

\section{Cross-habitat subsidies}

Many community and ecosystem processes are strongly affected by connections between different kinds of habitats. These effects can result from passive advection of propagules and resources, or from active movement of mobile predators among habitats. A striking example is the subsidy of deep-sea food webs by seagrass leaves advected away from tropical islands (Suchanek et al. 1985). Seagrass beds may also be recipients of advected material, as exemplified by the high diversity and biomass of epiphytic macroalgae measured on seagrasses near reefs in Western Australia (Van Elven et al. 2004). By recruiting propagules from both habitats, near-reef seagrasses supported $20 \%$ higher algal diversity than on the adjacent reef, and $43 \%$ higher diversity than on seagrasses distant from the reef. Epiphytic algal biomass on near-reef seagrasses was $>3$-fold greater than on the reefs, and nearly 6 -fold higher than on distant seagrasses.

Active movement of predators between habitats can enhance densities and direct impacts of predators, and enhance primary producer growth indirectly via transport and excretion of inorganic nutrients by migrating predators. As an example of the first type of process, pinfish were more abundant in salt marshes adjoining seagrass beds than in marshes without seagrass beds (Irlandi \& Crawford 1997). Similarly, Micheli \& Peterson (1999) showed that oyster reefs isolated from seagrass beds and salt marshes supported higher macroinvertebrate species richness and higher survival of transplanted clams than reefs adjacent to vegetated areas. Experiments demonstrated that surrounding vegetation served as corridors facilitating access by predatory blue crabs to oyster reefs. Hence, in this instance, landscape-level diversity enhanced the strength of top-down control. The second process, transport of nutrients among habitats, was documented by Meyer et al. (1983). They showed that haemulid fishes (grunts) fed on invertebrates in seagrass beds by day and, during the night, moved to shelters among coral heads, where their excretion fertilized nutrient-limited corals and enhanced their growth rates. Subsidies moving in the opposite direction, into seagrass beds, are mediated by piscivorous birds that deposit nitrogen-rich guano near their roosts; seagrass beds surrounding bird islands had higher seagrass biomass and different seagrass species composition than islands without bird colonies (Powell et al. 1991).

Habitat diversity and complex life histories

A major functional consequence of landscape diversity derives from the complex ontogenic habitat shifts characteristic of many large marine animals with longlived larvae. Tropical seagrass and mangrove habitats serve as nursery areas for many fishes that live as 
adults on nearby reefs. Thus, proximity of different habitats in the landscape is critical to the populations of these fishes. As a specific example, comparisons of otherwise similar Belizean reef islands with and without fringing mangroves showed that biomass of several commercially important reef fishes was more than twice as great on the reefs adjacent to mangrove nurseries (Mumby et al. 2004). Size-frequency distributions indicated that mangroves served as a way-station between larval settlement into seagrass habitats and migration to adult reef habitat. Most striking is the case of Scarus guacamaia, the largest herbivorous fish in the Atlantic, whose juveniles were found only among mangroves; this species has suffered extinction on several reefs after mangrove removal (Mumby et al. 2004). A similar phenomenon has been implicated for spiny lobsters that recruit into seagrass beds and eventually migrate to reefs and mangrove habitats, where they live as adults. Acosta (1999) found that mangrove and coral islands surrounded by seagrass supported higher lobster densities, and higher proportions of juvenile size classes, than islands surrounded by unvegetated rubble. The seagrass habitats apparently served as safe migration corridors for juvenile lobsters, since measured emigration and immigration rates were 3 to 4 times higher on islands surrounded by seagrass.

These results from seagrass beds associated with oyster reefs, coral reefs, salt marshes, and mangroves illustrate that landscape diversity - the variety and arrangement of different habitats in a landscape-can strongly affect population dynamics of key species, primary and secondary production, and trophic transfer, including productivity and stability of commercially important species.

\section{CONCLUSIONS AND FUTURE DIRECTIONS}

\section{Implications for conservation and management}

Human activities have strong and direct negative impacts on the functioning of ecosystems (Sala et al. 2000, Foley et al. 2005), including seagrass beds (Short \& Wyllie-Echeveria 1996, Duarte 2002). Changes in ecosystem functioning mediated indirectly by changing biodiversity are likely to be modest compared with these strong direct effects (Srivastava \& Vellend 2005). Nevertheless, over the long term, the capacity of ecosystems to continue adapting to environmental change must ultimately be compromised by continuing extinctions of species. Empirical research reviewed here suggests that biodiversity at a hierarchy of scales can influence the stable functioning of seagrass systems and the several services they provide to humans. These results have several practical implications. First, evidence that genetic diversity enhances seagrass growth and resistance to disturbance supports arguments that seagrass mitigation and restoration efforts should strive to minimize the genetic bottlenecks common to such programs (Williams 2001). Genetic diversity within populations is demonstrably important, not only to the long-term evolutionary potential of a species, but also for flexibility in the face of environmental change on ecological time scales ('resilience' in the parlance of Holling 1973). Because dominant species, such as seagrasses in many low-diversity temperate beds, have pervasive bottom-up influences on associated communities, genetic diversity within such species can influence the structure and functioning of entire ecosystems (Whitham et al. 2003, Reusch \& Hughes 2006). Experiments also show that resistance to perturbations can be fostered by response diversity among otherwise similar species, cautioning that 'functional redundancy' can be a misleading concept (Loreau 2004). Conservation measures that result in maintaining multiple species within functional groups (e.g. of seagrasses, grazers, or fishes) should provide seagrass beds with some insurance against impacts of environmental change.

There is growing evidence that trophic interactions can have important stabilizing and stimulating effects on ecosystem processes in many systems, i.e. that vertical diversity is functionally important. In seagrass beds specifically, epiphyte grazers have impacts on seagrasses that are comparable in magnitude, but opposite in sign, to those of the water-column nutrient loading widely recognized as a major threat to seagrass systems (Williams \& Ruckelshaus 1993, Heck et al. 2000, Hughes et al. 2004). As diverse assemblages of algal grazers are both more efficient consumers and more resistant to predator control, on average (Duffy et al. 2003, 2005), biodiversity at the grazer level may also benefit seagrass systems. Vertical diversity can also be important in reducing exotic invasions; in California, USA, native predatory snails killed $95 \%$ of the exotic mussels Musculista senhousia in native eelgrass beds, and preferentially attacked these invaders over native bivalve prey (Reusch 1998). These patterns underscore the premium on understanding how changing foodweb structure affects the structure and functioning of seagrass ecosystems (Williams \& Heck 2001, Hughes et al. 2004, Valentine \& Duffy 2005).

Finally, the interactions among communities of different habitats within a landscape, and particularly the complex, spatially distributed life histories of many commercially important tropical fishes and decapods, emphasize the importance of a landscape-level perspective in conserving both biodiversity and marine ecosystem services. Landscapes and species are mutually related, as large consumers serve as mobile links 
between habitats, and loss of those consumers can disrupt essential cross-habitat resource subsidies or important top-down control mediated by animals visiting from other habitats (Polis et al. 1997, Lundberg \& Moberg 2002). Humans, of course, are the ultimate 'mobile link' species, and our activities often have unanticipated consequences at landscape and regional scales, such as the increased hunting pressure on endangered African forest animals when overexploitation reduced fishery production in adjacent marine waters (Brashares et al. 2004).

\section{Future research priorities}

\section{Scaling up}

Some of the most pressing priorities for research to understand seagrass systems are common to ecology and conservation as a whole. One critical, general challenge for ecology is finding creative and rigorous means of scaling up understanding based on small-plot experiments to the large scales over which marine population and community processes typically occur (see Naeem 2006, in this Theme Section). As one example, small-scale mesocosm experiments show that invertebrate grazers can counteract the negative effects of eutrophication on seagrass systems by cropping the increased algal biomass (reviewed by Hughes et al. 2004). In nature, however, this grazer control may be reduced by emigration of highly mobile grazers in search of more favorable habitat (Christie \& Kraufvelin 2003) and by shifts in dominance from epiphytic microalgae to macroalgae, which negatively affect dissolved oxygen in the water column and reduce grazer abundance (Deegan et al. 2002). While there is a continuing need for controlled experiments to identify mechanisms of diversity effects on ecosystem functioning, there is an even greater need for creative approaches, such as rigorous comparative studies, exploitation of 'natural experiments', and community modeling (e.g. Estes et al. 1998, Terborgh et al. 1999, Dulvy et al. 2004, Mumby et al. 2004, Ebenman \& Jonsson 2005) to evaluate the effects of changing biodiversity at the ecosystem scale.

\section{Realistic scenarios of biodiversity loss (and gain)}

A second frontier for BEF research involves developing experimental designs that incorporate realistic trajectories of biodiversity change. Several non-marine experiments have shown that preferential extinction of species with particular traits (e.g. large body size, sensitivity to pollutants) produces quite different changes in ecosystem functioning than does random species loss (Jonsson et al. 2002, Ostfeld \& LoGiudice 2003, Zavaleta \& Hulvey 2004). An obvious part of most extinction trajectories is the loss of large consumers (Duffy 2003, Worm et al. 2005). Thus, BEF research would profit from hybridization with food-web and predator-prey ecology (Duffy 2002, Worm \& Duffy 2003, Ives et al. 2005, Ebenman \& Jonsson 2005), again exploiting 'natural experiments' as well as research opportunities provided by the return of large predators in marine protected areas (Palumbi 2001, Micheli \& Halpern 2005). Moreover, while BEF research has focused almost exclusively on loss of species, an equally pressing concern is the gain of exotic species, which can have pervasive effects on ecosystems. Species loss and gain are often coupled, in that interactions with non-native species are a leading cause of extinction and endangerment of native species (Czech \& Krausman 1997, Clavero \& Garcia-Berthou 2005). Developing a rigorous ecological understanding of the causes and consequences of invasion (Sax et al. 2005) and of how invasion is affected by native species richness (Levine \& D'Antonio 1999, Stachowicz \& Tilman 2005) will be important in predicting ecosystem-level consequences of changing biodiversity.

\section{Landscape interactions}

Other research priorities are more specific to marine ecosystems, or seagrass ecosystems specifically. The openness of marine systems, characterized by relatively long-distance advection of materials and larvae and by long-distance migration of many large vertebrates, challenges ecologists to incorporate metapopulation, meta-community, and regional perspectives into BEF research. Ecological theory has begun to do so (Holt \& Loreau 2002, Loreau et al. 2003, Holt 2004). Most importantly, theory shows that the relationship of community structure generally, and diversity specifically, to ecosystem functioning depends strongly on the overall degree of openness and the relative openness at different trophic levels (Holt 2004). There is a need to understand better how qualitatively distinct habitat types, such as seagrass beds and coral or oyster reefs, interact within landscapes. As summarized above, such linkages are probably important in most marine systems.

Acknowledgements. I thank M. Solan for the invitation to contribute to the special Theme Section; the NCEAS Working Group on Marine Biodiversity and Ecosystem Services for stimulating discussion; J. Bruno, E. Canuel, J. Douglass, K. France, P. Richardson, A. Spivak, J. Stachowicz, and B. Worm for discussions that influenced my thinking, J. Douglass and 3 
anonymous reviewers for comments that improved the MS, and the NSF for support (OCE 00-99226 and 03-52343). This paper is Contribution \# 2729 from the Virginia Institute of Marine Science.

\section{LITERATURE CITED}

Abele LG (1974) Species diversity of decapod crustaceans in marine habitats. Ecology 55:156-161

Acosta CA (1999) Benthic dispersal of Caribbean spiny lobsters among insular habitats: implications for the conservation of exploited marine species. Conserv Biol 13(3):603-612

Aller RC, Yingst JY (1978) Biogeochemistry of tubedwellings: a study of the sedentary polychaete Amphitrite ornata (Leidy). J Mar Res 36:201-254

Aller RC, Yingst JY (1985) Effects of the marine depositfeeders Heteromastis filiformis (Polychaeta), Macoma baltica (Bivalvia), and Tellina texana (Bivalvia) on averaged sedimentary solute transport, reaction rates, and microbial distributions. J Mar Res 43:615-645

Anderson EA (1989) Economic benefits of habitat restoration: seagrass and the Virginia hard-shell blue crab fishery. N Am J Fish Manage 9:140-149

Bell SS, Foneseca MS, Stafford NB (2006) Seagrass ecology: new contributions from a landscape perspective. In: Larkum AWD, Orth RJ, Duarte CM (eds) Seagrasses: biology, ecology, and conservation. Springer, New York, p 625-645

Bologna PAX, Heck KL Jr (2000) Impacts of seagrass habitat architecture on bivalve settlement. Estuaries 23:449-457

Bologna PAX, Heck KL Jr (2002) Impact of habitat edges on density and secondary production of seagrass-associated fauna. Estuaries 25:1033-1044

Borer ET, Seabloom EW, Shurin JB, Anderson KE, Blanchette CA, Broitman B, Cooper SD, Halpern BS (2005) What determines the strength of a trophic cascade? Ecology 86: 528-537

Brashares JS, Arcese P, Sam MK, Coppolillo PB, Sinclair ARE, Balmford A (2004) Bushmeat hunting, wildlife declines, and fish supply in West Africa. Science 306:1180-1183

Bruno JF, O'Connor MI (2005) Cascading effects of predator diversity and omnivory in a marine food web. Ecol Lett 8: 1048-1056

Butler MJ IV, Hunt JH, Herrnkind WF, Childress MJ and 5 others (1995) Cascading disturbances in Florida Bay, USA: cyanobacteria blooms, sponge mortality, and implications for juvenile spiny lobsters Panulirus argus. Mar Ecol Prog Ser 129:119-125

Cardinale BJ, Palmer MA, Collins SL (2002) Species diversity enhances ecosystem functioning through interspecific facilitation. Nature 415:426-429

Carlton JT, Geller JB, Reaka-Kudla M, Norse EA (1999) Historical extinctions in the sea. Annu Rev Ecol Syst 30: 515-538

Carpenter SR, Kitchell JF, Hodgson JR (1985) Cascading trophic interactions and lake productivity. BioScience 35: 634-639

Cebrián J, Duarte CM, Marba N, Enriquez S (1997) Magnitude and fate of the production of four co-occurring western Mediterranean seagrass species. Mar Ecol Prog Ser 155:29-44

Chalfoun AD, Thompson FR, Ratnaswamy MJ (2002) Nest predators and fragmentation: a review and meta-analysis. Conserv Biol 16:306-318

Christie H, Kraufvelin P (2003) Mechanisms regulating amphipod population density within macroalgal commu- nities with low predator impact. Sci Mar 68(Suppl 1): 189-198

Clavero M, Garcia-Berthou E (2005) Invasive species are a leading cause of animal extinctions. Trends Ecol Evol 20: 110

Cloern JE (2001) Our evolving model of the coastal eutrophication problem. Mar Ecol Prog Ser 210:223-253

Costanza R, d'Arge R, de Groot R, Farber S and 9 others (1997) The value of the world's ecosystem services and natural capital. Nature 387:253-260

Cyr H, Pace ML (1993) Magnitude and patterns of herbivory in aquatic and terrestrial ecosystems. Nature 361:148-150

Czech B, Krausman PR (1997) Distribution and causation of species endangerment in the United States. Science 277: 1116-1117

Deegan LA (2002) Lessons learned: the effects of nutrient enrichment on the support of nekton by seagrass and salt marsh ecosystems. Estuaries 25:727-742

Deegan LA, Wright A, Ayvazian SG, Finn JT, Golden H, Merson RR, Harrison J (2002) Nitrogen loading alters seagrass ecosystem structure and support of higher trophic levels. Mar Freshw Ecosyst 12:193-212

deVilléle X, Verlaque M (1995) Changes and degradation in a Posidonia oceanica bed invaded by the introduced tropical alga Caulerpa taxifolia in the north western Mediterranean. Bot Mar 38:79-87

Diaz MC, Ward BB (1997) Sponge-mediated nitrification in tropical benthic communities. Mar Ecol Prog Ser 156: 97-107

Domning DP (2001) Sirenians, seagrasses, and Cenozoic ecological change in the Caribbean. Palaeogeogr Palaeoclimatol Palaeoecol 166:27-50

Duarte CM (1991) Allometric scaling of seagrass form and productivity. Mar Ecol Prog Ser 77:289-300

Duarte CM (2000) Marine biodiversity and ecosystem services: an elusive link. J Exp Mar Biol Ecol 250:117-131

Duarte CM (2002) The future of seagrass meadows. Environ Conserv 29:192-206

Duarte CM, Cebrián J (1996) The fate of marine autotrophic production. Limnol Oceanogr 41:1758-1766

Duarte CM, Chiscano CL (1999) Seagrass biomass and production: a reassessment. Aquat Bot 65:159-174

Duarte CM, Terrados J, Agawin, NSR, Fortes MD, Bach S, Kenworthy WJ (1997) Response of a mixed Philippine seagrass meadow to experimental burial. Mar Ecol Prog Ser 147:285-294

Duffy JE (2002) Biodiversity and ecosystem function: the consumer connection. Oikos 99:201-219

Duffy JE (2003) Biodiversity loss, trophic skew, and ecosystem functioning. Ecol Lett 6:680-687

Duffy JE, Canuel EA, Richardson JP (2003) Grazer diversity and ecosystem functioning in seagrass beds. Ecol Lett 6 : $1-9$

Duffy JE, Richardson JP, France KE (2005) Ecosystem consequences of diversity depend on food chain length in estuarine vegetation. Ecol Lett 8:301-309

Dulvy NK, Freckleton RP, Polunin NVC (2004) Coral reef cascades and the indirect effects of predator removal by exploitation. Ecol Lett 7:410-416

Ebenman B, Jonsson T (2005) Using community viability analysis to identify fragile systems and keystone species. Trends Ecol Evol 20:568-575

Elmqvist T, Folke C, Nyström M, Peterson G, Bengtsson J, Walker B, Norberg J (2003) Response diversity, ecosystem change, and resilience. Front Ecol Environ 1:488-494

Emmerson MC, Huxham M (2002) How can marine ecology contribute to the biodiversity-ecosystem functioning 
debate? In: Loreau M, Naeem S, Inchausti P (eds) Biodiversity and ecosystem functioning: synthesis and perspectives. Oxford University Press, New York, p 139-146

Emmerson MC, Raffaelli D (2004) Predator-prey body size, interaction strength and the stability of a real food web. J Anim Ecol 73:399-409

Emmerson MC, Solan M, Emes C, Paterson DM, Raffaelli D (2004) Consistent patterns and the idiosyncratic effects of biodiversity in marine systems. Nature 411:73-77

Estes JA, Duggins DO (1995) Sea otters and kelp forests in Alaska: generality and variation in a community paradigm. Ecol Monogr 65:75-100

Estes JA, Tinker MT, Williams TM, Doak DF (1998) Killer whale predation on sea otters linking oceanic and nearshore ecosystems. Science 282:473-476

Finke DL, Denno RF (2004) Predator diversity dampens trophic cascades. Nature 429:407-410

Foley JA, DeFries R, Asner GP, Barford C and 15 others (2005) Global consequences of land use. Science 309:570-574

Grabowski JH, Powers SP (2004) Habitat complexity mitigates trophic transfer on oyster reefs. Mar Ecol Prog Ser 277:291-295

Grime JP (1998) Benefits of plant diversity to ecosystems: immediate filter and founder effects. J Ecol 86:902-910

Haahtela I (1984) A hypothesis of the decline of the bladder wrack (Fucus vesiculosus L.) in SW Finland in 1975-1981. Limnologica 15:345-350

Hairston NG, Smith FE, Slobodkin LG (1960) Community structure, population control, and competition. Am Nat 94: 421-425

Hartley MJ, Hunter ML Jr (1998) A meta-analysis of forest cover, edge effects, and artificial nest predation rates. Conserv Biol 12:465-469

Hauxwell J, Cebrián J, Furlong C, Valiela I (2001) Macroalgal canopies contribute to eelgrass (Zostera marina) decline in temperate estuaries. Ecology 82:1007-1022

Heck KL Jr, Orth RJ (1980) Seagrass habitats: the roles of habitat complexity, competition and predation in structuring associated fish and motile macroinvertebrate assemblages. In: Kennedy VS (ed) Estuarine perspectives. Academic Press, New York, p 449-464

Heck KL Jr, Orth RJ (2006) Predation in seagrass meadows. In: Larkum AWD, Orth RJ, Duarte CM (eds) Seagrasses: biology, ecology, and conservation. Springer, New York, p 537-550

Heck KL Jr, Pennock JR, Valentine JF, Coen LD, Sklenar SA (2000) Effects of nutrient enrichment and small predator density on seagrass ecosystems: an experimental assessment. Limnol Oceanogr 45:1041-1057

Heck KL Jr, Hays C, Orth RJ (2003) Critical evaluation of the nursery role hypothesis for seagrass meadows. Mar Ecol Prog Ser 253:123-136

Hector A, Schmid B, Beierkuhnlein C, Caldeira MC and 30 others (1999) Plant diversity and productivity experiments in European grasslands. Science 286:1123-1127

Hemminga MA, Duarte CM (2000) Seagrass ecology. Cambridge University Press, New York

Hillebrand H, Cardinale BJ (2004) Consumer effects decline with prey diversity. Ecol Lett 7:192-201

Holling CS (1973) Resilience and stability of ecological systems. Annu Rev Ecol Syst 4:1-23

Holt RD (2004) Implications of system openness for local community structure and ecosystem function. In: Polis GA, Power ME, Huxel GR (eds) Food webs at the landscape level. University of Chicago Press, Chicago, p 96-114

Holt RD, Loreau M (2002) Biodiversity and ecosystem functioning: the role of trophic interactions and the importance of system openness. In: Kinzig AP, Pacala SW, Tilman D (eds) The functional consequences of biodiversity. Princeton University Press, Princeton, p 246-262

Hooper DU, Vitousek PM (1997) The effects of plant composition and diversity on ecosystem processes. Science 277: 1302-1305

Hovel KA, Lipcius RN (2002) Effects of seagrass habitat fragmentation on juvenile blue crabs survival and abundance. J Exp Mar Biol Ecol 271:75-98

Howarth R, Anderson D, Cloern J, Elfring C and 7 others (2000) Nutrient pollution of coastal rivers, bays, and seas. Issues Ecol 7:1-15

Hughes AR, Stachowicz JJ (2004) Genetic diversity enhances the resistance of a seagrass ecosystem to disturbance. Proc Natl Acad Sci USA 101:8998-9002

Hughes AR, Bando KJ, Rodriguez LF, Williams SL (2004) Relative effects of grazers and nutrients on seagrasses: a meta-analysis approach. Mar Ecol Prog Ser 282:87-99

Huston MA (1994) Biological diversity. The coexistence of species on changing landscapes. Cambridge University Press, New York

Huston MA (1997) Hidden treatments in ecological experiments: re-evaluating the ecosystem function of biodiversity. Oecologia 110:449-460

Huston MA, McBride AC (2002) Evaluating the relative strengths of biotic versus abiotic controls on ecosystem processes. In: Loreau M, Naeem S, Inchausti P (eds) Biodiversity and ecosystem functioning. Synthesis and perspectives. Oxford University Press, Oxford, p 47-60

Huston MA, Aarssen LW, Austin MP, Cade BS and 8 others (2000) No consistent effect of plant diversity on productivity. Science 289:1255 (abstract)

Irlandi EA (1994) Large- and small-scale effects of habitat structure on rates of predation: how percent coverage of seagrass affects rates of predation and siphon nipping on an infaunal bivalve. Oecologia 98:176-183

Irlandi EA, Crawford MK (1997) Habitat linkages: the effect of intertidal salt marshes and adjacent subtidal communities on abundance, movement, and growth of an estuarine fish. Oecologia 110:222-230

Irlandi EA, Ambrose WG, Orlando BA (1995) Landscape ecology and the marine environment: how spatial configuration of seagrass habitat influences growth and survival of the bay scallop. Oikos 72:307-313

Ives AR, Cardinale BJ, Snyder WE (2005) A synthesis of subdisciplines: predator-prey interactions, and biodiversity and ecosystem functioning. Ecol Lett 8:102-116

Jackson JBC, Kirby MX, Berger WH, Bjorndal KA and 15 others (2001) Historical overfishing and the recent collapse of coastal ecosystems. Science 293:629-638

Jernakoff P, Nielsen J (1998) Plant-animal associations in two species of seagrasses in Western Australia. Aquat Bot 60: 359-376

Johnson MR, Williams SL, Lieberman CH, Solbak A (2003) Changes in the abundance of the seagrasses Zostera marina L. (eelgrass) and Ruppia maritime L. (widgeiongrass) in San Diego, California, following an El Niño event. Estuaries 26:106-115

Jones CG, Lawton JJ, Shachak M (1994) Organisms as ecosystem engineers. Oikos 69:373-386

Jones JI, Sayer CD (2003) Does the fish-invertebrate-periphyton cascade precipitate plant loss in shallow lakes? Ecology 84:2155-2167

Jonsson M, Malmqvist B (2000) Ecosystem process rate increases with animal species richness: evidence from leaf-eating, aquatic insects. Oikos 89:519-523

Jonsson M, Dangles O, Malmqvist B, Guerold F (2002) Simu- 
lating species loss following perturbation: assessing the effects on process rates. Proc R Soc Lond B 269:1047-1052

Kangas P, Autio H, Hällfors G, Luther H, Niemi Å, Salemaa H (1982) A general model of the decline of Fucus vesiculosus at Tvärminne, south coast of Finland in 1977-1981. Acta Bot Fenn 118:1-27

Kenworthy WJ, Reid JP (2003) Can the calcifying macroalga Halimeda opuntia increase $\mathrm{CO}_{2}$ availability and enhance the growth of Thalassia testudinum? Gulf Mex Sci 21:101-102

Kinzig AP, Pacala SW, Tilman D (eds) (2002) The functional consequences of biodiversity. Empirical progress and theoretical expectations. Princeton University Press, Princeton, NJ

Klumpp DW, Howard RK, Pollard DA (1989) Trophodynamics and nutritional ecology of seagrass communities. In: Larkum AWD, McComb AJ, Shepherd SA (eds) Biology of seagrasses. Elsevier, Amsterdam, p 394-457

Kohn AJ (1967) Environmental complexity and species diversity in the gastropod genus Conus on Indo-West Pacific reef platforms. Am Nat 101:251-259

Kotler BP, Brown JS (1988) Environmental heterogeneity and the coexistence of desert rodents. Annu Rev Ecol Syst 19: 281-307

Leibold MA (1989) Resource edibility and the effects of predators and productivity on the outcome of trophic interactions. Am Nat 134:922-949

Leibold MA (1996) A graphical model of keystone predators in food webs: trophic regulation of abundance, incidence, and diversity patterns in communities. Am Nat 147: $784-812$

Lemmens JWTJ, Clapin G, Lavery Pl, Cary J (1996) Filtering capacity of seagrass meadows and other habitats of Cockburn Sound, Western Australia. Mar Ecol Prog Ser 143: $187-200$

Levine JM, D'Antonio CM (1999) Elton revisited: a review of evidence linking diversity and invasibility. Oikos 87:15-26

Lewis FG III (1987) Crustacean epifauna of seagrass and macroalgae in Apalachee Bay, Florida, USA. Mar Biol 94: 219-229

Lipcius RN, Eggleston DB, Miller DL, Luhrs TC (1998) The habitat-survival function of Caribbean spiny lobster: an inverted size effect and non-linearity in mixed algal and seagrass habitats. Mar Freshw Res 49(8):807-816

Lohrer AM, Thrush SF, Gibbs MM (2004) Bioturbators enhance ecosystem function through complex biogeochemical interactions. Nature 431:1092-1095

Loreau M (2004) Does functional redundancy exist? Oikos 104:606-610

Loreau M, Naeem S, Inchausti P, Bengtsson J and 8 others (2001) Biodiversity and ecosystem functioning: current knowledge and future challenges. Science 294:804-808

Loreau M, Downing A, Emmerson M, Gonzalez A and 5 others (2002a) A new look at the relationship between diversity and stability. In: Loreau M, Naeem S, Inchausti P (eds) Biodiversity and ecosystem functioning: synthesis and perspectives. Oxford University Press, Oxford, p 79-91

Loreau M, Naeem S, Inchausti P (eds) (2002b) Biodiversity and ecosystem functioning. Oxford University Press, Oxford

Loreau M, Mouquet N, Gonzalez A (2003) Biodiversity as spatial insurance in heterogeneous landscapes. Proc Natl Acad Sci USA 100:12765-12770

Lotze HK, Milewski I (2004) Two centuries of multiple human impacts and successive changes in a North Atlantic food web. Ecol Appl 14:5:1428-1447

Lundberg J, Moberg F (2002) Mobile link organisms and eco- system functioning: implications for ecosystem resilience and management. Ecosystems 6:87-98

Meyer JL, Schultz ET, Helfman GS (1983) Fish schools: an asset to corals. Science 220:1047-1049

Micheli F, Halpern BS (2005) Low functional redundancy in coastal marine assemblages. Ecol Lett 8:391-400

Micheli F, Peterson CH (1999) Estuarine vegetated habitats as corridors for predator movements. Conserv Biol 13: 869-881

Montoya JM, Rodriguez MA, Hawkins BA (2003) Food web complexity and higher-level ecosystems services. Ecol Lett 6:587-593

Mulder CPH, Koricheva J, Huss-Danell K, Högberg P, Joshi J (1999) Insects affect relationships between plant species richness and ecosystem processes. Ecol Lett 2:237-246

Mumby PJ, Edwards AJ, Arias-Gonzalez JE, Lindeman KC and 8 others (2004) Mangroves enhance the biomass of coral reef fish communities in the Caribbean. Science 427:533-536

Myers RA, Worm B (2003) Rapid worldwide depletion of predatory fish communities. Nature 423:280-283

Naeem S (1998) Species redundancy and ecosystem reliability. Conserv Biol 12:39-45

Naeem S (2002) Ecosystem consequences of biodiversity loss: the evolution of a paradigm. Ecology 83:1537-1552

Naeem S (2006) Expanding scales in biodiversity-based research: challenges and solutions for marine systems. Mar Ecol Prog Ser 311:273-283 (in this Theme Section)

Naeem S, Li S (1998) Consumer species richness and autotrophic biomass. Ecology 79:2603-2615

Naeem S, Wright JP (2003) Disentangling biodiversity effects on ecosystem functioning: deriving solutions to a seemingly insurmountable problem. Ecol Lett 6:567-579

Naeem S, Hahn DR, Schuurman G (2000) Producer-decomposer co-dependency influences biodiversity effects. Nature 403: 762-764

Norberg J, Swaney DP, Dushoff J, Lin J, Casagrandi R, Levin SA (2001) Phenotypic diversity and ecosystem functioning in changing environments: a theoretical framework. Proc Natl Acad Sci USA 98:11376-11381

Orth RJ (1992) A perspective on plant-animal interactions in seagrasses: physical and biological determinants influencing plant and animal abundance. In: John DM, Hawkins SJ, Price JH (eds) Plant-animal interactions in the marine benthos. Clarendon Press, Oxford, p 147-164

Orth RJ, Heck KL Jr, van Montfrans J (1984) Faunal communities in seagrass beds: a review of the influence of plant structure and prey characteristics on predator-prey relationships. Estuaries 7:339-350

Ostfeld RS, LoGiudice K (2003) Community disassembly, biodiversity loss, and the erosion of an ecosystem service. Ecology 84:1421-1427

Pace ML, Cole JJ, Carpenter SR, Kitchell JF (1999) Trophic cascades revealed in diverse ecosystems. Trends Ecol Evol 14:483-488

Palumbi SR (2001) The ecology of marine protected areas. In: Bertness MD, Gaines SD, Hay ME (eds) Marine community ecology. Sinauer Associates, Sunderland, MA, p 509-530

Pandolfi JM, Bradbury RH, Sala E, Hughes TP and 8 others (2003) Global trajectories of the long-term decline of coral reef ecosystems. Science 301:955-958

Parker JD, Duffy JE, Orth RJ (2001) Plant species diversity and composition: experimental effects on marine epifaunal assemblages. Mar Ecol Prog Ser 224:55-67

Pauly D, Christensen V, Dalsgaard J, Froese R, Torres F Jr (1998) Fishing down marine food webs. Science 279: 
$860-863$

Pfisterer AB, Schmid B (2002) Diversity-dependent production can decrease the stability of ecosystem functioning. Nature 416:84-86

Polis GA, Anderson WB, Holt RD (1997) Toward an integration of landscape and food-web ecology: the dynamics of spatially subsidized food webs. Annu Rev Ecol Syst 28: 289-316

Polis GA, Power ME, Huxel GR (eds) (2004) Food webs at the landscape level. University of Chicago Press, Chicago

Posey MH (1988) Community changes associated with the spread of an introduced seagrass, Zostera japonica. Ecology 69:974-983

Powell GVN, Fourqurean JW, Kenworthy WJ, Aieman JC (1991) Bird colonies cause seagrass enrichment in a subtropical estuary: observational and experimental evidence. Estuar Coast Shelf Sci 32:6:567-579

Power ME, Tilman, Estes JA, Menge BA and 6 others (1996) Challenges in the quest for keystones. BioScience 46: 609-620

Raffaelli D, Raven JA, Poole LJ (1998) Ecological impacts of green macroalgal blooms. Oceanogr Mar Biol Annu Rev $36: 97-125$

Reusch TBH (1998) Native predators contribute to invasion resistance to the non-indigenous bivalve Musculista senhousia in southern California, USA. Mar Ecol Prog Ser 170:159-168

Reusch TBH, Hughes AR (2006) The emerging role of genetic diversity for ecosystem functioning: estuarine macrophytes as model systems. Estuaries (in press)

Reusch TBH, Williams SL (1998) Variable responses of native eelgrass Zostera marina to a non-indigenous bivalve Musculista senhousia. Oecologia 113:428-441

Reusch TBH, Ehlers A, Hämmerli A, Worm B (2005) Ecosystem recovery after climatic extremes enhanced by genotypic diversity. Proc Natl Acad Sci USA 102:2826-2831

Rosenzweig ML (1971) Paradox of enrichment: destabilization of exploitation ecosystems in ecological time. Science 171: 385-387

Sala OE, Chapin FS, Armesto JJ, Berlow E and 15 others (2000) Global biodiversity scenarios for the year 2100 . Science 287:1770-1774

Sax DF, Gaines SD (2003) Species diversity: from global decreases to local increases. Trends Ecol Evol 18:561-566

Sax DF, Stachowicz JJ, Gaines SD (eds) (2005) Species invasions: insights into ecology, evolution, and biogeography. Sinauer, Sunderland, MA

Schmitz OJ, Hambaeck PA, Beckerman AP (2000) Trophic cascades in terrestrial systems: a review of the effects of carnivore removals on plants. Am Nat 155:141-153

Schwartz MW, Brigham CA, Hoeksema JD, Lyons KG, Mills $\mathrm{MH}$, van Mantgem PJ (2000) Linking biodiversity to ecosystem function: implications for conservation ecology. Oecologia 122:297-305

Short FT, Wyllie-Echeverria S (1996) Natural and humaninduced disturbances of seagrasses. Environ Conserv 23: $17-27$

Shurin JB, Borer ET, Seabloom EW, Anderson K, Blanchette CA, Broitman Cooper SD, Halpern BS (2002) A crossecosystem comparison of the strength of trophic cascades. Ecol Lett 5:785-791

Siemann E, Tilman D, Haarstad J, Ritchie M (1998) Experimental tests of the dependence of arthropod diversity on plant diversity. Am Nat 152:738-750

Silliman BR, Bertness MD (2002) A trophic cascade regulates salt marsh primary production. Proc Natl Acad Sci USA 99: 10500-10505
Simberloff D, Parker IM, Windle PN (2005) Introduced species policy, management, and future research needs. Front Ecol Environ 3:12-20

Solan M, Cardinale BJ, Downing AL, Engelhardt KAM, Ruesink JL, Srivastava DS (2004) Extinction and ecosystem function in the marine benthos. Science 306: $1177-1180$

Srivastava DS, Vellend M (2005) Biodiversity-ecosystem function research: Is it relevant to conservation? Annu Rev Ecol Evol Syst 36:267-294

Stachowicz JJ, Tilman D (2005) Species invasions and the relationships between species diversity, community saturation, and ecosystem functioning. In: Sax DF, Stachowicz JJ, Gaines SD (eds) Species invasions: insights into ecology, evolution, and biogeography. Sinauer, Sunderland, MA, p 41-64

Stachowicz JJ, Whitlatch RB, Osman RW (1999) Species diversity and invasion resistance in a marine ecosystem. Science 286:1577-1579

Stachowicz JJ, Fried H, Osman RW, Whitlatch RB (2002) Biodiversity, invasion resistance and marine ecosystem function: reconciling pattern and process. Ecology 83: $2575-2590$

Stoner AW, Lewis FG III (1985) The influence of quantitative and qualitative aspects of habitat complexity in tropical seagrass meadows. J Exp Mar Biol Ecol 94:19-40

Strong DR (1992) Are trophic cascades all wet? Differentiation and donor control in speciose ecosystems. Ecology 73: $747-754$

Suchanek TH, Williams SL, Ogden JC, Hubbard DK, Gill IP (1985) Utilization of shallow-water seagrass detritus by Caribbean deep-sea macrofauna: Del ${ }^{13} \mathrm{C}$ evidence. DeepSea Res 32:201-214

Tegner MJ, Dayton PK (1987) El Niño effects on southern California kelp forest communities. Adv Ecol Res 17: 243-279

Terborgh J, Estes JA, Paquet P, Ralls K, Boyd-Heger D, Miller BJ, Noss RF (1999) The role of top carnivores in regulating terrestrial ecosystems. In: Soulé ME, Terborgh J (eds) Continental conservation. Island Press, Washington, DC

Thébault E, Loreau M (2003) Food-web constraints on biodiversity-ecosystem functioning relationships. Proc Natl Acad Sci USA 100:14949-14954

Thrush SF, Dayton PK (2002) Disturbance to marine benthic habitats by trawling and dredging: implications for marine biodiversity. Annu Rev Ecol Syst 33:449-473

Tilman D (1999) The ecological consequences of changes in biodiversity: a search for general principles. J Ecol 80: 1455-1474

Valentine JF, Duffy JE (2005) The central role of grazing in seagrass ecosystems. In: Larkum AWD, Orth RJ, Duarte CM (eds) Seagrasses: biology, ecology, and conservation. Springer, New York

Valiela I, McClelland J, Hauxwell J, Behr PJ, Hersh D, Foreman K (1997) Macroalgal blooms in shallow estuaries: controls and ecophysiological and ecosystem consequences. Limnol Oceanogr 42:1105-1118

Van Elven BR, Lavery PS, Kendrick GA (2004) Reefs as contributors to diversity of epiphytic macroalgae assemblages in seagrass meadows. Mar Ecol Prog Ser 276:71-83

Virnstein RW, Howard RK (1987a) Motile epifauna of marine macrophytes in the Indian River Lagoon, Florida. I. Comparisons among three species of seagrasses from adjacent beds. Bull Mar Sci 41:1-12

Virnstein RW, Howard RK (1987b) Motile epifauna of marine macrophytes in the Indian River Lagoon, Florida. II. Com- 
parisons between drift algae and three species of seagrasses. Bull Mar Sci 41:13-26

Waldbusser GG, Marinelli RL, Whitlatch RB, Visscher PT (2004) The effects of infaunal biodiversity on biogeochemistry of coastal marine sediments. Limnol Oceanogr 49: 1482-1492

Wardle DA, Huston MA, Grime JP, Berendse F, Garnier E, Lauenroth WK, Setälä H, Wilson SD (2000) biodiversity and ecosystem function: an issue in ecology. Bull Ecol Soc Am Jul 2000:235-239

Watling L, Norse EA (1998) Disturbance of the seabed by mobile fishing gear: a comparison to forest clearcutting. Conserv Biol 12:1180-1197

Whitham TG, Young WP, Martinsen GD, Gehring CA and 8 others (2003) Community and ecosystem genetics: a consequence of the extended phenotype. Ecology 84:559-573

Widdicombe S, Austen MC, Kendall MA, Olsgard F, Schaanning MT, Dashfield SL, Needham HR (2004) Importance of bioturbators for biodiversity maintenance: indirect effects of fishing disturbance. Mar Ecol Prog Ser 275:1-10

Wigand C, Stevenson JC, Cornwell JC (1997) Effects of different submersed macrophytes on sediment biogeochemistry. Aquat Bot 56:233-244

Williams SL (1990) Experimental studies of Caribbean seagrass development. Ecol Monogr 60:449-469

Williams SL (2001) Reduced genetic diversity in eelgrass transplantations affects both population growth and individual fitness. Ecol Appl 11:1472-1488

Editorial responsibility: Martin Solan (Guest Editor), Newburgh, UK
Williams SL, Heck KL Jr (2001) Seagrass community ecology. In: Bertness MD, Hay ME, Gaines SD (eds) Marine community ecology. Sinauer Associates, Sunderland, MA, p 120-150

Williams SL, Ruckelshaus MH (1993) Effects of nitrogen availability and herbivory on eelgrass (Zostera marina) and epiphytes. Ecology 74:904-918

Wing SR, Wing ES (2001) Prehistoric fisheries in the Caribbean. Coral Reefs 20:1-8

Witman JD, Ellis JC, Anderson WB (2004) The influence of physical processes, organisms, and permeability on crossecosystem fluxes. In: Polis GA, Power ME, Huxel GR (eds) Food webs at the landscape level. University of Chicago Press, Chicago, p 335-358

Worm B, Duffy JE (2003) Biodiversity, productivity, and stability in real food webs. Trends Ecol Evol 18:628-632

Worm B, Myers RA (2003) A meta-analysis of cod-shrimp interactions reveals top-down control in oceanic food webs. Ecology 84:162-173

Worm B, Sandow M, Oschlies A, Lotze HK, Myers RA (2005) Global patterns of predator diversity in the open oceans. Science 309:1365-1369

Yachi S, Loreau M (1999) Biodiversity and ecosystem productivity in a fluctuating environment: the insurance hypothesis. Proc Natl Acad Sci USA 96:1463-1468

Zavaleta ES, Hulvey K (2004) Realistic species losses disproportionately reduce grassland resistance to biological invaders. Science 306:1175-1177

Submitted: February 10, 2005; Accepted: November 10, 2005 Proofs received from author(s): March 9, 2006 


\title{
Species diversity, invasion success, and ecosystem functioning: disentangling the influence of resource competition, facilitation, and extrinsic factors
}

\author{
John J. Stachowicz*, Jarrett E. Byrnes
}

Section of Evolution and Ecology and Center for Population Biology, University of California at Davis, Davis, California 95616, USA

\begin{abstract}
Experimental manipulations and observational surveys often produce conflicting conclusions regarding the effects of native species diversity on community susceptibility to invasion. Both provide useful pieces of information, but typically each asks fundamentally different questions. Surveys tell us that locations with species-rich native communities are characterized by conditions that promote exotic species richness, whereas experiments tell us that, within a location, the loss of resident species increases the likelihood of the establishment of new species. In the present study, we apply observational data to a study of the consequences of species loss for invasion in order to assess the generality across scales and the relative importance of experimental results. We begin by using long-term recruitment data to explore how small-scale mechanisms of biotic resistance could operate on a landscape scale. We find that individual species have complementary seasonal recruitment patterns such that more diverse communities might be able to more consistently fill space that opens throughout the season, leading to reduced invasion success. However, field surveys of native and invader richness show that the slope of the relationship between native and invader diversity changes with the availability of resources (space) and the presence of habitat-forming foundation species. In these systems, biotic resistance appears to be important only when resources are scarce and foundation species are rare. Thus, we conclude that biotic resistance, as identified in experiments, is a consistent effect of diversity that can be explained mechanistically at even a landscape scale, but that it plays a dominant role only when total diversity is constrained by resource limitation. This situation is common in experimentally constructed communities, but may be less so in nature.
\end{abstract}

KEY WORDS: Diversity-invasibility $\cdot$ Sessile invertebrates $\cdot$ Competition $\cdot$ Facilitation $\cdot$ Recruitment Temporal niche $\cdot$ Diversity-ecosystem functioning

\section{INTRODUCTION}

In this paper we focus on the often-contested relationship between diversity and invasibility of a community by exotic (non-indigenous) species. This question relates to the broader theme of this Theme Section on the consequences of diversity for ecosystem functioning in 2 ways. First, exotic species invasions in marine systems can have major effects on the structure and functioning of ecosystems (Grosholz 2002). If diversity enhances invasion resistance, it may help to buffer ecosystems from some of these changes. Second, the major mechanism by which diversity is ex- pected to enhance invasion resistance is via more complete use of resources (e.g. Elton 1958, Case 1990, Byers \& Noonburg 2003, Tilman 2004). The effect of diversity on resource use should affect other critical ecosystem processes such as productivity, nutrient retention and cycling, and community stability. Furthermore, understanding the mechanistic relationship between diversity and invasibility bears directly on the questions of whether contemporary communities are saturated with species and the extent to which there are limits on local diversity. If communities are generally saturated, then the consequences of new species introductions may be severe, whereas if communities 
are generally unsaturated, the consequences of most invasions may be relatively minor. Thus, the study of diversity-invasibility relationships provides a lens through which many important basic and applied issues in ecology may be profitably addressed.

A review of the empirical literature (mostly from terrestrial plant ecology) highlights the lack of consensus on the strength and direction of the effects of diversity on community resistance to invasion (Levine \& D'Antonio 1999). The discordant results between studies employing observational and experimental approaches are a major characteristic of this 'debate'. Most observational studies find that more-diverse native communities support more invaders (e.g. Knops et al. 1995, Planty-Tabacchi et al. 1996, Rejmanek 1996, Wiser et al. 1998, Lonsdale 1999, Stohlgren et al. 1999). These studies are often conducted at large scales (e.g. 10 to $1000 \mathrm{~km}^{2}$ or more, but see Sax 2002, Dunstan \& Johnson 2004), involve many species, and are favored by some because they involve 'natural' communities. But many other factors correlated with diversity can affect the establishment and spread of invasions, confounding the interpretation of such studies (e.g. see discussion in Rejmanek 2003). In contrast, most (but not all) experimental manipulations (necessarily conducted at smaller scales) support the idea that species richness decreases invasion success (McGrady-Steed et al. 1997, Knops et al. 1999, Lavorel et al. 1999, Stachowicz et al. 1999, 2002a, Levine 2000, Naeem et al. 2000, Symstad 2000, Kennedy et al. 2002, Fargione et al. 2003). The most commonly offered mechanism underlying this result is that species differ, or are complementary, in their use of resources such that increasing the number of species decreases the success of future invaders by decreasing total resource availability (e.g. Stachowicz et al. 1999, 2002a, Naeem et al. 2000). Such experiments reveal the potential of diversity to reduce invasion success, but rarely assess whether diversity is important relative to other factors such as propagule supply, disturbance, or predation for generating patterns of invasion in the field (but see Levine 2000, Stachowicz et al. 2002a).

The apparent paradox created by contrasting observational and experimental results occurs because each approach has addressed fundamentally different questions. Observational approaches often answer the question of which sites have the most exotics in them and, thus, might be in need of greatest attention from management efforts. Experimental approaches, in contrast, address the consequences of species loss (declining diversity) for the susceptibility of a community to invasion. These 2 approaches offer subtly different pieces of information that can be drawn together to produce a broader understanding of the relationship between native and exotic species richness. Patches that support diverse native communities are likely to support many exotic species, because the characteristics that favor high native diversity also favor high exotic diversity (e.g. Davies et al. 2005). However, within a given patch, the elimination of a native species due to anthropogenic disturbance should increase the probability of a successful invasion (e.g. Shea \& Chesson 2002).

Because of the difficulty of conducting multifactorial experiments on large scales, observational studies can also help refine hypotheses about the relative role of diversity versus other factors and assess the applicability of small-scale mechanistic experiments to largerscale processes. For example, when combined with field experiments, observational approaches have clarified where the mechanistic effects of diversity are (and are not) important relative to environmental factors such as disturbance or propagule supply in determining patterns of exotic species richness (Levine 2000, Stachowicz et al. 2002a). In the present study, we use two complementary observational approaches to address the mechanistic relationship between diversity and biotic resistance. First, we examine long-term recruitment patterns from the field that address an explicit landscape-scale mechanism of biotic resistance. Secondly, we examine patterns of native and invader richness in the field at a single time point, but tease out factors that correlate with the ability of a community to support more species, allowing us to determine under what conditions biotic resistance is important. Both approaches have in common that mechanisms elucidated from experiments are incorporated, yet we still consider a larger spatial and/or temporal perspective. We close with broader implications of our findings for the role of species diversity on ecosystem functioning.

\section{STUDY SYSTEM}

We focus in this paper on subtidal sessile marine invertebrate communities (i.e. fouling communities) that occur worldwide on natural rock outcrops, as well as on man-made structures like docks, wharves, and pilings. Studies of the role of diversity in community invasibility have been conducted in few, if any, other marine systems of which we are aware. Fouling communities are comprised of a diverse array of solitary and colonial marine invertebrates, including ascidians (sea squirts), bryozoans, bivalve molluscs, tubebuilding polychaete worms, sponges, barnacles, and sea anemones. Most of these taxa are suspension feeders, relying on planktonic food. The limiting resource in these systems most often appears to be space (Osman 1977, Sutherland \& Karlson 1977, Stachowicz 
et al. 1999, 2002a), although sometimes competition for food and space can be difficult to separate (Buss 1979). Because these communities readily occur in harbors and ports, they have been colonized by many species from other biogeographic provinces that have been transported on the bottom of boat hulls or as larval stages in ballast water (Carlton \& Geller 1993, Ruiz et al. 2000). The fossil record for many of these organisms is poor (e.g. soft-bodied ascidians), so the actual status of some of these species as natives or invader is uncertain. All the species we refer to as 'native' were present in the system at the time that humans began studying them, usually in the mid-1800s (see references in Van Name 1945). We thus define as 'exotic' any species that was not recorded in the first comprehensive monographs for a taxonomic group from a given region. While our distinctions may not reflect actual native versus exotic status, they separate species that have been resident for a lengthy period of time and those that are recent, documented invaders into an already established community.

We manipulated the species richness of sessile marine invertebrate communities in Long Island Sound, Connecticut, USA, and challenged these communities with different potential invaders (Stachowicz et al. 1999, 2002a). We found that in all cases invasion success decreased with increasing resident diversity (Fig. 1A). This was because individual species were complementary in their temporal patterns of space occupation. Individual species all fluctuated in abundance, but these fluctuations were out of phase, such that at least 1 species was always abundant and occupying space in the high-diversity treatments, whereas there were periods of high space availability in the low-diversity treatments (Fig. 1B). Thus, more diverse communities exhibit changes in the relative abundance of species over time, but maintain consistently high occupancy of space, while those with fewer species experience longer periods of high space availability. This is in agreement with theory that suggests, more broadly, that diversity should enhance the stability of community properties (i.e. space occupancy), but that it should decrease or have no effect on the stability of individual species' populations (May 1974, Tilman 1996). We confirmed that resource availability was a major contributor to invasion success by holding diversity constant, but manipulating space availability. These experiments showed a strong positive relationship between space availability and invasion success, and that even a brief window of open space (2 wk) could increase invasion success by an order of magnitude (Stachowicz et al. 2002a).

Studies in terrestrial plant communities have stressed that fluctuating resource availability in general often enhances invasion success (Davis et al.


Fig. 1. Effects of experimental manipulation of diversity on the success of introduced species (from Stachowicz et al. 2002a). (A) Survival of the colonial ascidian Botrylloides violaceous and the solitary ascidian Ascidiella aspersa as a function of resident community species richness. Larger dots indicate 2 data points that lie on top of one another. (B) Resource (space) availability over time as a function of initial community richness (mean $\pm \mathrm{SE}$ ); note that all communities are capable of occupying all the space, but that communities experience peaks in resource availability that are greater in communities with fewer species. See 'Study system' section and Stachowicz et al. (2002a) for details

2000), so we suspect that this mechanism is applicable to a wide variety of ecosystems in which diversity affects resource availability. The seasonal or temporal niches critical to the operation of this mechanism are likely to be common in a variety of environments, including such diverse taxa as marine invertebrates and herbaceous plants (Chesson 2000, Stachowicz \& Tilman 2005), phytoplankton (Rynearson \& Armbrust 2004, Duffy \& Stachowicz 2006 [in this Theme Section]), migratory fishes (Klimley et al. 2005), and any other groups with a strong seasonality to their distribution and abundance. Thus, while the identity of limiting resources may differ across ecosystems, we expect the patterns and conclusions of work on these communities to be applicable to any resource-limited system. 


\section{CONSEQUENCES OF SEASONAL NICHES FOR RESOURCE USE}

What underlies the differences in seasonal phenologies among species that lead to the temporal complementarity illustrated in Fig. 1? Despite differences in growth forms, marine invertebrates on hard substrates seem to compete primarily for space, the likely limiting resource. However, each species may differ in growth rates, patterns of mortality, in the timing, duration and magnitude of reproductive output, in the degree to which they are capable of local recruitment, and in their response to biotic and physical stresses (e.g. McDougall 1943, Osman 1977, Sutherland \& Karlson 1977). In seasonal environments, where conditions change predictably, each species thus may have a temporal or seasonal niche. These seasonal niches appear to provide the basis for complementary effects of species on resource use and invasion resistance (Fig. 1B; Stachowicz et al. 2002a).

While the results shown in Fig. 1 can largely be attributed to patterns of differential mortality in opening space to be invaded, when considering large spatial scales, stochastic events guarantee that there will always be patches of free space open to invaders in a dynamic marine environment. Whether a recruit of a new species can thrive and survive in an area depends on its ability to outcompete recruits of residents settling at the same time. Higher levels of total resident recruitment can lead to more intense competition and a lower probability of survival of recruits of nonresident species. If all resident species recruited during a single time interval, invaders would have a large window of opportunity during which establishment would be relatively easy. In contrast, if communities possess either 1 or more species that recruit at constant high densities or if species have complementary seasonal phenologies with respect to recruitment, creating constant high levels of recruitment through temporal complementarity, then invasion resistance should increase with diversity at large spatial scales.

To assess the degree to which the species on which we performed our experiments exhibit temporal complementarity in recruitment, we performed weekly surveys of recruitment of invertebrates onto artificial substrates (for full methods see Stachowicz et al. $2002 b)$. Briefly, the data consist of weekly censuses of newly settled sessile marine invertebrates on 4 panels of $100 \mathrm{~cm}^{2}$ suspended approximately $1 \mathrm{~m}$ below the water's surface. These data have been taken during the recruitment season since 1991 and continuously since 1997.

One sample year's worth of these data demonstrates that each species has a seasonal pattern of recruitment that appears to be complementary in time to those of other species (Fig. 2A, see below). If we assume that these reproductive cycles are dependent primarily on abiotic factors and that this leads to different seasonal patterns in adult abundance, then we can use seasonal patterns of recruitment to predict the effect of diversity on resource availability (space) for new exotic species. The effects of seasonal variation in temperature are widely known to affect the seasonality of marine invertebrate recruitment (e.g. McDougall 1943, Osman 1977, Sutherland \& Karlson 1977, Stachowicz et al. $2002 b)$ in the same way that seasonal patterns of temperature and moisture might affect the seasonal phenologies of annual plants, so we think this approach may be appropriate for a variety of systems. While competitive interactions can influence the magnitude of recruitment to some extent, our previous analyses of
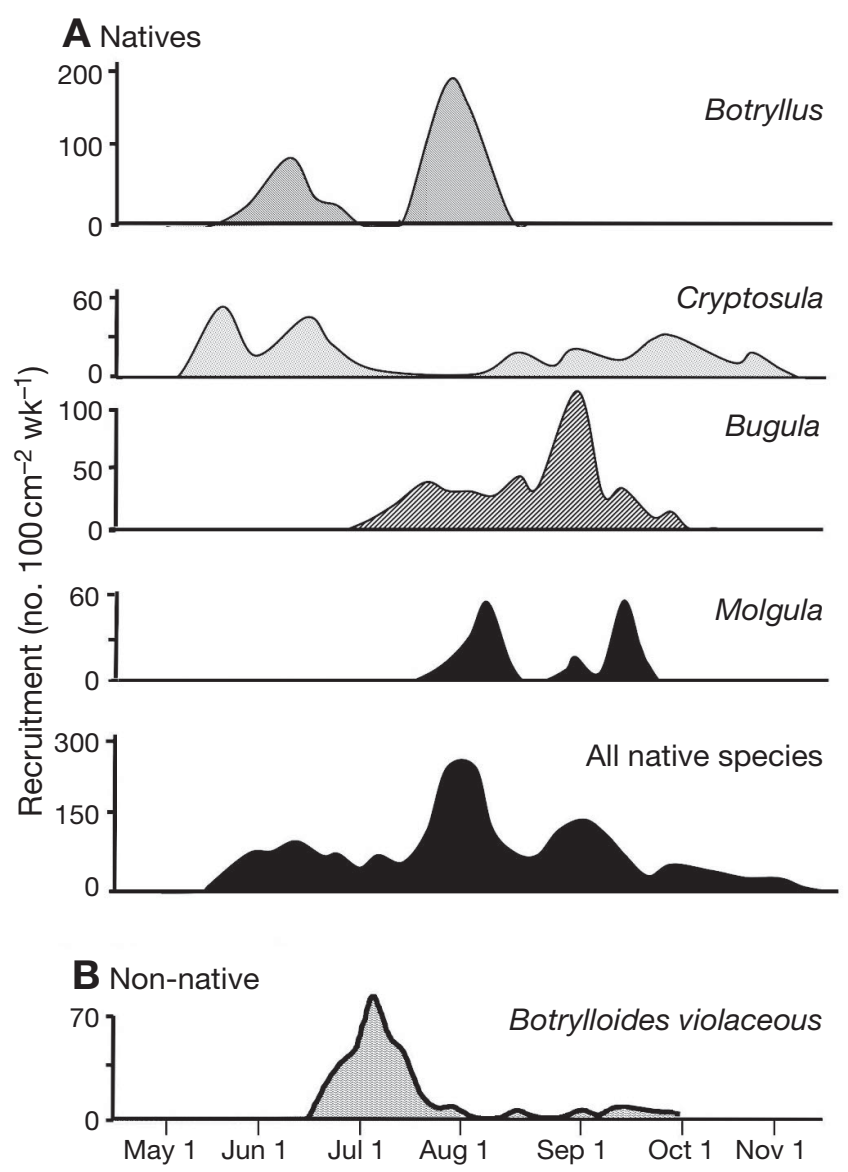

Fig. 2. Settlement of dominant marine invertebrate species at Avery Point, Connecticut, for the 1999 recruitment season. (A) Four of the more abundant native species (Botryllus schlosseri, Cryptosula pallasiana, Bugula turrita, Molgula manhattensis) and the record of all 4 species together, showing the complementary nature of their settlement patterns. (B) Settlement record for the introduced ascidian Botrylloides violaceous. Note that its recruitment pattern coincides with a period of relatively low recruitment by the resident species, particularly the ecologically similar resident species B. schlosseri 
these long-term data find that a large proportion of the variance in the timing of recruitment within species is attributable to within- and between-year variation in temperature (Stachowicz et al. 2002b).

Given these assumptions, we used our weekly recruitment data to assess how total recruitment might change as a function of the number of species recruiting into the community, as well as the extent to which invasion resistance was conferred by temporal complementarity versus individual species with consistently high recruitment. Recruitment can be plotted over time for each species to give a description of the ability of each species to fill new space that becomes available over the course of the season (Fig. 2A). We then assembled all possible combinations of species in each year, and tallied the total number of weeks that recruitment was $>100$ ind. $100 \mathrm{~cm}^{-2}$ panel for each species combination as a measure of the number of weeks per year that space might be saturated by the recruits of resident species. Species that never exceeded 5 recruits
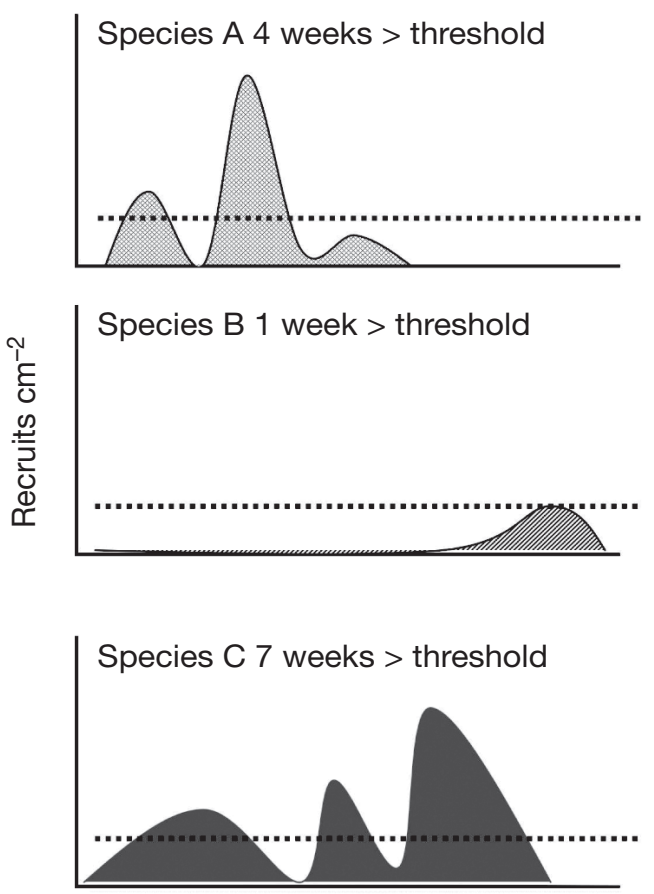

Time $\mathrm{wk}^{-1}$ in a given year were excluded from the simulation. For a given year in which $n$ species $\left(a_{1}, a_{2}, \ldots a_{n}\right)$ were recorded, we produced recruitment records for hypothetical communities that included all possible combinations of $\left(a_{1}, a_{2}, \ldots a_{n}\right)$. For example, if 3 species $(\mathrm{A}, \mathrm{B}$, and $\mathrm{C})$ were recorded in a year, we would assemble recruitment records for the 7 combinations shown in Fig. 3. For each combination we would record both the total number of weeks above the threshold recruitment and the number of weeks that the best species in that combination would be above the threshold if it occurred by itself. While it is obvious that the total number of recruits will increase as one adds species to the assemblage, whether this will increase the number of weeks above a threshold recruitment level depends on the degree to which species have complementary temporal patterns of recruitment. The multi-year record we have allows us to examine the extent to which the strength of such complementarity varies among years.


Time

\begin{tabular}{|c|c|c|}
\hline $\begin{array}{l}\text { Species } \\
\text { richness }\end{array}$ & $\begin{array}{c}\text { Average } \\
\text { combination (wk) }\end{array}$ & $\begin{array}{c}\text { Average of best single species } \\
\text { in each combination (wk) }\end{array}$ \\
\hline 1 & 4 & 4 \\
\hline 2 & $(5+9+8) / 3=7.33$ & $(4+7+7) / 3=6$ \\
\hline 3 & 10 & 7 \\
\hline
\end{tabular}

Fig. 3. Diagrammatic depiction of the methods used for assembling hypothetical communities of varying species richness and assessing the number of weeks that the recruitment for that assemblage exceeded a recruitment threshold (dotted line) indicative of saturation (thresholds of $0.1,0.5,1$, or 2 ind $\mathrm{cm}^{-2}$ were used in the analysis). The table at the bottom of the figure shows how the values of number of weeks at saturation were obtained for both the diverse assemblages and the best-recruiting single species in each assemblage 
We initially chose a threshold of 100 ind. $100 \mathrm{~cm}^{-2}$, based on the assumption that even the smallest species in our survey would occupy at least $1 \mathrm{~cm}^{2}$ as an adult or persistent juvenile, so recruitment levels of 100 ind. $100 \mathrm{~cm}^{-2}$ should be sufficient to completely occupy available space within a short period of time and reduce invasion. We also ran the simulation for recruitment thresholds of 10, 50, and 200 recruits $100 \mathrm{~cm}^{-2} \mathrm{wk}^{-1}$, to see if the results were sensitive to the threshold we chose. In reality, substrate saturation would be a more continuous variable, but the results obtained were robust to the choice of threshold value, so our relatively arbitrary choice of threshold is probably of little significance (see below and Fig. 4B).

No one species produced enough recruitment for the entire season to saturate the community (e.g. data for 1998 recruitment year, Fig. 4A). In 1998, the best single species occupied only $9 \mathrm{wk}$ at $>100$ recruits $100 \mathrm{~cm}^{-2}$, compared to 21 wk for the maximum diversity assemblage. Thus, $57 \%$ of the weeks that exceeded the threshold of 100 recruits $100 \mathrm{~cm}^{-2}$ would not have done so without some complementarity among species. While the actual percent of the maximum attained by the bestrecruiting single species is sensitive to the threshold set for recruitment saturation, the patterns hold regardless of which threshold we used (Fig. 4B). Only when the threshold is set as low as 10 recruits $100 \mathrm{~cm}^{-2} \mathrm{wk}^{-1}$, did we see the best-recruiting species begin to approximate the maximum diversity assemblage (Fig. 4B). In our experience, recruitment this low is relatively uncommon and would not be sufficient to inhibit establishment of additional species. However, even at this probably unreasonably low recruitment threshold, having the full complement of species increased the period of saturation by $6 \mathrm{wk}$ from 21 to $27 \mathrm{wk}$ $(22 \%)$. These simple simulations suggest that, for a range of potential saturating recruitment thresholds, complementarity in seasonal recruitment patterns is likely to lead to more consistent space occupation and thus increased resistance to invasion in diverse communities (Stachowicz et al. 2002a).

Because species vary among years in the timing and magnitude of their recruitment, the degree to which seasonal complementarity results in enhanced recruitment saturation may vary among years. We assembled all possible combinations for 3 yr with differing recruitment patterns (Fig. 4C). These data suggest that, while
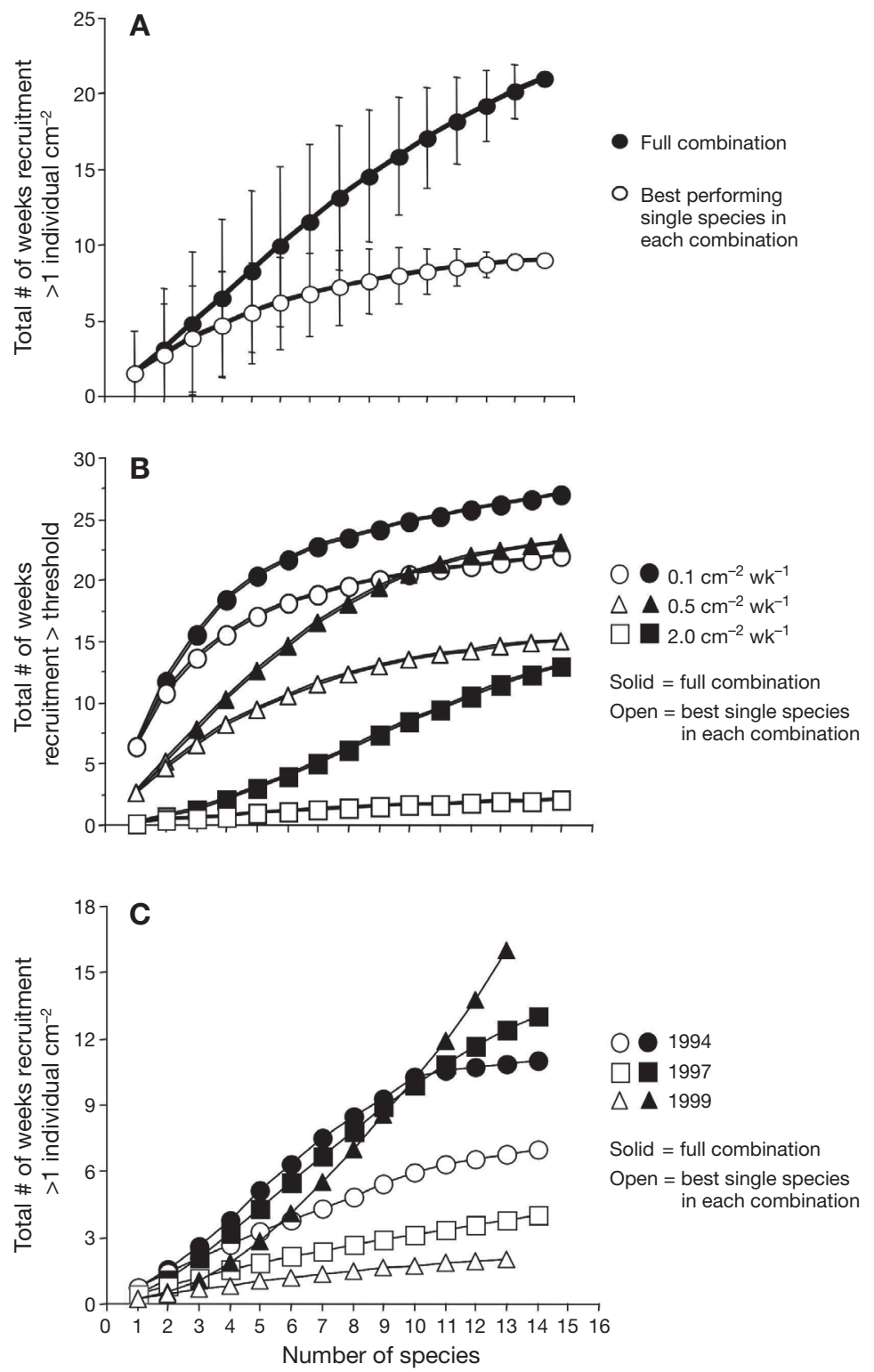

Fig. 4. Number of weeks in which recruitment exceeds the saturation threshold for hypothetical communities assembled from the long-term recruitment records as a function of the number of species in that community. (A) Data for the year 1998, showing separate curves for mean $( \pm 1 \mathrm{SD})$ values of number of weeks above a threshold of 1 recruit $\mathrm{cm}^{-2}$ for the mean of all combinations at each level of richness and for the best-recruiting species in each combination. (B) Effect of changing the threshold value $\left(0.1,0.5,2.0 \mathrm{~cm}^{-2} \mathrm{wk}^{-1}\right)$ of recruitment saturation on the relationship between diversity and number of weeks above the threshold recruitment for 1998. (C) Assembly of communities for 3 additional years that span a range of temperature conditions

the general phenomenon is consistent, the degree to which a single species can saturate recruitment surfaces does vary among years. In 1994, for example, the best-recruiting species reached the threshold on its own for $7 \mathrm{wk}$, while the all-species combination reached the threshold for only 11 ; thus the diversity 
added only 4 wk of 'resistance' (36\% of total resistance due to complementarity). In other years the effect was more dramatic: in 1999 the diverse assemblage saturated $16 \mathrm{wk}$, while the best monoculture reached the threshold for only 2 (86\% of 'saturation' due to complementarity). With such interannual variation, the effects of diversity on invasion success might vary substantially among years depending on the degree to which species were complementary in their seasonal niches. Thusfar, interannual success of invasive species in these communities has been assessed primarily in response to abiotic factors, but incorporating interannual variation in the strength of biotic interactions might prove informative.

For example, of the 3 yr depicted above, the strength of complementarity (percent of weeks above the threshold not accounted for by the best-recruiting species) increases with decreasing native recruitment. In 1994, when winter temperatures were coldest and native recruitment highest, complementarity was relatively weak (36\%); 1997 was an intermediate year in temperature, native recruitment, and complementarity $(69 \%) ; 1999$ was one of the warmest years on record, with low native recruitment and the highest complementarity (88\%) (see Stachowicz et al. 2002b for further exploration of temperature effects). These limited data suggest that complementarity might become more important as the recruitment of individual resident species declines. Intuitively, when total resident recruitment is lower, no one species has high recruitment, so complementarity among species in excluding invaders becomes more important; this explains why the number of weeks above threshold for the bestrecruiting species varies across years. However, it does not explain why the total number of weeks above the threshold is greatest in years with lowest recruitment. Unfortunately, we cannot use these data to independently assess the effect of changing biotic resistance on invasion across years, because increasing temperature has a direct positive effect on the introduced species (Stachowicz et al. 2002b).

Whether interannual variability in complementarity translates into differences in invasion success will also depend on the invader's seasonal recruitment patterns. While diversity should decrease the overall probability of invasion, theory and some empirical work suggest that the degree to which the invader's traits fill a void in the native community plays a role (e.g. Elton 1958, Fargione et al. 2003, Tilman 2004, Stachowicz \& Tilman 2005). Predicting the success of particular invaders within the framework set forth thusfar requires, not only knowing how many invader propagules arrive, but when during the season they arrive. There is evidence that some invaders recruit during 'lulls' in native recruitment. For example, Botrylloides viola- ceous recruits during the early summer, approximately 4 wk after the peak recruitment of Botryllus schlosseri, when few other natives are recruiting (Fig. 2B). In the year depicted in Fig. 2 (1999), in its peak week B. violaceous had 72 recruits $100 \mathrm{~cm}^{-2}$, which was more than all natives combined in that week. The timing of $B$. violaceous recruitment is sensitive to interannual variations in winter and spring temperature, whereas that of many natives, like B. schlosseri is not (Stachowicz et al. $2002 \mathrm{~b}$ ). Thus, the extent to which the recruitment of invaders 'fills holes' in the native community and the success of those invaders may vary among years, possibly leading to interannual variation in the strength of biotic resistance. This point remains speculative, however, as we have no consistent, independent measure of invasion success across years with which to test this hypothesis. Nevertheless, it seems reasonable to suggest that this 'ecological fitting' (sensu Janzen 1985) may be most critical during the establishment phase of the invasion and may determine the species or genotypes of invaders that can succeed in a new community. Once invaders build up a resident population, a large degree of overlap in the timing of recruitment might be more easily tolerated.

\section{EFFECT OF SPATIAL HETEROGENEITY ON NATIVE-INVADER DIVERSITY CORRELATIONS}

While it is clear that fluctuating resources may determine invasion success in a wide variety of communities (Davis et al. 2000), temporal shifts in the abundance of species is only 1 potential cause of such fluctuations. As previously discussed, positive native-invader diversity relationships may reflect that areas with conditions that favor high native diversity will be able to support more invasive species. Within an area of consistent environmental conditions, diversity and invasion should be negatively related (see Fig. 1 in Shea \& Chesson 2002). Thus, from positive correlations alone, it is not appropriate to conclude that decreasing native diversity via extinction would decrease invasion success. Instead, given a mechanistic reason to expect diversity per se to decrease invasion (Fig. 1), species extinction should consistently increase the susceptibility of any area to invasion, leading to an increase in invader species richness with every species extirpated from an area.

However, there are possible mechanisms by which increased diversity might lead mechanistically to increased invasion. Some of these have been explored in a similar epifaunal invertebrate community in Tasmania, where a positive correlation between native and invader diversity was found in temporally repeated surveys of sessile invertebrates that had naturally colonized a rock jetty (Dunstan \& Johnson 2004). 
In their study, species-rich patches consisted primarily of small colonies with rapid turnover, which may provide increased opportunity for the colonization of these patches by new species. Interestingly, although the hypothesized outcome is contrary to that shown in Fig. 1, the underlying mechanism (consistency of space occupancy) is the same. Unfortunately, it is not clear from this survey approach alone what the underlying causes of the differences in colony size among patches might be. Extrinsic conditions may differ significantly among patches, and forces that maintain small colony size (e.g. recent disturbance, grazing intensity, high propagule supply) enhance diversity of both resident and colonizing species.

A second means by which species richness might enhance colonization rates is via interspecific facilitation. Increasing community richness might increase the probability of including species that facilitate the colonization and establishment of a broad range of new species (see discussion in Crooks 2002, Bruno et al. 2003). Dunstan \& Johnson (2004) offer several examples of positive associations among species as a mechanism for a positive native-exotic richness correlation, although similar responses of species to extrinsic factors could also explain such patterns. Our own work has also shown positive pairwise interactions among natives and exotics (Stachowicz et al. 2002a). Still, such pairwise positive interactions will not, by themselves, result in a significant positive correlation between native and non-native diversity.

To further explore the extent to which positive correlations between native and invader diversity are mechanistic versus the result of environmental covariates, we included measurements of relevant resources and other covariates into the statistical model for invader diversity. As our resource reflecting competition and other temporal processes, we sampled for percentage of open space within plots (Stachowicz et al. 2002a). We also consider the effects of the presence and cover of the head-forming bryozoan Watersipora subtorquata on the native-invader diversity relationship, because the 3-dimensional growth form of this animal provides secondary space for colonization by both natives and non-natives (Floerl et al. 2004) and may increase habitat heterogeneity that might facilitate coexistence (Chesson 2000).

We surveyed the docks of the Spud Point Marina in Bodega Bay, California, during the summer of 2004. Five $0.125 \mathrm{~m}^{2}$ quadrats were haphazardly placed on every southern facing slip. Two of these quadrats were located on finger piers, while 3 were on the main pier itself. This was repeated for all 5 docks of the marina (89 slips, $\mathrm{n}=440$ quadrats). Quadrats were visually surveyed for every species present. We used a multiple regression model to examine the effects of native rich- ness and the percentage of open space on invader species richness. We also included an interaction term in each model, in order to examine whether the nativeinvader richness relationship changes under different levels of available space.

While there was no overall correlation between native and invader diversity $\left(F_{1,436}=2.28, \mathrm{p}=0.124\right)$, and a slightly negative correlation between available open space and native diversity $\left(F_{1,436}=25.4, \mathrm{p}<\right.$ $0.0001)$, there was a significant native diversity $\times$ free space interaction $\left(F_{1,436}=3.78, \mathrm{p}=0.05, \mathrm{r}^{2}=0.170\right)$. Specifically, at high levels of open space, there was a strong positive relationship between native and invader richness, whereas, at low levels of open space, the slope of the relationship did not differ from 0 (Fig. 5A). Similarly, there was a strong negative correlation between open space and invader diversity at low levels of native diversity, while the relationship became nearly flat at high levels of native diversity. The reduced invader diversity at high open space is likely due to non-selective disturbance agents that affect native and invader diversity in a similar negative manner, resulting in native and invader richness covarying positively as a reflection of extrinsic factors (e.g. Levine 2000, Shea \& Chesson 2002).

When resources are limiting (low space availability), experimental results predict a negative slope to the relationship between native and invader diversity, but the data instead show a flat relationship (Fig. 5A). As diversity increases, temporal complementarity among species may increase the consistency of space occupation and decrease the likelihood of invader establishment, as argued above. It could be that at low space availability this complementarity simply balances out the effects of extrinsic factors, resulting in a flat native-exotic richness relationship. However, increasing diversity may also increase the likelihood of adding individual species with facilitative effects to the community (Mulder et al. 2001, Cardinale et al. 2002), which could alter the slope of the native-exotic relationship (Bruno et al. 2003). For example species such as Watersipora subtorquata might support epibiotic growth, effectively increasing the surface area available for colonization (i.e. increasing levels of available resource) and potentially negating the effects of enhanced biotic resistance.

When we added the percent cover of Watersipora subtorquata to the regression model, there was a significant 3-way interactive effect of $W$. subtorquata cover, native diversity, and amount of open space on the number of exotics present $\left(F_{1,433}=5.59, \mathrm{p}=0.018\right)$. To visualize this 3 -way interaction, we ran 2 separate analyses, partitioning the data into plots with $>10 \%$ or $<10 \%$ W. subtorquata cover. When W. subtorquata cover is $>10 \%$, there is a consistent positive relation- 
A All data: facilitators common
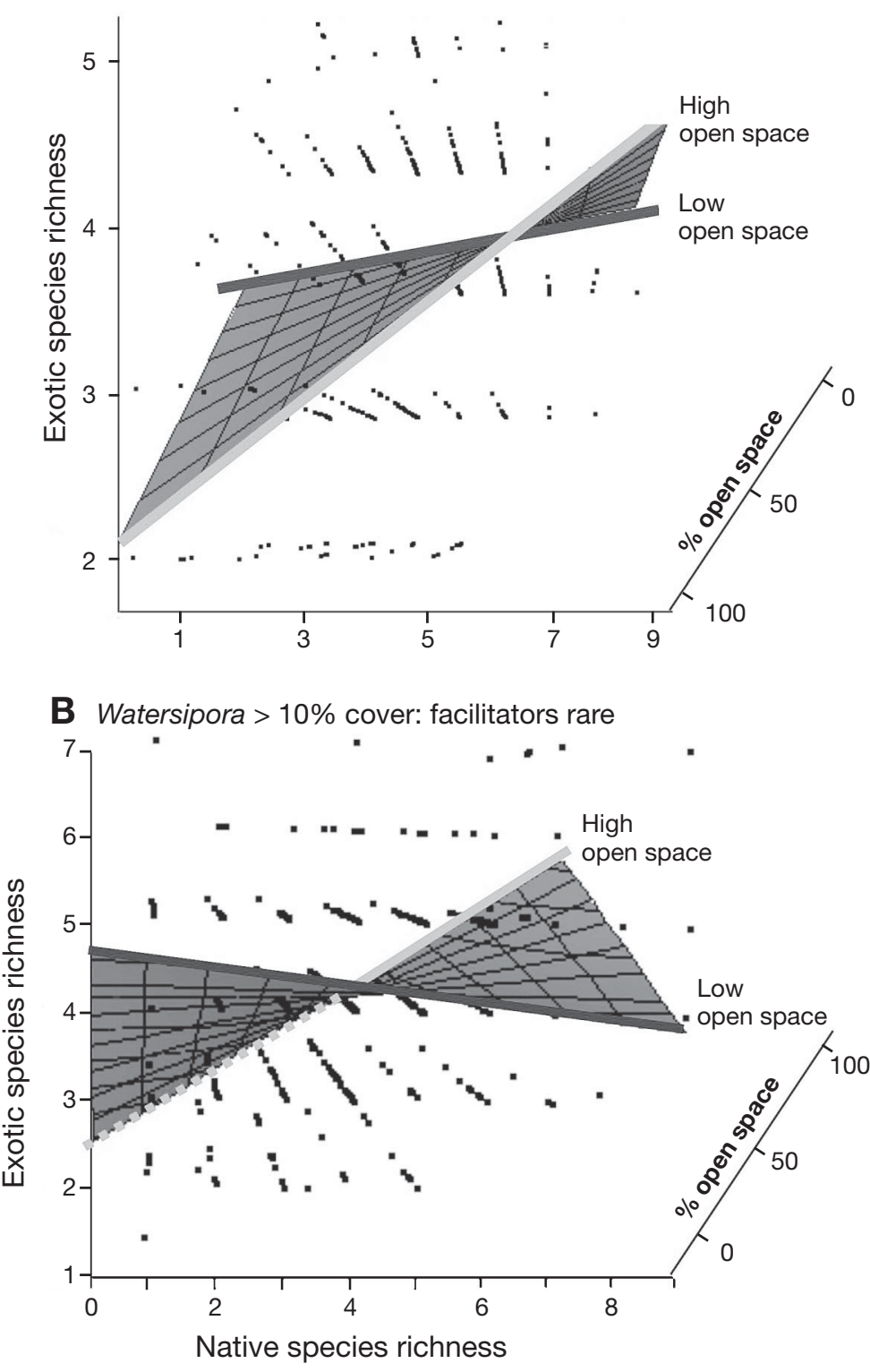

Fig. 5. Regression planes showing how the slope of the relationship between native and invader richness changes as a function of the amount of resources available (percent open space) and the presence of structurally complex species that provide additional attachment sites for sessile species. (A) Data for all plots, showing that as resources become limiting (as open space approaches 0 ) the slope of the relationship between native and invader richness decreases from strongly positive to nearly flat. (B) Data for plots in which the cover of the headforming bryozoan Watersipora subtorquata is $\leq 10 \%$, showing that the native-invader relationship becomes negative when $W$. subtorquata is absent and space is limiting. These figures combined suggest the following: (1) when resources (open space) are not limiting, the mechanism underlying biotic resistance cannot operate, and natives and invader diversities are positively correlated; (2) as free space becomes limiting, the signal of biotic resistance becomes stronger, shifting the relationship to negative at low levels of available space; and (3) the effect of biotic resistance can be offset by the presence of species (facilitators) that provide secondary substrate on their shells or tests, alleviating the resource limitation ship between native diversity and exotic diversity, regardless of the level of open space (open space $F_{1,360}=1.17, \mathrm{p}=0.28$; native richness $F_{1,360}$ $=6.72, \mathrm{p}=0.001$; interaction $F_{1,360}=0.14, \mathrm{p}=$ $\left.0.70, \mathrm{r}^{2}=0.070\right)$. In contrast, when $W$. subtorquata is rare ( $<10 \%$ cover $)$, there is a significant interactive effect of the availability of open space and native diversity on invader diversity $\left(F_{1,74}=5.99, \mathrm{p}=0.018, \mathrm{r}^{2}=0.430\right)$ : the native-invader relationship is positive at high levels of open space, but becomes negative at low levels of open space (Fig. 5B). We regularly observed many different species growing on dead and live parts of the W. subtorquata colony, and the 3-dimensional structure of colonies suggests that $W$. subtorquata may provide more space resources than it uses up. However, it may not just be that $W$. subtorquata provides more space, but that it increases heterogeneity, including the subdivision of space into discrete patches. Indeed, a recent analysis suggests that spatial heterogeneity may be the key to understanding how native-exotic correlations change across spatial scales (Davies et al. 2005).

These data suggest that the presence of a structure-forming species can alleviate space limitation and increase the number of both native and exotic species that can coexist in a given area, masking or eliminating the importance of biotic resistance. Interestingly, the field survey by Stachowicz et al. (2002a), one of the few to show a negative invader-native richness relationship in field survey data, was conducted in a system that lacked abundant foundation species such as these and had low availability of free space. Factorial field manipulations of space availability and facilitator presence are needed to more directly test their effect on biotic resistance, but these conclusions are in accord with those from other studies showing that exotic habitat modifiers often increase the diversity of both natives and exotics (e.g. Crooks 2002). Although our discussions here consider space as the relevant limiting resource in fouling communities, in principle this could work for any sort of resource limitation in other types of communities. For example, in nitrogen-limited terrestrial plant communities, it would be interesting to consider native-exotic relationships across gradients in nitrogen availability and the presence of N-fixing species such as legumes.

The results of these and other surveys suggest that the diversity of both native and introduced species often respond similarly to spatial variation in environmental conditions, leading to pos- 
itive correlations between native and invader diversity (Shea \& Chesson 2002, Davies et al. 2005). This is particularly apparent when resources are not limiting (high amount of open space). However, as available resources become scarce, invader diversity is ultimately determined by a mix of competitive and facilitative interactions between natives and invaders that control resource availability (summarized in Table 1). Looking at the shape of the relationships between native diversity, available resources (both primary and secondary space), and invader diversity can elucidate which of these processes are acting within a system, how they determine the invasibility of the system, and the relative importance of biotic resistance.

\section{CONCLUSION AND APPLICATION TO BROADER DIVERSITY-FUNCTION STUDIES}

The few studies on the relationship between diversity and invasion in marine systems are most noteworthy for their emphasis on assessing the mechanism(s) underlying the patterns of native-invader diversity relationships. The balance of the evidence suggests that diversity can and does enhance resource use, such that fewer resources remain unused over time in more diverse communities. Because resource use will relate to so many other ecosystem functions, these results provide a firm mechanistic basis for the diversityfunctioning relationship. For example, if more diverse communities have higher resource utilization, then they are also likely to have greater biomass or productivity and lower losses of energy or nutrient resources than less diverse communities. The suggestion that diversity enhances the consistency of resource use and space occupancy (e.g. Figs. 1B \& 2A) lends further evidence to the idea that diversity is related to community stability. For instance, in terrestrial studies and theoretical work, as diversity increases, the stability of individual species' populations tends to decrease slightly
(May 1974), whereas the stability of aggregate community properties, such as biomass or percent coverage, tends to increase (Tilman 1996, Tilman \& Lehman 2001). This is exactly what we have found in our study of diversity and invasion (Stachowicz et al. 2002a).

However, when resources do not limit invasion-or more broadly, when resource availability or use does not affect an ecosystem process-then the mechanisms we have identified can be overwhelmed by other factors. For example, as suggested above, the presence of a facilitator can generate additional resources that enhance both native and non-native species, leading to higher diversity of both (e.g. Crooks 2002). However, most work to date has been on sessile taxa, and resource limitation may be less common in other groups (e.g. mobile species). It would be interesting to test the robustness of diversity-invasibility relationships within such groups. Of course mechanisms other than resource depletion might link diversity and invasibility, and other papers in this Theme Section explicitly illustrate how diversity and other ecosystem functions can be linked via a variety of non-competitive mechanisms.

Our results and those of others (e.g. Levine 2000) suggest that the synthesis of observational, experimental, and simulation approaches, such as presented here, might also be profitable when examining the effect of diversity on other ecosystem functions. Indeed, observational approaches tested by Emmerson \& Huxam (2002) show promise for gaining insight into diversity-functioning relationships at larger scales and in high-diversity communities. Given the importance of the ocean to global ecosystem functioning, it seems clear that small-scale experiments will not be sufficient.

Finally, at least in the short term, many invasions have resulted in a net gain in the number of species present at the local/regional level (Sax \& Gaines 2003). This is not surprising and is similar to what is seen in geological-scale invasions: most regions gain in the

Table 1. Summary of how the effects of native richness on invader richness might change as a function of the availability of resources (open space) and the presence or absence of facilitators. Predictions based on data trends in Fig. 5

\begin{tabular}{|lll|}
\hline & Low native richness & High native richness \\
\hline $\begin{array}{l}\text { Low fraction } \\
\text { of resources } \\
\text { available }\end{array}$ & $\begin{array}{l}\text { Biotic resistance overwhelmed by invaders } \\
\text { Invader-invader competition may reduce } \\
\text { invader diversity } \\
\text { INVADER DIVERSITY HIGH TO MODERATE }\end{array}$ & $\begin{array}{l}\text { Biotic resistance reduces invasion success } \\
\text { Greater likelihood of facilitator presence that } \\
\text { increases diversity of natives and invaders } \\
\text { INVADER DIVERSITY LOW TO MODERATE }\end{array}$ \\
$\begin{array}{l}\text { High fraction } \\
\text { of resources } \\
\text { available }\end{array}$ & $\begin{array}{l}\text { Exploitative competition and biotic } \\
\text { resistance unimportant }\end{array}$ & $\begin{array}{l}\text { Exploitative competition and biotic resistance } \\
\text { unimportant }\end{array}$ \\
& by extrinsic factors (e.g. recruitment, disturbance, flow) & $\begin{array}{l}\text { Native and invader diversity determined by } \\
\text { extrinsic factors (e.g. recruitment, disturbance, flow) } \\
\text { INVADER DIVERSITY HIGH }\end{array}$ \\
\hline
\end{tabular}


total number of species, though some resident species eventually go extinct (e.g. Marshall et al. 1982, Vermeij 1991). The diversity-ecosystem functioning debate has mostly been framed in the context of what will happen to ecosystem functioning as species richness declines due to extinctions. But in cases where invasions cause a net increase in diversity at the scale at which ecosystem processes are measured, it is worth considering what effects this might have on ecosystem functioning. There are virtually no data to address this question, although it is clear that invasive species can affect ecosystem structure and function. For example, ecosystems lacking dominant filter-feeding organisms (either because natives have been driven ecologically extinct or because there were none to begin with) are dramatically altered when such species are introduced (e.g. Alpine \& Cloern 1992). Assessing the effects of invasion-caused increases in diversity on a range of ecosystem processes would allow for a more robust test of the diversity-functioning relationship. Additionally, such studies would contribute to a fuller understanding of the degree to which ecosystem functioning saturates at high levels of diversity and provide a more balanced view of the consequences of species introductions.

Acknowledgements. Thanks to Martin Solan for organizing this Theme Section and to 4 anonymous reviewers for comments that improved the manuscript. R. Whitlatch and R. Osman initiated the long-term recruitment record and generously permitted the use of these data for this paper. Maintenance of long-term data collection has been funded by the National Science Foundation (grants from Biological Oceanography and Long-Term Research in Environmental Biology) and the Jessie B. Cox Charitable Trust. Additional support for the work described in this paper was provided by NSF Awards OCE 00-82049 and 03-51778 to J.J.S. C. Coates assisted in the collection of field data in California.

\section{LITERATURE CITED}

Alpine AE, Cloern JE (1992) Trophic interactions and direct physical control of phytoplankton biomass in an estuary. Limnol Oceanogr 37:946-955

Bruno JF, Stachowicz JJ, Bertness MD (2003) Inclusion of facilitation into ecological theory. Trends Ecol Evol 18: 119-125

Buss LW (1979) Bryozoan overgrowth interactions: the interdependence of competition for space and food. Nature 281:475-477

Byers JE, Noonburg EG (2003) Scale dependent effects of biotic resistance to biological invasion. Ecology 84: 1428-1433

Cardinale BJ, Palmer MA, Collins S (2002) Species diversity enhances ecosystem functioning through interspecific facilitation. Nature 415:426-429

Carlton JT, Geller JB (1993) Ecological roulette: the global transport of nonindigenous marine organisms. Science 261:78-82

Case TJ (1990) Invasion resistance arises in strongly inter- acting species-rich model competitive systems. Proc Natl Acad Sci USA 87:9610-9614

Chesson P (2000) Mechanisms of maintenance of species diversity. Annu Rev Ecol Syst 31:343-366

Crooks JA (2002) Characterizing ecosystem level consequences of biological invasions: the role of ecosystem engineers. Oikos 97:153-166

Davies KF, Chesson P, Harrison S, Inouye BD, Melbourne BA, Rice KJ (2005) Spatial heterogeneity explains the scale dependence of the native-exotic diversity relationship. Ecology 86:1602-1610

Davis MA, Grime JP, Thompson K (2000) Fluctuating resources in plant communities: a general theory of invasibility. J Ecol 88:528-534

Duffy JE, Stachowicz JJ (2006) Why biodiversity is important to oceanography: potential roles of genetic, species, and trophic diversity in pelagic ecosystem processes. Mar Ecol Prog Ser 311:179-189 (in this Theme Section)

Dunstan PK, Johnson CR (2004) Invasion rates increase with species richness in a marine epibenthic community by two mechanisms. Oecologia 138:285-292

Elton CS (1958) The ecology of invasions by animals and plants. Methuen, London

Emmerson M, Huxham M (2002) How can marine ecology contribute to the biodiversity-ecosystem functioning debate? In: Loreau M, Naeem S, Inchausti P (eds) Biodiversity and ecosystem functioning: synthesis and perspectives. Oxford University Press, Oxford, p 139-146

Fargione J, Brown CS, Tilman D (2003) Community assembly and invasion: an experimental test of neutral versus niche processes. Proc Natl Acad Sci USA 100:8916-8920

Floerl O, Pool TK, Inglis GJ (2004) Positive interactions between nonindiginous species facilitate transport by human vectors. Ecol Appl 14:1724-1736

Grosholz ED (2002) Ecological consequences of coastal invasions. Trends Ecol Evol 17:22-27

Janzen D (1985) On ecological fitting. Oikos 45:308-310

Kennedy TA, Naeem S, Howe KM, Knops JMH, Tilman D, Reich P (2002) Biodiversity as a barrier to ecological invasion. Nature 417:636-638

Klimley AP, Richert JE, Jorgensen SJ (2005) The home of blue water fish. Am Sci 93:42-49

Knops JMH, Griffin JR, Royalty AC (1995) Introduced and native plants of the Hastings reservation, central coastal California, a comparison. Biol Conserv 71:115-123

Knops JMH, Tilman D, Haddad NM, Naeem S and 7 others (1999) Effects of plant species richness on invasion dynamics, disease outbreaks, insect abundances and diversity. Ecol Lett 2:286-293

Lavorel S, Prieur-Richard AH, Grigulis K (1999) Invasibility and diversity of plant communities: from patterns to processes. Divers Distrib 5:41-49

Levine JM (2000) Species diversity and biological invasions: relating local process to community pattern. Science 288 : 852-854

Levine JM, D'Antonio CM (1999) Elton revisited: a review of evidence linking diversity and invasibility. Oikos 87:15-26

Lonsdale WM (1999) Global patterns of plant invasions and the concept of invasibility. Ecology 80:1522-1536

Marshall LG, Webb SD, Sepkoski JJ, Raup DM (1982) Mammalian evolution and the Great American interchange. Science 215:1351-1357

May RM (1974) Stability and complexity in model systems, 2nd edn. Princeton University Press, Princeton, NJ

McDougall KD (1943) Sessile marine invertebrates of Beaufort, North Carolina: a study of settlement, growth and seasonal fluctuations among pile-dwelling organisms. 
Ecol Monogr 13:321-374

McGrady-Steed J, Haris PM, Morin PJ (1997) Biodiversity regulates ecosystem predictability. Nature 390:162-165

Mulder C, Uliassi D, Doak D (2001) Physical stress and diversity-productivity relationships: the role of positive interactions. Proc Natl Acad Sci USA 98:6704-6708

Naeem S, Knops JMH, Tilman D, Howe KM, Kennedy T, Gale S (2000) Plant diversity increases resistance to invasion in the absence of covarying extrinsic factors. Oikos 91: 97-108

Osman RW (1977) The establishment and development of a marine epifaunal community. Ecol Monogr 47:37-63

Planty-Tabacchi AM, Tabacchi E, Naiman RJ, Deferrari C, Decamps H (1996) Invasibility of species-rich communities in riparian zones. Conserv Biol 10:598-607

Rejmanek M (1996) Species richness and resistance to invasions. In: Orians GH, Dirzo R, Cushman JH (eds) Biodiversity and ecosystem processes in tropical forests. Springer-Verlag, Berlin, p 153-172

Rejmanek M (2003) The rich get richer response. Frontiers Ecol Environ 1:122-123

Ruiz GM, Fofonoff PW, Carlton JT, Wonham MJ, Hines AH (2000) Invasion of coastal marine communities in North America: apparent patterns, processes, and biases. Annu Rev Ecol Syst 31:481-531

Rynearson T, Armbrust V (2004) Genetic differentiation among populations of the planktonic marine diatom Ditylum brightwellii (Bacillariophyceae). J Phycol 40:34-43

Sax DF (2002) Native and naturalized plant diversity are positively correlated in scrub communities of California and Chile. Divers Distrib 8:193-210

Sax DF, Gaines SD (2003) Species diversity: from global decreases to local increases. Trends Ecol Evol 18:561-566

Shea K, Chesson P (2002) Community ecology as a framework for biological invasions. Trends Ecol Evol 17:170-176

Stachowicz JJ, Tilman D (2005) Species invasions and the relationship between community saturation, diversity and ecosystem functioning. In: Sax DF, Stachowicz JJ, Gaines SD (eds) Species invasions: insights into ecology,

Editorial responsibility: Martin Solan (Guest Editor), Newburgh, UK evolution, and biogeography. Sinauer, Sunderland, MA, p 41-64

Stachowicz JJ, Whitlatch RB, Osman RW (1999) Species diversity and invasion resistance in a marine ecosystem. Science 286:1577-1579

Stachowicz JJ, Fried H, Whitlatch RB, Osman RW (2002a) Biodiversity, invasion resistance and marine ecosystem function: reconciling pattern and process. Ecology 83: $2575-2590$

Stachowicz JJ, Terwin JR, Whitlatch RB, Osman RW (2002b) Linking climate change and biological invasions: ocean warming facilitates non-indigenous species invasions. Proc Natl Acad Sci USA 99:15497-15500

Stohlgren TJ, Binkley D, Chong GW, Kalkhan MA and 6 others (1999) Exotic plant species invade hot spots of native plant diversity. Ecol Monogr 69:25-46

Sutherland JP, Karlson RH (1977) Development and stability of the fouling community at Beaufort, N.C. Ecol Monogr $47: 425-446$

Symstad A (2000) A test of the effects of functional group richness and composition on grassland invasibility. Ecology 81:99-109

Tilman D (1996) Biodiversity: population vs. ecosystem stability. Ecology 77:350-363

Tilman D (2004) A stochastic theory of resource competition, community assembly and invasions. Proc Natl Acad Sci USA 101:10854-10861

Tilman D, Lehman C (2001) Biodiversity, composition and ecosystem processes: theory and concepts. In: Kinzing AP, Pacala SW, Tilman D (eds) The functional consequences of biodiversity. Princeton University Press, Princeton, NJ, p 9-41

Van Name WG (1945) The North and South American ascidians. Bull Am Mus Nat Hist 84:1-475

Vermeij GJ (1991) Anatomy of an invasion: the trans-Arctic interchange. Paleobiology 17:281-307

Wiser SK, Allen RB, Clinton PW, Platt KH (1998) Community structure and forest invasion by an exotic herb over 23 years. Ecology 79:2071-2081

Submitted: April 22, 2005; Accepted: November 10, 2005

Proofs received from author(s): March 3, 2006 


\title{
How biodiversity affects ecosystem functioning: roles of infaunal species richness, identity and density in the marine benthos
}

\author{
Elena N. Ieno ${ }^{1,3}$, Martin Solan ${ }^{1, *}$, Paul Batty ${ }^{2}$, Graham J. Pierce ${ }^{1}$ \\ ${ }^{1}$ Oceanlab, University of Aberdeen, Main Street, Newburgh, Aberdeenshire AB41 6AA, UK \\ ${ }^{2}$ The Scottish Association for Marine Science, Dunstaffnage Marine Laboratory, Oban, Argyll PA37 1QA, UK \\ ${ }^{3}$ Present address: Highland Statistics, 6 Laverock Road, Newburgh, Aberdeenshire AB41 6FN, UK
}

\begin{abstract}
The extent to which changes in biodiversity are causally linked to key ecosystem processes is a primary focus of contemporary ecological research. Highly controlled manipulative experiments have revealed significant and positive effects of increased diversity on ecosystem functioning, but uncertainties in experimental design have made it difficult to determine whether such effects are related to the number of species or to effects associated with species identity and density. Using infaunal marine invertebrates, we established 2 parallel laboratory experiments to examine the hypothesis that changes in the composition of benthic macrofauna alter the biogeochemistry of coastal intertidal mudflats. Our study identified clear effects of increased infaunal species diversity on nutrient generation. However, significant species identity and density effects underpin the observed response, reflecting species-specific traits associated with bioturbation. Post-hoc examination of our conclusions using power analysis revealed that, given our experimental design, the probability of finding a correct significant effect, the minimum detectable difference necessary to detect a significant effect, and the minimum number of replicates necessary in order to achieve an acceptable power, all differed between species. Our study has important implications for the design of biodiversity-ecosystem function experiments because the disparity between the contributions that individual species make to ecosystem function demands the use of different levels of replication for each species within an experiment.
\end{abstract}

KEY WORDS: Biodiversity $\cdot$ Ecosystem function $\cdot$ Species richness $\cdot$ Experimental design $\cdot$ Nutrients . Bioturbation

Resale or republication not permitted without written consent of the publisher

\section{INTRODUCTION}

Following concerns that declining species diversity may impair the long-term functioning of ecosystems, an extensive body of literature has emerged over the last decade (for review, see Hooper et al. 2005) that focuses on the effects of biodiversity loss on key ecological processes. For the most part, and irrespective of habitat type, these studies have adopted an experimental approach (see Schmid et al. 2002, Raffaelli et al. 2003) that involves randomly assembling simple communities around a basal resource and examining the effect, if any, that varying numbers of species have on direct measures of ecosystem functioning, such as primary productivity, decomposition rates and nutrient cycling (see citations in Hooper et al. 2005). As these kinds of experiments are highly controlled, they offer the opportunity to apply rigorous parametric statistical models (most typically regression and ANOVA) in the absence of confounding variables. This approach has been important in understanding the generality of how biological diversity maintains ecological processes, and it has received widespread attention. Findings from microbial (e.g. Bell et al. 2005), terrestrial plant and soil communities (reviewed in Loreau et al. 2001), as well as freshwater and marine invertebrate commu- 
nities (reviewed in Covich et al. 2004) indicate that, on average, a reduction in biodiversity is likely to impair the short-term provision and long-term sustainability of ecosystem processes (Hooper et al. 2005).

While the ecological research community broadly agrees that biodiversity is causally related to many ecosystem processes (Schläpfer et al. 1999), and fully endorses many experimental conclusions, some uncertainties in experimental design and caveats to interpretation (e.g. heterogeneity of variance with increasing species richness) cast doubts on the wider applicability of some experimental findings (Hooper et al. 2005). Recognition that there have been difficulties with the appropriateness and discriminatory power of alternative experimental designs (Schmid et al. 2002) led to an extensive debate in the primary literature over whether the findings of first generation biodiversity-ecosystem function experiments (hereafter BEF) support the postulate that biodiversity regulates ecosystem processes (for a summary of debate, see Mooney 2002). Some investigators even questioned whether new BEF research was needed (Flint \& Kalke 2005) given the availability and efficacy of using historical data (e.g. Emmerson \& Huxham 2002, Statzner \& Moss 2004). It is important to realise, however, that such criticism does not undermine the validity of the hypotheses in BEF research, nor does it demand an unequivocal demonstration of the precise mechanisms that underpin the broad conclusions of specific BEF experiments. Rather, it draws attention to the inherent difficulty in identifying and attributing causal mechanisms associated with changes in biodiversity, and the need to explicitly identify and acknowledge the limitations of each study (Rosenfeld 2002). These interpretative difficulties arise because the detection of a significant effect of diversity may indicate (1) a true and intrinsic effect of diversity (= complementarity), (2) the effect of one or more 'hidden treatments' (sensu Huston 1997) caused by concurrent changes in species density, composition or identity when the main explanatory variable (species richness) is manipulated, or (3) a combination of both effects at the same time (e.g. Fargione \& Tilman 2005).

Distinguishing between the 'properties of complementarity' and the 'mechanisms of selection' (following Petchey 2003) is vitally important because they relate to how biodiversity regulates ecosystem function in the real world. Indeed, in most real communities, the provision of ecosystem processes will depend not only upon the number of species, but also on the relative contribution of dominant and minor species (i.e. species composition and identity effects; Emmerson et al. 2001, Solan et al. 2004), environmental context (Biles et al. 2003), density dependence (Marinelli \& Williams 2003) and how species interact with one another.
A 'complementarity effect' occurs when a partitioning of resources (i.e. niche differentiation) leads to increased total resource use, or when some other positive inter-specific interaction (e.g. facilitation) leads to an increase in ecosystem functioning (Cardinale et al. 2002). A 'sampling' or 'selection' effect (Huston 1997) may occur in higher diversity treatments because of the increased probability of including species that have a disproportionate effect on ecosystem functioning (which may in itself be a valid biodiversity effect; Tilman et al. 1997).

Several metrics have been put forward that effectively distinguish selection effects from complementarity effects (Loreau 1998, Emmerson \& Raffaelli 2000, Loreau \& Hector 2001, Špaèková \& Lepš 2001, Hector et al. 2002, Petchey 2003). These generally compare the relative performance of a multi-species mixture with those of monocultures comprising species that made up the original mixture (see Loreau 1998 for general framework). This approach allows the expected yield of each species in the mixture $\left(E_{\mathrm{i}}\right)$ to be predicted from its observed yield in monoculture $\left(M_{\mathrm{i}}\right)$. Any deviation of the observed total yield $\left(O_{\mathrm{T}}\right)$ in the mixture from its expected value $\left(E_{\mathrm{T}}=\right.$ summation of all $\left.E_{\mathrm{i}}\right)$ then provides a means to unambiguously assert that a mixture is more productive (= overyielding) than the corresponding monocultures. However, further analysis aiming to determine how species interactions give rise to overyielding is possible only if the relative contribution of each species $\left(O_{\mathrm{i}}\right)$ to the total observed yield $\left(O_{\mathrm{T}}\right)$ can be subsequently partitioned.

For many marine BEF experiments, where cumulative processes are routinely used as surrogates for ecosystem function (e.g. nutrient concentrations, Emmerson et al. 2001, Biles et al. 2003; bioturbation, Solan et al. 2004; oxygen flux, Waldbusser et al. 2004; grazing, O'Connor \& Crowe 2005; photosynthesis, Bruno et al. 2005), direct determination of the relative contribution of each species from the size of the observed effect in a mixture is not always possible, and such metrics are of limited use. Instead, the separation of species identity and density effects from those attributable to species richness can be achieved using a series of alternative ANOVA models (e.g. Schmid et al. 2002, O'Connor \& Crowe 2005), although problems can be encountered under some circumstances (see Benedetti-Cecchi 2004). While these and other methods (e.g. power analysis) are available, they are seldom used to cross-check the experimental design or the ensuing findings of BEF experiments.

In this study, using infaunal benthic invertebrate assemblages, we present an experimental design and validation procedure appropriate for distinguishing the compositional effects of diversity from those attributable to species richness. Our aim is to encourage the 
use of these techniques in BEF experimentation and, in so doing, explicitly recognise the limitations of such studies within a marine context.

\section{MATERIALS AND METHODS}

Faunal and sediment collection. Sediment and 3 infaunal invertebrates, the deposit-feeder Hediste diversicolor (Polychaeta), the surficial grazer Hydrobia ulvae (Gastropoda) and the suspension-feeder Cerastoderma edule (Bivalvia) were collected from mud flats in the Ythan Estuary, Aberdeenshire, Scotland (57²0.085' N, $\left.02^{\circ} 0.206^{\prime} \mathrm{W}\right)$. Sediment was sieved ( $0.5 \mathrm{~mm}$ mesh) in a seawater bath to remove macrofauna and then allowed to settle for $24 \mathrm{~h}$ to retain the fine fraction $(<63 \mu \mathrm{m})$. Excess water was removed and the settled sediment (total organic carbon content, $3.84 \%$; mean particle size $=49.79 \mu \mathrm{m}$; volume percentile range: $\mathrm{d}[\mathrm{v}, 0.05]=$ $4.42 \mu \mathrm{m}, \mathrm{d}[\mathrm{v}, 0.95]=309.30 \mu \mathrm{m})$ was homogenised to a slurry to facilitate distribution between mesocosms. Sediment and seawater (UV-sterilised, $10 \mu \mathrm{m}$ prefiltered, salinity 33) were added to each mesocosm $36 \mathrm{~h}$ prior to addition of invertebrate species. Seawater was siphoned off and replaced after $24 \mathrm{~h}$ to allow the removal of excess nutrients associated with sediment disruption during assembly. All mesocosms were continually aerated. Pre-filtered (Nalgene, $0.45 \mu \mathrm{m}$ ) water samples were taken on the final day of each experiment. Ammonium-nitrogen $\left(\mathrm{NH}_{4}-\mathrm{N}\right)$, nitrate-nitrogen $\left(\mathrm{NO}_{\mathrm{X}}-\mathrm{N}\right)$ and phosphate-phosphorus $\left(\mathrm{PO}_{4}-\mathrm{P}\right)$ concentrations were determined with a modular flow injection auto-analyser (FIA Star 5010 series) using an artificial seawater carrier solution.

Mesocosms for species diversity and identity. Replicate $(\mathrm{n}=5)$ macrofaunal communities were assembled in monoculture and in mixtures of 2 and 3 species (40 mesocosms, Table 1) to examine whether more diverse communities have a greater effect on sediment

Table 1. Species combinations used in the assembled macrofaunal communities for species richness and identity manipulations ( $\mathrm{n}=5$ in all cases). Realised biomass accuracy $($ mean $\pm \mathrm{SE}): 2.0082 \pm 0.0196 \mathrm{~g} ; \mathrm{n}=35)$. $H$ diversicolor: Hediste diversicolor; C. edule: Cerastoderma edule; H. ulvae: Hydrobia ulvae

\begin{tabular}{lccc}
\multirow{2}{*}{$\begin{array}{c}\text { Species } \\
\text { richness }\end{array}$} & \multicolumn{3}{c}{ Biomass $\left(\mathrm{g} \mathrm{mesocosm}^{-1}\right)$} \\
\hline 0 & H. diversicolor & C. edule & H. ulvae \\
1 & - & - & - \\
1 & 2.00 & 0 & 0 \\
1 & 0 & 2.00 & 0 \\
2 & 0 & 0 & 2.00 \\
2 & 1.0 & 1.0 & 0 \\
2 & 1.0 & 0 & 1.0 \\
3 & 0 & 1.0 & 1.0 \\
& 0.67 & 0.67 & 0.67 \\
\hline
\end{tabular}

nutrient release $\left(\mathrm{NH}_{4}-\mathrm{N}, \mathrm{NO}_{\mathrm{X}}-\mathrm{N}, \mathrm{PO}_{4}-\mathrm{P}\right)$ than communities containing fewer species. To minimise hidden treatment effects (sensu Huston 1997) and eliminate pseudo-replication, species richness treatments containing 1 and 2 species were replicated using different species permutations (Table 1). This was not possible for the 3-species mixture because of the limited species pool $(\mathrm{n}=3)$. Biomass was fixed at $2.0 \mathrm{~g}$ per mesocosm (equivalent to $255 \mathrm{~g} \mathrm{~m}^{-2}$ ), a level consistent with that found at the study site (e.g. Biles et al. 2003). Mesocosms were transparent perspex cores $(330 \mathrm{~mm}$ high, $100 \mathrm{~mm}$ internal diameter) containing $10 \mathrm{~cm}$ depth of sediment (equivalent to $785 \mathrm{~cm}^{3}$ ) and $20 \mathrm{~cm}$ of overlying seawater (equivalent to $2.35 \mathrm{l}$ ). These were randomly distributed in an environmental chamber (VC 4100, Vötsch Industrietechnik) and maintained at $14.0 \pm 0.1^{\circ} \mathrm{C}$ with a $12 \mathrm{~h}$ light $-12 \mathrm{~h}$ dark cycle $(2 \times 36 \mathrm{~W}$ fluorescent tube lights, Arcadia, model FO-30) for $21 \mathrm{~d}$.

Mesocosms for species density. We assembled 30 additional mesocosms and drew on previous data (Solan \& Ford 2003) obtained using the same experimental procedure and sample location to examine the effects of species density on sediment nutrient release $\left(\mathrm{NH}_{4}-\mathrm{N}, \mathrm{NO}_{\mathrm{X}}-\mathrm{N}, \mathrm{PO}_{4}-\mathrm{P}\right)$. Mesocosms consisted of nontransparent plastic aquaria $(210 \times 150 \times 150 \mathrm{~mm})$ containing $1.0 \mathrm{l}$ of homogenised sediment and $3.0 \mathrm{l}$ of seawater. Macrofaunal biomass was fixed across 5 levels (Hediste diversicolor and Cerastoderma edule: 0, 0.5, 1.0, 1.5 and $2.0 \mathrm{~g}$ ) or 6 levels (Hydrobia ulvae: 0, 1.0, 3.0, 5.0, 7.0 and $9.0 \mathrm{~g}$; Solan \& Ford 2003) and replicated within each biomass treatment $(n=3, n=3$ and $\mathrm{n}=5$, respectively). Mesocosms were maintained in the dark to prevent microphytobenthic activity. The experiment ran for $15 \mathrm{~d}$ at ambient temperature (ca. $8^{\circ} \mathrm{C}$ ).

Data analysis. The relationships between species richness and nutrient concentration, species identity and nutrient concentration, and between species density and nutrient concentration were defined using standard regression and ANOVA procedures followed by post hoc analyses where appropriate. Prior to analysis, graphical exploratory techniques were used to check for outliers and, where appropriate, a data transformation was applied to reduce their effect and also to linearise the relationships. Where outliers were identified, we removed them from the analysis. Where this was necessary ( 2 occasions), $\geq 94 \%$ of the data remained and a reanalysis with $100 \%$ of the data did not alter the conclusions. Following analysis, a model validation was applied to verify that underlying statistical assumptions were not violated; normality was assessed by plotting theoretical quantiles versus standardised residuals (Q-Q plots), homogeneity of variance was evaluated by plotting residuals versus fitted values, and influential datapoints were identified using Cook's distance (Quinn \& Keough 2002). Statistical tests were 
performed using the software package Brodgar 2.4.8 (www.brodgar.com). Post hoc analyses were performed with the software package SPSS 13.0.1 (SPSS).

Two separate ANOVAs tested for the effects of species richness on nutrient concentration. In the first model, we used a 1-way ANOVA with each of the 3 nutrients $\left(\mathrm{n}=3 ; \mathrm{NH}_{4}-\mathrm{N}, \mathrm{NO}_{\mathrm{X}}-\mathrm{N}\right.$ and $\left.\mathrm{PO}_{4}-\mathrm{P}\right)$ treated as separate response variables and species richness ( $\mathrm{n}=$ $4 ; 0,1,2$ and 3 ) as the nominal explanatory variable. In the second model, we used a 2-way ANOVA where nutrient concentration, irrespective of nutrient identity, was considered as the response variable with species richness $(n=4)$ and nutrient identity $(n=3)$ as nominal explanatory variables. For the latter, significant differences $(p<0.05)$ were identified with Tukey's and Sidak's (more conservative) post-hoc comparison tests. Use of the 2 separate ANOVA approaches (multiple response variables treated singularly versus grouped) allows predictions to be made regarding the importance of species richness for both the generation of individual nutrients and for nutrient generation per se.

To identify species identity effects on nutrient generation per se, we applied a 2-way ANOVA with nutrient concentration as the response variable and species identity $(\mathrm{n}=8$; representing each unique combination in Table 1$)$ and nutrient identity $(\mathrm{n}=3)$ as nominal explanatory variables. We assumed that the behaviour of each species was functionally different and that species effects were not additive (i.e. inter-specific interactions were present; see Emmerson et al. 2001, Biles et al. 2003), such that each unique species combination could be treated as a unique 'species'. Multiple comparisons to identify the source of any significant differences were performed using Tukey's and Sidak's post-hoc tests.

We tested species density effects for each of the 3 species using a 2-way ANOVA with nutrient concentration as the response variable and density (for Hediste diversicolor and Cerastoderma edule, $\mathrm{n}=5$; for Hydrobia ulvae, $\mathrm{n}=6$ ) and nutrient identity $(\mathrm{n}=3)$ as nominal explanatory variables.

Validation of experimental approach. We used a power analysis to test 3 related quantities: (1) the probability of finding a correct significant effect, i.e. the power of the performed analyses; (2) the minimum detectable difference required to detect a significant effect between the mean values for nutrient concentration in the monocultures and those of the multispecies assemblages or, for our density manipulations, between the lowest and largest mean values of nutrient concentration across biomass treatments; and (3) the minimum number of replicates necessary in order to achieve an acceptable power (>80\%) given our experimental design. We considered ecosystem function to be the sum of all 3 investigated nutrients because the minimum replication required for an experiment in which 3 re- sponses are being tested simultaneously is likely to be greater than that predicted from the behaviour of only 1 nutrient (i.e. we sought a conservative recommendation). As ecosystem performance may depend on the presence of specific functional groups and/or certain faunal traits more than it does on species richness per se (Solan et al. 2004), we reapplied the 2-way ANOVA, with species identity and nutrient identity as nominal explanatory variables, in the absence of the controls (no macrofauna). This yields a more appropriate fit of residuals versus predicted values and prevents species presence (non-controls) versus absence (controls) effects from distorting the analysis. We determined power function and sample size using the statistical graphs of Pearson \& Hartly (1951) at a significance level of $\alpha=$ 0.05 . All power analyses were performed using an addon software package for Brodgar 2.4.8.

\section{RESULTS}

\section{Species richness effects}

The concentration of $\mathrm{NH}_{4}-\mathrm{N}$ and $\mathrm{PO}_{4}-\mathrm{P}$ increased with species richness, while the concentration of $\mathrm{NO}_{\mathrm{X}^{-}}$ $\mathrm{N}$ decreased with species richness levels (Fig. 1). ANOVA confirmed significant effects of species richness on $\log _{10}$ transformed nutrient concentration for $\mathrm{NH}_{4}-\mathrm{N}(F=3.65, \mathrm{df}=3, \mathrm{p}<0.05)$ and $\mathrm{PO}_{4}-\mathrm{P}(F=5.44$, $\mathrm{df}=3, \mathrm{p}<0.01)$, but not for $\mathrm{NO}_{\mathrm{X}}-\mathrm{N}(F=2.12$, df $=3$, p $=0.12$ ). For the 2 -way ANOVA of nutrient concentration $\left(\log _{10}\right.$ transformed), where nutrient identity was treated as an additional explanatory variable to species richness, we found significant effects of species richness $(F=7.00$, df $=3, \mathrm{p}<0.001)$, nutrient identity $(F=$ 192.39, $\mathrm{df}=2, \mathrm{p}<0.001$ ) and the interaction of species richness $\times$ nutrient identity $(F=4.43, \mathrm{df}=6, \mathrm{p}<0.001)$.

Post hoc analyses of the 1-way ANOVA for $\mathrm{NH}_{4}-\mathrm{N}$ revealed that the controls were not significantly different from the monocultures (Tukey's, $\mathrm{p}=0.57$; Sidak's, $\mathrm{p}=$ 0.74 ) but there were marginal differences between the controls and the multiple species richness levels (Tukey's, $p \approx 0.05$; Sidak's, $p \approx 0.07$ ). The highest species richness treatment (=3) was not significantly different to the intermediate (1 and 2) species richness levels (Tukey's, $\mathrm{p} \geq 0.22$; Sidak's, $\mathrm{p} \geq 0.30$ ). For $\mathrm{PO}_{4}-\mathrm{P}$, controls were not significantly different from the monocultures (Tukey's, p = 0.34; Sidak's, p = 0.46) but there were significant differences between the controls and the multiple species richness levels (Tukey's and Sidak's, $\mathrm{p} \leq 0.01)$. The highest species richness treatment $(=3)$ was not significantly different to the intermediate species richness levels (Tukey's, $p \geq 0.12$; Sidak's, $p \geq 0.16$ ).

Post hoc analyses for the 2-way ANOVA confirmed that nutrient concentrations were dependent on nutri- 

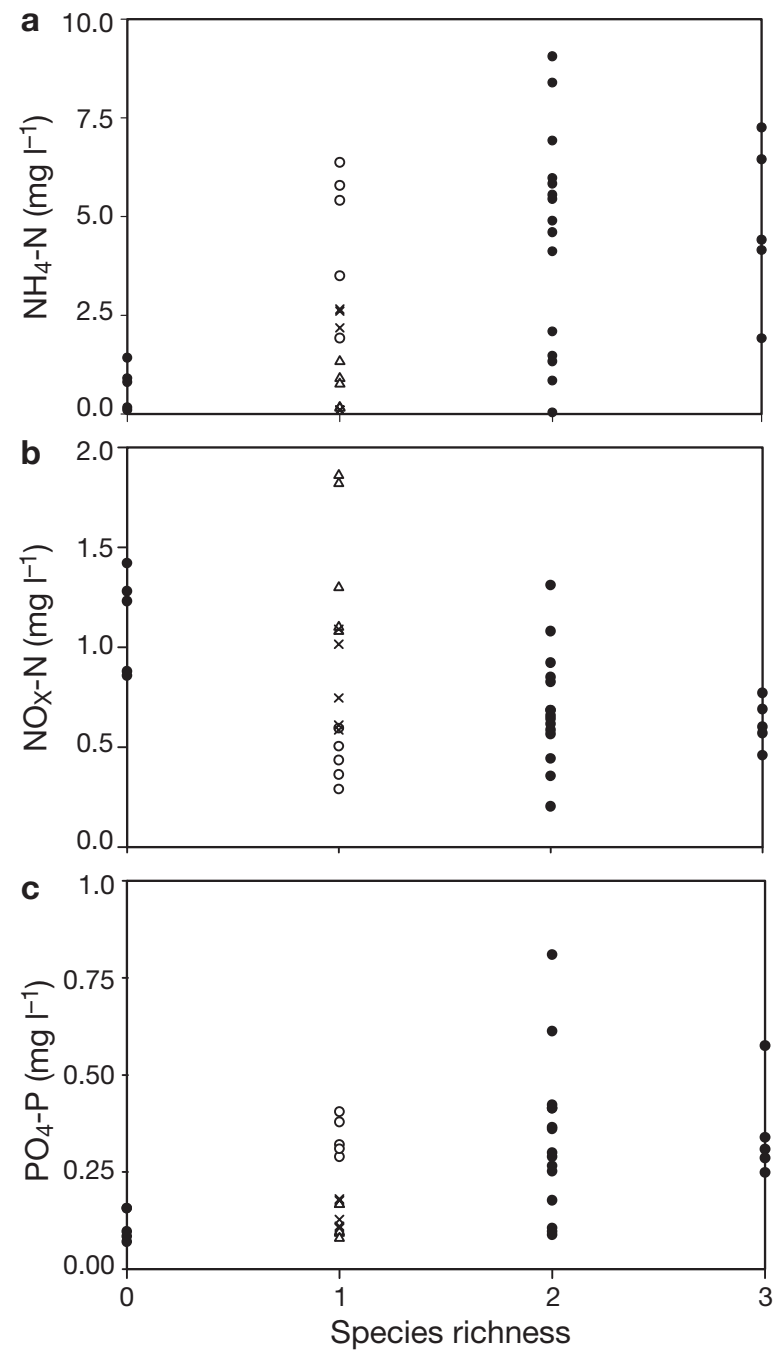

Fig. 1. Replicated $(n=5)$ accumulated nutrient concentrations of (a) $\mathrm{NH}_{4}-\mathrm{N}$ (b) $\mathrm{NO}_{\mathrm{X}}-\mathrm{N}$ and (c) $\mathrm{PO}_{4}$-P with increasing species richness. Species identity in the single species treatments are denoted by 0 : Hediste diversicolor; $\Delta$ : Cerastoderma edule; x: Hydrobia ulvae

ent identity (Tukey's and Sidak's, p < 0.001 for every nutrient identity comparison), and that there were significant species richness effects irrespective of nutrient identity. Although the controls were not significantly different from the monocultures (Tukey's, p = 0.28 ; Sidak's, $p=0.38$ ), the 2 -species combinations were significantly different to the controls (Tukey's and Sidak's, $\mathrm{p}<0.01$ ) and the monocultures (Tukey's and Sidak's, $\mathrm{p}<0.05$ ), but not from the 3 -species combinations (Tukey's and Sidak's, $\mathrm{p} \geq 0.89$ ); the 3 -species combinations were significantly different from the controls (Tukey's and Sidak's, $\mathrm{p}<0.01$ ) and monocultures (Tukey's and Sidak's, $p \leq 0.05$ ), but not from the 2-species combinations (Tukey's and Sidak's, $p \geq 0.87$ ).

\section{Species identity effects}

Our data reveal clear differences in the relative contribution of individual species to nutrient generation, irrespective of nutrient identity (Hediste diversicolor $>$ Hydrobia ulvae > Cerastoderma edule; Fig. 1). Twoway ANOVA of nutrient concentration $\left(\log _{10}\right.$ transformed), with species identity and nutrient identity treated as explanatory variables, confirmed significant effects of species identity $(F=12.39, \mathrm{df}=7, \mathrm{p}<0.001)$, nutrient identity $(F=335.43, \mathrm{df}=2, \mathrm{p}<0.001)$ and a significant interaction of species identity $\times$ nutrient identity $(F=13.55, \mathrm{df}=14, \mathrm{p}<0.001)$. Post hoc analyses on all treatments revealed that nutrient concentrations in monocultures of $H$. diversicolor were marginally greater than those in $H$. ulvae (Tukey's, $p=0.05$; Sidak's, $\mathrm{p}=0.07$ ) and significantly greater than those containing monocultures of $C$. edule (Tukey's and Sidak's, p $<0.001$ ). When comparisons were made between all species identity levels, post hoc analysis revealed that the presence of $H$. diversicolor in a multispecies combination, irrespective of the composition of the remaining species, led to a significant increase in nutrient concentration relative to those combinations where $H$. diversicolor was absent (Tukey's and Sidak's, p $\leq 0.05$; dark grey shaded entries, Table 2). When species combinations that contained $H$. diversicolor are compared to other multi-species combinations that also contained $H$. diversicolor, irrespective of proportional representation, differences in nutrient concentrations are non-significant (Tukey's and Sidak's, p > 0.05; non-shaded areas in HD column, Table 2). For treatments that contained H. ulvae, $C$. edule or $H$. ulvae and $C$. edule, nutrient concentrations

Table 2. Tukey's pairwise comparisons of species identity for controls (CNTRL) and all species combinations in the species richness manipulations; HD: Hediste diversicolor; CE: Cerastoderma edule; HU: Hydrobia ulvae. Light grey: HD absent in both pairwise combinations; dark grey: HD in one of the pairwise combinations. ${ }^{* * *} \mathrm{p}<0.001,{ }^{* *} \mathrm{p}<0.01,{ }^{*} \mathrm{p}<0.05, \mathrm{~ns}=$ not significant. Sidak's pairwise comparisons had identical results

\begin{tabular}{|c|c|c|c|c|c|c|c|c|}
\hline & CNTRL & $\mathrm{HD}$ & $\mathrm{CE}$ & $\mathrm{HU}$ & CEHU & CEHD & HDHU & HDCEHU \\
\hline CNTRL & - & & & & & & & \\
\hline HD & $* *$ & - & & & & & & \\
\hline $\mathrm{CE}$ & ns & $* * *$ & - & & & & & \\
\hline $\mathrm{HU}$ & ns & * & ns & - & & & & \\
\hline CEHU & $\mathrm{ns}$ & $\mathrm{ns}$ & ns & ns & - & & & \\
\hline CEHD & $* * *$ & $\mathrm{~ns}$ & $* * *$ & $* *$ & ** & - & & \\
\hline HDHU & $* * *$ & $\mathrm{~ns}$ & $* * *$ & $* * *$ & $* *$ & ns & - & \\
\hline HDCEHU & $* * *$ & $\mathrm{~ns}$ & $* * *$ & ** & * & $\mathrm{ns}$ & $\mathrm{ns}$ & - \\
\hline
\end{tabular}


were not significantly different from those generated in the controls or any other treatment where $H$. diversicolor was absent (Tukey's and Sidak's, p > 0.05; light grey shaded areas, Table 2). Thus, mesocosms that contained $H$. diversicolor had high mean $\mathrm{NH}_{4}-\mathrm{N}$ and $\mathrm{PO}_{4}-\mathrm{P}$ concentrations, and low $\mathrm{NO}_{\mathrm{X}}-\mathrm{N}$ concentrations.

Examination of our biomass treatments confirmed that inclusion of biomass as a covariate, or as an independent explanatory variable, was unnecessary in any of our models examining species richness or species identity effects, because the realised (mean $\pm \mathrm{SE}=$ $2.0082 \pm 0.0196 \mathrm{~g}, \mathrm{n}=35)$ and target $(2.0 \mathrm{~g})$ biomass were sufficiently similar $(\mathrm{CV}<0.01 \mathrm{~g}, \mathrm{n}=35)$.

\section{Species density effects}

Two-way ANOVA of nutrient concentration, with species density and nutrient identity treated as nominal explanatory variables, revealed significant effects of density (Fig. 2) relative to the controls for Hediste diversicolor $(F=5.20$, df $=4, \mathrm{p}<0.01)$, but not for Cerastoderma edule $(F=1.12, \mathrm{df}=4, \mathrm{p}=0.37)$ or Hydrobia ulvae $(F=1.86, \mathrm{df}=5, \mathrm{p}=0.11)$. The same analysis revealed significant effects for nutrient identity $(\mathrm{p}<0.001)$ and density $\times$ nutrient identity interactions $(p<0.01)$ for all 3 species. These results are consistent with the findings of the single species mesocosms in the species richness manipulations, although the magnitude of response is comparatively higher for $H$. ulvae (reflecting seasonal differences in sediment nutrient content).

\section{Validation of effects}

Application of a power analysis to the species richness and species identity data revealed that the minimal difference required for the detection of a significant species richness effect for nutrient concentration per se was $1.79 \mathrm{mg} \mathrm{l}^{-1}$. By comparing the nutrient concentrations for individual species in monocultures with that observed in the 3 -species combinations, results showed that both Hydrobia ulvae and Cerastoderma edule exhibited sufficiently large between-mean concentration values $\left(1.85 \mathrm{mg} \mathrm{l}^{-1}\right.$ and $2.30 \mathrm{mg} \mathrm{l}^{-1}$, respectively) in order to achieve a power $\geq 80 \%$ at the level of replication used in our study (minimum replication required, $n=5$ and $n=3$, respectively; Fig. 3). Thus, for a given density, nutrient concentrations were higher in a 3-species combination than would be expected for corresponding monocultures containing only H. ulvae or C. edule (i.e. evidence of a significant diversity effect). For Hediste diversicolor, however, the same comparison revealed an insufficiently large between-
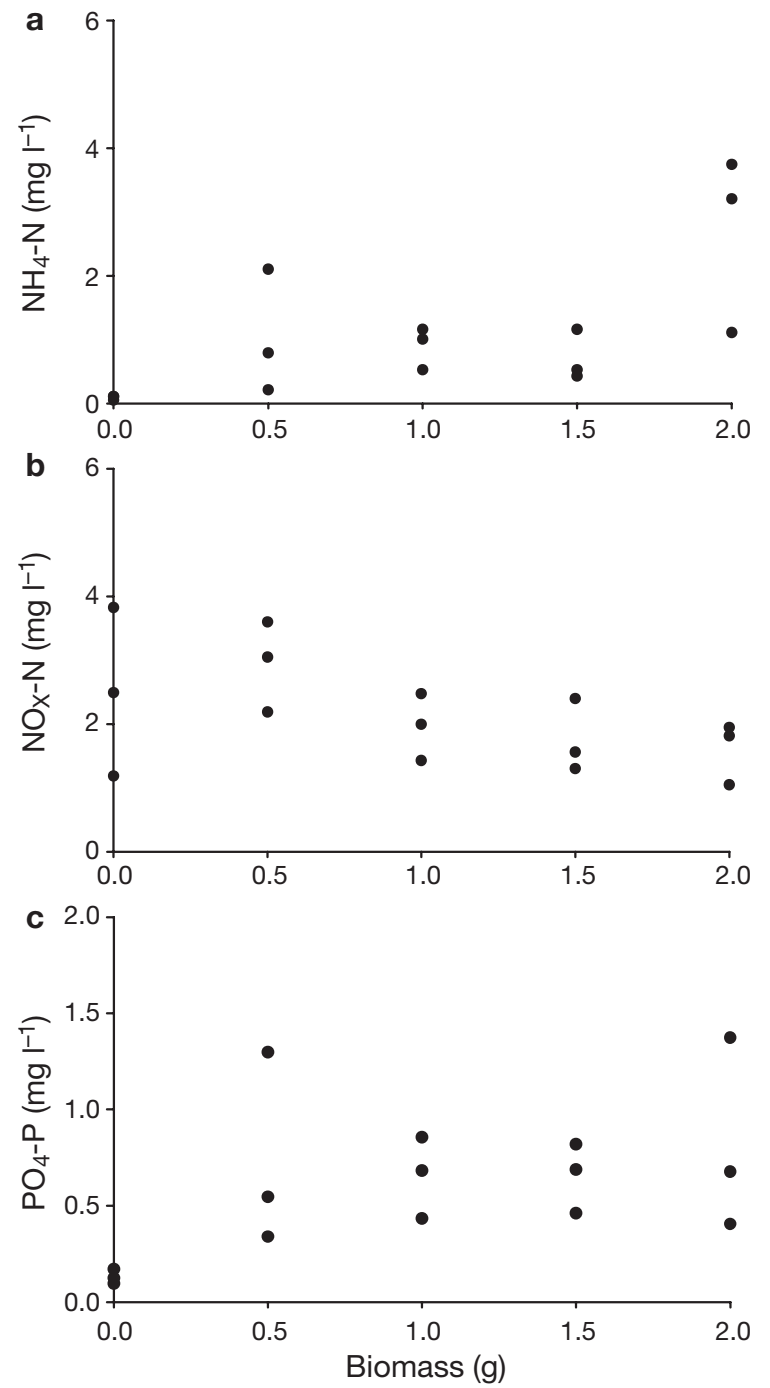

Fig. 2. Relationship between species biomass and (a) $\mathrm{NH}_{4}-\mathrm{N}$, (b) $\mathrm{NO}_{\mathrm{X}}-\mathrm{N}$ and (c) $\mathrm{PO}_{4}-\mathrm{P}$ nutrient concentration for Hediste diversicolor

mean concentration value $\left(1.14 \mathrm{mg} \mathrm{l}^{-1}\right)$ to detect a significant diversity effect. When treatments contain $H$. diversicolor, $>100$ replicates at each density level are necessary to detect a significant effect of diversity over that of species identity at a desirable power (Fig. 3).

When applied to the species density data, power analysis revealed that our design (replication $n=3$ or $\mathrm{n}=5$ per density level) was not sufficient in all cases to detect true density effects for the biomass levels used in our experiments. The minimum number of replicates per density interval required to detect a density effect with sufficient power $(1-\beta \geq 80 \%)$ was $\geq 3$ for Hediste diversicolor (Fig. 4a), $\geq 9$ for Hydrobia ulvae (Fig. 4b) and $\geq 80$ for Cerastoderma edule (Fig. 4c). Thus, only for $H$. diversicolor had we achieved the appropriate level of replication necessary to detect density effects in our experiments. 




Fig. 3. Sample size (replicates) required to distinguish species richness from species identity effects for Cerastoderma edule, Hydrobia ulvae and Hediste diversicolor at $\alpha=0.05$ for the present experimental set-up. The minimum level of replication occurs when power $(1-\beta) \geq 80 \%$. Large values of replication when $1-\beta=80 \%$ indicate strong effects of individual species

\section{DISCUSSION}

Our study identifies clear effects of increased infaunal species diversity on nutrient generation in the marine benthos, although significant species identity and density effects underpin the observed response. These findings support those of previous studies on marine benthic invertebrates where consistent diversity effects have been shown to develop from the idiosyncratic contributions of individual species (Emmerson et al. 2001, Biles et al. 2003, Waldbusser et al. 2004). Several studies have reported the relative importance of complementarity by using comparisons between the performances of species combinations and monocultures (Loreau 1998, Emmerson \& Raffaelli 2000, Loreau \& Hector 2001, Špaèková \& Lepš 2001,
Hector et al. 2002, Petchey 2003), though it has always been a difficult task to select the minimum subset of complementary species within the regional species pool in order to explain diversity effects. In the present study, nutrient concentrations varied between diversity treatments and undoubtedly correlate with the role that the component species play within the ecosystem. The bioturbation activities of the deposit-feeding polychaete Hediste diversicolor were of particular importance to nutrient generation, more so than either Cerastoderma edule (suspension feeder) or Hydrobia ulvae (surficial grazer), whose bioturbatory activities were masked when $H$. diversicolor was present (consistent with Mermillod-Blondin 2005). The decreasing patterns of $\mathrm{NO}_{\mathrm{X}}-\mathrm{N}$ with increasing $\mathrm{NH}_{4}-\mathrm{N}$ observed here indicate that macrofaunal bioturbation stimulated microbial denitrification, leading to a reduction of the internal pool of dissolved and particulate nutrients in the sediment and the associated increase in nutrients in the water column (Hansen \& Kristensen 1997).

The detection of strong species identity effects give credence to the view that functional diversity (groups of ecologically equivalent species) may be equally, if not more, important for the delivery of ecosystem services than species diversity (Solan et al. 2004). For certain ecosystem processes, some species within an assemblage will therefore be functionally less important than other species (in line with insurance; Yachi \& Loreau 1999), albeit for a given set of circumstances in time and/or space (i.e. context, e.g. Biles et al. 2003). This property of biological communities has important implications for the design of BEF experiments. If we are to distinguish identity effects from diversity effects, the disparity between the contributions that individual species make to ecosystem function demands the use of different levels of replication for each species within an experiment. Where species have a particularly strong and disproportionate effect on ecosystem func-
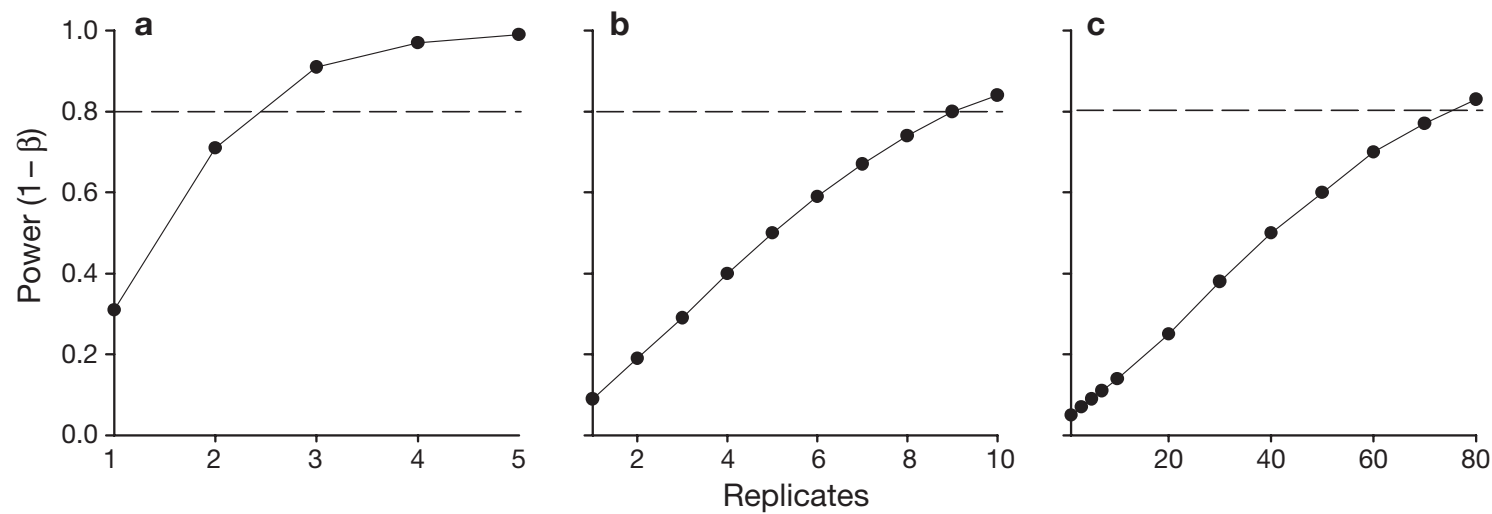

Fig. 4. Estimation of sample size (replicates) required to detect a significant effect of species density between the control and highest density level at a significance level of $\alpha=0.05$ for (a) Hediste diversicolor, (b) Hydrobia ulvae and (c) Cerastoderma edule. The minimum level of replication occurs when power $(1-\beta) \geq 80 \%$ (indicated by the dashed line). Large values of replication when $1-\beta=80 \%$ indicate weak density effects of individual species 
tion, such as Hediste diversicolor, a high number of replicates are required to statistically rule out the possibility that the observed response is a true diversity effect (complementarity) and not a product of species identity (sampling or selection). The converse is true when species have a comparatively less marked contribution to ecosystem function, such as Cerastoderma edule and Hydrobia ulvae. Thus, both types of factorial balanced designs used in the present study were sufficient to identify a diversity effect, but they were unable to eliminate the selection effect for treatments that included $H$. diversicolor.

A further complication is that a similar problem arises with the choice of density within each mesocosm (Marinelli \& Williams 2003). Although we independently found evidence for a significant effect of species density, the level of replication per density level to detect a true density effect is markedly different between species. These differences arise because speciesspecific traits mediate the functional contribution of each species, such that mesocosms containing species with strong per capita effects (e.g. Hediste diversicolor) require fewer replicates per density level to detect a true density effect from that of a presence versus absence effect. That said, there is some evidence that adopting a larger biomass interval, rather than increasing the minimum replication required, might solve the problem of insufficient discriminatory power between density treatments.

An appropriate solution may be a factorial balanced design in which species richness and biomass are manipulated in concert (Benedetti-Cecchi 2004) at appropriate replication levels that account for density and identity effects of the species under study. Adoption of such a design may also relieve some of the constraints imposed by inequality of variance with increasing levels of species richness, although when no significant differences among treatments are found in balanced samples, heterogeneity of variance is of no concern (p. 194, Underwood 1997). Nevertheless, whichever design is ultimately chosen it is clear that the density, identity and number of species richness levels within an experiment need to be chosen with care because they greatly influence the scope of inference permitted. This point is not trivial, because it raises concerns about experimentally manipulating unknown or uncharacterised species, whose contribution to ecosystem function is either more difficult to determine or unknown. Use of species that are functionally equivalent (i.e. selectively choosing species from within a functional group to standardise the comparative weighting of per capita effects between species) in BEF experiments would be unrepresentative of real biological communities and could misrepresent the relative importance of contrasting functional groups.
We contend that, in naturally occurring communities, the individual contribution of species to ecosystem function is a complex product of niche complementarity, species density, sampling and selection effects, although the relative contribution of each of these mechanisms most likely alters in time and space according to context (e.g. Biles et al. 2003). If we are to fully understand the causal relationship between biodiversity and the delivery of ecosystem processes, future experimental analyses will need to adopt a more holistic approach aimed at distinguishing the relative contribution of multiple mechanisms to ecosystem functioning.

Acknowledgements. We thank D. MacKinnon of Plant and Soil Sciences, University of Aberdeen for analysis of water samples. O. McPherson and T. Doherty-Bone assisted with fieldwork. The support and co-operation received from Forvie National Nature Reserve, Scottish Natural Heritage is gratefully acknowledged. All work was supported by NERC.

\section{LITERATURE CITED}

Bell T, Newman JA, Silverman BW, Turner SL, Lilley AK (2005) The contribution of species richness and composition to bacterial services. Nature 436:1157-1160

Benedetti-Cecchi L (2004) Increasing accuracy of causal inference in experimental analyses of biodiversity. Funct Ecol 18:761-768

Biles C, Solan M, Isaksson I, Paterson DM, Emes C, Raffaelli DG (2003) Flow modifies the effect of biodiversity on ecosystem functioning: an in situ study of estuarine sediments. J Exp Mar Biol Ecol 285/286:165-177

Bruno JF, Boyer KE, Duffy JE, Lee SC, Kertesz JS (2005) Effects of macroalgal species identity and richness on primary production in benthic marine communities. Ecol Lett 8:1165-1174

Cardinale BJ, Palmer MA, Collins SL (2002) Species diversity enhances ecosystem functioning through interspecific facilitation. Nature 415:426-429

Covich AP, Austen M, Bärlocher F, Chauvet E and 7 others (2004) The role of biodiversity in the functioning of freshwater and marine benthic ecosystems. BioScience 54(8): 767-775

Emmerson M, Huxham M (2002) How can marine ecology contribute to the biodiversity-ecosystem functioning debate? In: Loreau M, Naeem S, Inchausti P (eds) Biodiversity and ecosystem functioning: synthesis and perspectives. Oxford University Press, Oxford, p 139-146

Emmerson MC, Raffaelli DG (2000) Detecing the effects of diversity on measures of ecosystem function: experimental design, null models and empirical observations. Oikos 91(1):195-203

Emmerson MC, Solan M, Emes C, Paterson DM, Raffaelli D (2001) Consistent patterns and the idiosyncratic effects of biodiversity in marine ecosystems. Nature 411:73-77

Fargione JE, Tilman D (2005) Diversity decreases invasion via both sampling and complementarity effects. Ecol Lett 8:604-611

Flint RW, Kalke RD (2005) Reinventing the wheel in ecology research? Science 307:1875

Hansen K, Kristensen E (1997) Impact of macrofaunal recolo- 
nization on benthic metabolism and nutrient fluxes in a shallow marine sediment previously overgrown with macroalgal mats. Estuar Coast Shelf Sci 45(5):613-628

Hector A, Bazeley-White E, Loreau M, Otway S, Schmid B (2002) Overyielding in grassland communities: testing the sampling effect hypothesis with replicated biodiversity experiments. Ecol Lett 5(4):502-511

Hooper DU, Chapin FS, Ewel JJ, Hector A and 11 others (2005) Effects of biodiversity on ecosystem functioning: a consensus of current knowledge. Ecol Monogr 75(1):3-35

Huston MA (1997) Hidden treatments in ecological experiments: re-evaluating the ecosystem function of biodiversity. Oecologia 110:449-460

Loreau M (1998) Separating sampling and other effects in biodiversity experiments. Oikos 82:600-602

Loreau M, Hector A (2001) Partitioning selection and complementarity in biodiversity experiments. Nature 412:72-76

Loreau M, Naeem S, Inchausti P, Bengtsson J and 8 others (2001) Biodiversity and ecosystem functioning: current knowledge and future challenges. Science 294:804-808

Marinelli RL, Williams TJ (2003) Evidence for densitydependent effects of infauna on sediment biogeochemistry and benthic-pelagic coupling in nearshore systems. Estuar Coast Shelf Sci 57:179-192

Mermillod-Blondin F, François-Carcaillet F, Rosenberg R (2005) Biodiversity of benthic invertebrates and organic matter processing in shallow marine sediments: an experimental study. J Exp Mar Biol Ecol 315:187-209

Mooney HA (2002) The debate on the role of biodiversity in ecosystem functioning. In: Loreau M, Naeem S, Inchausti $\mathrm{P}$ (eds) Biodiversity and ecosystem functioning: synthesis and perspectives. Oxford University Press, Oxford, p 12-17

O'Connor NE, Crowe TP (2005) Biodiversity loss and ecosystem functioning: distinguishing between number and identity of species. Ecology 86(7):1783-1796

Pearson ES, Hartly HO (1951) Charts for the power function for analysis of variance tests, derived from the non-central F-distribution. Biometrika 38:112-130

Petchey O (2003) Integrating methods that investigate how complementarity influences ecosystem functioning. Oikos 101:323-330

Quinn GP, Keough MJ (2002) Experimental design and data analysis for biologists. Cambridge University Press, Cambridge

Editorial responsibility: David Raffaelli (Guest Editor), Heslington, UK
Raffaelli D, Emmerson M, Solan M, Biles C, Paterson D (2003) Biodiversity and ecosystem functioning in shallow coastal waters: an experimental approach. J Sea Res 49(2): 133-141

Rosenfeld JS (2002) Functional redundancy in ecology and conservation. Oikos 98(1):156-162

Schläpfer F, Schmid B, Seidl I (1999) Expert estimates about effects of biodiversity on ecosystem processes and services. Oikos 84(2):346-352

Schmid B, Hector A, Huston MA, Inchausti P, Nijs I, Leadley PW, Tilman D (2002) The design and analysis of biodiversity experiments. In: Loreau M, Naeem S, Inchausti P (eds) Biodiversity and ecosystem functioning: synthesis and perspectives. Oxford University Press, Oxford, p 61-75

Solan M, Ford R (2003) Macroalgal-induced changes on the distribution, composition and diversity of benthic macrofauna: implications for ecosystem functioning. In: Raffaelli D, Solan M, Paterson D, Buck AL, Pomfret JR (eds) The estuaries and coasts of north-east Scotland. Coastal zone topics 5. Proc ECSA local meet, Aberdeen, 2001. Estuarine and Coastal Sciences Association, p 77-87

Solan M, Cardinale BJ, Downing AL, Engelhardt KAM, Ruesink JL, Srivastava DS (2004) Extinction and ecosystem function in the marine benthos. Science 306: $1177-1180$

Špaèková I, Lepš J (2001) Procedure for separating the selection effect from other effects in diversity-productivity relationship. Ecol Lett 4:585-594

Statzner B, Moss B (2004) Linking ecological function, biodiversity and habitat: a mini-review focusing on older ecological literature. Basic Appl Ecol 5:97-106

Tilman D, Lehman C, Thompson K (1997) Plant diversity and ecosystem productivity: theoretical considerations. Proc Natl Acad Sci USA 94:1857-1861

Underwood AJ (1997) Experiments in ecology: their logical design and interpretation using analysis of variance. Cambridge University Press, Cambridge

Waldbusser GG, Marinelli RL, Whitlatch RB, Visscher PT (2004) The effects of infaunal biodiversity on biogeochemistry of coastal marine sediments. Limnol Oceanogr 49(5):1482-1492

Yachi S, Loreau M (1999) Biodiversity and ecosystem productivity in a fluctuating environment: the insurance hypothesis. Proc Nat Acad Sci USA 96:1463-1468

Submitted: April 12, 2005; Accepted: October 21, 2005 Proofs received from author(s): March 13, 2006 



\title{
Expanding scales in biodiversity-based research: challenges and solutions for marine systems
}

\author{
Shahid Naeem* \\ Department of Ecology, Evolution, and Environmental Biology, Columbia University, 1200 Amsterdam Avenue, New York, \\ New York 10027, USA
}

\begin{abstract}
As in terrestrial biodiversity, human influences over marine biodiversity will alter the way ecosystems contribute to biogeochemical or ecosystem processes. While many studies have documented how alterations of terrestrial biology affect ecosystem functioning, few studies have examined marine systems. The main challenge faced by biodiversity and ecosystem functioning (BEF) research in marine ecology is dealing with the large scales of marine systems and the logistical difficulties of attempting to conduct the kinds of complex, combinatorial experiments that have been done in terrestrial ecology. BioMERGE (Biotic Mechanisms of Ecosystem Regulation in the Global Environment) has developed a framework for relating biodiversity, via biomass, to ecosystem functioning and for employing extinction scenarios to explore the realm of possible changes in ecosystem functioning that biodiversity loss could create. This approach may find much utility in marine BEF research because it obviates the need for complex experiments. I provide an overview of the issues, the framework, and some directions marine ecology could take to further our understanding of the ecosystem consequences of marine biodiversity loss.
\end{abstract}

KEY WORDS: Biodiversity $\cdot$ Ecosystem function $\cdot$ Marine $\cdot$ Extinction $\cdot$ Biogeochemistry Resale or republication not permitted without written consent of the publisher

\section{INTRODUCTION}

At one extreme, in the absence of a biota, Earth's biogeochemical processes by definition become geochemical processes that yield an uninhabitable planet, with conditions something between those of Venus and Mars. At the other extreme, today's biota regulate biogeochemical processes that annually move gigatons $\left(10^{15} \mathrm{~g}\right)$ of materials among the hydro-, litho-, and atmosphere, yielding an environment conducive to life and defining its surface for the last 1.5 billion yr (Lovelock 1979, Schlesinger 1997a, Ernst 2000, Kasting \& Siefert 2002, Mathez \& Webster 2004).

Earth systems (e.g. global biogeochemical systems) and ecosystems (e.g. local biogeochemical systems) in general are moving to a point somewhere between these extremes in the sense that the role the biota plays in regulating geochemical processes is changing dramatically in the face of human domination of ecosystems (Vitousek et al. 1997, Hollowell 2001, Duraiappah
\& Naeem 2005). There are 2 components to this change. The first concerns change in the biologically active mass of the Earth's biota (henceforth, biomass), which can be visualized as a sort of diffuse green or brown slime coating the Earth's surface. Biomass is variously defined, often simply referring to the mass of biogenic organic material, living or dead. Here, I use biomass to refer only to metabolically active or living biomass, which includes standing (static) as well as growing components of organisms.

The second concerns change in the structure of this living mass. Though often modeled as a homogeneous slime in ecosystem, climate, or biogeochemical models, biomass is, of course, actually made up of organisms structured by taxonomy, biotic interactions, functional differences, genetic differences, and differences in distribution over space and time (henceforth, biodiversity). Part of the structure of this biomass stems from inter-specific differences in apportionment of biomass to the standing crop or productivity, inter-specific 
differences in impacts on elemental cycles, and intraand inter-specific interactions, especially trophic interactions, which can dramatically affect ecosystem functioning. Clearly, changes in biodiversity mean changes in the structure of biomass which, in turn, means changes in the ways biomass influences ecosystem functioning. For example, it is possible that fluctuations in atmospheric $\mathrm{CO}_{2}$ may have been driven almost entirely by the biosphere over the last 370 million yr (Rothman 2001). This implies that human dominance over the biosphere, either directly by changes in the mass of living organisms or indirectly by changes in biodiversity, leaves the carbon cycle (and by extension, all other biogeochemical cycles) increasingly in the hands of humans.

Tremendous uncertainty surrounds estimates of how much biomass or biodiversity there is at most scales, let alone how much they have changed or will change under scenarios of continuing human growth and development. Some back-of-the-envelope calculations are, however, instructive. If we consider that estimates of the global biomass of plants range from 501 to $829 \mathrm{Gt} \mathrm{C}$, and estimates of heterotrophic biomass range from 353 to $565 \mathrm{Gt}$, this gives us roughly a biosphere made up of about 1000 Gt C (summed from Appendix F in Smil 2002). This biomass moves about 110.2 Gt C among the spheres annually (assuming all the carbon taken up by the biosphere in a year is released in the same year) (Schlesinger 1997b). If we consider that the total amount of carbon in the atmosphere is about $750 \mathrm{Gt}$, the biosphere moves that much in about $7 \mathrm{yr}$. Of the active carbon in soils, the biosphere moves an equivalent amount in about $15 \mathrm{yr}$. To move an amount of active carbon equivalent to what is present in the oceans, however, would take $40 \mathrm{yr}$.

Continuing with this simplistic exercise, given Balmford et al.'s (2002) estimates of biome reductions of 1.2 to $11.4 \%$ over the previous decade (see discussion above), significant declines in global biomass and global biodiversity are very likely during the next century. What are the consequences of such loss? The simplest conclusion would be that for every $10 \mathrm{Gt}$ of global biomass lost, roughly $1.1 \mathrm{Gt}$ of $\mathrm{C}$ will not cycle per year, which can be readily translated into reductions in other ecosystem functions. But what would happen if the bulk of the biomass lost consists of standing rather than growing biomass, or consists entirely of rare species, or the loss occurs predominantly in the oceans rather than terrestrial systems, or consists of declines in heterotrophic biomass rather than autotrophic biomass? Clearly, global changes in biomass have impacts, but how biodiversity changes (e.g. the spatial, trophic, taxonomic, and other components of biomass) is equally important. If we wish to understand how Earth, its biomes, or its ecosystems are shifting between the biogeochemically active systems they are now towards depauperate, predominantly geochemical systems (i.e. uninfluenced by biology), intense ecological research is necessary now and in the near future (Naeem et al. 2000, Hooper et al. 2005).

Certainly there is evidence that both biodiversity and biomass are declining on large scales. If we consider global changes to major biome types as an indicator of changing biomass, with the exception of boreal forests, Balmford et al. (2002) estimated that between 1992 and 2002, the Earth's major biomes shrunk in area or extent at an annual rate of 1.2 to $11.4 \%$. Given that species occurrences and biomass are positively related to area, then there is little doubt that biodiversity (at least locally) and biomass have declined on a global scale. Although such large-scale changes suggest correlated changes in biomass and biodiversity in natural systems, and paleoecologically the 2 seem to have been correlated for a long time (Rothman 2001), there is no a priori reason to believe that they are causally coupled in any way (Falkowski \& Rosenthal 2001). From the standpoint of conservation, for example, a biodiversity hotspot (e.g. Myers et al. 2000, e.g. Rodrigues et al. 2004) or marine protected area (e.g. Balmford et al. 2004, Browman \& Stergiou 2004) can contain a significant fraction of the Earth's taxonomic diversity, yet represent an insignificant portion of the global biomass. From the standpoint of unsustainable use, when humans construct managed systems, such as fish or shrimp farms, they often locally increase biomass well beyond anything previously observed in the system, but at extraordinarily low levels of biodiversity (although this is generally achieved by subsidization Naylor et al. 1998). One can legitimately ask whether either activity is desirable - creating a landscape with small areas that contain tremendous biodiversity, but show next to no biogeochemical activity, to large subsidized areas that show a tremendous amount of biogeochemical activity, but contain almost no biodiversity (Millennium Ecosystem Assessment 2003).

Clearly, changes in biomass lead to changes in biogeochemistry, but less clear is whether changes in biodiversity, beyond the trivial point of no biodiversity, are of any biogeochemical significance. Scientific exploration of the biogeochemical or ecosystem consequences of changes in biodiversity began a little over a decade ago (Schulze \& Mooney 1993). This research is dominated by terrestrial studies, all small in spatial and temporal scale. With the exception of Steinberg \& Geller's (1993) contribution on plankton diversity and ecosystem processes, virtually no treatment of marine biodiversity and marine ecosystem functioning was covered in the founding volume on the topic by Schulze \& Mooney (1993). A decade later, only a handful of experimental studies have examined the ecosystem con- 
sequences of biodiversity loss in marine systems (e.g. Emmerson \& Raffaelli 2000, Duffy et al. 2001, Emmerson et al. 2001, Stachowicz et al. 2002, Callaway et al. 2003, Covich et al. 2004, Solan et al. 2004).

The need to address the terrestrial bias of biodiversity and ecosystem functioning (henceforth, BEF) research is clear (Emmerson \& Huxhan 2002). Given that widespread alteration of the Earth's biota is undoubtedly at least as significant for marine ecosystems (Roberts \& Hawkins 1999, Jackson et al. 2001, Myers \& Worm 2003) as it is for terrestrial ecosystems, the motivation for terrestrial biodiversity and ecosystem functioning research applies to both marine and terrestrial systems. Given that the biosphere is $71 \%$ marine in surface area and probably much more in terms of volume (Groombridge \& Jenkins 2000), that it is responsible for nearly half of the Earth's net primary production (NPP) (Schlesinger 1997b), that more than half the world's population lives within $60 \mathrm{~km}$ of the sea, and that marine fisheries consume 24 to $35 \%$ of the NPP (Roberts \& Hawkins 1999), a terrestrial bias in BEF research limits its ability to address global environmental issues.

The primary challenge for marine BEF research is that of scaling up, which is actually the same challenge terrestrial BEF faces, but because of fewer logistical constraints, terrestrial systems have had more options. BEF studies will continue in the foreseeable future to be small in scale and short in duration, and are critical for the evolution of theory and testing of mechanisms in BEF research (Loreau et al. 2001, Naeem 2001, Bengtsson et al. 2002). To meet the challenge of going beyond the limited scales of current BEF studies, a research-coordinating network known as BioMERGE (Biotic Mechanisms of Ecosystem Regulation in the Global Environment) was created (see www. columbia.edu/cu/biomerge/ and Naeem \& Wright 2003). The majority of BEF studies to date, including the few marine studies, have all explored only a limited portion of the spatial, temporal, and biological realm of biodiversity and ecosystem functioning (Fig. 1). BioMERGE's mission is to coordinate efforts that lead to the development of BEF methods that allow exploration of a greater range of ecosystems over much larger scales than have currently been achieved.

The focus of the present paper is the framework developed by BioMERGE developed for scaling up BEF research by the participants of the research-coordinating network (note, henceforth, when referring to BioMERGE it will be explicitly in refer- ence to its framework). This framework is explicitly non-experimental, aiming to provide insights on the relationship between biodiversity and ecosystem functioning by making use of the wealth of past, existing, and planned studies of biodiversity and ecosystem functioning. Using this framework, I will offer some suggestions for possible directions for future marine BEF research that can address the needs for working at large scales with limited information about both biomass and biodiversity in marine ecosystems.

\section{GLOBAL BIODIVERSITY AND ECOSYSTEM FUNCTIONING IN TERRESTRIAL AND MARINE SYSTEMS}

\section{Terrestrial BEF research as a springboard for marine research}

Even though BEF research is currently largely terrestrial in nature, there are sufficient similarities between marine and terrestrial systems that enable current BEF research to serve as a springboard for developing ideas concerning the scaling up of marine BEF research. For starters, there are many similarities at the global scale between marine and terrestrial environmental concerns. For example, in many cases



Fig. 1. The realms of current research in biodiversity and ecosystem functioning (BEF) and BioMERGE (Biotic Mechanisms of Ecosystem Regulation in the Global Environment). Each axis abstractly and approximately represents the scales of biodiversity and ecosystem functioning, illustrating the latter as a dependent function of the former. The center box illustrates the average domain of current BEF research, which has focused on relating species diversity to ecosystem functioning at small spatial (in the realm of square meters) and temporal scales (in the realm of weeks to years). Arrows indicate directions of new research necessary for the expansion of BEF research. The larger box encompassing the upper right quadrant represents the domain of BioMERGE, which seeks to extend BEF research to larger scales (after Naeem et al. in press) 
marine zooplankton and phytoplankton show unimodal relationships with their own biomass (Irigoien et al. 2004), much like what is seen in terrestrial systems (Mittelbach et al. 2003). Marine ecosystems are experiencing rates of change similar to major terrestrial biomes (Balmford et al. 2002). And both terrestrial (e.g. Purvis et al. 2000) and marine ecosystems have proportionally larger percentages of top predators or carnivores threatened or vulnerable than species at lower trophic levels (e.g. Myers \& Worm 2003, e.g. Hutchings \& Reynolds 2004). Furthermore, marine NPP, estimated at $48.5 \times 10^{15} \mathrm{~g} \mathrm{C}$, is similar to terrestrial NPP, estimated at $56.4 \times 10^{15} \mathrm{~g} \mathrm{C}$ (Schlesinger 1997b).

Estimates for both terrestrial and marine biodiversity are completely lacking, because of the difficulties of documenting the many dimensions of biodiversity (e.g. functional diversity, and spatial and temporal patterns of distribution), but to the extent that taxonomic diversity may serve as a crude proxy (Naeem 2002a, Petchey \& Gaston 2002), marine and terrestrial systems may be similar. Deep-sea macrofaunal diversity, based on box-core samples, has been estimated to be as high as 10 million species (Grassle \& Maciolek 1992), but the uncertainty surrounding this number is similar to the uncertainty surrounding the estimate of 30 million species of terrestrial insects estimated by Erwin (1982). Conservatively, dismissing some of the very high estimates for species richness, the global total is more likely to be about 14 million species (Groombridge \& Jenkins 2000), with a sense that marine taxonomic diversity is lower (in species), but certainly larger in phyla.

Perhaps the greatest uncertainty surrounds microbial species richness (Tiedje 1995, Pace 1997, Torsvik et al. 2002, Nee 2004), which, given that microbes dominate biogeochemical processes (Fenchel et al. 1998), represents a major gap in our knowledge of taxonomic diversity. For example, one of the most thorough molecular estimates of prokaryotic diversity is that of Venter et al. (2004) in which they estimated 1800 genomic species in the samples they collected from the Sargasso Sea. Analyses of their data, however, suggest that a 12-fold greater depth of sampling is needed before they would be within $95 \%$ of the likely diversity. This study illustrates the difficulty in attempting to quantify prokaryotic diversity, even from 1 marine site.

One interesting difference between terrestrial and marine systems, however, is that vast though the marine realm is, it may contain a smaller proportion of the global biomass. Total marine biomass (in terms of carbon) is estimated at 5 to $10 \times 10^{15} \mathrm{~g} \mathrm{C}$, while land contains $560 \times 10^{15} \mathrm{~g} \mathrm{C}$ - or almost 2 orders of magnitude more biomass (Groombridge \& Jenkins 2000). Nevertheless this does not affect the way the question of how biodiversity and ecosystem functioning are related (see next section).

\section{Diversifying the slime}

At one level, it is not uncommon in ecology to treat the biosphere or an ecosystem as simply autotrophic biomass - the equivalent of a homogeneous, photonfuelled slime coating the Earth or an ecosystem. Likewise, microbial biomass (a brown slime) in sediment and soil is often associated with decomposition, mineralization, and other ecosystem functions without consideration of microbial diversity.

Crude though it is, this slime approach provides a means of determining the role our biota play in governing biogeochemical processes or ecosystem functioning by a simple formula that might look like this:

$$
E=B R
$$

in which some measure of ecosystem function $(E)$ is equal to the product of the biomass $(B)$ of the biological community in the ecosystem and the per unit biomass rate of biogeochemical activity $(R)$. Note that there are many possible metrics or currencies one could use for biomass, such as $\mathrm{C}, \mathrm{N}$, and $\mathrm{P}$ for all biomass (though dead biomass would have to be removed) or RNA and ATP for active biomass. As mentioned previously, one can also divide biomass into standing, growing, and reproductive biomass (e.g. Reekie \& Bazzaz 1987a,b,c), but for simplicity, I ignore these divisions here.

This slime, however, is made up of individuals whose body sizes range from $10^{-6} \mathrm{~cm}$ (e.g. viruses) to nearly $10^{4} \mathrm{~cm}$ (e.g. blue whale Balaenoptera musculus), though the vast majority of such organisms are very small $\left(10^{-5}\right.$ to $10^{-3} \mathrm{~cm}$, such as prokaryotes and protists) (Fenchel 1987, Nee 2004) and their individual densities range from substantially $<1$ individual (e.g. vertebrates) to trillions (e.g. microbes) per square meter. Each unit of biodiversity, such as a species, a group of organisms sharing functional traits, or ecosystem type, represents some portion of community biomass. By calculating the sum of the biomass of all individuals in the unit of diversity, we can determine its relative role in ecosystem processes by comparing it to the sum of the biomass of all individuals across all units of diversity in the ecosystem. Adding diversity to the equation, or diversifying the slime, changes the formula to:

$$
E=\sum_{i=1}^{D} B_{i} R_{i}
$$

or simply the sum of biomass $\times$ function for each unit (i) of diversity (e.g. species, functional group, ecosystem type, or other unit of biodiversity) for all the units of diversity in the estimate $(D)$.

Solan et al. (2004) followed this approach to model ecosystem functioning relevant for a benthic marine community. The function was biogenic mixing depth (BMD), or the depth to which animals burrow from the 
sediment surface, and Solan et al. related this to biodiversity by the simple formula:

$$
\mathrm{BMD}=0.719 \log \left(\sum_{i=1}^{D} \bar{B}_{i}^{0.5} R_{i}\right)+4.55
$$

where $\bar{B}_{i}$ is the mean biomass of the $i$ th unit of diversity, and $R_{i}$ for their system was defined as the product of the propensity to move and the reworking mode (the functional sediment mixing class of the organism such as surface modifier, burrower, excavator, or other class of impact on the sediment) of the $i$ th unit of diversity, and for their system the unit of diversity, $i$, is a species and $D$ is the total number of species in the community or ecosystem. The constants and log transformation were derived from curve-fitting a formula that bounded BMD to observed depths (see Solan et al. 2004, supplementary information, for further details). One can see the similarity between Eqs. (2) \& (3) and also appreciate how relatively simple the task can be for relating biodiversity and biomass to ecosystem functioning. Admittedly, BMD may represent a case in which ecosystem functioning was readily related to biodiversity and biomass. Complications arise when ecosystem functioning is not so readily related to biomass, and other factors must be included in the formulation.

Additional complications arise when attempting to use units of diversity that are not as readily defined or obtained as taxonomic diversity. For example, one can define the unit of diversity as a group of organisms clustered by similarities in their phenotypes (e.g. body size, morphology, physiology, behavior, biochemistry, reproductive rates and dispersal patterns) or by their functional traits (e.g. traits related to the ecosystem function of interest) (Díaz \& Cabido 2001, Lavorel \& Garnier 2002, Naeem 2002b, Petchey \& Gaston 2002). Such classification schemes tend to be hierarchical in nature, the basic unit being the species in taxonomic classifications and individuals sharing functional traits in functional classifications. With respect to the latter, as noted by Lavorel \& Garnier (2002), one must further distinguish between traits that are associated with the ecosystem function and traits associated with responses to environmental change, a fact that is particularly important when considering extinction scenarios (see 'Modeling biodiversity, loss: extinction drivers and scenarios' section).

\section{Adding macroecology}

The units of diversity are not randomly, uniformly spread over space and time, which allows for the possibility of using patterns of association between diversity and biotic and abiotic factors in developing BEF mod- els. Statzner \& Moss (2004) point to the long history in ecology of studying allometric relationships among biodiversity, ecosystem function, habitat properties (e.g. area, structure, and abiotic factors), and species properties (e.g. body size, longevity), much of which constitutes the current field of macroecology (Brown 1995, Gaston 2000, Blackburn \& Gaston 2003a,b), as a source for guiding the development of BEF studies at larger scales than our current experiments permit. These macroecological relationships provide, not only a foundation for structuring and testing descriptive models of the relationship between biodiversity and ecosystem functioning, but may serve as a means for approximating BEF variables when data are lacking.

As an example of the utility of macroecology, consider attempting to apply the method developed by Solan et al. (2004) described above to another marine system in which only the taxa are known. One needs estimates of relative abundance of species which Solan et al. derived from actual photographs of the fauna, but one seldom has such data to hand. In the absence of such information about distribution and abundance, however, macroecology provides useful insights into what the patterns of relative abundance might be and how one might estimate a biologically plausible range of relative abundances for a given biota (Brown 1995, Gaston 2000, Blackburn \& Gaston 2003a,b). Species within trophic groups, for example, often show predictable patterns with respect to area, productivity, climate, and other geographical features, and relative abundance typically exhibits log-normal like distributions (Preston 1962, Sugihara 1980, Hubbell 2001, Hubbell \& Lake 2003, Nee 2003), in which many species are rare and a few dominant. Hypothetically, it is possible to approximate abundance of other species using macroecological methods in terrestrial systems (and hypothetically all systems for the neutral, unified model), even if one has only limited information on such aspects as presence/absence data and total biomass (or density) of the community, as well as some knowledge about relative abundance (e.g. which species are rare and which are numerically dominant). In comparison to terrestrial ecosystems, macroecology is less well developed for marine systems, but some studies suggest macroecological principles may be usefully employed in marine studies (McKinney 1998, Belgrano et al. 2002, Li 2002, Foggo et al. 2003, Statzner \& Moss 2004).

\section{Modeling biodiversity loss: extinction drivers and scenarios}

Achieving the primary goal of BEF research requires knowing how biodiversity will change over time in order to predict how ecosystem functioning will 
change as biodiversity changes. Empirical studies, with few exceptions (e.g. Zavaleta \& Hulvey 2004, e.g. Schlapfer et al. 2005), have largely sidestepped the issue by exploring all possible patterns of loss of biodiversity, which effectively involves employing a scenario in which every unit of diversity (e.g. species, functional group, or some other unit of biodiversity) has a uniform, random probability of going extinct. This is the most general approach one can take that will lead to results that can relate to all possible extinction scenarios. It is also the most difficult to employ, however, because of the large number of replicate communities one would have to construct to explore biodiversity loss. Further, the relationship between a specific path of biodiversity loss and ecosystem functioning may be masked by the large number of pathways of loss that come from random-extinction models. Even more disturbing for some is the fact that randomextinction models lead to the construction or modeling of communities that are unlikely to exist in nature. For example, in a random-extinction grassland experiment (e.g. Tilman et al. 1996, Naeem et al. 1999) one constructs communities that completely lack grassesfine for theory, but troublesome for those concerned explicitly with the loss of biodiversity in grasslands. One might take comfort in knowing that somewhere in the hodge-podge of results from a combinatorial BEF experiment lies the pattern of biodiversity loss of interest, but one will also be dismayed by the fact that identifying it in a cloud of data may be impossible.

In reality, biodiversity loss involves local (or global) extinctions that follow trait-based probabilities of loss based on the extinction driver or ecological, evolutionary, or anthropogenic process that governs extinction. How does one incorporate such trait-based extinction drivers into the BioMERGE framework? The framework uses extinction scenarios. 'Extinction scenarios' were used by Sala et al. (2000) in which the authors explored scenarios for how loss would shape biodiversity by the year 2100. They used expert opinion, not data, in which anthropogenic drivers that lead to biodiversity loss were ranked separately for each biome. These extinction drivers included land use, climate change, nitrogen deposition, invasion or biotic exchange, and elevated atmospheric $\mathrm{CO}_{2}$. They explored 3 kinds of scenarios based on these 5 extinction drivers. In the first case, all drivers had additive effects. In the second, the dominant driver governed the change. In the third, the drivers interacted synergistically such that each driver's effect was multiplied by the other. Rather than using expert opinion, however, scenarios in which extinction drivers (e.g. increasing pollution in an estuary) are explicitly associated with trait-based extinction probabilities (e.g. marine invertebrate sensitivity to pollution) provide a more direct way of assess- ing the realm of possible ecosystem responses to biodiversity loss than expert opinion. Below, I review Solan et al. (2004) as an example.

There are many extinction scenarios one could employ. The first study to employ extinction scenarios in an observational BEF study was, again, that of Solan et al. (2004). The authors employed 4 extinction scenarios for their marine system: (1) random, (2) body size (smaller has a higher extinction probability), (3) population size (smaller has a higher extinction probability), and (4) sensitivity to pollution. Zavaleta \& Hulvey (2004), in contrast, employed a single nested extinction scenario (all depauperate communities were taxonomically nested sets of higher diversity communities) without stipulating what extinction driver would produce such a pattern. The defense of using a nested scenario of biodiversity loss is that nestedness is widely observed in nature (Patterson \& Atmar 1986, Atmar \& Patterson 1993). One could additionally use trophic position, home range size, population growth rates, or other traits identified by comparative methods (e.g. Purvis et al. 2003) that allow one to relate diversity loss with extinction drivers.

In summary, an extinction scenario describes the realm of possible biodiversities likely to be obtained based on probabilities of extinction that are governed by species traits and their sensitivities to extinction drivers, or the ecological, evolutionary, or anthropogenic processes that drive units of diversity to extinction.

\section{The BioMERGE framework for scaling up BEF}

The BioMERGE framework for scaling up BEF research (Naeem \& Wright 2003, Naeem et al. in press) is one in which fundamental ecological principles can be employed to provide first approximations of the role of biodiversity in ecosystem functioning. The most extreme version of the BioMERGE approach involves being able to indicate what the biogeochemical or ecosystem consequences of biodiversity loss would be for a region in which the only information one has is a list of the existing taxa and the global positioning system (GPS) coordinate. A more feasible BioMERGE approach involves having, not only the taxa and geography, but the relative growth rates of all species, their relative abundance (e.g. commonness and rarity), the trophic interactions that structure the community, the dynamics of the different populations, and spatial and temporal patterns of both the biota and ecosystem functions and properties. In such a case, however, one hardly needs the BioMERGE framework, since traditional community and ecosystem ecology can be combined to model the relationship between biodiversity and functioning and how changes in community composition change ecosystem functioning. 
Every study will fall somewhere between these 2 extremes - having just a list of taxa and GPS coordinates to having a well-documented study of biodiversity and ecosystem functioning (empirical and observational) over space and time. There will be a tradeoff in the precision with which one can predict the ecosystem consequences of biodiversity loss with the degree of information one employs in the analysis, but the BioMERGE goal is to not be paralyzed by a lack of information that could require far too many resources or far too long to provide answers.

\section{The 3 step BioMERGE framework}

As the above outlines, there are essentially 3 major steps in the BioMERGE framework. The assumption is that one has the biota, basic ecosystem measures, and a specific ecosystem function selected for investigation (Naeem \& Wright 2003, Naeem et al. in press). From there, 3 steps are important:

(1) Diversify the slime. As described above, ecosystem functions are often readily related to biomass; thus, one has to estimate biomass and structure it according to known or observed relationships between a unit of diversity, the amount of biomass in that unit, and the function that converts that biomass to a unit of ecosystem function. For NPP in pelagic marine systems, this requires determining phytoplankton biomass and phytoplankton diversity which can, again, be taxonomic, functional, or some other unit. In coral reef systems, calcium carbonate production and coral diversity may be the function-diversity pair of interest. In an estuary, BMD and infaunal (sediment-dwelling animal) diversity may be the function-diversity pair of interest. In most cases, allometric relationships between body size and metabolic rates or other physiological functions may be used to derive the relationship between unit biomass and ecosystem functioning, a suggestion for BEF research first made by Steinberg \& Geller (1993).

(2) Determine the macroecology. Depending on the unit of diversity, biomass (or densities), patterns of distribution and abundance become important for weighting each unit's contribution to ecosystem functioning. If the diversity unit is species, then one would expect that many species are probably rare and a few domi- nant, as described above. Either way, this necessitates biotic inventories that go beyond taxonomic diversity-they need to include, at a minimum, relative abundance and, ideally, measures of traits relevant to extinction drivers.

(3) Develop extinction scenarios. The BioMERGE approach combines extinction drivers with trait-based extinction probabilities which are referred to as extinction scenarios. Again, we may borrow from Roberts \& Hawkins (1999) whose review of marine extinctions identified natural causes (e.g. disease), biotic exchange, unsustainable harvest, habitat alteration or destruction, and multiple causes as drivers that are associated with known marine extinctions. As in Sala et al. (2000), one has to determine whether the scenario considers single drivers, the additive effects of drivers, or the multiplicative effects of drivers. For marine systems, we can begin with Roberts \& Hawkins (1999) whose list of traits that relate to threats of extinction for marine species can be used in scenarios (Table 1). What marine ecologists need to do is to identify which drivers warrant investigation (e.g. unsustainable harvest, climate change, or pollution), which traits are relevant to which drivers, and to document these traits for the species in the ecosystems being modeled.

After completing these steps, one can plot ecosystem functioning against biodiversity loss for as many communities as one wishes to model, for as many scenarios as one wishes to explore. The results one obtains would look something like that shown in Fig. 2 in which the scenario determines the gradient of biodiversity, the empirically derived formula relating biomass, biodiversity, and function provides the estimate

Table 1. Three classes of traits of marine species that can be used for extinction scenarios in BioMERGE (Biotic Mechanisms of Ecosystem Regulation in the Global Environment) modeling based on expert opinion. Parenthetical classifications describe end of spectrum for possible values that would describe species at greater risk of extinction (adapted from Roberts \& Hawkins 1999)

\begin{tabular}{|c|c|c|}
\hline $\begin{array}{l}\text { Life history or } \\
\text { ecological traits }\end{array}$ & $\begin{array}{l}\text { Capacity for } \\
\text { recovery }\end{array}$ & $\begin{array}{l}\text { Range and } \\
\text { distribution }\end{array}$ \\
\hline $\begin{array}{l}\text { Longevity (short) } \\
\text { Growth rate (slow) } \\
\text { Natural mortality rate (low) } \\
\text { Production biomass (low) } \\
\text { Reproductive effort (low) } \\
\text { Reproductive frequency } \\
\text { (semilparity) } \\
\text { Age or size at sexual maturity } \\
\text { (old or large) } \\
\text { Sex change occurs (occurs) } \\
\text { Spawning (aggregations at } \\
\text { predictable locations and time) } \\
\text { Allee effects on reproduction } \\
\text { (strong) } \\
\text { Trophic level (high) }\end{array}$ & $\begin{array}{l}\text { Regeneration from fragments } \\
\text { (does not occur) } \\
\text { Dispersal (short distance) } \\
\text { Competitive ability (poor) } \\
\text { Colonizing ability (poor) } \\
\text { Adult mobility (low) } \\
\text { Recruitment by larval } \\
\text { settlement (irregular or } \\
\text { low-level) } \\
\text { Allee effects on recovery } \\
\text { (strong) }\end{array}$ & $\begin{array}{l}\text { Horizontal distribution } \\
\text { (nearshore) } \\
\text { Vertical depth range } \\
\text { (narrow) } \\
\text { Geographic range (small) } \\
\text { Patchiness of population } \\
\text { within range (high) } \\
\text { Habitat specificity (high) } \\
\text { Habitat vulnerability to } \\
\text { people (high) } \\
\text { Commonness and/or } \\
\text { rarity (rare) }\end{array}$ \\
\hline
\end{tabular}




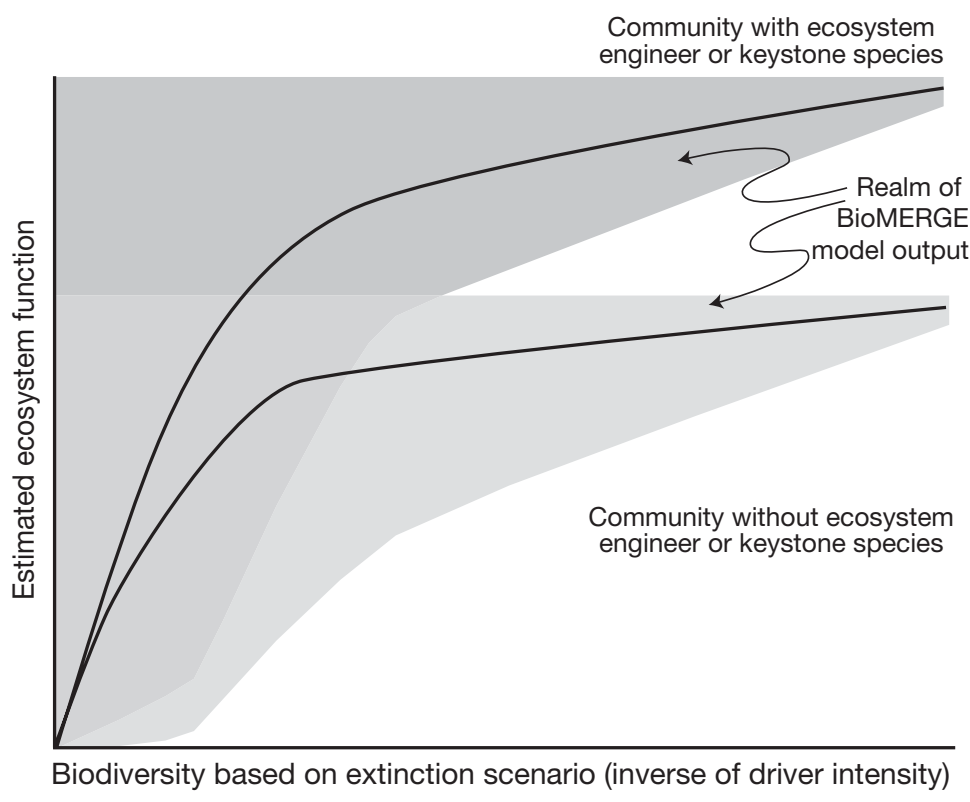

Fig. 2. Example outcomes from a BioMERGE model exploring the ecosystem consequences of biodiversity loss. The $x$-axis describes biodiversity as quantified by the model, which may be species, functional, landscape, or some other measure of biodiversity. The $y$-axis describes a single selected function that is modeled by the BioMERGE framework. The lines represent the central tendencies of the model output. Model output would reflect multiple iterations in which maximum diversity is driven to lower levels by incremental changes in extinction driver intensity. The higher the intensity, the lower the biodiversity; hence, the $x$ axis also represents the inverse of driver intensity. If there are ecosystem engineers or keystone species the presence of which dramatically alters ecosystem functioning, then multiple curves are possible. Here, only 2 possible curves are shown, each surrounded by gray areas indicating the range of possible values. This range may be considered the inverse of biological insurance as larger areas imply greater uncertainty with respect to biodiversity loss

for ecosystem functioning for any simulated community, and the scatter of points around any given level of biodiversity provides an estimate of the variability (instability) or biological insurance (inverse of the spread) associated with a level of biodiversity. As the study of Solan et al. (2004) revealed, it is possible that some species can have such dramatic impacts on ecosystem functioning and that several curves are likely. Such multiple curves would indicate the possible existence of ecosystem engineers, keystone species, or other species with distinct, strong impacts on ecosystems.

In reality, ecosystem functioning is more than just the sum of biomass $\times$ function for each unit of diversity. Biotic interactions (e.g. competition, predation, disease) are incredibly important in governing how populations will fluctuate, which, in turn, determines compensatory growth and system stability (McNaughton 1977, Grover \& Loreau 1996, Yachi \& Loreau 1999, McCann 2000, Hughes et al. 2002, Loreau et al. 2002).
Niche partitioning, redundancy, and complementarity are also very important to separate out selection and complementarity effects (Hooper 1998, Naeem 1998, Duffy et al. 2001, Emmerson et al. 2001, Loreau \& Hector 2001, Pfisterer \& Schmid 2002). But to tackle such dimensions requires obtaining relative growth rates, interaction coefficients (strengths and directions), niche breadth, carrying capacities, and much more-all well-developed fields in ecology, but generally never known to any degree of sufficiency for ecosystems to relate biodiversity to ecosystem function at large scales. The BioMERGE framework motivates the necessary synthesis and unification of many existing ecological disciplines (i.e. population, community, macro-, ecosystem, biogeographical, physiological, and functional ecology) to address BEF issues by observational means. The end result may be fairly complex models of ecosystems, but in the same way that climate modelers have not been dissuaded by the complexity necessary to address global warming in climate models and contend with the uncertainties that surround such approaches (e.g. Murphy et al. 2004), ecologists should not be dissuaded from developing complex models. Meeting the challenge is especially important for marine systems in which biotic changes due to anthropogenic influences are widespread and large scale (e.g. Roemmich \& McGowan 1995, Kleypas et al. 1999, Sanford 1999, Jackson et al. 2001, Baum et al. 2003, Abram et al. 2004, Coleman et al. 2004, Hutchings \& Reynolds 2004, e.g. Richardson \& Schoeman 2004, Duraiappah \& Naeem 2005).

\section{CONCLUSIONS}

Scaling up the findings of ecological research to larger and longer scales has been a challenge to mathematical and experimental ecology since its beginning (e.g. Levin et al. 1997, Gardner et al. 2001), and BEF is no exception (Naeem 2001, Bengtsson et al. 2002). Experimental approaches will always be limited in size, replication, and duration, and theory will always employ simplifying assumptions. Principles learned from such approaches, however, in combination with observational work, can be combined in BioMERGEtype models that will provide insights into the ecosystem consequences of biodiversity loss both in terrestrial (Emmerson et al. 2001, Stachowicz et al. 2002, Solan et al. 2004) and marine systems. 
Given the urgency of many marine conservation and management issues concerning biodiversity (Roberts \& Hawkins 1999), we should not shy away from providing scientific insights to managers and policy makers. The range of options spans using little more than expert opinion (e.g. Sala et al. 2000) to data-rich models (Solan et al. 2004). The more work done in this area, the stronger the case, the more we can identify general principles, and the more precise we can be in our recommendations. One thing that is certain is that if we do nothing, then the options to sustainably manage, protect, or restore degraded marine ecosystems and the services they provide will continue to be dominated by species- or ecosystem-oriented approaches although the proper approach is to integrate both.

Acknowledgements. I thank M. Solan, B. Schmid, S. F. Tjossem, and 2 anonymous reviewers for critically evaluating the manuscript and all members of the BioMERGE network for the development of the framework reviewed in this paper. BioMERGE is supported by NSF DEB 0435178.

\section{LITERATURE CITED}

Abram NJ, Gagan MK, McCulloch MT, Chappell J, Hantoro WS (2004) Coral reef death during the 1997 Indian Ocean Dipole linked to Indonesian wildfires. Science 301: 952-955

Atmar W, Patterson BD (1993) The measure of order and disorder in the distribution of species in fragmented habitat. Oecologia 96:373-382

Balmford A, Bruner A, Cooper P, Costanza R and 15 others (2002) Economic reasons for conserving wild nature. Science 297:950-953

Balmford A, Gravestock P, Hockley N, McClean CJ, Roberts CM (2004) The worldwide costs of marine protected areas. Proc Natl Acad Sci USA 101:9694-9697

Baum JK, Myers RA, Kehler DG, Worm B, Harley SJ, Doherty PA (2003) Collapse and conservation of shark populations in the Northwest Atlantic. Science 299:389-392

Belgrano A, Allen AP, Enquist BJ, Gillooly JF (2002) Allometric scaling of maximum population density: a common rule for marine phytoplankton and terrestrial plants. Ecol Lett 5:611-613

Bengtsson J, Engelhardt K, Giller P, Hobbie S, Lawrence D, Levine JM, Vilà M, Wolters V (2002) Slippin' and slidin' between the scales: the scaling components of biodiversity-ecosystem functioning relations. In: Loreau $M$, Naeem S, Inchausti P (eds) Biodiversity and ecosystem functioning: syntheses and perspectives. Oxford University Press, Oxford, p 209-220

Blackburn TM, Gaston KJ (2003a) Introduction: Why macroecology? In: Blackburn TM, Gaston KJ (eds) Macroecology: concepts and consequences. Blackwell Publishing, Malden, MA, p 1-14

Blackburn TM, Gaston KJ (eds) (2003b) Macroecology: concepts and consequences. Blackwell Publishing, Malden, MA

Browman HI, Stergiou KI (2004) Marine Protected Areas as a central element of ecosystem-based management: defining their location, size and number. Mar Ecol Prog Ser 274: 271-272
Brown JH (1995) Macroecology. University of Chicago Press, Chicago, IL

Callaway JC, Sullivan G, Zedler JB (2003) Species-rich plantings increase biomass and nitrogen accumulation in a wetland restoration experiment. Ecol Appl 13:1626-1639

Coleman FC, Figueira WF, Ueland JS, Crowder LB (2004) The impact of United States recreational fisheries on marine fish populations. Science 305:1958-1960

Covich AP, Austen MC, Barlocher F, Chauvet E and 8 others (2004) The role of biodiversity in the functioning of freshwater and marine benthic ecosystems. BioScience 54: $767-775$

Díaz S, Cabido M (2001) Vive la différence: plant functional diversity matters to ecosystem processes. Trends Ecol Evol 16:646-655

Duffy JE, McDonald SK, Rhode JM, Parker JD (2001) Grazer diversity, functional redundancy, and productivity in seagress beds: an experimental test. Ecology 82:2417-2434

Duraiappah AK, Naeem S (2005) Ecosystems and human well-being: biodiversity synthesis. World Resources Institute, Washington, DC

Emmerson MC, Huxhan M (2002) How can marine ecology contribute to the biodiversity-ecosystem functioning debate? In: Loreau M, Naeem S, Inchausti P (eds) Biodiversity and ecosystem functioning: syntheses and perspectives.Oxford University Press, Oxford, p 139-146

Emmerson MC, Raffaelli DG (2000) Detecting the effects of diversity on measures of ecosystem functioning: experimental design, null models and empirical observations. Oikos 91:195-203

Emmerson MC, Solan M, Emes C, Paterson DM, Raffaelli DG (2001) Consistent patterns and the idiosyncratic effects of biodiversity in marine ecosystems. Nature 411:73-77

Ernst WG (2000) The Earth's place in the solar system. In: Ernst WG (ed) Earth systems: processes and issues. Cambridge University Press, Cambridge, p 45-58

Erwin TL (1982) Tropical forests: their richness in Coleoptera and other arthropod species. Coleopterists Bull 36:74-75

Falkowski PG, Rosenthal Y (2001) Biological diversity and resource plunder in the geological record: Casual correlations or causal relationships? Proc Natl Acad Sci USA 98: 4290-4292

Fenchel T (1987) Ecology of protozoa. Springer-Verlag, Berlin

Fenchel T, King GM, Blackburn TH (1998) Bacterial biogeochemistry: the ecophysiology of mineral cycling. Academic Press, San Diego, CA

Foggo A, Frost MT, Attrill MJ (2003) Abundance-occupancy patterns in British estuarine macroinvertebrates. Mar Ecol Prog Ser 265:297-302

Gardner RH, Kemp M, Kennedy VS, Petersen JE (eds) (2001) Scaling relations in experimental ecology. Columbia University Press, New York

Gaston K (2000) Global patterns in biodiversity. Nature 405: 220-227

Grassle JF, Maciolek NJ (1992) Deep-sea species richness: regional and local diversity estimates from quantitative bottom samples. Am Nat 139:313-341

Groombridge B, Jenkins MD (2000) Global biodiversity: Earth's living resources in the 21st century. World Conservation Press, Cambridge

Grover JP, Loreau M (1996) Linking communities and ecosystems: trophic interactions as nutrient cycling pathways. In: Hochberg ME, Clobert J, Barbault R (eds) Aspects of the genesis and maintenance of biological diversity. Oxford University Press, Oxford, p 180-193

Hollowell VC (ed) (2001) Managing human dominated ecosystems. Missouri Botanical Garden Press, St. Louis, MO 
Hooper DU (1998) The role of complementarity and competition in ecosystem responses to variation in plant diversity. Ecology 79:704-719

Hooper DU, Ewel JJ, Hector A, Inchausti P and 10 others (2005) Effects of biodiversity on ecosystem functioning: a consensus of current knowledge and needs for future research. Ecol Appl 75:3-35

Hubbell SP (2001) The unified neutral theory of biodiversity and biogeography. Princeton University Press, Princeton, NJ

Hubbell SP, Lake JK (2003) The neutral theory of biodiversity and biogeography, and beyond. In: Blackburn TM, Gaston KJ (eds) Macroecology: concepts and consequences. Blackwell Publishing, Malden, MA, p 45-63

Hughes JB, Ives AR, Norberg J (2002) Do species interactions buffer environmental variation (in theory)? In: Loreau M, Naeem S, Inchausti P (eds) Biodiversity and ecosystem functioning: synthesis and perspectives. Oxford University Press, Oxford, p 92-101

Hutchings JA, Reynolds JD (2004) Marine fish population collapses: consequences for recovery and extinction risk. BioScience 54:297-309

Irigoien X, Huisman J, Harris RP (2004) Global biodiversity patterns of marine phytoplankton and zooplankton. Nature 429:863-867

Jackson JBC, Kirby MX, Bergre WH, Bjorndal KA and 15 others (2001) Historical overfishing and the recent collapse of coastal ecosystems. Science 293:629-638

Kasting JF, Siefert JL (2002) Life and the evolution of Earth's atmosphere. Science 296:1066-1067

Kleypas JA, Buddemeier RW, Archer D, Gattuso JP, Langdon C, Opdyke BN (1999) Geochemical consequences of increased atmospheric carbon dioxide on coral reefs. Science 284:118-120

Lavorel S, Garnier E (2002) Predicting changes in community composition and ecosystem functioning from plant traits: revisiting the Holy Grail. Funct Ecol 16:545-556

Levin SA, Grenfell B, Hastings A, Perelson AS (1997) Mathematical and computational challenges in population biology and ecosystem science. Science 275:334-343

Li WKW (2002) Macroecological patterns of phytoplankton in the northwestern North Atlantic Ocean. Nature 419: $154-157$

Loreau M, Hector A (2001) Partitioning selection and complementarity in biodiversity experiments. Nature 412:72-76

Loreau M, Naeem S, Inchausti P, Bengtsson J and 8 others (2001) Biodiversity and ecosystem functioning: current knowledge and future challenges. Science 294:806-808

Loreau M, Downing AL, Emmerson MC, Gonzalez A and 5 others (2002) A new look at the relationship between diversity and stability. In: Loreau M, Naeem S, Inchausti P (eds) Biodiversity and ecosystem functioning: synthesis and perspectives. Oxford University Press, Oxford, p 79-91

Lovelock J (1979) Gaia. Oxford University Press, Oxford

Mathez EA, Webster JD (2004) Life and conditions on early Earth. Columbia University Press, New York, p 37-48

McCann KS (2000) The diversity-stability debate. Nature 405:228-233

McKinney M (1998) On predicting biotic homogenization: species-area patterns in marine biota. Global Ecol Biogeogr Lett 7:297-301

McNaughton SJ (1977) Diversity and stability of ecological communities: a comment on the role of empiricism in ecology. Am Nat 111:515-525

Millennium Ecosystem Assessment (2003) Ecosystems and human well-being. Island Press, Washington, DC

Mittelbach GG, Scheiner SM, Steiner CF (2003) What is the observed relationship between species richness and productivity? Reply. Ecology 84:3390-3395

Murphy JM, Sexton DMH, Barnett DN, Jones GS, Webb MJ, Collins M, Stainforth DA (2004) Quantification of modelling uncertainties in a large ensemble of climate change simulations. Nature 430:768-772

Myers N, Mittermeier RA, Mittermeier CG, De Fonesca GAB, Kent J (2000) Biodiversity hotspots for conservation priorities. Nature 403:853-858

Myers RA, Worm B (2003) Rapid worldwide depletion of predatory fish communities. Nature 423:280-283

Naeem S (1998) Species redundancy and ecosystem reliability. Conserv Biol 12:39-45

Naeem S (2001) Experimental validity and ecological scale as tools for evaluating research programs. In: Gardner RH, Kemp WM, Kennedy VS, Petersen JE (eds) Scaling relationships in experimental ecology. Columbia University Press, New York, p 223-250

Naeem S (2002a) Disentangling the impacts of diversity on ecosystem functioning in combinatorial experiments. Ecology 83:2925-2935

Naeem S (2002b) Functioning of biodiversity. In: Munn T (ed) The encyclopedia of global environmental change, Vol 2. John Wiley \& Sons, Chichester, p 20-36

Naeem S, Wright JP (2003) Disentangling biodiversity effects on ecosystem functioning: deriving solutions to a seemingly insurmountable problem. Ecol Lett 6:567-579

Naeem S, Byers D, Tjossem SF, Bristow C, Li S (1999) Plant neighborhood diversity and production. Ecoscience 6: 355-365

Naeem S, Chapin FSI, Costanza R, Ehrlich P and 8 others (2000) Biodiversity and ecosystem functioning. Report No. 4, Ecological Society of America, Washington, DC

Naeem S, Colwell R, Dias S, Hughes J and 6 others (in press) Predicting the ecosystem consequences of biodiversity loss at the lanscape level. Island Press, Washington, DC

Naylor RL, Goldburg RJ, Mooney H, Bevridge M and 6 others (1998) Nature's subsidies to shrimp and salmon farming. Science 282:883-884

Nee S (2003) The unified neutral phenomenological theory of biodiversity. In: Blackburn TM, Gaston KJ (eds) Macroecology: concepts and consequences. Blackwell Publishing, Malden, MA, p 31-42

Nee S (2004) More than meets the eye. Nature 429:804-805

Pace NR (1997) A molecular view of microbial diversity and the biosphere. Science 276:734-740

Patterson BD, Atmar W (1986) Nested sub-sets and the structure of insular mammalian faunas and archipelagos. Biol J Linn Soc 28:65-82

Petchey OL, Gaston K (2002) Functional diversity (FD), species richness and community composition. Ecol Lett 5: 402-411

Pfisterer AB, Schmid B (2002) Diversity-dependent productivity can decrease the stability of ecosystem functioning. Nature 416:85-86

Preston FW (1962) The canonical distribution of commonness and rarity. Ecology 43:185-215 \& 410-432

Purvis A, Gittleman JL, Cowlishaw G, Mace GM (2000) Predicting extinction risk in declining species. Proc $\mathrm{R}$ Soc Lond B 267:1947-1952

Purvis A, Orme CDL, Dolphin K (2003) Why are most species small-bodied? A phylogenetic view. In: Blackburn TM, Gaston KJ (eds) Macroecology: concepts and consequences. Blackwell Publishing, Malden, MA, p 155-173

Reekie EG, Bazzaz FA (1987a) Reproductive effort in plants. 1. Carbon allocation to reproduction. Am Nat 129:876-896 Reekie EG, Bazzaz FA (1987b) Reproductive effort in plants. 
2. Does carbon reflect the allocation of other resources? Am Nat 129:897-906

Reekie EG, Bazzaz FA (1987c) Reproductive effort in plants. 3. Effect of reproduction on vegetative activity. Am Nat 129:907-919

Richardson AJ, Schoeman DS (2004) Climate impact on plankton ecosystems in the Northeast Atlantic. Science 305:1609-1612

Roberts CM, Hawkins JP (1999) Extinction risk in the sea. Trends Ecol Evol 14:241-246

Rodrigues ASL, Andelman SJ, Bakarr MI, Boitani L and 17 others (2004) Effectiveness of the global protected area network in representing species diversity. Nature 428: 640-643

Roemmich D, McGowan J (1995) Climatic warming and the decline of zooplankton in the California Current. Science 267:1324-1326

Rothman DH (2001) Global biodiversity and the ancient carbon cycle. Proc Natl Acad Sci USA 98:4305-4310

Sala OE, Stuart SF III, Armesto JJ, Berlow E and 15 others (2000) Biodiversity: global biodiversity scenarios for the year 2100. Science 287:1770-1774

Sanford E (1999) Regulation of keystone predation by small changes in ocean temperature. Science 283:2095-2097

Schlapfer F, Pfisterer AB, Schmid B (2005) Non-random species extinction and plant production: implications for ecosystem functioning. J Appl Ecol 42:13-24

Schlesinger WH (1997a) Introduction. In: Biogeochemistry, 2nd edn. Academic Press, San Diego, CA, p 3-14

Schlesinger WH (1997b) Biogeochemistry, 2nd edn. Academic Press, San Diego, CA

Schulze ED, Mooney HA (eds) (1993) Biodiversity and ecosystem function. Springer-Verlag, New York

Smil V (2002) The Earth's biosphere: evolution, dynamics, and change. MIT Press, Cambridge, MA

Solan M, Cardinale BJ, Downing AL, Engelhardt KAM, Ruesink JL, Srivastava DS (2004) Extinction and ecosystem function

Editorial responsibility: Martin Solan (Guest Editor), Newburgh, UK in the marine benthos. Science 306:1177-1180

Stachowicz JJ, Fried H, Osman RW, Whitllatch RB (2002) Biodiversity, invasion resistance, and marine ecosystem function. Reconciling pattern and process. Ecology 83: $2575-2590$

Statzner B, Moss B (2004) Linking ecological function, biodiversity and habitat: a mini-review focusing on older ecological literature. Basic Appl Ecol 5:97-106

Steinberg CEW, Geller W (1993) Biodiversity and interactions within pelagic nutrient cycling and productivity. In: Schulze ED (ed) Biodiversity and ecosystem function. Springer-Verlag, Berlin, p 43-64

Sugihara G (1980) Minimal community structure: an explanation of species abundance patterns. Am Nat 116:770-787

Tiedje JM (1995) Approaches to the comprehensive evaluation of prokaryote diversity of a habitat. In: Allsopp D, Colwell RR, Hawksworth DL (eds) Microbial diversity and ecosystem function. CAB International, Wallingford, p 73-87

Tilman D, Wedin D, Knops J (1996) Productivity and sustainability influenced by biodiversity in grassland ecosystems. Nature 379:718-720

Torsvik V, Øvreås L, Thingstad TF (2002) Prokaryotic diversity-magnitude, dynamics, and controlling factors. Science 296:1064-1066

Venter JC, Remington K, Heidelberg JF, Halpern AL and 19 others (2004) Environmental genome shotgun sequencing of the Sargasso Sea. Science 304:66-74

Vitousek PM, Mooney HA, Lubchenco J, Melillo JM (1997) Human domination of Earth's ecosystems. Science 277: 494-499

Yachi S, Loreau M (1999) Biodiversity and ecosystem functioning in a fluctuating environment: the insurance hypothesis. Proc Natl Acad Sci 96:1463-1468

Zavaleta ES, Hulvey KB (2004) Realistic species losses disproportionately reduce grassland resistance to biological invaders. Science 306:1175-1177

Submitted: December 20, 2004; Accepted: October 21, 2005

Proofs received from author(s): March 7, 2006 



\title{
Biodiversity and ecosystem functioning: issues of scale and trophic complexity
}

\author{
David G. Raffaelli* \\ Environment Department, University of York, Heslington, York YO10 5DD, UK
}

\begin{abstract}
Research on the relationship between biodiversity and ecosystem functioning is entering a new phase. The main driver behind this is an awareness that biodiversity loss operates at large spatial scales and generally involves reductions and changes in species at different trophic levels simultaneously. Evaluating how ecosystem processes are likely to change following species loss at multiple trophic levels will be difficult because of the feedbacks between levels and between levels and the ecosystem processes of interest. Similarly, carrying out manipulative experiments designed to accommodate multiple trophic levels at the landscape scales in which society is interested will be extremely challenging. Novel approaches, such as the BioMERGE (Biotic Mechanisms of Ecosystem Regulation in the Global Environment) initiative, are needed. In addition, future work should be more services-oriented, rather than process-oriented, if effects of biodiversity change on services are to be properly assessed. Finally, the application of mainstream ecosystem ecology to biodiversity-ecosystem functioning research seems to have been neglected to date. In this respect, there is potential for the mass-balance approach to contribute to the debate.
\end{abstract}

KEY WORDS: Food webs $\cdot$ Ecosystem services $\cdot$ Spatial scale $\cdot$ Species loss scenarios Resale or republication not permitted without written consent of the publisher

\section{INTRODUCTION}

The search for a relationship between biodiversity and ecosystem processes that underpin ecological services has led to an emerging paradigm (Naeem 2002), dominated by terrestrial ecologists to date. Whilst there were a few publications which explored this topic in the 1970s and 1980s, the bulk of published material comes from the 1990s, with an almost exponential increase to date, but relatively few papers that are marine oriented. Initially, this lack of engagement is surprising given the global importance of the marine environment $197 \%$ of the available living volume for biodiversity on the planet, $75 \%$ of the planet's surface area), the acknowledged importance of the oceans for the regulation of global geochemical cycles and the delivery by the oceans of goods and services to the world's population, the majority of which live along coastlines (Roberts \& Hawkins 1999). The reasons lie, in part, in the differences between the ways in which marine and terrestrial ecologists approach their science and in the cultural barriers between the 2 groups that have developed over the past 30 yr: the 2 groups read different journals, attend different meetings and speak different 'languages' (Raffaelli 2000a, 2005). It could be argued that there is as great a need for exchange between the different sub-disciplines of ecology as between the different disciplines of, say, ecology and economics.

Such barriers have certainly slowed the communication of novel approaches and perspectives concerning the relationships between biodiversity and ecosystem functioning from mainstream ecology to marine science. But the converse is also true: mainstream ecology has long neglected the exciting developments and opportunities provided by marine science. With respect to biodiversity and ecosystem functioning, one of the main issues under discussion has become which variable is dependent and which is independent. In other words, the degree to which biodiversity is shaped by, or shapes, ecosystem processes. There has been a shift in mainstream ecology in recent years such that the role of species composition in determining both qualitative and quantitative aspects of ecosystem processes is now clearly recognised (Naeem 2002). However, many 
marine ecologists are still adjusting to this perspective, and, thus, a widespread misperception remains that marine ecology has already addressed most aspects of biodiversity-ecosystem functioning (see for instance correspondence in Science, March 2005). This does not mean that earlier work in this area cannot be usefully re-focused to specifically address the presently emerging biodiversity-ecosystem paradigm (Naeem 2002). For instance, Emmerson \& Huxham (2002) have illustrated the potential of re-analysing data sets from earlier research programmes for generating novel insights at much larger spatial and temporal scales than is generally available from small-scale experimental studies. Indeed, marine ecologists are well accustomed to tackling issues of complexity and scale with which terrestrial ecologists are only now being confronted.

Here, I argue that the marine ecological community can build on the terrestrial-based studies that have been carried out to date (see also Bulling et al. 2006, in this Theme Section), draw on the rich history of established research in this general area and develop alternative approaches that may be more appropriate to the complexity and large-scale challenges of marine systems. First, I deal with issues of spatial and temporal scale, with respect to the utility of field experiments. This is followed by an exploration of the need to acknowledge the multi-trophic nature of real systemsthe differential losses of biodiversity at different trophic levels and how this varies with loss scenarios - and the complexity of the habitat networks operating within the essentially open nature of the marine system. I then discuss the difficult issues involved in linking biodiversity change to changes in the provision of goods and services in coastal systems, and, finally, I argue that an ecosystem-level approach is required for addressing what is essentially an ecosystem-level question.

\section{ISSUES OF SCALE}

A dominant feature of much research on biodiversity and ecosystem functioning is the use of manipulative field experiments (Bulling et al. 2006). Such experiments generate outcomes that are highly persuasive, because of the statistical rigour and power with which the data can be analysed. Research that involves experimental falsification of hypotheses is generally more persuasive than modelling studies, observations, logical argument and anecdote (Lawton 1996). Moreover, such research is much more likely to be published. However, there is always a trade-off to be made between spatial and temporal scales and the degree of replication of experimental and control plots (Raffaelli \& Moller 2000). This inevitably means that large-plot experiments tend to have relatively few replicates, and, in many cases, there are no replication or control plots at all (Raffaelli \& Moller 2000). Many of the earlier generation of biodiversity-ecosystem function experiments had a high degree of replication, but small plot sizes (Bulling et al. 2006); in the new generation of terrestrial studies, experiments are not as constrained (e.g. Schilthuizen 2003, Scherer-Lorenzen et al. 2004).

What then is the appropriate plot size for biodiversity-ecosystem functioning experiments? Not surprisingly, many experimentalists take a purely pragmatic approach to this question. Thus, in an interview survey of ecologists who have carried out predator-prey manipulation experiments at the largest plot sizes (hectares or square kilometres), the stated reasons for choosing a particular size included the following: this was the maximum plot size that could be handled by the researcher, that was all the space available for the work, and this was the minimum area required to ensure that the response variable was informative (Raffaelli \& Moller 2000). Of all the responses, only the last was not purely pragmatic, but based instead on the attributes of the system and experiment, in other words, the aspects that should drive experiments in biodiversity-ecosystem functioning. It is important to define a priori the response variable of interest and its characteristic scale of heterogeneity. However, it is tempting to measure many different kinds of response variables from the same plots for the sake of economy, but this could result in a mismatch of scale if the manipulation (e.g. number of species) is maintained at square metre scales and response variables are measured at much smaller scales. For instance, many response variables measured in marine (and terrestrial) experiments can now be measured at micro-scales, such as oxygen concentration or redox potential in intact cores of benthic material (see papers in Solan et al. 2003). Whilst technically impressive, there is clearly a mismatch between the scale at which the response or dependent variable is measured (microns to millimetres) and the scale at which the independent variable (macrofaunal biodiversity) operates (100s to $1000 \mathrm{~s} \mathrm{~cm}^{2}$ or even many square metres). A central question is whether the bulk (entire plot) estimate of oxygen concentration is likely to be different from that estimated by replicate micro-measurements. Until the effects of measurement of such variables at different scales can be properly compared, it will be difficult to design and interpret experiments with complete confidence. In addition, there is often some confusion about plot size and scale in the design of manipulative experiments (Raffaelli \& Moller 2000). Large plot sizes will only be large scale relative to the life space of the species (or system) of interest. For instance, a $1 \mathrm{~m}^{2}$ plot that represents the home range of a rocky shore limpet may be 
equivalent to a $10000 \mathrm{~km}^{2}$ plot for a polar bear. Few experiments really explore the effects of increasing scale per se, and those that do (e.g. Thrush et al. 1996, 1997) indicate that outcomes are often scale dependent.

Reasons for deciding on a particular duration of a field experiment have, like plot size, been mostly based on pragmatic considerations (Raffaelli \& Moller 2000), including the need to accommodate the work within the time available in a research studentship or grant and the difficulties of maintaining the experimental set-up in a hostile physical environment. This latter point is extremely relevant to work in marine systems where ecologists are often faced with severe practical difficulties in carrying out their experiments. A few respondents to the survey of Raffaelli \& Moller (2000) estimated the required duration of the experiment based on the dynamics of the response variables (prey species generation times). There are few 'rules' available for making such decisions a priori. A ruleof-thumb similar to that proposed for food-web experiments by the late Peter Yodzis (Yodzis 1988) needs, urgently, to be developed for work on biodiversity-ecosystem functioning. Based on experience from other kinds of experiments, it is likely that the outcome of any experiment will be scale dependent and that short-term responses will be qualitatively and quantitatively different from longer-term responses (Raffaelli \& Moller 2000).

Carrying out experiments on biodiversity-ecosystem functioning at the spatial and temporal scales appropriate to those questions in which society is interested will inevitably involve large plot sizes and reduced replication, perhaps no replication at all, as well as long time scales. But should lack of replication deter an experimental approach? Assuming grant-awarding agencies are satisfied by the arguments, it should be possible to present a case as persuasive as that presented by highly replicated experiments. The persuasive power of large-scale experiments will lie not in the number of degrees of freedom available, but in whether the magnitude of the response to the manipulation (the effect size) is large. In contrast, quite small effect sizes (a few percent difference between controls and treatment) will be statistically significant if sufficient replicates are used, but such effects may be trivial as far as society is concerned. This point is well made by experiments in marine intertidal systems on the role of starfish as keystone predators (Paine 1974) and of the limpet Patella as a grazer on rocky shores (Lodge 1948, Jones 1948, reviewed in Hawkins \& Hartnol 1983). These experiments were large scale, poorly or un-replicated, and 2 of them lacked control plots altogether. The persuasive power of these experiments lay in the magnitude of the observed effect (extremely large and impressive), and, just as importantly per- haps, its direction; the response observed was entirely at odds with the accepted view of how those systems were normally structured (for a more detailed treatment see Raffaelli \& Moller 2000)). The downside of performing large-scale, unreplicated experiments is that if the effect size is small, say on the order of $10 \%$, then the scientific world will remain unconvinced. The approach is not for the faint hearted.

\section{ISSUES OF COMPLEXITY}

The majority of manipulative experiments designed to address the relation between biodiversity and ecosystem functioning have focused largely on a single trophic level or taxonomic grouping within a much larger food web (Raffaelli et al. 2002, Bulling et al. 2006), for example, the early experiments by Tilman (1997) at Cedar Creek on grassland plants, the Biodepth experiments made across Europe (Hector et al. 1999) and the experiments carried out on marine benthic systems by our own group (Emmerson et al. 2001, Raffaelli et al. 2003). In studies where the effects of, and on, trophic levels other than those directly manipulated have been investigated, these investigations have tended to be supplementary experiments rather than something which was explicitly accommodated for within the main design (Raffaelli et al. 2002).

Whilst the work with single trophic levels has advanced the biodiversity-ecosystem functioning debate significantly, particularly for improving the understanding of mechanisms and the development of models, the single trophic level approach has a number of limitations. One of the motivations for exploring the relation between biodiversity and ecosystem function has been to predict the consequences of species loss from ecological systems. However, the majority of single trophic level approaches have not addressed the effects of species loss per se (communities are artificially assembled, not dissembled), or the ways in which biodiversity loss at several trophic levels affects functioning either through simultaneous loss of species or through subsequent cascading effects. In addition, different causes of biodiversity loss are expected to affect different trophic levels in very different ways. This is not by any means a rejection of single-level experiments; such designs will remain important for exploring biodiversity effects and identifying mechanisms. However, they need to be complemented by other approaches, with a focus on larger scales and the effects of biodiversity loss per se.

Carrying out whole food web experiments at large scales is probably neither feasible nor ethical, and alternative approaches need to be identified for which marine ecologists are well equipped. Re-analysis of 
earlier large-scale studies involving many species, but which were not framed within the biodiversityecosystem functioning paradigm (e.g. Emmerson \& Huxham 2002), is potentially a cost-effective way to explore, confirm, or refute novel hypotheses and to formulate new ones, which could then be tested experimentally, perhaps in small-scale systems. However, data-mining approaches are not without their problems, and one needs to proceed with caution. For instance, in much of the historical literature, the assumption has been that biodiversity is the dependent variable which responds to changes in ecosystem processes (the independent variable). Although a case can be made for the converse using the same data (Emmerson \& Huxham 2002), those data were never collected with this particular form of the relationship in mind. It will always be difficult to tease out the cause-effect relationships in such data, and the possibility of confounding effects is high. Nevertheless, it makes sense to use this wealth of literature on marine (and terrestrial) systems to, at least, establish whether the data are consistent with current theory, before embarking on novel and expensive experimental research programmes.

A different approach to the use of existing biodiversity and ecosystem process data is provided by the recent BioMERGE (Biotic Mechanisms of Ecosystem Regulation in the Global Environment) initiative on the functioning of benthic communities under a variety of realistic loss scenarios (Solan et al. 2004, Naeem 2006, in this Theme Section). Here, a specific ecosystem process, the depth of biological perturbation (biological mixing depth, BMD) of the upper sediment layers, a proxy for the fluxes of major nutrients, can be estimated from empirical knowledge of a few of the biological traits (e.g. size, mobility) of the species present. Different species-loss scenarios (over-fishing, enrichment, habitat destruction) were applied by Solan et al. to assemblages so that species were lost from those assemblages according to their sensitivities to each scenario (see also below). Using this approach, Solan et al. (2004) were able to show that the effects of biodiversity loss on the functioning of ecosystems will depend largely on the order in which species are lost, in turn, determined by their susceptibilities to different types of impact. Such approaches have a high potential for successfully exploring the consequences of biodiversity loss at large spatial and long temporal scales using the extensive datasets already available for many marine areas.

The assemblages analysed by Solan et al. (2004) also comprised many different trophic types, an advance in com- parison to single trophic level experiments. Even so, these assemblages do not reflect the larger food web including fish and other consumers, although there is no reason why the approach could not be extended to include higher trophic levels if such data were available. One of the challenges in this respect will be to develop ways of accommodating the different spatial and temporal scales over which different trophic levels operate. Larger-bodied taxa at higher trophic levels usually have greater longevity, longer generation times and range over a larger area than those at lower trophic levels, which are typically recorded at scales smaller than square metres.

Taking a multi-trophic approach to biodiversityecosystem functioning research really does matter. There are likely to be significant feedbacks between the trophic level manipulated and the higher and lower trophic levels, as well as with the response process of interest (Fig. 1). If these feedbacks are not recognised and accounted for, the outcomes of single trophic level experiments will be of limited value for policy makers interested in the impacts of biodiversity loss (Raffaelli et al. 2002). For instance, our own benthic biodiversity experiments demonstrate that the greater the biodiversity of macroinvertebrates within the sediment, the more ammonium is released from the sediment due their bioturbation activities (Emmerson et al. 2001, Raffaelli et al. 2003). It is also known that benthic macroalgae (Enteromorpha intestinalis, Chaetomorpha linzii and Ulva lactuca) in this particular system can use ammonium as a source of nitrogen (Taylor \& Raven 2003), so that algal growth will be stimulated by a higher macrofaunal species richness within the sediment; this has now been demonstrated experimentally in a series of mesocosm experiments (M. Solan et al. unpubl. data). Enhanced growth of benthic macroalgae, in turn, depresses macrofaunal biodiversity and changes the redox chemistry within



Fig. 1. Interactions and feedbacks between macrofaunal species richness (manipulated variable), nutrient release (ecosystem function response variable) and other trophic levels. Based on known relationships within the Ythan estuary food web, Aberdeenshire, Scotland 
the sediment (Raffaelli 2000b), as well as presenting a barrier to the selective feeding of higher trophic levels, especially fish and shorebirds (Raffaelli et al. 1998), and these species may then leave the location altogether (Raffaelli et al. 1999) (Fig. 1). The feedbacks on macrofaunal diversity will, in turn, alter ammonium release, so that the net effects of macrofaunal species richness on ecosystem functioning will be much more complex than is revealed in single trophic level experiments.

A further reason for adopting a multi-trophic perspective is the need to recognise that impacts which lead to biodiversity loss usually occur across all trophic levels and that, as Solan et al. (2004) have shown, taxa will differ in their sensitivities to particular loss scenarios (Fig. 2). Thus, top predators in marine systems tend to have a large body size, low abundance and greater longevity than species lower in the food web. Largebodied taxa are particularly vulnerable to habitat fragmentation/destruction, but may be less susceptible to contaminant stress, which hits smaller species disproportionately hard. In contrast, there are usually more species at lower trophic levels, resulting in greater functional redundancy and more insurance against the effects of biodiversity loss. These species also have higher generation rates and, thus, a greater capacity for adaptive change. Biodiversity loss is, therefore, likely to be distinctly non-random and dependent on


Fig. 2. Variation in traits, species richness and vulnerability to extinction in a model food web

the loss scenario. There is empirical evidence for the distribution of the traits shown in Fig. 2 (Petchey et al. 2004) in freshwater food webs, and an example is provided in Fig. 3 for an estuarine food web.



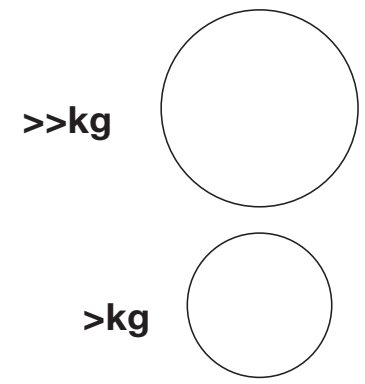

kg<smiles>C1=CCCCCCC1</smiles>

9<smiles>c1ccccc1</smiles>

mg

Fig. 3. Variation in body size (circles) and species richness (numbers) with trophic position in the Ythan estuary food web. From Hall \& Raffaelli (1991) and Leaper \& Raffaelli (1999) 
Future research aiming to mimic realistic extinction scenarios needs to recognise that ecological systems are often subjected simultaneously or sequentially to a board range of stressors. For example, key estuarine stressors include habitat loss and alteration, eutrophication, sewage, fisheries overexploitation, altered freshwater flows, invasive species and sea level rise (Kennish 2002). For many estuaries, these stressors act simultaneously, and their combined effects are not easy to predict: stressors can act synergistically, antagonistically, or additively, depending on the system and stressor. Thus, low oxygen and high contaminant loads may be insufficient to cause biodiversity change on their own, but, in combination, the effects may be overwhelming. Also, different stressors may act on different life-stages of commercially or ecologically important marine species, depending on their body size and, hence, sensitivities. A combination of commercial exploitation of fish and shellfish targeted at adults and habitat destruction of spawning grounds might be expected to have a greater impact than either stressor alone. In other words, impacts regarded as less acute, or even benign, may become significant when they operate in combination. Incorporating such considerations into approaches to biodiversity-ecosystem function research will be a major but necessary challenge.

A neglected area of ecological complexity that is highly pertinent to biodiversity-ecosystem functioning research is the level at which biodiversity is considered. Much of the recent work in this field focuses on species as the basic datum, with an increasing recognition that functional groupings of species may be more relevant than species per se. However, the term 'biodiversity' can mean all things to all people, and the working concept used by many policy makers is just as likely to be an even higher level property such as landscape units or communities, as defined by the Convention on Biological Diversity (CBD 2004). In a thoughtful essay, Hawkins (2004) points out that, unlike the terrestrial environment, marine coastal systems are much more open, with connections between major habitat patches driven by water movement at a variety of scales: upwelling, currents and waves. For example, kelp forests are amongst the most productive habitat units on Earth, but most of the production can be exported to other habitat units, such as sandy beaches (Raffaelli \& Hawkins 1996). He argues that in the case of such complex, open systems the highly reductionist experimental approach that focuses on species within a habitat type is inappropriate. A more holistic approach is required, combining in situ estimates of ecosystem processes with modelling of the connectivity between habitat units (see also Giller et al. 2004).

\section{LINKING BIODIVERSITY TO ECOSYSTEM SERVICES}

Whilst the measurement of ecosystem processes under different levels of biodiversity is relatively straightforward, extending the linkages to ecosystem goods and services has been more difficult for a number of reasons. First, many of the services which ecosystems provide to society are underpinned by several, often many, ecosystem processes making direct mapping of biodiversity loss onto changes in the provision of services difficult (Fig. 4). A second issue is that the further the process or service from the biodiversity itself, the weaker the relationship will be, generating uncertainties in management and policy decisions. For instance, there is an intimate linkage between plant species richness and primary production, so that the effects of biodiversity change on this process are direct and strong. In other words, there is likely to be a large effect size in such experiments. In contrast, there will be several steps (sediment disturbance, changes in the sediment microbial assemblages and their activities) involved between changes in benthic invertebrate species richness and primary production by phytoplankton in the overlying water column, and the effects observed are expected to be weaker. Additional linkages to ecosystem services may also reduce the magnitude of a biodiversity effect, since many different processes will be involved, some direct, some indirect (Fig. 4). As Hawkins (2004) has argued (see above), this is likely to be particularly true for open marine systems. Thirdly, different biodiversity loss scenarios will affect processes and services in quite different ways depending on the identity or function of the species most affected (Fig. 2), so that it may be difficult to establish general rules linking biodiversity changes to ecosystem service delivery.

Given these issues, especially the multi-process underpinning of services, perhaps ecologists should not be attempting to link effects from biodiversity to

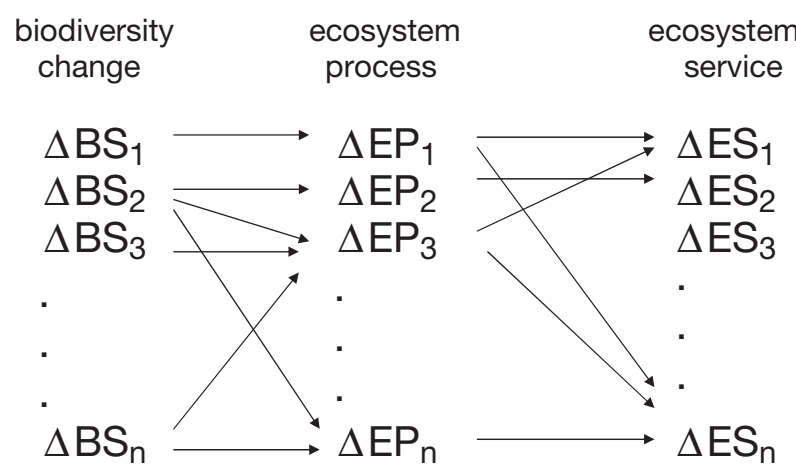

Fig. 4. Possible links between changes in biodiversity $(\Delta \mathrm{BS})$, ecosystem processes $(\Delta \mathrm{EP})$ and services $(\Delta \mathrm{ES})$ 
processes and then on to services, but start from the service itself. First, identify the service of interest (e.g. coastal protection, detoxification, or spiritual enhancement), then identify the key processes affecting delivery of that service, and then design research programmes that explore the effects of changes in the relevant biodiversity on those processes (Table 1). The service-orientated approach has the advantage that the importance of changes in relevant biodiversity can be assessed much less ambiguously, and, hence, more persuasively to policy makers, than is presently the case. Kremer (2005) provides some thoughtful insights into some general issues related to establishing linkages between biodiversity and services.

\section{PUTTING THE ECOSYSTEM INTO BIODIVERSITY-ECOSYSTEM FUNCTIONING RESEARCH}

I have argued that the marine research community is well equipped to move beyond small-scale approaches and adopt landscape-scale initiatives with a multitrophic perspective and, almost certainly, using a nonexperimental, macro-ecological approach of the kind exemplified by Solan et al. (2004). Naeem (2006) makes a similar plea. Working at the ecosystem scale on ecosystem processes requires an ecosystem science approach. Ecosystem science has a long history in both the aquatic and terrestrial sciences, but is not well articulated within the present biodiversity-ecosystem functioning research community. In part, this must be because many of the personalities involved in biodiversity-ecosystem functioning research come from the academic stable of population and community ecology, rather than ecosystem ecology. The division between population and ecosystem ecologists seems to be a cultural phenomenon, consistent with Holling's (1992) comment that 'community ecology and ecosystem ecology seem to have existed in different worlds'. Population and community ecology has traditionally focussed

Table 1. A service-orientated approach for identifying the relevant underpinning processes and biodiversity elements in marine coastal systems. Note that some ecological goods, such as marine pharmaceuticals and culture, aesthetics and recreation, have no obvious 'process' underpinning them

\begin{tabular}{|lll|}
\hline Service & Ecosystem process & Relevant biodiversity \\
\hline Fibre/timber/fuel & Primary production & Mangrove trees \\
Fertility/nutrient cycling & Nutrients from sediment & Benthic infauna \\
Waste processing & Nutrient stripping & Salt marsh plants \\
Flood protection & Primary production & Marine vegetation \\
Pharmaceutical & & Corals, sponges \\
Cultural/amenity & & Shorebirds \\
Food & Secondary production & Estuarine bivalves \\
\hline
\end{tabular}

on basic studies, interactions amongst biota and the formulation of general and simple theories, whilst ecosystem ecology has concerned itself with specific applied problems, biotic, abiotic and human interactions, producing a catalogue of specific examples from which generalisation is difficult (Holling 1992). As with terrestrial and marine ecologists, there has been a divergence between the population ecology and systems ecology communities; these communities now seem to have different languages, attend different conferences and publish in different journals (Raffaelli 2000a, 2005). However, the divide has recently become less pronounced, with population and community ecologists increasingly tackling applied issues in sustainable resource management, whilst ecosystem ecologists are starting to generate general theories from the wide range of applied studies now available (Holling 1992), especially in the areas of network analysis and thermodynamics (e.g. Ulanowicz 1986, Christensen \& Pauly 1992, Jørgensen 1997). In addition, there is a growing awareness by all ecologists that ecosystems are, in part, shaped by the activities of their biodiversity.

In addition to the logic of taking an ecosystem approach to an ecosystem-level question, there is a second benefit of unifying efforts with respect to policies on biodiversity protection, in particular through the Convention on Biological Diversity. The signatories of this convention are requested to apply the ecosystem approach to biodiversity conservation and management, based on a set of principles (the Malawi principles) agreed upon in 1998 and formally adopted by the Conference of the Parties in 2000. The ecosystem approach was adopted by the World Summit on Sustainable Development in Johannesburg 2002, and has been recommended for adoption for many major policy initiatives in Europe, including the EU Water Framework Directive, Common Fisheries Policy and the European Marine Strategy (CBD 2004). An important feature of the ecosystem approach is that it is truly interdisciplinary and involves many socio-economic components. For instance, the objectives of management are regarded as a matter of societal choice, and the system should be understood and managed in an economic context. In addition, the approach should be taken at the appropriate (large) spatial and temporal scales, recognising temporal lags between different scales, and the conservation of ecosystem functioning should be a priority, in order to maintain ecosystem services (CBD 2004). There are clearly many points of contact between this policy and biodiversity-ecosystem research, as well as mainstream ecosys- 
tem ecology, which enlists a large-scale approach that has increasingly considered socio-economic dimensions (Gunderson \& Holling 2002).

Developments in ecosystem ecology have been based largely on the way energy (or rather its useful form, exergy; Jørgensen 1997) is distributed amongst system components and on how this distribution changes from early to mature stages of ecosystem development. Much of ecosystem ecology can thus be understood within a thermodynamics framework (Odum 1969, 1985), where systems are seen to move further away from thermodynamic equilibrium as they develop or mature. Whilst the approach has always had its critics (e.g. Mansson \& McGlade 1993), recent work by Joao Marques, Sven Jørgensen and their colleagues (Jørgensen \& Marques 2001, Marques \& Jørgensen 2002) has illustrated how population and community ecology-based approaches can be accommodated within a thermodynamics framework, thereby potentially bringing ecosystem ecology to bear on biodiversity-ecosystem functioning issues. Of particular relevance is their interpretation of the study by Wilsey \& Potvin (2000) on the effects of changes in the evenness component of plant species diversity on primary productivity (Marques \& Jørgensen 2002). They equate increasing evenness with information manipulation that artificially moved the system further from dynamic equilibrium to create a more efficient dissipative structure that increased exergy storage as biomass. By translating the biodiversity effects observed by Wilsey \& Potvin (2000) into the language of ecosystem ecology, Marques \& Jørgensen (2002) illustrated the potential of ecosystem ecology in the arena of biodiversity-ecosystem functioning research.

Mass-balance models and network analysis (Ulanowicz 1986, Christensen \& Pauly 1992) provide reasonably accessible frameworks within which the effects of biodiversity change within a food web can be explored in relation to ecosystem-level attributes related to ecological functioning. Here, I provide an example, purely for illustrative purposes, based on a mass-balance model developed for the food web of Ythan estuary, Aberdeenshire. The functions of interest are measures of the information content, the cycling of energy and the distribution of flows within the ecosystem; all are related to how far the system moves from its 'stable' configuration and the amount of whole-system productivity. By deleting species from the system (biodiversity loss) and re-balancing the model, the effects of these functions on a food web scale can be appreciated. Of course, the species deletion approach has been commonly used in stability analysis of food web models (e.g. Pimm 1981), but here a range of whole-system attributes rather than a single function, dynamic stability, can be evaluated.
The version of the Ythan food web used here comprises 28 taxa: shorebirds-cormorant, shelduck, eider, red breasted merganser, oystercatcher, dunlin, redshank, wigeon, mute swan; dominant fish-flounder, goby, 'other fish'; epibenthic crustaceans-shore crab, brown shrimp; benthic invertebrates-Mytilus edulis, Nereis diversicolor, Corophium volutator, Gammarus spp., Littorina spp., Hydrobia ulvae, Macoma balthica and meiofauna; zooplankton; benthic green algae; other macrophytes; benthic microphytes; and detritus. These taxa are distributed across 4 trophic levels. For computational reasons, this version of the Ythan web is somewhat smaller than the version with ca.100 taxa described elsewhere (Hall \& Raffaelli 1991, Huxham et al. 1995), but the web contains all of the major elements with which the species to be manipulated are connected. The model was constructed within the package Ecopath 5.0 (Christensen et al. 2002).

Three benthic species within the food web have provided the main focus for previous work on biodiversity-ecosystem functioning relationships in the sediments of the Ythan (Emmerson et al. 2001, Raffaelli et al. 2003), specifically the polychaete Nereis diversicolor, the amphipod Corophium volutator and the snail Hydrobia ulvae. Several sets of mesocosm experiments in which each of these species were maintained individually and in different combinations indicate that the 3 species differ markedly in their relative contributions to ecosystem functioning (ammonium release from the sediment), with $N$. diversicolor having the greatest effects, and $H$. ulvae, the least. The effects of species loss will, thus, depend greatly on the order in which species are lost (Emmerson et al. 2001, Solan et al. 2004). Whilst the mesocosm experiments focussed on a single process (i.e. nutrient release), the mass-balance model approach allows effects of species loss on a variety of whole-system attributes (i.e. ecosystem functions) to be explored.

Each of the 3 invertebrate species was removed from the food web model, and the model was then re-balanced to calculate the new values for ecosystem functions (Table 2). Loss of any of the 3 species reduced ascendancy, overhead (hence, capacity), throughput and total respiration and increased throughput cycling, indicating that the system had moved nearer to thermodynamic equilibrium. Not surprisingly, the loss of only 1 of 28 species from the system had little effect on the system's overall information content (Table 2). Of the 3 species, Nereis diversicolor changed key system attributes more than either Corophium volutator or Hydrobia ulvae, but there is no consistent association between species biomass and effects for the latter 2 species (Table 1). N. diversicolor has by far the largest standing stock biomass, but $C$. volutator and $H$. ulvae have higher production to biomass $(P / B)$ ratios, so that their roles in shunting energy through the food web 
Table 2. Nereis diversicolor, Corophium volutator, Hydrobia ulvae. Effects on ecosystem-level functions of removing key species of macrofauna from a mass-balance model of the Ythan estuary food web. Percent of total values in parentheses. P/B ratio: production to biomass ratio; ascendancy: the average information in a system, scaled by system throughput, and believed to increase with system development; overhead: how much 'strength in reserve' the system has to cope with future perturbations; capacity: the upper limit for ascendancy; information: the information content in the system; throughput: the sum of all the flows in the system; respiration: the sum of the respiration across all taxa; Finn's index: the fraction of a system's throughput which is recycled

\begin{tabular}{|c|c|c|c|c|c|}
\hline Ecosystem attribute & sturbed food web & Nereis removed & Corophium removed & Hydrobia removed & Species effects \\
\hline Biomass $\left(\mathrm{t} \mathrm{km}^{-2}\right)$ & - & 185 & 82 & 17 & \\
\hline$P / B$ ratio & - & 1 & 3 & 3 & \\
\hline Ascendancy & $\begin{array}{l}29228 \\
(24.9)\end{array}$ & $\begin{array}{c}24949 \\
(25.9)\end{array}$ & $\begin{array}{l}27957 \\
(25.6)\end{array}$ & $\begin{array}{c}27304 \\
(25.8)\end{array}$ & $\mathrm{N}>\mathrm{C}>\mathrm{H}$ \\
\hline Overhead & $\begin{array}{l}88342 \\
(75.1)\end{array}$ & $\begin{array}{c}71489 \\
(74)\end{array}$ & $\begin{array}{l}81111 \\
(74.4)\end{array}$ & $\begin{array}{l}78677 \\
(74.2)\end{array}$ & $\mathrm{N}>\mathrm{H}>\mathrm{C}$ \\
\hline Capacity & 117586 & 96438 & 109101 & 105997 & \\
\hline Information & 1.17 & 1.16 & 1.17 & 1.16 & $\mathrm{~N}, \mathrm{H}>\mathrm{C}$ \\
\hline Throughput & 24900 & 21502 & 23916 & 23569 & $\mathrm{~N}>\mathrm{H}>\mathrm{C}$ \\
\hline Respiration & 4410 & 3565 & 4243 & 4011 & $\mathrm{~N}>\mathrm{H}>\mathrm{C}$ \\
\hline Finn's index (\% total throughput) & 35.4 & 32.4 & 34.9 & 34.9 & $\mathrm{~N}>\mathrm{H}, \mathrm{C}$ \\
\hline Throughput cycled $\left(\mathrm{t} \mathrm{km}^{-2} \mathrm{yr}^{-1}\right)$ & 4.31 & 5.26 & 5.26 & 4.51 & $\mathrm{~N}, \mathrm{C}>\mathrm{H}$ \\
\hline
\end{tabular}

are much greater than their standing stock biomass indicates. It would appear that, at least compared to $C$. volutator and $H$. ulvae, the loss of $N$. diversicolor from the Ythan food web would have system-level impacts in addition to those already documented for nutrient cycling (Emmerson et al. 2001, Raffaelli et al. 2003).

\section{CONCLUSIONS}

It is clear that marine ecologists are well equipped to explore the relationships between biodiversity and ecosystem functioning, building on the strong foundations laid by previous marine research programmes. As is the case for terrestrial systems, there is a need to move towards larger spatial and temporal scales, towards greater trophic complexity and towards connections to biodiversity policy being developed at the ecosystem level. Small-scale experiments will remain useful for identifying mechanisms and testing specific hypotheses, but macro-ecological and ecosystem ecology approaches have potential for successfully addressing issues of scale, complexity and socio-economic concerns. In particular, marine ecologists need to recognise that their system is much more open than most of the terrestrial systems in which much of the biodiversity-ecosystem functioning research has been carried out to date, and they have, by necessity, an opportunity to explore how local-scale relationships and processes might be manifested at larger regional scales.

Acknowledgements. It is a great pleasure to acknowledge the constructive suggestions and advice of Steve Hawkins and Beccy Leaper on an earlier version of this paper. Steve reminded me of the important ideas and exchanges on the open nature and connectivity of landscape units that came out of the ESF Ascona workshops, April 2002, whilst Beccy enabled me to see that marine ecologists have much to be proud of in this area and need not slavishly repeat the approaches taken by terrestrial ecologists. Thanks.

\section{LITERATURE CITED}

Bulling MT, White PCL, Raffaelli D, Pierce GJ (2006) Using model systems to address the biodiversity-ecosystem functioning process. Mar Ecol Prog Ser 311:295-309 (in this Theme Section)

CBD (Convention on Biological Diversity) (2004) Available at www.biodiv.org/programmes/cross-cutting/ecosystem/

Christensen V, Pauly D (1992) ECOPATH-a software for balancing steady-state ecosystem models and calculating network characteristics. Ecol Model 61:169-185

Christensen V, Walters CJ, Pauly D (2002) Ecopath with ecosim, Ver 5. Available at www.ecopath.org

Emmerson MC, Huxham M (2002) How can marine ecologists contribute to the biodiversity ecosystem functioning debate? In: Loreau M, Inchausti P, Naeem S (eds) Biodiversity and ecosystem functioning: synthesis and perspectives, Oxford University Press, Oxford, p 139-146

Emmerson MC, Solan M, Emes C, Paterson DM, Raffaelli DG (2001) Consistent patterns and the idiosyncratic effects of biodiversity in marine ecosysytems. Nature 411:73-77

Giller PS, Hillebrand H, Berninke UG, Gessner MO and 8 others (2004) Biodiversity effects on ecosystem functioning: emerging issues and their experimental test in aquatic environments. Oikos 104:423-436

Gunderson LH, Holling CS (2002) Panarchy: understanding transformations in human and natural systems. Island Press, Washington, DC

Hall SJ, Raffaelli DG (1991) Food web patterns: lessons from a species rich web. J Anim Ecol 60:823-841

Hawkins SJ (2004) Scaling up: the role of species and habitat patches in functioning of coastal ecosystems. Aquat Conserv Mar Freshw Ecosyst 14:217-219

Hawkins SJ, Hartnol R (1983) Grazing of intertidal algae by marine invertebrates. Annu Rev Mar Biol Oceanogr 21: 195-282

Hector A, Schmid B, Beierkuhnlein C, Caldeira MC and 30 
others (1999) Plant diversity and productivity experiments in European grasslands. Science 286:1123-1127

Holling CS (1992) Cross-scale morphology, geometry and dynamics of ecosystems. Ecol Monogr 62:447-502

Huxham M, Raffaelli DG, Pike AW (1995) Parasites and food web patterns. J Anim Ecol 64:168-176

Jones NS (1948) Observations and experiments on the biology of Patella vulgata at Port St. Mary, Isle of Man. Proc Trans Liverpool Biol Soc 56:60-77

Jørgensen SE (1997) Integration of ecosystem theories: a pattern, 2nd edn. Kluwer, Dordrecht

Jørgensen SE, Marques JC (2001) Thermodynamics and ecosystem theory, case studies from hydrobiology. Hydrobiologia 445:1-10

Kennish M (2002) Environmental future of estuaries. Environ Conserv 29:78-107

Kremer C (2005) Managing ecosystem services: What do we need to know about their ecology? Ecol Lett 8:468-479

Lawton J (1996) Patterns in ecology. Oikos 75:145-147

Leaper R, Raffaelli DG (1999) Defining the body sizeabundance constraint space: data from a real web. Ecol Lett 2:191-199

Lodge SM (1948) Algal growth in the absence of Patella on an experimental strip of foreshore, Port St. Mary, Isle of Man. Proc Trans Liverpool Biol Soc 56:78-83

Mansson BA, McGlade JM (1993) Ecology, thermodynamics and H. T. Odum's conjectures. Oecologia 93:582-596

Marques JC, Jørgensen SE (2002) Three selected ecological observations interpreted in terms of a thermodynamic hypothesis. Contribution to a general theoretical framework. Ecol Model 158:1-9

Naeem S (2002) Ecosystem consequences of biodiversity loss: the evolution of a new paradigm. Ecology 83:1537-1552

Naeem S (2006) Expanding scales in biodiversity-based research: challenges and solutions for marine systems. Mar Ecol Prog Ser 311:273-283 (in this Theme Section)

Odum EP (1969) The strategy of ecosystem development. Science 164:262-270

Odum EP (1985) Trends expected in stressed ecosystems. BioScience 35:419-422

Paine RT (1974) Intertidal community structure: experimental studies on the relationship between a dominant competitor and its principal predator. Oecologia 15:93-120

Petchey OL, Downing AL, Mittelbach GG, Persson L, Steiner CF, Warren PH, Woodward G (2004) Species loss and the structure and functioning of multitrophic aquatic ecosystems. Oikos 104:467-478

Pimm SL (1981) Food webs. Chapman \& Hall, London

Raffaelli DG (2000a) Trends in marine food research. J Exp Mar Biol Ecol 250:223-232

Raffaelli DG (2000b) Interactions between macro-algal mats and invertebrates in the Ythan estuary, Aberdeenshire, Scotland. Helgol Meersunters 54:71-79

Raffaelli D, Hawkins SJ (1996) Intertidal ecology. Chapman \& Hall, London

Raffaelli DG, Moller H (2000) Manipulative experiments in animal ecology-Do they promise more than they can deliver? Adv Ecol Res 30:299-330

Editorial responsibility: Martin Solan (Guest Editor), Newburgh, UK
Raffaelli DG, Raven J, Poole L (1998) Ecological impact of green macroalgal blooms. Annu Rev Mar Biol Oceanogr 36:97-125

Raffaelli DG, Balls P, Way S, Patterson IJ, Hohman SA, Corp N (1999) Major changes in the ecology of the Ythan estuary, Aberdeenshire: How important are physical factors? Aquat Conserv Mar Freshw Ecosyst 9: $219-236$

Raffaelli DG, van der Heijden M, van der Putten W, Kennedy E and 6 others (2002) Multi-trophic processes and ecosystem function. In: Loreau M, Naeem S, Inchausti P (eds) Biodiversity and ecosystem functioning. Oxford University Press, Oxford, p 147-154

Raffaelli D, Emmerson M, Solan M, Biles C, Paterson D (2003) Biodiversity and ecosystem processes in shallow coastal waters: an experimental approach. J Sea Res 49:133-141

Raffaelli D, Solan M, Webb TJ (2005) Do marine and terrestrial ecologists do it differently? Mar Ecol Prog Ser 304:283-289

Roberts CM, Hawkins JP (1999) Extinction risk in the sea. Trends Ecol Evol 14:241-246

Scherer-Lorenzen M, Potvin C, Koricheva J, Bornik Z, Hector A, Reynolds G, Schmid B (2004) The design of experimental tree plantations for functional biodiversity research. In: Scherer-Lorenzen M, Körner C, Schulze ED (eds) The functional significance of forest diversity. Springer-Verlag, Berlin, p 347-376

Schilthuizen M (2003) Forest ecologists go mega. Science 300: 1872

Solan M, Germano JD, Raffaelli DG, Warwick RM (2003) Benthic dynamics: in-situ surveillance of the sediment-water interface. J Exp Mar Biol Ecol 285(6):1-511

Solan M, Cardinale BJ, Downing AL, Engelhardt KAM, Ruesink JL, Srivastava DS (2004) Extinction and ecosystem function in the marine benthos. Science 306: $1177-1180$

Taylor R, Raven JA (2003) Survival strategies of Enteromorpha from eutrophic sites. In: Raffaelli DG, Solan M, Paterson D (eds) The estuaries of north-east Scotland. Coast Zone Top 5:31-40

Thrush SF, Whitalch RB, Pridmore RD, Hewitt JE, Cummings VJ, Wilkinson MR (1996) Scale-dependent recolonisation: the role of sediment stability in a dynamic sandflat habitat. Ecology 77:2472-2487

Thrush SF, Schneider DC, Legendre P, Whitalch RB, Dayton PK, Hewitt JE (1997) Scaling up from experiments to complete ecological systems: Where to next? J Exp Mar Biol Ecol 216:243-254

Tilman D (1997) Biodiversity and ecosystem properties. Science 278:1866-1867

Ulanowicz RE (1986) Growth and development: ecosystem phenomenology. Springer-Verlag, New York

Wilsey BJ, Potvin C (2000) Biodiversity and ecosystem functioning: importance of species evenness in an old field. Ecology 81:887-892

Yodzis P (1988) The indeterminacy of ecological interactions, as perceived through perturbation experiments. Ecology 69:508-515

Submitted: April 12, 2005; Accepted: October 21, 2005

Proofs received from author(s): March 7, 2006 


\title{
OPEN ACCESS \\ Using model systems to address the biodiversity-ecosystem functioning process
}

\author{
M. T. Bulling ${ }^{1, *}$, P. C. L. White ${ }^{1}$, D. G. Raffaelli ${ }^{1}$, G. J. Pierce ${ }^{2}$ \\ ${ }^{1}$ Environment Department, University of York, Heslington, York YO10 5DD, UK \\ ${ }^{2}$ School of Biological Sciences, Zoology Building, University of Aberdeen, Aberdeen AB24 2TZ, UK
}

\begin{abstract}
Declines in biodiversity resulting from anthropogenic disturbance to ecosystems have focused attention on the role of biodiversity in ecosystem functioning. However, the high level of complexity of ecosystems has made this a difficult topic to investigate. Much simpler model systems incorporating small-scale, spatially delimited, artificial assemblages of species have been widely used recently to address the link between biodiversity and ecosystem functioning (BEF). Their simplicity lends tractability to these systems, but has also resulted in much criticism in the literature over their relevance. Here, we examine the strengths and limitations of model systems and examine how useful these systems might be in addressing several issues that are likely to represent future challenges to understanding BEF: spatial scale, multiple trophic levels, variation, environmental stochasticity and the choice of representative combinations of species. We find that model systems have already played an important role in enhancing our understanding of BEF and are likely to continue this role in the future. However, they do have important limitations, and it is essential to take these into account when putting results into the broader context of ecosystems and to improve the level of integration of results with those from other methodologies.
\end{abstract}

KEY WORDS: Biodiversity $\cdot$ Ecosystem functioning $\cdot$ Model systems $\cdot$ Hidden treatments $\cdot$ Spatial scale $\cdot$ Multiple trophic levels $\cdot$ Mesocosms

\section{INTRODUCTION}

There is a long history of the use of model systems to address questions in marine ecology, probably reflecting the more difficult working environment of the sea and seabed compared to more accessible terrestrial systems. Benthic and pelagic micro- and mesocosms have been employed extensively in research, ranging from pollution effects to benthic-pelagic coupling (Lalli 1991), such that they are now a routine tool for marine investigations. In addition, marine ecologists have played a major role in developing appropriate and rigorous experimental designs and subsequent analyses (Gamble 1991, Underwood 1998), and the techniques required to maintain and monitor environmental processes under different experimental treatments are well established.

Few marine ecologists would therefore need convincing of the utility of model systems for exploring relationships between biological and physico-chemical processes. It is somewhat surprising therefore that relatively few attempts (compared to freshwater and terrestrial ecology) have been made to take advantage of such systems for exploring one of the key emerging issues in ecology, the effects of biodiversity on ecosystem functioning. There is a strong tradition in ecology of investigating the abiotic drivers of ecosystem structure and dynamics, whilst biotic factors have been highlighted only comparatively recently (Lawton 1994, Chapin et al. 1997, Loreau 2000). This change in emphasis has been given impetus due to current rates of species loss and concerns as to how biodiversity change will affect the efficiency with which ecosystems will function, especially with regard to the provision of ecological goods and services (Ehrlich \& Wilson 1991, Pimm et al. 1995, Costanza et al. 1997, Vitousek et al. 1997, Chapin et al. 2000). 
Investigating the relationships between biodiversity and ecosystem functioning is extraordinarily challenging given the complexity of real ecosystems. Model systems are a subset of experimental models that have been at the centre of biodiversity-ecosystem functioning (BEF) research (Lawton et al. 1998, Emmerson et al. 2001, Hector et al. 2002, Petchey et al. 2002b, Tilman et al. 2002). These systems use spatially delimited replicates of precisely controlled starting conditions (including identity, number and density of species), and have been at the heart of much of the controversy surrounding BEF research (see 'Combinations of species' below). BEF is a shift from much of the earlier biodiversity research in marine ecosystems, but a field where marine ecologists can play a key role by virtue of their experience and expertise in the use of model systems. Here, we review the strengths and limitations of the model system approach as revealed by studies of BEF issues, mainly conducted in terrestrial and freshwater systems. We then examine how model systems might be used to address future challenges, and how they may be better integrated with other studies in order to obtain a more rigorous understanding of BEF relationships.

\section{MODEL SYSTEMS}

The majority of model systems have been based on microcosms or mesocosms, defined as 'spatially delimited artificially constructed model ecosystems' (Petchey et al. 2002b). In the present paper, we use this as the basis of our definition of model systems as 'small-scale, spatially delimited, artificially constructed ecosystems, allowing fine control over initial composition'. The difference between micro- and mesocosms is rather arbitrary (Lawler 1998), with mesocosms tending to be larger in absolute size and, therefore, of greater biological and spatial complexity (Petchey et al. 2002b). In the present paper we do not distinguish between micro- and mesocosms, but differences in scale in the 2 types of systems will affect the strengths of some of the criticisms of model systems in general. Our definition of model systems also embraces spatially larger experimental projects such as Biodepth (Hector et al. 2002) and the biodiversity experiments in grasslands (Tilman et al. 2002). The use of model systems for addressing BEF questions has typically involved experimental designs with biodiversity as the independent (explanatory) variable and the levels of a particular ecosystem function (often productivity) as the dependent (response) variable. The biodiversity metric most often used is species richness (i.e. the number of species).

The main advantage of model systems is the high level of control possible over initial conditions, includ- ing the choice of species, numbers of individuals and starting physico-chemical conditions. This and the relatively small size of the individual treatment plots means that configurations can easily be replicated (Lawton 1995, Drake et al. 1996), increasing the level of statistical power in the experimental design and the persuasiveness of findings. Related to this is reproducibility (Lawton 1995, Drake et al. 1996), whereby starting conditions can be set up precisely and repeatedly with minimal variation. This high level of control over initial configurations means that specific factors, such as biodiversity, can be isolated and their role in ecosystem functioning can be assessed unambiguously. Small-scale systems are also easily monitored and maintained. Model systems therefore potentially offer a high level of tractability.

However, these high levels of control and replication mean that model system experiments are very specific to the system, organisms and experimental configuration being used. In turn, this specificity means that results are unlikely to be generally applicable across systems, or indeed between different configurations of the same system. In the same way, model systems are designed to focus on specific independent factors, allowing little understanding of the relative importance of these factors in relation to others in the full and more complex system.

Model systems at the lower end of the spatial scale (meso- and microcosms) involve smaller organisms, with short generation times, making them well suited to addressing questions requiring many generations (Drake et al. 1996, Petchey et al. 2002b). This is an important consideration, particularly when trying to relate results from micro- and mesocosm experiments to those from larger-scale terrestrial plant experiments (Petchey et al. 2002b). If the experimental duration encompasses many generations, the results will be strongly driven by population dynamics. However, terrestrial plant experiments tend to last for only a few generations, and can therefore be more affected by transient effects of initial species composition (Petchey et al. 2002b). Comparison of results between model systems at different spatial scales may thus be inappropriate and misleading.

However, whilst smaller model systems might appear to have advantages over field experiments, these same advantages are seen by some as potential problems. The short time required to run the experiments, the modest cost and the ability to conduct the experiment in the laboratory, rather than having to regularly visit a field site, have been claimed as enticements leading scientists to use these experimental designs at the expense of experimental rigour (Carpenter 1996). A more subtle concern is that of mean field approximations (Petersen \& Hastings 2001). In the 
tight experimental design of many small-scale systems (cf. more open systems, e.g. Hector et al. 2002, Tilman et al. 2002) levels of environmental variables are approximated and constant, based on average levels of environmental factors (e.g. light, temperature, humidity). There is thus an implicit assumption that average levels of environmental factors, rather than their extreme levels or variability, determine ecosystem dynamics (Petersen \& Hastings 2001). This may not be true and could lead to false conclusions being drawn from such experiments. However, mean field approximation can be an advantage in the integration of model systems with mathematical models and theory. Mathematical ecosystem models generally use mean field approximations for environmental variables, and there is therefore a close conceptual link between these types of approaches. This is particularly so for aquatic model systems (Petchey et al. 2002b). Mathematical models and theory often implicitly assume a closed system and a lack of spatial structure, the trademark of many aquatic model systems and quite different from most field experiments done in terrestrial systems. Reduced spatial environmental variation coupled with generally mobile individuals, leads to limited spatial aggregation of individuals and therefore dynamics approximating mean field conditions (Tilman \& Kareiva 1997).

By definition, model systems are taxonomically and structurally simplistic (Lawton 1995, 1996, Carpenter 1996, Drake et al. 1996). For example, there is little or no spatial or temporal heterogeneity (Lawton 1995), seasonal variation, disturbance, or large environmental perturbation (Lawton 1996). Whilst such simplicity provides for an elegant and tractable experimental design, important characteristics of real communities and ecosystems will be excluded or distorted (Carpenter 1996). Carpenter (1996) cites examples from limnology (Gerhart \& Likens 1975, Stephenson et al. 1984, Bloesch et al. 1988) in which container size and experimental duration have affected experimental results.

There are also criticisms of the identities of the species that have been used in these experiments which may contain unnatural assemblages (Lawton 1996) and, hence, be a poor reflection of the real ecosystem. Also, species may be used because they survive well in microcosms, rather than being representative of the wider community (Lawton 1995) in which the species have long interconnected evolutionary histories (Lawton 1996). If species composition in individual-richness treatments is not realistic, between-treatment differences may not represent the differences likely under natural extinction/colonisation scenarios (Solan et al. 2004), leading to difficulties in interpretation.

Given these limitations and abstractions, it is not surprising that model systems have attracted hostility.
For example, Carpenter (1996) has argued that the limitations of this experimental approach mean that most important questions in applied ecology cannot be investigated by mesocosms, with statistical advantages not offsetting the problems of limited scale, so that there is considerable risk of obtaining misleading results from these experiments. Despite the strong views expressed by proponents and critics, there are areas of general agreement. All realise that model systems are great simplifications of ecosystems, which are highly complex, making it foolish and misleading to extrapolate results from these experiments directly to ecosystems. Another area of agreement is that these model systems form only one part of a suite of tools for studying ecosystems, including mathematical and conceptual models, as well as field observations, experiments and manipulations. However, views about the contribution that model systems make do vary, from 'supportive' (Carpenter 1996) to 'a unifying thread for the development of a conceptual framework for understanding higher levels of organization' (Drake et al. 1996).

Clearly, model systems have an important role to play in BEF issues. Observations and correlations on their own do not allow us to distinguish between cause and effect (Manly 1992), whilst field studies do not allow the level of control and measurement permitted in model systems, required to develop theories and required to test hypotheses. Model systems therefore provide us with an extremely valuable starting point in our understanding of ecosystems. They should be viewed as one component in an integrated suite of methodologies that we can use to develop theories and test hypotheses of ecosystem processes (Lawton 1995, 1996, Petchey et al. 2002b). They are extremely useful, but must be used with care and in context.

\section{FUTURE CHALLENGES FOR MODEL SYSTEMS}

The sheer complexity of ecosystems has meant that most research into understanding BEF has been of the reductionist philosophy. This, combined with initial limitations imposed by the experimental design of model systems, has meant that many of the model systems used to date appear simplistic. Many of the future challenges for model systems stem from the requirement to bridge the gap between these simple systems and real ecosystems by incorporating further key aspects of ecosystems in their design. Incorporating additional ecological complexity in these systems without losing their tractability requires careful thought about which aspects should be included and about experimental design. Below, we review a number of ecosystem features that are likely to be important dri- 
vers in a BEF relationship, most of which have so far not been addressed by model systems. We consider why these features are likely to be important, the problems of incorporating them into model system designs, and how these problems may be overcome.

\section{Combinations of species}

The majority of model systems have used terrestrial plants (Schlapfer \& Schmid 1999, Hector et al. 2002, Tilman et al. 2002), and, as noted below, this is a trophic bias that needs to be corrected. However, the particular combinations of species used in model systems are also open to criticism. The independent variable that is usually adopted in model system experiments is species richness, with different levels of this factor assembled in a controlled fashion, usually species being chosen at random from a species pool. This has generated a debate over whether effects on ecosystem functioning are due to biodiversity through resource partitioning or positive interactions, or are due to 'hidden treatments'. The hidden treatment that has received the most attention has been 'sampling effects' (Huston et al. 2000, Fridley 2001, Loreau \& Hector 2001, Huston \& McBride 2002, Tilman et al. 2002). A sampling effect occurs when randomly chosen (without replacement) combinations with more species have a greater probability of containing a species or groups of species with strong functional characteristics than those combinations with fewer species, and therefore are likely to demonstrate a greater level of ecosystem functioning through this chance selection. Consequently, it is difficult to determine if an increase in ecosystem functioning is genuinely due to an increase in the number of species or due to this sampling effect.

One approach that allows the distinction of complementarity and species-selection effects on ecosystem functioning has been described (Loreau \& Hector 2001, Sala 2001). This requires replications of single-species treatments so that levels of ecosystem functioning in multi-species configurations can be separated according to sampling effects and species complementarity through additive partitioning. Although this methodology is a significant step forward in interpreting results, it is an a posteriori approach with limitations and cannot replace experiments that explicitly address actual mechanisms operating between biodiversity and ecosystem functioning (Loreau \& Hector 2001). An important limitation of this methodology is that it allows separation of the 'complementarity effect' and the 'selection effect', but that an underlying mechanism resulting from complementarity can influence both effects (Petchey 2003). Thus, it is not possible to link a single mechanism or class of mechanisms to the 'com- plementarity effect', an error that has been made frequently (Petchey 2003). This technique of separating effects has been used as part of an explicit ANOVA (analysis of variance) design in conjunction with separate ANOVAs, with each species as a dummy variable to assess the level of species-selection effects with changing soil fertility in a terrestrial plant experiment (Fridley 2002).

The methodology of Loreau \& Hector (2001) for separating complementarity and species-selection effects relies on a replacement series experimental design that assumes no density-dependent effects (BenedettiCecchi 2004). These designs require compensatory reductions in abundance of species with increasing diversity to keep total density constant. This allows confounding of complementarity and species-selection effects with density-dependent effects. Many of these issues of separating the different effects and their interactions have been examined through the use of Monte Carlo simulations (Benedetti-Cecchi 2004). This work investigated a new design, with biodiversity (species richness) and density of species as fixed, crossed treatments. Species assemblage was treated as a random factor, which was nested within richness treatments and crossed with density of species treatments. This allows the identification of speciesrichness effects even with the added complication of density-dependent effects, whilst controlling for species-identity effects, which can also be identified (Benedetti-Cecchi 2004).

Views of the relevance of these sampling effects fall into 2 camps. Some authors consider such effects as experimental artefacts that interfere with the correct interpretation of biodiversity effects on ecosystem functioning (Huston 1999, Wardle 1999, Huston et al. 2000, Huston \& McBride 2002). Others see them as a natural consequence of the inherent differences between species and therefore as a mechanism through which species richness may affect ecosystem functioning (Lawton et al. 1998, Chapin et al. 2000, Purvis \& Hector 2000). However, the validity of the sampling effect must rest with how well random species addition/deletion in the experiment matches the processes of species addition and deletion in real ecosystems (Fridley 2001), and this is likely to vary considerably. It is probable that the environment will strongly affect the level of this matching, with resulting immigration and emigration processes that are highly stochastic likely to lead to strong matching (Fridley 2001). The significance of sampling effects in model systems must therefore be considered on a case-by-case basis in relation to the ecosystem being modelled, rather than assigning it the constant value of a true effect of biodiversity or a statistical artefact. The sampling effect is a mechanism through which levels of ecosystem func- 
tioning can be affected, and therefore the differences are largely semantic (Cottingham et al. 2001).

Two other potential hidden treatments are the 'quasi-replication effect' and the 'variance-reduction effect' (Huston \& McBride 2002). These are subtler than the sampling effect. The term 'quasi-replication' (Huston \& McBride 2002) refers to the fact that drawing species randomly from a species pool for each replicate at a particular species richness means that replicates will not be true replicates, as they will not contain exactly the same species.

With a given pool of species to randomly draw from (without replacement), treatments with intermediate numbers of species have a much larger number of possible combinations of species than treatments with low or high numbers of species. This means that with the same number of replicates for each treatment the species combinations that are used for intermediate biodiversities will represent only a small proportion of the total number of potential combinations. Replicates of lowest and highest biodiversity treatments will represent much greater proportions of the potential species combinations at these species richnesses. This underrepresentation of species combinations at the intermediate diversity levels means that with the usual small number of replications in each richness treatment, it is unlikely that resulting statistical properties are representative of the population of species combinations (Huston \& McBride 2002). This is the quasi-replication effect (Huston \& McBride 2002). This implies that the level of variance will change with richness treatment, introducing heterogeneity of variance and therefore breaking one of the assumptions made by ANOVA and linear regression models, both used extensively to analyse BEF model systems.

The variance-reduction effect (Huston 1997, Huston \& McBride 2002) results from the similarity of replicates within a species-richness treatment changing with species richness (Fig. 1). The similarity of quasireplicates within a richness treatment level increases at an increasing rate with species richness, assuming random selection without replacement. This asymmetry in similarity results in high-richness treatments containing almost true replicates, and those treatments with low species numbers being very far from true replicates. As a result, statistical behaviour of replicates is likely to change with species richness. The range of 'real' (i.e. statistical population parameter) levels of ecosystem functioning from the quasi-replicates in high species treatments is likely to be smaller than the range at low species richness due to the different levels in similarity of replicates within a treatment. A consequence of this is that, in high-richness treatments, levels of ecosystem functioning are more likely to be proportionately more strongly affected by exper-

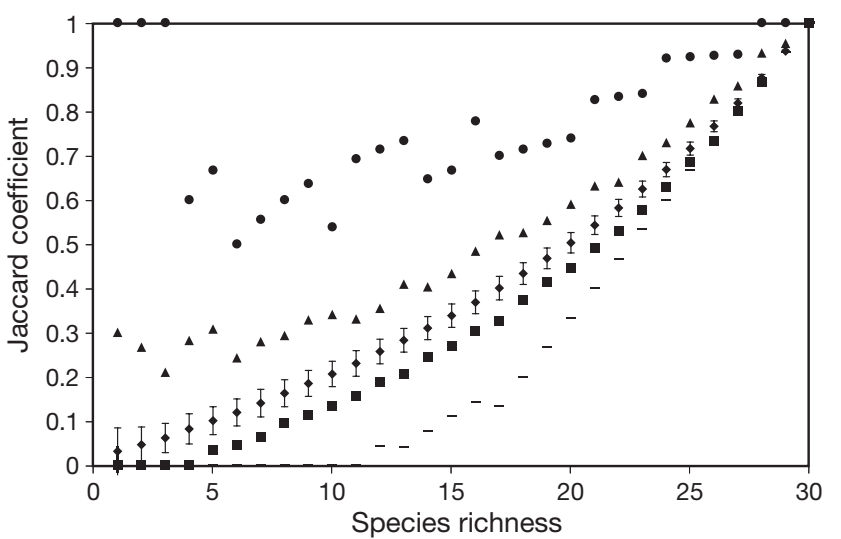

Fig. 1. Levels of similarity between 'quasi-replicates' (Huston \& McBride 2002) with increasing species richness. Similarity between 2 replicates is measured with the Jaccard coefficient, which is the number of species in both replicates divided by the number of species in just one or the other replicate. A coefficient of 0 indicates no similarity, and a coefficient of 1 indicates the replicates contain the same species. Simulations were run using a pool of 30 species from which species were selected at random without replacement and placed in a replicate. An experiment with 5 replicates per species-richness treatment was simulated. The mean coefficient over all unique pairings of replicates was calculated for each set of 5 replicates to get an 'overall similarity'; 1000 simulations were run, and the mean level of overall similarity at each species richness is shown $(\bullet)$ with the standard deviation. The minimum (घ) and maximum ( $(\boldsymbol{\Delta})$ levels of 'overall similarity' in the 1000 simulations are also shown. The minimum (-) and maximum (•) individual Jaccard coefficients that occurred between pairs of replicates are shown to indicate the likely range of similarity in different species-richness treatments

imental error than by biodiversity effects. Due to the parallel sampling effect making it more likely that these high-richness treatments will contain the more productive species, the effect of experimental error is likely to be in the direction of increased ecosystem functioning. This increase in ecosystem functioning due to experimental error cannot be separated from increases due to species richness and therefore may lead to a misrepresentation of the meaning of experimental results.

The variance-reduction effect means that there will be a breakdown of the assumption of homogeneity of variance across treatments, an assumption made by ANOVA, which has been used extensively to analyse the results from BEF experiments. The variance-reduction effect could be avoided through the use of true replicates in the experimental design. If this is done, then the experimental design advocated by BenedettiCecchi (2004) will allow a formal test of the variancereduction effect.

Such concerns have led some to call for conclusions based on results from experiments involving random sampling from a species pool to be re-evaluated and 
for future experimental designs to focus on the mechanistic drivers of BEF (Huston \& McBride 2002). The level of error due to environmental variation can be accounted for in 2 main ways (Huston \& McBride 2002). Firstly, using the usual experimental design (biodiversity as an independent factor and ecosystem functioning as a dependent variable), environmental parameters can be measured and incorporated into the statistical analysis as covariates. Secondly, a more controlled approach involves the deliberate manipulation of environmental conditions and for these levels to be included as factors in the experimental design. The levels of interactions between these environmental factors with diversity (as a fixed factor) in an ANOVA experimental design can also be obtained. This approach has been successfully used in a grassland model system experiment, which demonstrated that the effect of diversity on productivity significantly increased with soil fertility (the environmental variable) (Fridley 2002).

The need to address BEF via a mechanistic framework has been recognised, and several experimental designs have focussed on functional diversity rather than species richness (McGrady-Steed et al. 1997, Naeem \& Li 1997, Mulder et al. 1999, Paine 2002). However, this change in focus has its own associated problems. The functional approach has not been particularly successful in achieving an understanding of how taxonomic or functional diversity can affect ecosystem functioning, because the functional groups used have been subjective or defined via statistical segregation based on ecophysiological data (Naeem \& Wright 2003). A general framework for identifying appropriate functional groups has been proposed that splits response traits from effect traits, and selects the relevant functional traits based on the driver and ecosystem function of interest (Naeem \& Wright 2003). A more appropriate measure of functional diversity than functional richness has been proposed (Petchey \& Gaston 2002). FD is a functional diversity index that is a continuous and simultaneous estimate of the dispersion of species in trait space at all hierarchical scales. Another proposed measure is functional attribute diversity (FAD) (Walker et al. 1999), which uses an estimate of the total distance between species in trait space. These 2 measures explained a greater level of variation in above-ground biomass production than species richness and functional group richness in a comparison of functional diversity measures (Petchey et al. 2004). This greater explanatory power was partly explained by FD and FAD not arbitrarily assigning species to functional groups, enabling continuous measures of biodiversity and the greater amount of biological information that the 2 measures contain (Petchey et al. 2004). An alternative approach is to use a test of statis- tical significance that accounts for the effects of grouping per se (Petchey 2004). This is done through a randomisation test that compares the observed statistic against a distribution determined using repeated random assignment of species to functional groups, allowing the testing of the null hypothesis that functional group richness has no effect on ecosystem functioning.

Whether experimental design focuses on species richness or functional richness, the choice of species or functional group treatments has still been primarily based on random selection (Naeem \& Wright 2003). This is equivalent to random extinction, but, in the real world, extinction tends to be non-random (Pauly et al. 1998, Srivastava 2002, Smith \& Knapp 2003). Therefore random selection of species or functional groups in experimental design is unlikely to produce combinations representative of the real world (Wardle 1999, Schwartz et al. 2000), although this is possible in systems with strong stochastic drivers (Fridley 2001). The possible significance of non-random extinctions on BEF has recently been demonstrated using data from marine invertebrate communities to parameterise models predicting the effects of extinctions on sediment bioturbation (Solan et al. 2004). The models demonstrated that the magnitude of the effect of species loss on bioturbation depends on how the functional traits of species co-vary with their risk of extinction. Similarly, loss of rare (and therefore more prone to extinction) species had no effect on above-ground net primary productivity in plots on a prairie grassland over 2 growing seasons, whereas loss of dominant species led to decreased productivity (Smith \& Knapp 2003). These results contrast with decreases in ecosystem functioning with decreasing species richness found in similar studies, but with random species assemblages (Hector et al. 2002, Tilman et al. 2002).

Acknowledging this in experimental designs could be done by selecting combinations of species as before, but with weighting for a species to be included based on a measure of the relative likelihood of that species going extinct (Srivastava 2002). However, this would mean that a general effect of biodiversity on ecosystem functioning would be confounded by systematic changes in species composition (Lawton et al. 1998, Hector et al. 2002). A possible solution to this would be to use both approaches in the experimental design (Srivastava 2002). The replicates based on randomly selected combinations of species would act as a nullmodel, and comparison with replicates with weighted selection of species would allow the separation of the effect of losing biodiversity per se from the effect of losing biodiversity selectively (Srivastava 2002). A further step would be to allow the experiment to continue over many generations and so allow extinction events to occur naturally (Srivastava 2002). This type of 
approach combined with some form of perturbation has been applied (Petchey et al. 1999, Griffiths et al. 2000), but without the null-model treatments.

Concern over the consequences of how species have been selected for replicates in BEF experiments has led to much strong debate over the role of 'hidden treatments'. Overall, this debate has been very healthy, resulting in a greater rigour in BEF experimental designs. There is still much to debate, and methods of choosing which species to include in replicates in model system experiments will remain critical in interpreting the results and placing them in their correct context.

\section{Spatial scale}

Here, spatial scale is defined as the dimension of observed entities and phenomena in space (O'Neill \& King 1998, Schneider 2001). Most research into BEF has focussed on the small spatial scale, and experimental design has required these systems to be closed to the surroundings (Bengtsson et al. 2002). It could be misleading to simply extrapolate results from smallscale experiments to a larger scale, assuming that processes and mechanisms do not change, an assumption unlikely to be true for ecosystems. There have been 3 main hypotheses proposed to explain increased ecosystem functioning with increased species richness at the small spatial scales used in model systems: species complementarity, positive interactions between species and hidden treatments. These mechanisms work at the small, local scale, assuming that species interactions and their functional traits drive the BEF relationship (Bengtsson et al. 2002). However, at larger spatial scales, it is likely to be variation in resources and abiotic factors that are the main drivers (Huston 1994, Anderson 1995). It has been suggested that these scale differences may lead to differences in the main effects of changing diversity, with changes at the small scale mainly affecting rates of ecosystem processes, whereas, at the larger scale, changing diversity will tend to alter levels of ecosystem resilience and stability (Bengtsson et al. 2002).

Not only may scale change the type of relationship between biodiversity and ecosystem functioning, it may also alter the level of effect. As one moves towards community-wide scales in heterogeneous systems, effects of biodiversity could be overwhelmed by other factors (Levine et al. 2002), such as abiotic factors. Thus, at increasing scales, effects of biodiversity may become harder to detect against a background of other effects.

Integration of scale as a factor in model system design will be intimately related to, and complicated by, the integration of multiple trophic levels (see 'Mul- tiple trophic levels' section). Species in the higher trophic levels tend to have larger home ranges, and the scales at which their dynamics operate will be greater. This implies that studies conducted at one trophic level may not be directly relevant to studies at another trophic level, even if the studies have been conducted at the same spatial resolution (Bengtsson et al. 2002). A further implication is that including multiple trophic levels will change the model system from working at a single spatial scale, to working at multiple interacting spatial scales. If changes in biodiversity at different scales have different effects (Bengtsson et al. 2002), interaction of mechanisms between scales could be significant in determining which are the main effects of biodiversity loss in an ecosystem.

One way of allowing a range of spatial scales in model systems would be to simply expand the size of enclosure or plot used in the experiments. This approach has been utilised (Petchey et al. 1999, Hulot et al. 2000), but as part of research of multi-trophic interactions and not to specifically examine biodiversity-ecosystem functioning. A similar approach might be to connect blocks of micro- or mesocosms together, allowing interactions over a larger spatial scale (Bengtsson et al. 2002). These approaches allow only a limited increase in the range of scales for model ecosystems, but offer an important next step in addressing the role of scale in BEF relations.

Other methodologies such as utilising large-scale enclosures of ecosystems, either using natural boundaries such as lakes and islands (Carpenter et al. 2001), or artificial boundaries (Krebs et al. 1995), have been used. These designs would be better for continuing to address the role of scale in BEF at larger spatial scales, but offer much less control of starting conditions, fewer replicates (often only 1), and are far more difficult and costly to monitor. Realistically, model systems will be limited in the scales that they can incorporate. However, if they can be expanded in size, albeit to a limited degree, from the current small spatial scales, it may be possible to integrate results from these experiments with experiments based on different experimental designs and incorporating larger spatial scales. Simply having multiple spatial scales will allow a start to be made in addressing the role of scale in BEF.

Working at increasing spatial scales has the associated problems of increased requirements of space, time and financial costs, with a possible compromise being obtained by a reduction in the number of replicates. The great need to address the role of scale in BEF with the associated likelihood of decreasing the number of experimental replicates has led to the suggestion that we may have to be prepared to accept a lower level of statistical rigour in experimental design and analysis (Bengtsson et al. 2002). 
Dimensional analysis offers potential for designing model systems that will allow results to be extrapolated to larger spatial scales (Petersen \& Hastings 2001, Englund \& Cooper 2003). The technique involves determining dimensionless variables by rearranging different measurements of the systems so that their units cancel each other out. The relative values of the component variables can be adjusted to maintain the same value of the dimensionless variable in the model system as in the ecosystem. The lack of flexibility in controlling organism characteristics for scaling in this way strongly limits this approach (Englund \& Cooper 2003). However, the greatest limitation is due to our lack of knowledge of the scaling relationships that drive ecosystem dynamics (Petersen \& Hastings 2001, Englund \& Cooper 2003). These limitations will be exacerbated in multi-trophic studies, since the level and dynamics of scaling will vary between species, making a common scaling relationship for all species involved unlikely.

An alternative approach is the translation of results across scales using scaling models, incorporating known empirical relationships or mechanistic models (Schneider et al. 1997, Englund \& Cooper 2003). Application of this methodology to open predation experiments (Englund et al. 2001) has been used to identify scale domains (Wiens 1989), ranges in scale over which there is no or only weak scale dependence, but between which there is strong scale dependence or changes in the drivers of the process of interest. The defining of scaling relationships in the open predation experiments was accomplished via a meta-analysis of past experiments performed at different scales (Englund et al. 2001). Identifying such scale domains explicitly shows the scales over which we need to be particularly careful about scaling effects. Again the major limitation in translating results between spatial scales is our lack of knowledge of scaling processes; complex multi-scale experiments or meta-analyses are required to develop empirical scaling relationships, and scaling mechanisms are poorly understood. Multiscale experiments in which the same treatment is applied at different spatial scales as part of an integrated experimental design will generate less ambiguous results than meta-analyses (Chen et al. 1997).

As part of an assessment of the various research paradigms for addressing multi-scale processes, strategic cyclical scaling was considered to be the most appropriate paradigm to use (Root \& Schneider 1995). This paradigm involves using observations at large scales to direct the testing of mechanistic processes in smallscale experiments, the results of which are used to make predictions at larger scales. This cyclic process builds up knowledge of processes and mechanisms across a spectrum of scales. Gaps in our knowledge of scaling processes for a particular system can be explicitly visualised with scope diagrams (Schneider et al. 1997), and these represent a possible guiding methodology in the recommended strategic cyclical scaling paradigm.

\section{Multiple trophic levels}

Ecosystems are composed of several trophic levels with interactions between these trophic levels. Therefore, any theory of BEF that does not take this dimension of ecosystems into account will necessarily be incomplete. This raises concerns about current work using model systems. There has been an overwhelming concentration on experimentation with plants (a single trophic level), and multiple trophic levels have been explicitly incorporated into only a few model systems addressing BEF (Naeem \& Li 1997, Petchey et al. 1999, Naeem et al. 2000, Duffy et al. 2001, 2003, 2005).

Effects of biodiversity are just as likely, or more likely, to be driven by the consumer level as the level of plants (Petchey et al. 1999, Duffy 2002, 2003), and these effects will lead to further effects via trophic interactions (Naeem et al. 2000, Worm \& Duffy 2003, Duffy et al. 2005). It has been suggested that changes in ecosystem processes resulting from changes in biodiversity at the consumer level are likely to be more idiosyncratic than would be the case with changes in plant biodiversity (Duffy 2002). So, not only is there the complication of added complexity due to interaction between individuals in the different trophic levels, but changes in biodiversity at these different levels could result in very different ecosystem responses (Petchey et al. 1999, Duffy 2002, 2003, Worm \& Duffy 2003). This has experimental support. Aquatic microcosms have shown different patterns of species loss at different trophic levels, resulting in complex responses in ecosystem functioning (Petchey et al. 1999). In estuarine mesocosms increased grazer diversity led to increased seagrass diversity only when a predator species was present (Duffy et al. 2005).

Many of the problems of extending model systems to incorporate multiple trophic levels are in common with those of extending spatial and/or temporal scale, these 3 aspects of ecosystems being intimately linked. The inclusion of multiple trophic levels requires systems of larger spatial scales and therefore has higher financial and physical costs, resulting in a trade-off with replication. A further complication is that the effects of different trophic levels can operate at different temporal and spatial scales (Bengtsson et al. 2002, Raffaelli et al. 2002, Raffaelli 2006, in this Theme Section). For example, the soil community appears to respond with a marked time lag behind plants, indicating a decou- 
pling of temporal dynamics between these 2 trophic compartments (Van der Putten et al. 2000).

Organisms at some trophic levels tend to be more easily identified, and by more people, than those at other trophic levels, so that taxonomic resolution declines at lower trophic levels, especially in invertebrate (but not plant-based) webs (Raffaelli et al. 2002). Although model systems can overcome this problem in principle by using clearly separate species in the system, biases will inevitably result, whilst the systematics of many lower taxa, such as those in sediments (meiofauna) and soils (mites), are extremely challenging or even unresolved.

Despite these issues, multi-trophic model systems have been constructed, although they have rarely addressed BEF directly and have incorporated limited numbers of species (Naeem \& Li 1997, Petchey et al. 1999, Naeem et al. 2000, Duffy et al. 2001, 2003, 2005). As with incorporating larger spatial scales, there is potential here also for using naturally enclosed ecosystems such as lakes and islands (Carpenter et al. 1995, 2001, Krebs et al. 1995). However, the level of control, the number of replicates and the level of information on the states of the system with time in these experiments will be inherently much lower.

Understanding BEF dynamics in the context of multiple-trophic levels will be essential to making properly informed predictions of the consequences of decreasing biodiversity. As a result, the need for incorporating multiple-trophic levels in model systems is probably the most pressing (Raffaelli 2006). However, achieving this represents a considerable challenge.

\section{Variation}

There are 3 principal sources of variation which need to be considered when addressing BEF issues. Firstly, biodiversity, viewed as a constant and independent factor within each biodiversity treatment in the experimental design, will be variable over space and time in real ecosystems. Secondly, there will be variation in the level of ecosystem functioning under consideration due to biodiversity and, thirdly, residual variation due to other independent factors.

Ecosystem functioning will vary in space and time, and these dynamics need to be understood. Model systems, with high levels of replication, and strong control over initial conditions are ideal for measuring this inherent variation in functioning at constant biodiversity, at least at small spatial scales. However, current experimental designs are not conducive to measuring the effect of variation (temporal or spatial) in biodiversity on ecosystem functioning (Benedetti-Cecchi 2003).

The majority of ecological experiments attempt to relate the effect of mean intensity of the independent variable (biodiversity) to the resulting mean intensity and variation in the dependent variable (ecosystem functioning). Variation in the independent variable tends to be ignored, with experimental design incorporating the independent variable as a constant factor (Benedetti-Cecchi 2003). However, experimental designs that begin to address the role of temporal and spatial variation in the independent variable are starting to appear (e.g. Navarrete 1996, BenedettiCecchi 2000). For example, variance in the spatial distribution of resource populations can be sensitive to changes in the variance of the consumer-resource trophic interaction (Benedetti-Cecchi 2000), in addition to the mean effect of the consumers. A consumerresource model incorporating this effect was able to replicate patterns in empirical data, which previous models had not been able to produce (BenedettiCecchi 2000).

Such considerations have not yet been applied to most BEF experiments. The general experimental design has been addressed recently (Benedetti-Cecchi 2003), allowing the separation of effects between the intensity and variability (temporal or spatial) of an ecosystem process driver. The design must be structured so that the intensity and variability are arranged as independent factors (i.e. orthogonal). It should also be noted that this independence does not hinder examining relationships between the 2 factors via tests on interaction terms (Benedetti-Cecchi 2003).

Although these experimental designs separating intensity and variability of independent factors were constructed with consumer-resource interactions in mind, it should be possible to adapt them for addressing BEF questions, and model systems offer great potential in this respect. The strong control in determining starting conditions and the relative ease of producing replicates should provide for experimental designs in which biodiversity level and variation are orthogonal, therefore allowing for the separation of effects due to variation in biodiversity. However, since heterogeneity is linked intricately to scale, the small spatial and short temporal scales of most model systems impose a limitation on the levels of variation in biodiversity that can be addressed using this methodology.

\section{Environmental stochasticity}

Related to the role of the environment in BEF is the issue of environmental stochasticity. In the real world, environmental variables change with time, and these changes incorporate a stochastic component. A stochastic variable has a random probability distribution that can be analysed statistically, but not predicted precisely. Demographic stochasticity describes un- 
certainties relating to characteristics of individuals, whereas environmental stochasticity describes uncertainties imposed at the population level by the environment (Bonsall \& Hastings 2004). Stochasticity in models has often been treated as random fluctuations, with no temporal correlation (Halley 1996), also known as white noise. However, so-called 'reddened' spectra, with positive temporal autocorrelation between fluctuations (Halley 1996), may be more appropriate for environmental fluctuations (Mandelbrot \& Wallis 1969), particularly in marine systems (Steele 1985). Environmental stochasticity is a well-known determinant of population dynamics (May 1973, Lande 1993), and long-term population records appear to show reddened spectra (Pimm \& Redfearn 1988), suggesting a connection between reddening of environmental drivers and reddening of population dynamics. If this connection is real, the level of temporal autocorrelation in environmental drivers is likely to play a role in BEF dynamics, possibly causing BEF relationships to change independently of changes in species composition (Johnson 2000).

Aquatic microbial systems are excellent for testing connections between characteristics of environmental variation and $\mathrm{BEF}$, providing high levels of control over environmental conditions and the capacity to run experiments over many generations (ensuring that the results are driven by population dynamics). They have already been used to demonstrate that single-species microbial population dynamics can be sensitive to the colour of temperature fluctuation with time (constant, white, or reddened) (Petchey 2000). In a more recent experiment, similar temperature fluctuations have been applied in conjunction with varying species richness to test for effects on changing total community biomass (Petchey et al. 2002a). Results indicated that change in total biomass was unaffected by the temperature regime. However, the authors point out that biomass in each microcosm was estimated only twice and therefore measured long-term change in biomass and not fluctuations in biomass, and that this restriction meant they were unable to separate change due to stochastic fluctuations and change due to directional changes (Gaston \& McArdle 1994). To do this requires experimental designs with a number of samples and a frequency of sampling appropriate for obtaining an estimate of the general trend and therefore enabling the partitioning of change due to stochastic environmental fluctuations (Gaston \& McArdle 1994). Future experiments aiming to relate environmental stochasticity to variation in ecosystem functioning through time will also need to ensure that a number of samples is taken from each microcosm at each time. This will enable an estimate of sampling error for each ecosystem functioning estimate and therefore enable an esti- mate of the true but unknown level of ecosystem functioning (Gaston \& McArdle 1994). Any measure of variation of ecosystem functioning across time will then be an estimate of the variation in ecosystem functioning, rather than an estimate of the variation in ecosystem functioning estimates (Gaston \& McArdle 1994).

\section{CONCLUSIONS AND RECOMMENDATIONS}

This review has shown that model systems have been much used recently in trying to gain an understanding of BEF. Generally using isolated, small-scale collections of species, they are simplistic systems that are designed to be tractable whilst distilling out essential characteristics of BEF. The high level of control over starting and environmental conditions, along with good levels of reproducibility and replication make model systems a potentially very powerful tool for understanding BEF.

These systems have been heavily criticised in the literature because of their artificiality and their simplicity compared to real ecosystems. But this is to view model systems in the wrong context. The criticisms are really limitations to the methodology; they do not make the methodology invalid or less valid than alternative approaches which have their own faults. Model systems need to be viewed as part of a holistic approach to understanding BEF that utilises a range of methodologies. In this context model systems are a tool with strengths and weaknesses, but with strengths that complement those from other methodologies. The complexity of ecosystems is enormous, and model systems are a reductionist methodology designed to address possible links between biodiversity and ecosystem functioning in a simplistic and therefore understandable context. They are tools for examining these links in isolated fine detail; they are not designed to address how ecosystems function as a whole. The high level of control and monitoring that is possible makes these systems particularly suitable for investigating mechanistic processes. We therefore endorse the strategic cyclic paradigm (Root \& Schneider 1995) with an emphasis on the use of model systems to investigate possible mechanisms underlying $\mathrm{BEF}$, evidence of which can then be tested for in larger-scale experiments and field observations (Fig. 2). Although this paradigm was suggested originally to deal with issues of different scales between the different methodologies used to investigate $\mathrm{BEF}$, the cyclic procedure is just as valid for dealing with other issues, such as multiple trophic levels.

Model systems, particularly the microbial microcosms, offer a strong connection with theoretical mod- 
Fig. 2. Suggested nested hierarchical integration of different methodologies in understanding mechanisms driving biodiversity-ecosystem functioning (BEF) based on the strategic cyclical scaling paradigm (Root \& Schneider 1995). Light grey arrows indicate verification processes, dark grey arrows indicate the generation of mechanistic hypotheses and predictions. Connections between any 2 methodologies are not precluded but would represent cases where extra caution in interpretation may be required

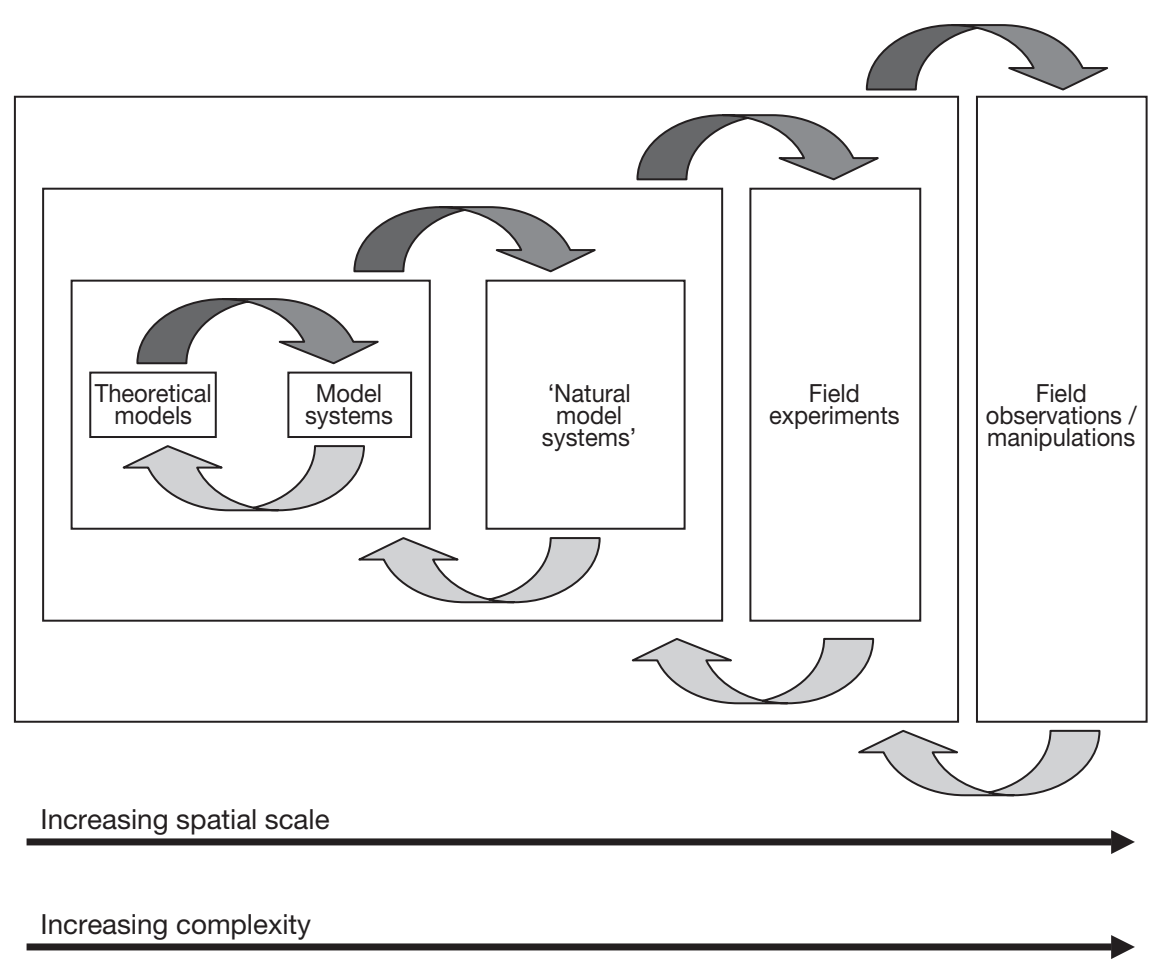

elling. This is of great potential benefit as predictions from theoretical models (including many of the simplifying assumptions) can be rigorously tested under highly controlled conditions. We suggest that particular use of this strong link be made to generate theoretical models of BEF that can be strengthened by the validation of matching of model predictions from theoretical models with model system behaviour.

If there is to be effective integration of the different methodologies, there will need to be a common language. Although dimensional analysis (Petersen \& Hastings 2001, Englund \& Cooper 2003) can be difficult and care must be taken to provide ecologically meaningful dimensions, it provides a framework for translating results and concepts across different methodologies and between different systems. We therefore advocate its regular use in model systems and suggest that it be part of an increase in metaanalyses trying to identify commonalities and differences across systems as well as scales, providing a more complete view of mechanisms underlying BEF.

A greater effort needs to be made to put the results of model systems into proper ecological context. This will enhance coherency in the general BEF debate by highlighting common factors and differences between different model systems, and between model systems and other methodologies. For example, some model systems will be driven by population dynamics, whereas others will be strongly driven by initial starting conditions, making it difficult to integrate the results from the 2 groups. Similarly some model systems will be based on ecosystems strongly influenced by stochastic factors and others on ecosystems where this is not the case. BEF dynamics will alter according to such considerations, and results from model systems need to be put into context to facilitate an understanding of how these considerations can alter BEF. This needs to be recognised so that debate is not over differences due to a lack of understanding of relevant contexts, but over true differences and similarities in different situations.

A second vigorous debate in the literature has been over the implications of hidden treatments with species selection conducted randomly, leading to the questioning of the significance of results from BEF model systems. The debate over the sampling effect is illustrative of what can be gained from the use of model systems. It has led to a clarification and increased understanding of possible mechanisms linking biodiversity to ecosystem functioning, and to much more robust and rigorous experimental designs for the future.

There are 2 main concerns over hidden treatments: the match between the random selection of species method and reality and the resulting effects of the statistical sample distributions on the validity of the statistical analyses. The random-selection method can reflect reality in ecosystems in which population dynamics are strongly driven by stochastic processes or by a number of interacting processes (Fridley 2001). The relevance of randomisation must therefore be 
judged in the context of the ecosystem being addressed. If random selection is not realistic, speciesrichness treatments could be chosen using expert knowledge or using weighted choices based on likelihood of extinction. Microcosm experiments in which many generations will elapse could be allowed to progress for different amounts of time, allowing extinction of species to occur 'naturally' and therefore determine realistic species combinations to be used in BEF model systems.

ANOVA has been used extensively in the analysis of BEF model systems. Hidden treatment effects can lead to heterogeneity of variance, breaking one of the assumptions underlying this method. However, ANOVA is robust to this assumption under certain circumstances. Problems are much more pronounced when sample sizes differ (Box 1953). However, if samples are balanced, heterogeneity of variance is usually only a serious problem when one of the samples has a larger variance than the others (Underwood 1998). The effects of heterogeneity of variance are also significantly reduced as the number of treatments increases and when sample sizes are large (usually taken to be >6) (Underwood 1998). If heterogeneity of variance is judged to be likely, these considerations in experimental design should be regarded as a priority.

A second concern about the effects of hidden treatments on the interpretation of results from ANOVA is asymmetry in similarity of quasi-replicates between species-rich and species-poor treatments, leading to differences in the interpretation of experimental error. This can be minimised, as well as gaining more information about the mechanisms involved, by explicitly incorporating the likely environmental sources of experimental error as factors in the ANOVA design.

Ecosystem functioning has usually been measured by a single metric (e.g. primary production). This collapsing of a multi-dimensional characteristic into a single dimension offers tractability, but decreases the level of information gained, as well as leading to possible misinterpretations due to a lack of perspective. We suggest an expansion in the number of metrics used to measure ecosystem functioning in a model system as a way of increasing the level of understanding of the mechanistic processes driving BEF.

Similarly, 'biodiversity' is a multi-dimensional concept that is collapsed into 1 dimension for BEF modelsystem studies, usually species richness, since this is a metric that is both intuitive and easily measured and manipulated. Future experiments will need to address other components of biodiversity (e.g. evenness) to gain a more complete understanding of BEF. This could be done by repeating experiments using a measure of biodiversity other than species richness or with the new measure plus richness. Dealing with the mul- tiple dimensions of biodiversity is likely to be harder than expanding the dimensionality of ecosystem functioning, as biodiversity is a treatment rather than a response, and the possible permutations within and amongst the newly applied metrics of biodiversity will increase the already large number of replicates required for BEF model system studies. An ANOVA design with crossed biodiversity factors would be appropriate and allow for the measurement of interaction terms between the different biodiversity dimensions.

The focus on species richness as the metric for biodiversity has started to change towards functional richness. This is a trend that should continue, but it will not be without difficulties. Functional richness is a measure based on ecological behaviour and is therefore much more suitable than species richness for generating a mechanistic understanding of BEF. Where functional richness has been compared to species richness, it has shown greater explanatory power for levels of ecosystem functioning (Petchey et al. 2004). The main difficulty is generating sensible functional groupings that relate properly to the ecosystem function of interest, although progress in this has already been made (Petchey \& Gaston 2002, Petchey 2004).

Although model systems are by design simplistic, it is clear that they can be extended or experimental designs can be altered, in order to investigate issues of BEF not yet addressed. Complexity can be increased, whilst keeping the systems tractable, so that the role of vital components of BEF can be investigated, such as spatial scale and multiple trophic levels. The key is to ensure that these extensions integrate well with other experimental methodologies.

Natural microcosms are small, contained habitats that are naturally populated by minute organisms (Srivastava et al. 2004). Although they offer a valuable link between the simpler model systems and extremely complex ecosystems (Srivastava et al. 2004), they have been used relatively little and not to address BEF. Examples of such systems include aquatic rock pools (Romanuk \& Kolasa 2002), marine pen shells (Munguia 2004), pitcher plants (Kneitel \& Miller 2002) and tree holes (Fincke et al. 1997, Srivastava \& Lawton 1998). These systems offer several benefits: real multiple trophic combinations of species with a shared evolutionary past and a level of openness of individual microcosms arranged in a natural hierarchical spatial structure (Srivastava et al. 2004). These benefits result in a reduction in the level of control and tractability, but not to the levels of whole ecosystems. The decrease in tractability and increase in generality mean that use of model systems and natural microcosms can be complementary methodologies - model systems testing if hypothesised effects occur, whilst natural microcosms 
test if these effects are important in the real world (Srivastava et al. 2004).

Model systems have already proved to be of value in BEF research and are likely to continue to be useful. They will not provide us with an overall understanding of how ecosystems function, but they are capable of providing valuable insights into how small, isolated components of ecosystems work. Model systems have great strengths, but also strong limitations that must be recognised when trying to put experimental results into context. They offer an extremely valuable methodology that must be integrated with other methodologies, such as observation and manipulation of ecosystems, in order to provide a more complete understanding of BEF. This integration of methodologies will be challenging, but is a necessity if we are to understand BEF. Marine ecology has a long history in the experimental design of, and interpretation of results from, model systems. This knowledge and experience can play a valuable role in enhancing our understanding of BEF in marine ecosystems and more generally.

Acknowledgements. This work was funded by the Natural Environment Research Council (NERC) (Ref.: NER/A/S/ 2003/00577). We thank L. Benedetti-Cecchi and 3 anonymous reviewers for helpful comments and criticism on the manuscript. M. Termansen and J. Chamberlain provided helpful comments on an earlier draft of this paper, and J. Smart and J. Minx were always available for helpful discussions.

\section{LITERATURE CITED}

Anderson J (1995) Soil organisms as engineers: microsite modulation of macroscale processes. In: Jones CG, Lawton JH (eds) Linking species and ecosystems. Chapman \& Hall, New York, p 94-106

Benedetti-Cecchi L (2000) Variance in ecological consumerresource interactions. Nature 407:370-374

Benedetti-Cecchi L (2003) The importance of the variance around the mean effect size of ecological processes. Ecology 84:2335-2346

Benedetti-Cecchi L (2004) Increasing accuracy of causal inference in experimental analyses of biodiversity. Funct Ecol 18:761-768

Bengtsson J, Engelhardt K, Giller P, Hobbie S, Lawrence D, Levine J, Vilà M, Wolters V (2002) Slippin' and slidin' between the scales: the scaling components of biodiversity-ecosystem functioning relations. In: Loreau $M$, Naeem S, Inchausti P (eds) Biodiversity and ecosystem functioning: synthesis and perspectives. Oxford University Press, Oxford, p 209-220

Bloesch J, Bossard P, Buhrer H, Burgi HR, Uehlinger U (1988) Can results from limnocorral experiments be transferred to in situ conditions? Hydrobiologia 159:297-308

Bonsall MB, Hastings A (2004) Demographic and environmental stochasticity in predator-prey metapopulation dynamics. J Appl Ecol 73:1043-1055

Box GEP (1953) Non-normality and tests on variances. Biometrika 40:318-335

Carpenter SR (1996) Microcosm experiments have limited relevance for community and ecosystem ecology. Ecology 77:677-680

Carpenter SR, Chisholm SW, Krebs CJ, Schindler DW, Wright RF (1995) Ecosystem experiments. Nature 269:324-327

Carpenter SR, Cole JJ, Hodgson JR, Kitchell JF and 6 others (2001) Trophic cascades, nutrients, and lake productivity: whole-lake experiments. Ecol Monogr 71:163-186

Chapin FS III, Walker BH, Hobbs RJ, Hooper DU, Lawton JH, Sala OE, Tilman D (1997) Biotic control over the functioning of ecosystems. Science 277:500-504

Chapin FS III, Zavaleta ES, Eviner VT, Naylor RL and 8 others (2000) Consequences of changing biodiversity. Nature 405:234-242

Chen CC, Petersen JE, Kemp WM (1997) Spatial and temporal scaling of periphyton growth on walls of estuarine mesocosms. Mar Ecol Prog Ser 155:1-15

Costanza R, dArge R, deGroot R, Farber S and 9 others (1997) The value of the world's ecosystem services and natural capital. Nature 387:253-260

Cottingham KL, Brown BL, Lennon JT (2001) Biodiversity may regulate the temporal variability of ecological systems. Ecol Lett 4:72-85

Drake JA, Huxel GR, Hewitt CL (1996) Microcosms as models for generating and testing community theory. Ecology 77 : $670-677$

Duffy JE (2002) Biodiversity and ecosystem function: the consumer connection. Oikos 99:201-219

Duffy JE (2003) Biodiversity loss, trophic skew and ecosystem functioning. Ecol Lett 6:680-687

Duffy JE, Macdonald KS, Rhode JM, Parker JD (2001) Grazer diversity, functional redundancy, and productivity in seagrass beds: an experimental test. Ecology 82:2417-2434

Duffy JE, Richardson JP, Canuel EA (2003) Grazer diversity effects on ecosystem functioning in seagrass beds. Ecol Lett 6:637-645

Duffy JE, Richardson JP, France KE (2005) Ecosystem consequences of diversity depend on food chain length in estuarine vegetation. Ecol Lett 8:301-309

Ehrlich PR, Wilson EO (1991) Biodiversity studies: science and policy. Science 253:758-762

Emmerson MC, Solan M, Emes C, Paterson DM, Raffaelli D (2001) Consistent patterns and the idiosyncratic effects of biodiversity in marine ecosystems. Nature 411:73-77

Englund G, Cooper SD (2003) Scale effects and extrapolation in ecological experiments. Adv Ecol Res 33:161-202

Englund G, Cooper SD, Sarnelle O (2001) Application of a model of scale dependence to quantify scale domains in open predation experiments. Oikos 92:501-514

Fincke OM, Yanoviak SP, Hanschu RD (1997) Predation by odonates depresses mosquito abundance in water-filled tree holes in Panama. Oecologia 112:244-253

Fridley JD (2001) The influence of species diversity on ecosystem productivity: How, where, and why? Oikos 93: $514-526$

Fridley JD (2002) Resource availability dominates and alters the relationship between species diversity and ecosystem productivity in experimental plant communities. Oecologia 132:271-277

Gamble JC (1991) Mesocosms, statistical and experimental design considerations. In: Lalli CM (ed) Experimental marine ecosystems: a review and recommendations. Springer-Verlag, Heidelberg, p 188-196

Gaston KJ, McArdle BH (1994) The temporal variability of animal abundances: measures, methods and patterns. Philos Trans R Soc Lond B 345:335-358

Gerhart DZ, Likens GE (1975) Enrichment experiments for determining nutrient limitation: four methods compared. 
Limnol Oceanogr 20:649-653

Griffiths BS, Ritz K, Bardgett RD, Cook R and 8 others (2000) Ecosystem response of pasture soil communities to fumigation-induced microbial diversity reductions: an examination of the biodiversity-ecosystem function relationship. Oikos 90:279-294

Halley JM (1996) Ecology, evolution and 1/f-noise. Trends Ecol Evol 11:33-37

Hector A, Loreau M, Schmid B, BIODEPTH project (2002) Biodiversity manipulation experiments: studies replicated at multiple sites. In: Loreau M, Naeem S, Inchausti P (eds) Biodiversity and ecosystem functioning: synthesis and perspectives. Oxford University Press, Oxford, p 36-46

Hulot FD, Lacroix G, Lescher-Moutoue F, Loreau M (2000) Functional diversity governs ecosystem response to nutrient enrichment. Nature 405:340-344

Huston MA (1994) Biological diversity. The coexistence of species on changing landscapes. Cambridge University Press, Cambridge

Huston MA (1997) Hidden treatments in ecological experiments: re-evaluating the ecosystem function of biodiversity. Oecologia 110:449-460

Huston MA (1999) Microcosm experiments have limited relevance for community and ecosystem ecology: synthesis of comments. Ecology 80:1088-1089

Huston MA, McBride AC (2002) Evaluating the relative strengths of biotic versus abiotic controls on ecosystem processes. In: Loreau M, Naeem S, Inchausti P (eds) Biodiversity and ecosystem functioning: synthesis and perspectives. Oxford University Press, Oxford, p 47-60

Huston MA, Aarssen LW, Austin MP, Cade BS and 8 others (2000) No consistent effect of plant diversity on productivity. Science 289:1255 (abstract)

Johnson KH (2000) Trophic-dynamic considerations in relating species diversity to ecosystem resilience. Biol Rev Camb Philos Soc 75:347-376

Kneitel JM, Miller TE (2002) Resource and top-predator regulation in the pitcher plant (Sarracenia purpurea) inquiline community. Ecology 83:680-688

Krebs CJ, Boutin S, Boonstra R, Sinclair ARE, Smith JNM, Dale MRT, Martin K, Turkington R (1995) Impact of food and predation on the snowshoe hare cycle. Nature 269: $1112-1115$

Lalli CM (ed) (1991) Experimental marine ecosystems: a review and recommendations. Springer-Verlag, Heidelberg

Lande R (1993) Risks of population extinction from demographic and environmental stochasticity and random catastrophes. Am Nat 142:911-927

Lawler SP (1998) Ecology in a bottle: using microcosms to test theory. In: Bernardo J (ed) Experimental ecology: issues and perspectives. Oxford University Press, Oxford, p 236-253

Lawton JH (1994) What do species do in ecosystems? Oikos 71:367-374

Lawton JH (1995) Ecological experiments with model systems. Science 269:328-331

Lawton JH (1996) The Ecotron facility at Silwood Park: the value of "big bottle" experiments. Ecology 77:665-669

Lawton JH, Naeem S, Thompson LJ, Hector A, Crawley MJ (1998) Biodiversity and ecosystem function: getting the Ecotron experiment in its correct context. Funct Ecol 12: 848-852

Levine JM, Kennedy T, Naeem S (2002) Neighbourhood scale effects of species diversity on biological invasions and their relationship to community patterns. In: Loreau M, Naeem S, Inchausti P (eds) Biodiversity and ecosystem functioning: synthesis and perspectives. Oxford University Press, Oxford, p 114-124

Loreau M (2000) Biodiversity and ecosystem functioning: recent theoretical advances. Oikos 91:3-17

Loreau M, Hector A (2001) Partitioning selection and complementarity in biodiversity experiments. Nature 413:548-548

Mandelbrot B, Wallis J (1969) Some long-run properties of geophysical records. Water Resour Res 5:321-340

Manly B (1992) The design and analysis of research studies. Cambridge University Press, Cambridge

May RM (1973) Stability in randomly fluctuating versus deterministic environments. Am Nat 107:621-650

McGrady-Steed J, Harris PM, Morin PJ (1997) Biodiversity regulates ecosystem predictability. Nature 390:162-165

Mulder CPH, Koricheva J, Huss-Danell K, Högberg P, Joshi J (1999) Insects affect relationships between plant species richness and ecosystem processes. Ecol Lett 2:237-246

Munguia P (2004) Successional patterns on pen shell communities at local and regional scales. J Anim Ecol 73:64-74

Naeem S, Li S (1997) Biodiversity enhances ecosystem reliability. Nature 390:507-509

Naeem S, Wright JP (2003) Disentangling biodiversity effects on ecosystem functioning: deriving solutions to a seemingly insurmountable problem. Ecol Lett 6:567-579

Naeem S, Hahn DR, Schuurman G (2000) Producerdecomposer co-dependency influences biodiversity effects. Nature 403:762-764

Navarrete SA (1996) Variable predation: effects of whelks on a mid-intertidal successional community. Ecol Monogr 66: 301-321

O'Neill RV, King AW (1998) Homage to St. Michael; or, why are there so many books on scale. In: Peterson DL, Parker VT (eds) Ecological scale: theory and applications. Columbia University Press, New York, p 3-15

Paine RT (2002) Trophic control of production in a rocky intertidal community. Science 296:736-739

Pauly D, Christensen V, Dalsgaard J, Froese R, Torres F Jr (1998) Fishing down marine food webs. Science 279: 860-863

Petchey OL (2000) Environmental colour affects aspects of single-species population dynamics. Proc R Soc Lond B 267:747-754

Petchey OL (2003) Integrating methods that investigate how complementarity influences ecosystem functioning. Oikos 101:323-330

Petchey OL (2004) On the statistical significance of functional diversity effects. Funct Ecol 18:297-303

Petchey OL, Gaston KJ (2002) Functional diversity (FD), species richness and community composition. Ecol Lett 5: 402-411

Petchey OL, McPhearson PT, Casey TM, Morin PJ (1999) Environmental warming alters food-web structure and ecosystem function. Nature 402:69-72

Petchey OL, Casey T, Jiang L, McPhearson PT, Price J (2002a) Species richness, environmental fluctuations, and temporal change in total community biomass. Oikos 99:231-240

Petchey OL, Morin PJ, Hulot FD, Loreau M, McGrady-Steed J, Naeem S (2002b) Contributions of aquatic model systems to our understanding of biodiversity and ecosystem functioning. In: Loreau M, Naeem S, Inchausti P (eds) Biodiversity and ecosystem functioning: synthesis and perspectives. Oxford University Press, Oxford, p 127-138

Petchey OL, Hector A, Gaston KJ (2004) How do different measures of functional diversity perform? Ecology 85:847-857

Petersen JE, Hastings A (2001) Dimensional approaches to scaling experimental ecosystems: designing mousetraps to catch elephants. Am Nat 157:324-333 
Pimm SL, Redfearn A (1988) The variability of population densities. Nature 334:613-614

Pimm SL, Russell GJ, Gittleman JL, Brooks TM (1995) The future of biodiversity. Science 269:347-350

Purvis A, Hector A (2000) Getting the measure of biodiversity. Nature 405:212-219

Raffaelli D (2006) Biodiversity and ecosystem functioning: issues of scale and trophic complexity. Mar Ecol Prog Ser 311:285-294 (in this Theme Section)

Raffaelli D, van der Putten WH, Persson L, Wardle DA and 5 others (2002) Multi-trophic dynamics and ecosystem processes. In: Loreau M, Naeem S, Inchausti P (eds) Biodiversity and ecosystem functioning: synthesis and perspectives. Oxford University Press, Oxford, p 147-154

Romanuk TN, Kolasa J (2002) Environmental variability alters the relationship between richness and variability of community abundances in aquatic rock pool microcosms. Ecoscience 9:55-62

Root TL, Schneider SH (1995) Ecology and climate: research strategies and implications. Science 269:334-341

Sala OE (2001) Ecology-Price put on biodiversity. Nature 412: 34-36

Schlapfer F, Schmid B (1999) Ecosystem effects of biodiversity: a classification of hypotheses and exploration of empirical results. Ecol Appl 9:893-912

Schneider DC (2001) The rise of the concept of scale in ecology. BioScience 51:545-553

Schneider DC, Walters R, Thrush S, Dayton P (1997) Scale-up of ecological experiments: density variation in the mobile bivalve Macomona liliana. J Exp Mar Biol Ecol 216: $129-152$

Schwartz MW, Brigham CA, Hoeksema JD, Lyons KG, Mills MH, van Mantgem PJ (2000) Linking biodiversity to ecosystem function: implications for conservation ecology. Oecologia 122:297-305

Smith MD, Knapp AK (2003) Dominant species maintain ecosystem function with non-random species loss. Ecol Lett 6:509-517

Solan M, Cardinale BJ, Downing AL, Engelhardt KAM, Ruesink JL, Srivastava DS (2004) Extinction and ecosystem function in the marine benthos. Science 306: $1177-1180$

Srivastava DS (2002) The role of conservation in expanding

Editorial responsibility: Martin Solan (Guest Editor), Newburgh, UK biodiversity research. Oikos 98:351-360

Srivastava DS, Lawton JH (1998) Why more productive sites have more species: an experimental test of theory using tree-hole communities. Am Nat 152:510-529

Srivastava DS, Kolasa J, Bengtsson J, Gonzalez A and 6 others (2004) Are natural microcosms useful model systems for ecology? Trends Ecol Evol 19:379-384

Steele JH (1985) A comparison of terrestrial and marine ecological systems. Nature 313:355-358

Stephenson GL, Hamilton P, Kaushik NK, Robinson JB, Solomon KR (1984) Spatial distribution of plankton in enclosures of three sizes. Can J Fish Aquat Sci 41: 1048-1054

Tilman D, Kareiva P (1997) Spatial ecology. The role of space in population dynamics and interspecific interactions. Princeton University Press, Princeton, NJ

Tilman D, Knops J, Wedin D, Reich P (2002) Plant diversity and composition: effects on productivity and nutrient dynamics of experimental grasslands. In: Loreau $M$, Naeem S, Inchausti P (eds) Biodiversity and ecosystem functioning: synthesis and perspectives. Oxford University Press, Oxford, p 21-35

Underwood AJ (1998) Experiments in ecology. Their logical design and interpretation using analysis of variance. Cambridge University Press, Cambridge

Van der Putten WH, Mortimer SR, Hedlund K, Van Dijk C and 10 others (2000) Plant species diversity as a driver of early succession in abandoned fields: a multi-site approach. Oecologia 124:91-99

Vitousek PM, Mooney HA, Lubchenco J, Melillo JM (1997) Human domination of Earth's ecosystems. Science 277: 494-499

Walker B, Kinzig A, Langridge J (1999) Plant attribute diversity, resilience, and ecosystem function: the nature and significance of dominant and minor species. Ecosystems 2: 95-113

Wardle DA (1999) Is "sampling effect" a problem for experiments investigating biodiversity-ecosystem function relationships? Oikos 87:403-407

Wiens JA (1989) Spatial scaling in ecology. Funct Ecol 3: 385-397

Worm B, Duffy JE (2003) Biodiversity, productivity and stability in real food webs. Trends Ecol Evol 18:628-632

Submitted: April 12, 2005; Accepted: November 10, 2005

Proofs received from author(s): March 6, 2006 